\title{
Guidance for Performing Preliminary Assessments Under CERCLA
}

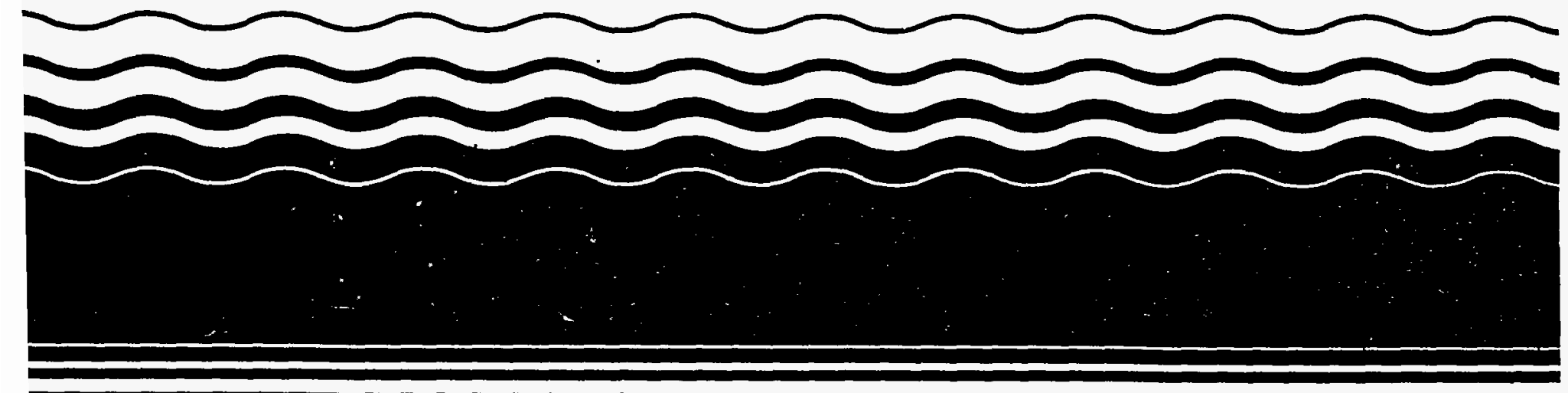




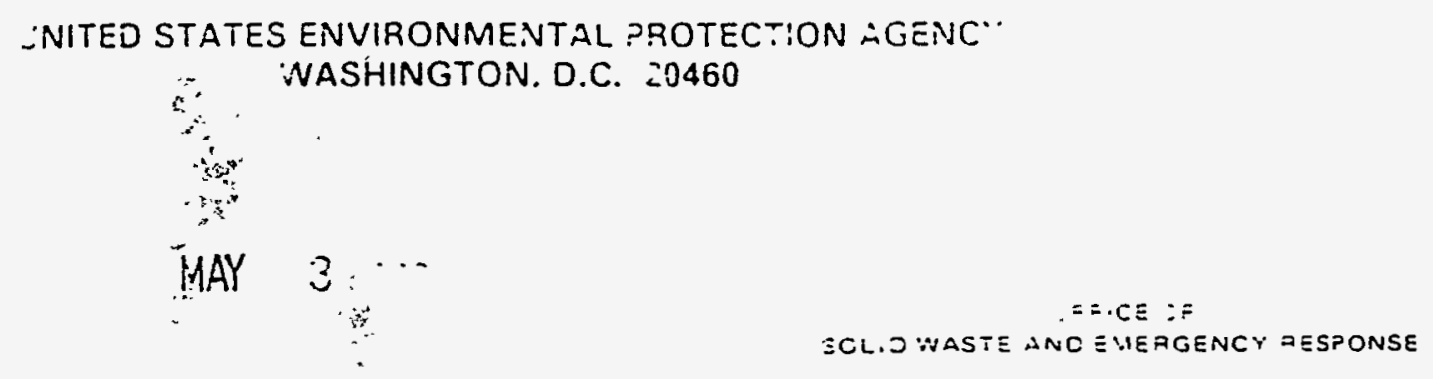

\section{MEMORANDUM}

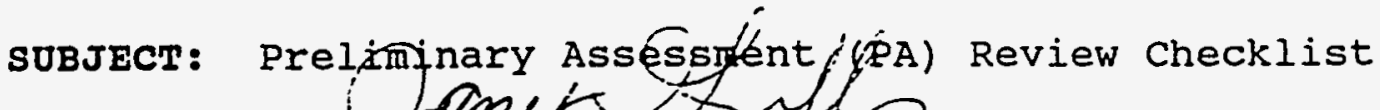

FROM: Janetfabibs, Chlef

site/ Assessment Branch (OS-5204G)

TO:

Federal Facility Contacts

I am providing the attached PA review checklist as a supplement to the Guidance for Performing Preliminary Assessments Under CERCLA (EPA/540/G-91013, september 1991) that you had previously received.

This checklist summarizes the most important factors that each PA may need to evaluate and each PA report may need to address. Anyone conducting a PA can use this checklist to ensure the adequacy of the PA report. Likewise, PA reviewers can use the checklist as a review guide.

If you have any comments or questions on this checklist, please call John Hollister atid (703)

Attachment

CC: Don Franklin (OFFE)

Site Assessment Section Chiefs (Regions 1 - 10) 
is

\title{
PA REVIEW CHECKLIST
}

\author{
Site Name: \\ CERCLIS ID No.: \\ Location (City, County, State): \\ Prepared by (Agency): \\ Date:
}

Reviewer Name:

Agency:

Document Reviewed:

(PA Report/Scoresheets/Both)

Date of Review: 
::e Name:

\section{PA REPORT REVIEW CHECKLIST}

The preliminary assessment (PA) review checklist was designed to evaluate the quality of PA work products. The review will ensure that EPA decisions concerning the disposition of sites are made in a nationally consistent, scientifically ased, and efficient manner.

The order in which information is presented in the PA does not have to be consistent with the checklist, but the PA should be organized in a logical sequence and consistent with PA guidance. Relevant pages of the PA guidance manual (Guidance for Performing Preliminary Assessments Under CERCLA, OSWER Directive 9345.0-01A, September 1991) are provided in parentheses throughout the checklist.

All factual information should be referenced in the PA report and PA scoresheets with page numbers provided. The reviewer should place a checkmark in the "Ref(s) Checked" column when information is verified in the references. If the information is not supported by the reference material or the information is not referenced, the reviewer should place an NS (not supported) in this column. The reviewer may write in the space provided and attach sheets as necessary.

The reviewer should indicate in the left column whether the following information is included in the PA narrative by placing a $\mathbf{Y}$ (yes), $\mathbf{N}$ (no), or $\mathbf{N A}$ (does not apply to the site) in the space provided. Place an I (incomplete) in the left column for information that is included but is not complete, and an S (scoresheets) if the information is included in the scoresheets but not in the PA report. The bold, italicized areas highlight several critical factors.

This checklist and the PA guidance manual can be ordered from the National Technical Information Service (NTIS) by calling 703-487-4650. To order both documents, the order number is PB92-963303. The checklist by itself is order number PB93-963342. 
I. PA Content

$\operatorname{Ref}(s)$

Introduction

Does the PA include the following information:

Agency/name of organization performing PA (p. 145)

Authority under which PA was conducted (p. 145)

Site name (p. 14)

Site alias (names other than that entered in CERCLIS) (p. 15)

Site address (street, city, county, state) (p. 145)

CERCLIS ID number ( $p .15)$

Site name and ID number identical to CERCLIS entry?

Purpose of PA (p. 145)

RCRA status (p. 16)

Comments:

Did PA activities include:

File review? (pp. 21-23) $\mathrm{Y} / \mathrm{N}$

Target survey? (pp. 31-32) Y/N

Site reconnaissance? (pp. 27-29) $\bar{Y} / \mathrm{N}$

Comments: 
Site Location/Description

Does the PA include the following information:

_ Geographic coordinates (latitude/longitude) (p. 40)

Worksheets for latitude/longitude coordinate calculations (p. 40)

Site setting/nearby land use (Appendix D, p. 4)

Type of site (e.g., plating facility, landfill) (p. 41)

Site status (activelinactive) (p. 14)

Years of operation (p. 40)

Current site activities/use (p. 145)

Current disposal/storage practices (p. 40)

Source characterization (active, inactive, and historical sources) (p. 42)

Description (p. 43)

_ Dimensions ( $p$. 14)

Known or suspected wastes and hazardous substances ( $p .40)$

- Description of containment and condition ( $p .40)$

Size of site (p. 14)

Site accessibility (identification of access restrictions, natural barriers)

Site location map (p. 145) and other figures

1-mile source radius (pp. 23, 145)

Overland drainage route(s) (p. 145)

Probable point of entry (PPE) to surface water (Appendix C, p. 5)

Nearest well, intake, residence (p. 145)

Sensitive environments (p. 145) 
Site sketch (p. 4 )

Major structures (e.g., buildings, paved areas, fences)

(p. 14)

_ Source areas (p. 44)

Comments:

Operational History and Waste Characteristics

Does the PA adequately include the following information:

_ Ownership (public/private/other) (p. 40)

_ Current owners, address(es), and dates of ownership (p. 40)

- Current operators, address(es), and dates of operation (p. 40)

- Former owners, address(es), and dates of ownership (p. 40)

- Former operators, address(es), and dates of operation (p. 40)

- Description of historical site activities (p. 40)

_ Description of wastes generated on site (p. 40)

_ Historical disposal/storage practices (p. 40)

_ Historical information on spills (p. 40)

__ Past source areas (if a removal has occurred) (p. 40)

Removal actions, including descriptions, dates, agencies that conducted the removal, and destination of wastes removed ( $p$. 145)

Known/estimated waste quantity (i.e., constituent, wastestream, volume, and area, as applicable) for each source ( $p p .44-51$ )

Information on permits, including issuing agency, date, discussion of inspection results, permit numbers, and violations (p. 145) Information on other regulatory agency involvement ( $p$. 145) 
Other investigations, including identıïcation of investigating agency, date, and results (pp. 21-30)

Previous sampling, if any, including discussion of analytical data and summary of results (p. 145)

Comments:

Ground Water Pathway

Does the PA include the following information:

_ Physiographic province underlying site/sources

Permeability of strata overlying shallowest aquifer (p. 145)

Net precipitation (p. 54)

Identification of aquifers in order of increasing depth (p. 145)

Aquifer description, including use, thicknesses, general flow direction (p. 145)

Confining layers (p. 145)

Aquifer interconnections within 4 miles of the site (or within 2 miles if source boundaries are well defined) (p. 145)

Aquifer discontinuities within 4 miles of the site (p. 145) (pp. 55, 57-58)

Citizen complaints

Well closures (p. 26) 
Comments:

Is sufficient information provided to assess the likelihood of a release of hazardous substances to ground water? (pp. 53-58) YIN

Comments:

\section{Ground Water Targets}

Is the following ground water target information included:

Distance to nearest drinking water well (p. 73)

Description of municipal and stand-by wells, including location/ distance from site, depth of wellaquifer from which water is drawn (pp. 14, 62-65)

_- If municipal and stand-by wells are part of a blended system, total number of wells/intakes that contribute to the overall system and the percent contribution of each well/intake within the target distance limit (pp. 62-64) Populations seroed by municipal well(s), including stand-by wells, by distance category within 4 miles of the site (pp. 14, 62-65)

Description of prioate wells within 4 miles of the site, including aquifer(s) from which water is drawn and associated population per distance category (pp. 14, 65)

Other uses of ground water (e.g., irrigation, industrial) (p. 75)

Wellhead Protection Areas. (p. 74) 
Cumments:

As presented, does the ground water population description provide enough information toA calculate an HRS target value? (pp. 68-75) $Y / N$

Comments:

Surface Water Pathway

Does the PA include the following information:

Sketch of surface water migration path indicating probable point of entry (PPE) and target locations (pp. 82, 86-88, 146)

Facility discharges to surface water (including permit information)

Distance to surface water (p. 81)

Floodplain designations/flood frequency (p. 83)

Surface soil type and permeability of overland drainage route (p. 79)

Drainage area description (p. 79)

2-year, 24-hour rainfall (p. 79)

Mean annual precipitation (p. 79)

Water body types along 15-stream-mile migration route, including segment description and intermittent/perennial depiction (p. 91)

Stream flow characteristics of each segment (p. 91) 
"isuai signs or contamınation (e.s., wil sineen, stressed

$\because$ egetation, sediment discoloration, absence of wildlifes

pp. 80, 95)

Fishery, intake, and/or surface water recreational

area closures (p. 95)

Comments:

ist

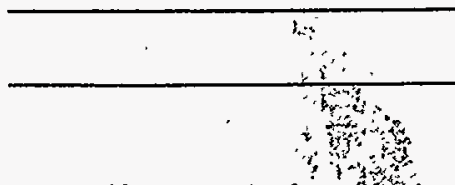

Is sufficient information provided to assess the likelihood of a release of hazardous substances to surface water? (pp. 78-85) Y/N

Comments:

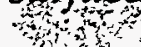

Comments: $\frac{1}{\frac{3}{3}}$

Surface Water Targets

Is the following surface water target information included:

Checked?

Identification and location of drinking water intakes, including standby intakes (p. 88)

Population served by each intake (apportioned population if the intake is part of a blended system) ( $p .90)$

Description and location of fisheries (p. 91)

Organisms fished

Other uses of surface water (p. 102)

Description and location of sensitive environments in or contiguous to the surface water migration path (p. 92) 
Comments:

As presented, does the surface water population description provide enough information to calculate an HRS target value for the drinking water threat? pp. 8890, 94-102) YIN/NA__ For - _e human food chain threat? (pp. 91-92, 103-104) YIN/NA For the enoiro ental threat? (pp. 92-93, 105-107) Y/N/NA

Comments:

Soil Exposure Pathway

Does the PA include the following information:

\section{Identification of known/suspected areas of contamination} (pp. 110-111)

_ Discussion of previous surface soil sampling, including analytical data and summary of results (p. 145-146)

Attractiveness/accessibility of areas of contamination

\section{Soil Exposure Targets}

Is the following soil exposure target information included:

\section{Residences, schools, and day care centers and associated populations} within 200 feet of an area of known/suspected contamination (or within 200 feet and on the property of an area of contamination if boundaries of the are: tre well defined) ( $p .118)$

Work aresis and number of workers on site within 200 feet of an area of known/suspected contamination (p. 115) 
Lse of site/areas of contamination (1iè., resources) (p. i23)

Terrestrial sensitive environments located on an area of known/suspected contamination (pp. 116, 122)

Nearby population within a 1 -mile travel distance in 0 to $1 / 4$ mile, $>1 / 4$ to $1 / 2$ mile, and $>1 / 2$ to 1 mile distance categories (p. 124)

Comments:

As presented, does the soil exposure population description provide enough information to calculate a resident population target value? (pp. 118-123) Y/N/NA Nearby population target value? (p. 124) Y/N

Comments:

Air Pathway

Does the PA include the following information:

Direct observation of substances released to air (p. 127)

Site reconnaissance safety monitoring instrument $(\mathrm{HNu}$, OVA) results

Description of cover material/containment (p. 40)

Discussion of previous air sampling, if any, including analytical data and summary of results (p. 127)

Reported odors/citizen complaints (p. 127) 
:ire Name:

- Known reports of adverse health errects associated with

. a suspected/known release (p. 127)

Comments:

Is sufficient information provided to assess the likelihood of a release of hazardous substances to air? (p. 126-130) YIN

Comments:

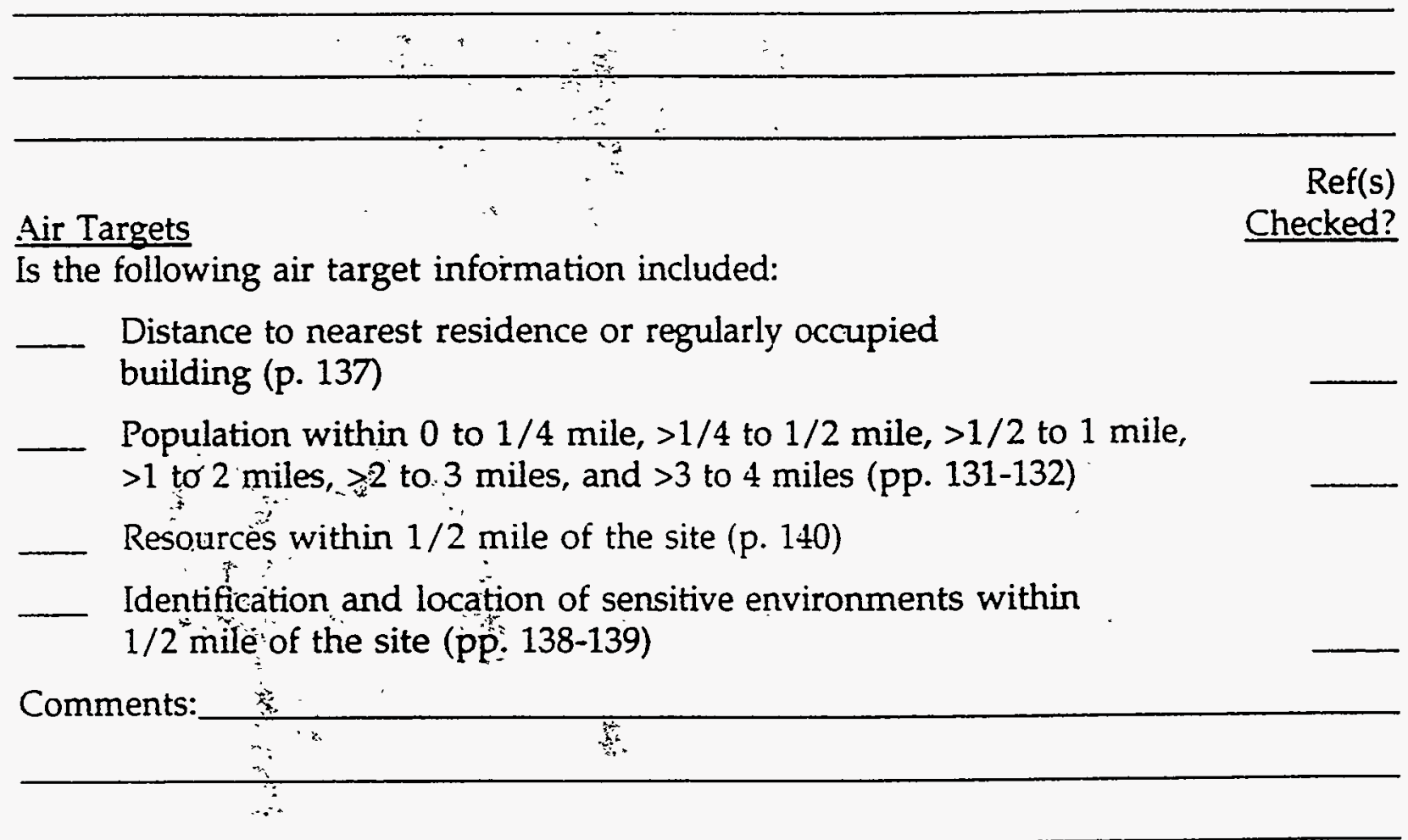


As presented, does the air population description provide enough information to calculate an HRS target value? (pp. 131-140) Y/N

Comments:

Photodocumentation Log

Are photos of the site, accompanied by a written description and reference to their location on a site map, included as an attachment to the PA report? (p. 147) $\mathrm{Y} / \mathrm{N}$

Comments:

Documentation

Are the following references included with the report?

_ Topographic map with 4-mile radius indicated (p. 23)

Population apportionment and calculation worksheets (Appendix C, p. 30)

County census data or population database (e.g., GEMS) (p. 24)

Field reconnaissance logbook (p. 29)

Comments:

Is the information throughout the narrative adequately referenced? (p. 143) $\mathrm{Y} / \mathrm{N}$

Comments: 
Are statements in the narrative supported by the reterences cited? $Y^{\prime} / \mathrm{N}$

Comments:

Are page numbers provided in reference citations? $Y / N$

Comments:

II. PA Quality

Does the PA provide sufficient information for SI planning? $Y / N$

Comments:

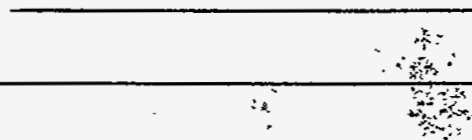

\section{and}

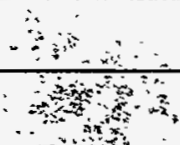

25 Is the information in the PATepor resented in a format consistent with PA guidance? (pp. 143-144) $Y / N^{\prime}$

Tomments:

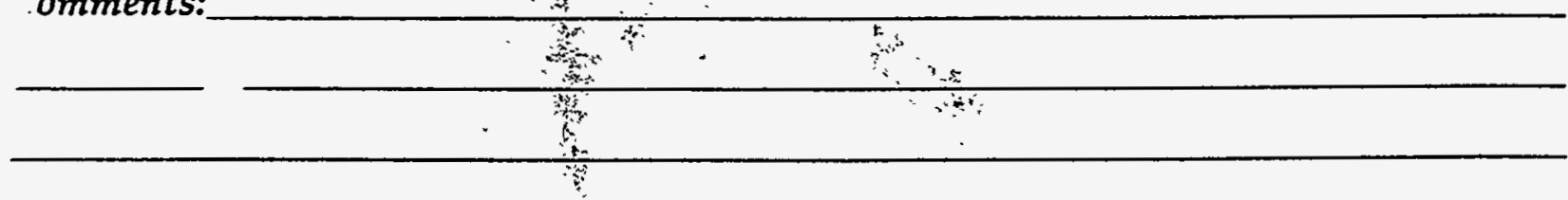


Does the P.t sufficiently address all pathway characterstics that could significantly inpace the site decision? Y/N All site operational information? Y/N Comments: All target information? Y/N

Are wastes adequately characterized based on available information? ( $p p$. 44-51) $Y / N$

Comments:

Did the PA highlight concerns that may not be addressed by HRS factors? (e.g., imminent explosion potential, Emergency Response notification) Y/NINA Comments:

Is the information presented in the PA report consistent with the information provided in the preliminary HRS scoresheets? Y/N

Comments: 

appropriate for the site? Y/N/NA

Comments:

Is the designation of primary and secondary targets appropriate for significant or potentially significant pathways? YIN

Comments:

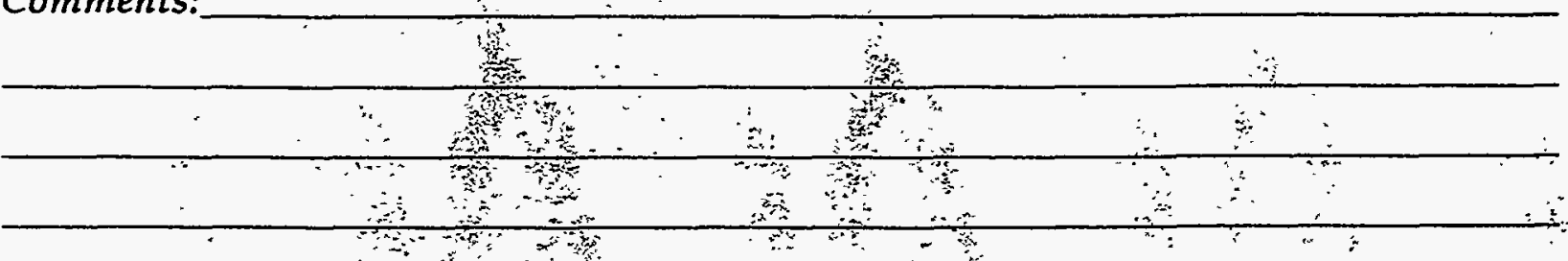

Does the PA provide sufficient information to support a recommendation? $Y(N$ Does the reoiewer agree with the $P A$ recommenidation? (i.e., $S E A, H$, or $L$ ) $Y / N$ Comments:

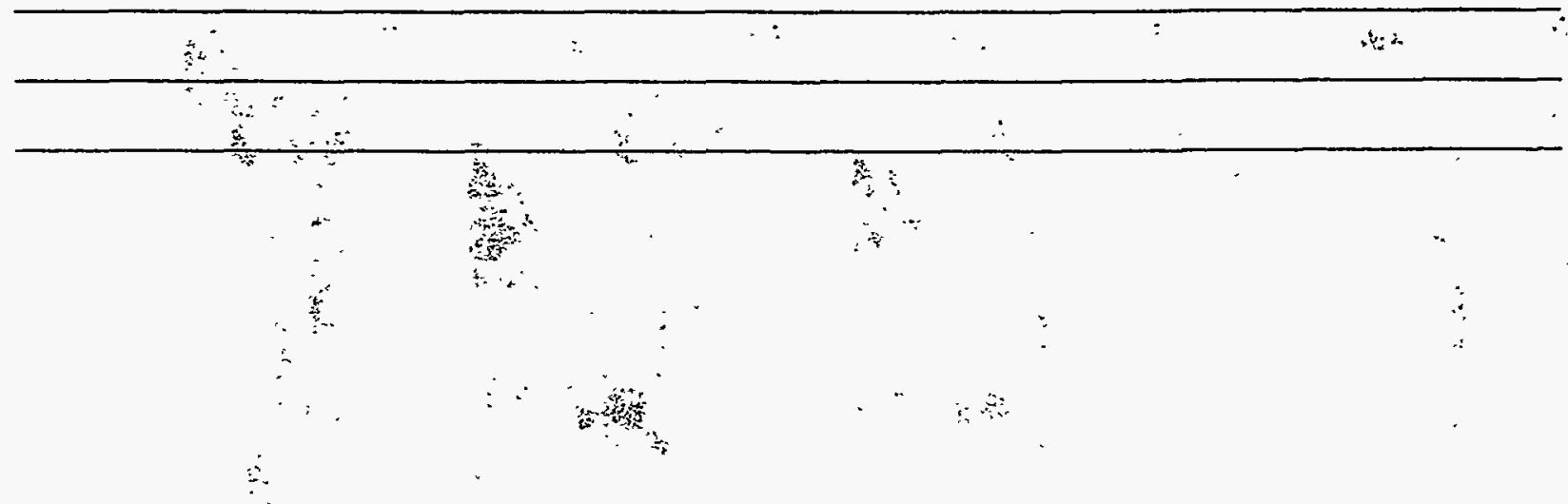


EPA/540/G-91/013

Publication 9345.0-01A

September 1991

\section{Guidance for Performing Preliminary Assessments Under CERCLA}

Hazardous Site Evaluation Division

Office of Emergency and Remedial Response Office of Solid Waste and Emergency Response

U.S. Environmental Protection Agency

Washington, DC 20460

Printed on Recycled Paper

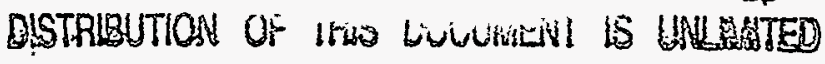




\section{NOTICE}

The procedures set forth in this document are intended as guidance to employees of the U.S. Environmental Protection Agency (EPA), States, and other government agencies. EPA officials may decide to follow the guidance provided in this directive, or to act at variance with it, based on analysis of specific site circumstances. EPA also reserves the right to modify this guidance at any time without public notice.

These guidelines do not constitute EPA rulemaking and cannot be relied upon to create any rights enforceable by any party in litigation with the United States.

Mention of company or product names in this document should not be considered as an endorsement by EPA. 


\section{DISCLAIMER}

This report was prepared as an account of work sponsored by an agency of the United States Government. Neither the United States Government nor any agency thereof, nor any of their employees, make any warranty, express or implied, or assumes any legal liability or responsibility for the accuracy, completeness, or usefulness of any information, apparatus, product, or process disclosed, or represents that its use would not infringe privately owned rights. Reference herein to any specific commercial product, process, or service by trade name, trademark, manufacturer, or otherwise does not necessarily constitute or imply its endorsement, recommendation, or favoring by the United States Government or any agency thereof. The views and opinions of authors expressed herein do not necessarily state or reflect those of the United States Government or any agency thereof. 


\section{DISCLAIMER}

Portions of this document may be illegible in electronic image products. Images are produced from the best available original document. 


\section{CONTENTS}

1. INTRODUCTION $\ldots \ldots \ldots \ldots \ldots \ldots \ldots \ldots \ldots \ldots \ldots \ldots \ldots \ldots \ldots \ldots \ldots$

1.1 PURPOSE OF THIS GUIDANCE $\ldots \ldots \ldots \ldots \ldots \ldots \ldots \ldots \ldots \ldots \ldots \ldots$

1.2 CERCLA/SARA LEGISLATION $\ldots \ldots \ldots \ldots \ldots \ldots \ldots \ldots \ldots \ldots \ldots \ldots \ldots \ldots \ldots$

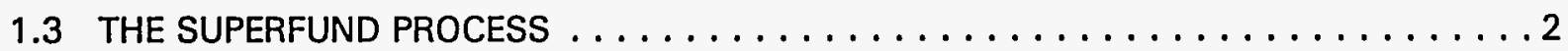

1.4 PURPOSE AND SCOPE OF THE PA $\ldots \ldots \ldots \ldots \ldots \ldots \ldots \ldots \ldots \ldots \ldots$

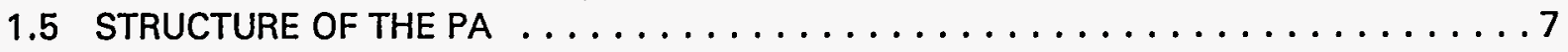

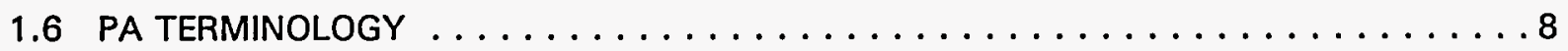

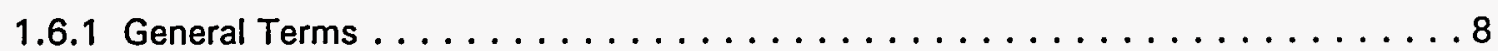

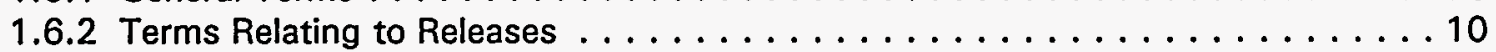

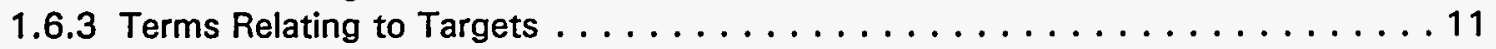

2. CONDUCTING THE PA INVESTIGATION $\ldots \ldots \ldots \ldots \ldots \ldots \ldots \ldots \ldots \ldots$

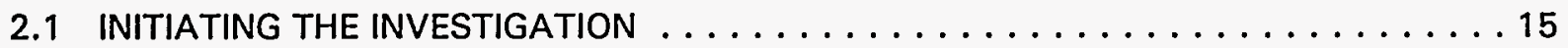

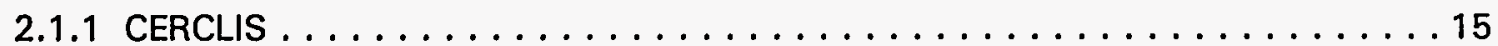

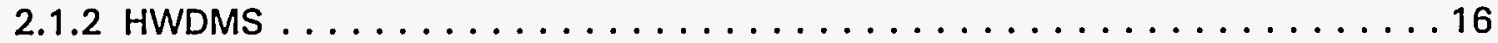

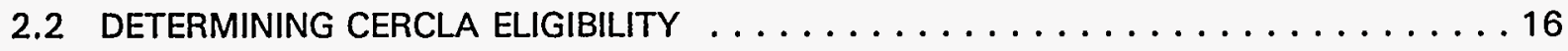

2.2 .1 RCRA Sites . . . . . . . . . . . . . . . . . . . 16

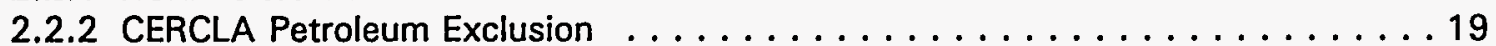

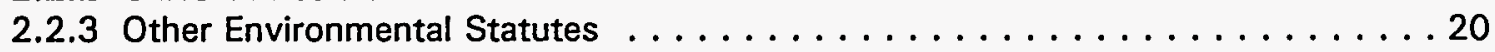

2.2.4 Sites With No Hazardous Substances . . . . . . . . . . . . . . . 20

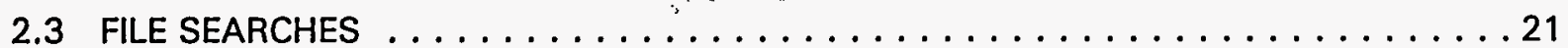

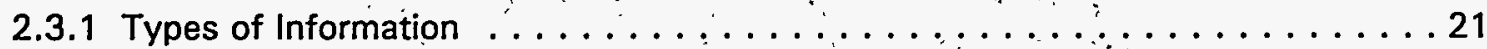

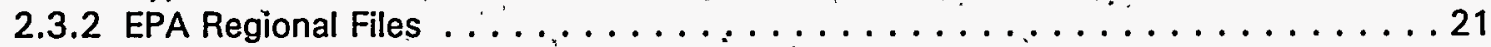

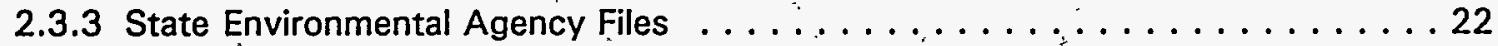

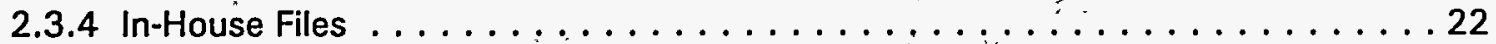

2.4 OBTAINING "DESKTOP" INFORMATION $\ldots \ldots \ldots \ldots \ldots \ldots \ldots \ldots \ldots \ldots \ldots \ldots \ldots \ldots$

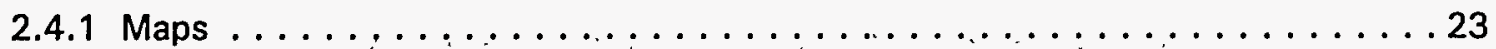

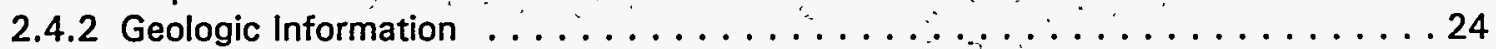

2.4.3 Databases and Geographic Information Systems . . . . . . . . . . . 24

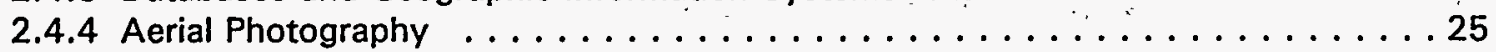

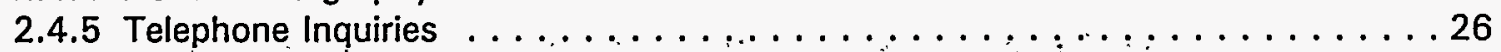




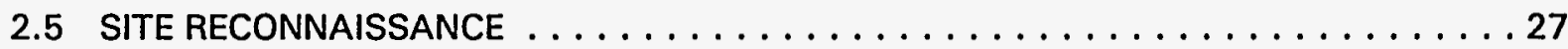

2.5.1 Preparing for the Site Reconnaissance $\ldots \ldots \ldots \ldots \ldots \ldots \ldots \ldots \ldots$

2.5.2 Conducting Onsite Reconnaissance . . . . . . . . . . . . . . . 29

Source Characterization and Target Identification

Additional Data Collection

Site Sketch and Photodocumentation

Health and Safety Considerations

2.5.3 Conducting Offsite Reconnaissance $\ldots \ldots \ldots \ldots \ldots \ldots \ldots \ldots \ldots \ldots \ldots \ldots \ldots$

Perimeter Survey

Site Environs Survey

Additional Data Collection

2.6 EMERGENCY RESPONSE CONSIDERATIONS $\ldots \ldots \ldots \ldots \ldots \ldots \ldots \ldots \ldots$

2.7 POTENTIAL RADIOACTIVE WASTE SITES $\ldots \ldots \ldots \ldots \ldots \ldots \ldots \ldots \ldots$

3. SITE EVALUATION AND SCORING $\ldots \ldots \ldots \ldots \ldots \ldots \ldots \ldots \ldots \ldots \ldots \ldots$

3.1 IMPORTANCE OF PROFESSIONAL JUDGMENT $\ldots \ldots \ldots \ldots \ldots \ldots \ldots$

3.1.1 Applying Existing Analytical Data . . . . . . . . . . . . . . . . 37

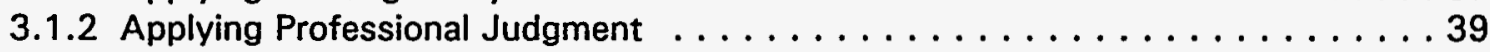

3.2 SITE, SOURCE, AND WASTE CHARACTERIZATION $\ldots \ldots \ldots \ldots \ldots \ldots$

3.2.1 Site Description and Source Characterization $\ldots \ldots \ldots \ldots \ldots \ldots \ldots \ldots$

General Site Description

Source Identification and Characterization

Pathway Considerations

Sample Site Description

Site Sketch

3.2.2 Waste Quantity and Waste Characteristics

Tiered Approach to Evaluate Waste Quantity (WQ)

General Instructions to Score Waste Characteristics (WC)

Scoring Waste Characteristics (WC) for Specific Source Types

Concluding Note

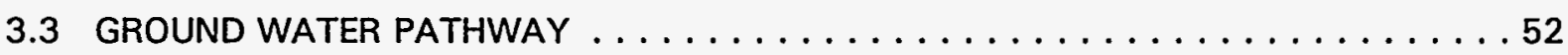

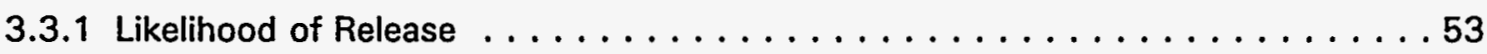

Criteria List for Suspected Release to the Ground Water Pathway

Suspected Release Considerations

Special Considerations When a Release Is Not Suspected

Depth to Aquifer 

Karst Terrain
Scoring Likelihood of Release
Factor: Suspected Release
Factor: No Suspected Release

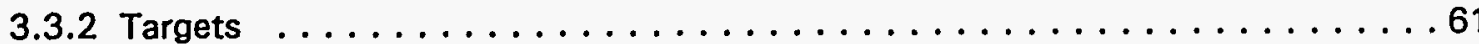

Multiple-Aquifer Systems

Municipal Drinking Water Supplies

Drinking Water Supplies in Areas Not Served by a Municipal System

Identifying the Nearest Drinking Water Well

Evaluating Drinking Water Populations Served by Ground Water

Populations Served by "Blended" Municipal Systems

Populations Served by Other Municipal Systems

Populations Served by Private Domestic or Community Wells

Worker and Student Populations

Criteria List for Primary Target Wells

Primary Target Well Considerations

Factor: Primary Target Population

Factor: Secondary Target Population

Factor: Nearest Well

Factor: Wellhead Protection Area

Factor: Resources

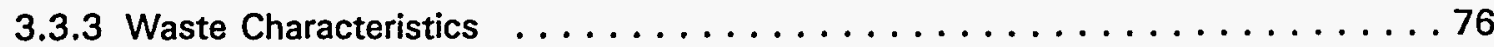

3.3.4 Calculating the Ground Water Pathway Score . . . . . . . . . . . . . 76

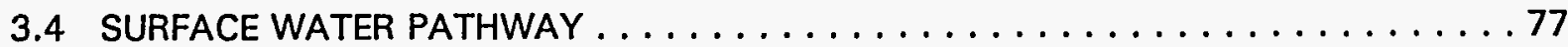

3.4.1 Likelihood of Release $\ldots \ldots \ldots \ldots \ldots \ldots \ldots \ldots \ldots \ldots \ldots \ldots$

Criteria List for Suspected Release to the Surface Water Pathway

Suspected Release Considerations

Special Considerations When a Release Is Not Suspected

Distance to Surface Water

Flood Frequency

Scoring Likelihood of Release

Factor: Suspected Release

Factor: No Suspected Release

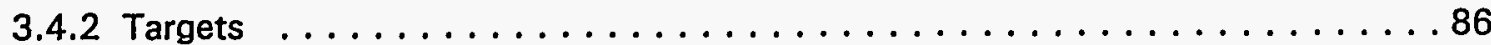

Target Distance Limit

Drinking Water Threat Targets

Identifying Drinking Water Intakes

Flow at Target Intakes

Evaluating Drinking Water Populations

Human Food Chain Threat Targets

Environmental Threat Targets

Criteria List for Primary Targets

Primary Target Considerations

Factor: Primary Target Population 
Factor: Secondary Target Population

Factor: Nearest Intake

Factor: Resources

Factor: Primary Target Fisheries

Factor: Secondary Target Fisheries

Factor: Primary Target Sensitive Environments

Factor: Secondary Target Sensitive Environments

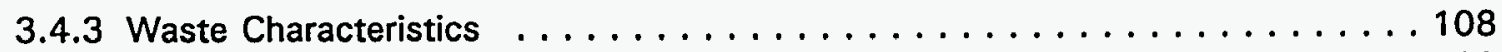

3.4.4 Calculating Surface Water Threat and Pathway Scores . . . . . . . . . . 108

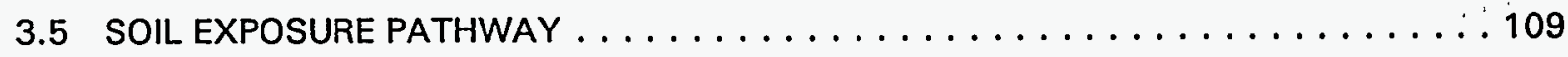

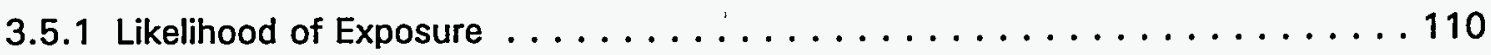

Factor: Suspected Contamination

3.5.2 Targets

Identifying Resident Population

Criteria List for Resident Population

Resident Population Considerations

Evaluating Resident Populations

Identifying and Evaluating Workers

Identifying and Evaluating Terrestrial Sensitive Environments

Factor: Resident Population

Factor: Resident Individual

Factor: Workers

Factor: Terrestrial Sensitive Environments

Factor: Resources

3.5.3 Waste Characteristics ... . . . . . . . . . . . . . . . . . 124

3.5.4 Calculating Soil Exposure Threat and Pathway Scores . . . . . . . . . . . 124

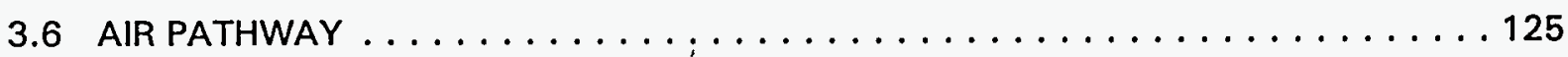

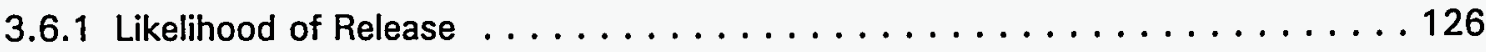

Criteria List for Suspected Release to the Air Pathway

Suspected Release Considerations

Scoring Likelihood of Release

Factor: Suspected Release

Factor: No Suspected Release

3.6.2 Targets

Residential Populations

Worker and Student Populations

Sensitive Environments

Primary Targets

Factor: Primary Target Population

Factor: Secondary Target Population 
Factor: Nearest Individual

Factor: Primary Target Sensitive Environments

Factor: Secondary Target Sensitive Environments

Factor: Resources

3.6.3 Waste Characteristics ........................... 141

3.6.4 Calculating the Air Pathway Score . . . . . . . . . . . . . . 141

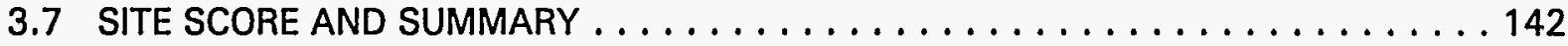

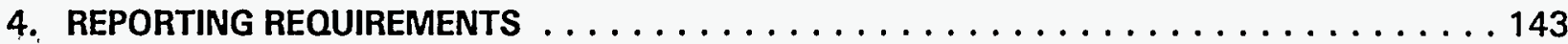

4.1 PA DATA AND SITE CHARACTERISTICS FORM $\ldots \ldots \ldots \ldots \ldots \ldots \ldots \ldots \ldots$

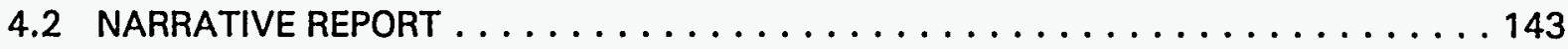

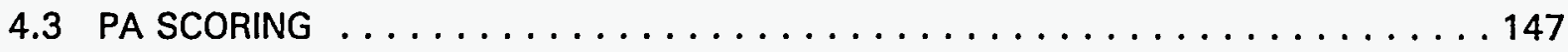

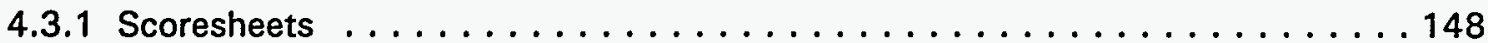

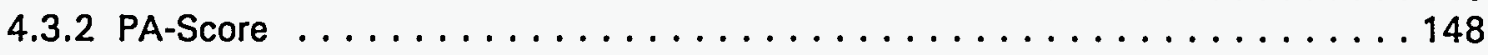

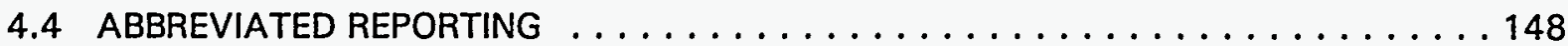

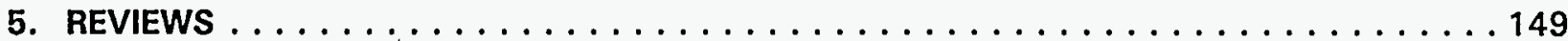

5.1 REVIEW FOR INTERNAL CONSISTENCY $\ldots \ldots \ldots \ldots \ldots \ldots \ldots \ldots \ldots \ldots \ldots$

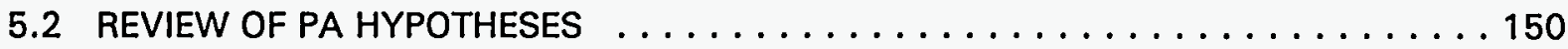

5.3 REVIEW OF AVAILABLE ANALYTICAL DATA $\ldots \ldots \ldots \ldots \ldots \ldots \ldots \ldots \ldots$

5.3.1 Rationale for the Standard PA Approach to Analytical Data . . . . . . . 153

Releases and Target Contamination

Differentiating Levels of Target Contamination

Waste Characteristics

5.3.2 Assessing the Applicability of Available Analytical Data $\ldots \ldots \ldots \ldots \ldots \ldots 154$

5.3.3 Applying Analytical Data ........................ 155

5.4 REVIEW OF GROUND WATER PATHWAY POTENTIAL TO RELEASE $\ldots \ldots \ldots \ldots 156$

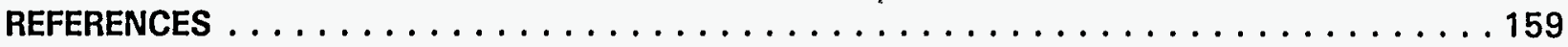

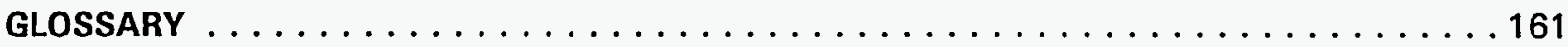




\section{APPENDICES}

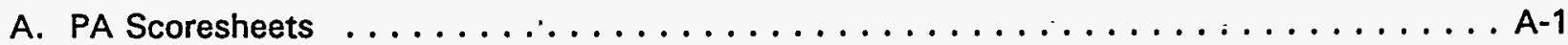

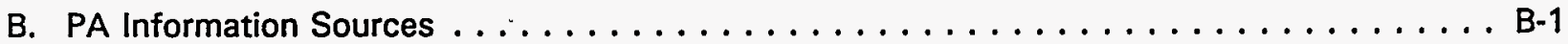

C. Sample PA Narrative Report . . . . . . . . . . . . . . . . . . C-1

D. PA Data and Site Characteristics Form . . . . . . . . . . . . . . . . . D-1

E. Standard Operating Procedure to Determine Site Latitude and Longitude Coordinates .... E-1

\section{FIGURES}

1-1 The Superfund Process $\ldots \ldots \ldots \ldots \ldots \ldots \ldots \ldots \ldots \ldots \ldots \ldots \ldots \ldots \ldots \ldots$

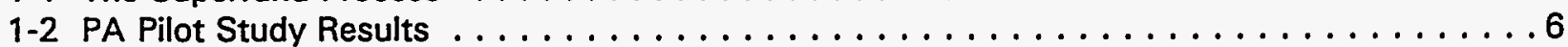

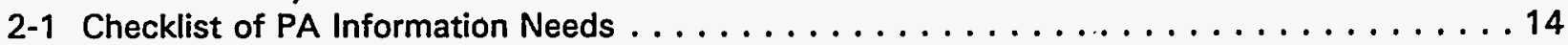

2-2 CERCLA Eligibility Decision Tree . . . . . . . . . . . . . . . . . . . . . 17

2-3 Sample Logbook Page . . . . . . . . . . . . . . . . . . . . . . . . . . . . 30

5-1 Decision Tree for Review of Ground Water Pathway Potential to Release . . . . . . . . 157

\section{TABLES}

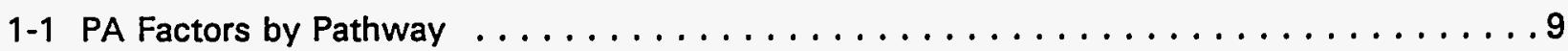

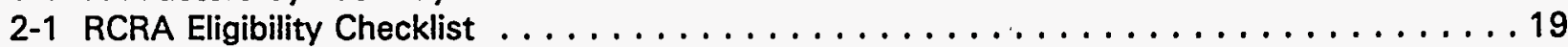

3-1 Source Type Descriptions . . . . . . . . . . . . . . . . . . . . . 43

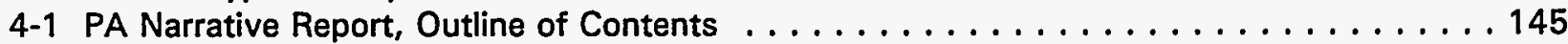

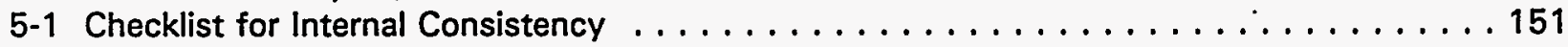




\section{INTRODUCTION}

EPA headquarters and a national site assessment workgroup produced this guidance for Regional, State, and contractor staff who manage or perform preliminary assessments (PAs). EPA has focused this guidance on the types of sites and site conditions most commonly encountered. The PA approach described in this guidance is generally applicable to a wide variety of sites. However, because of the variability among sites, the amount of information available, and the level of investigative effort required, it is not possible to provide guidance that is equally applicable to all sites. PA investigators should recognize this and be aware that variation from this guidance may be necessary for some sites, particularly for PAs performed at Federal facilities, PAs conducted under EPA's Environmental Priorities Initiative (EPI), and PAs at sites that have previously been extensively investigated by EPA or others.

\subsection{PURPOSE OF THIS GUIDANCE}

The purpose of this guidance is to provide instructions for conducting a PA and reporting results. This guidance discusses the information required to evaluate a site and how to obtain it, how to score a site, and reporting requirements. This document also provides guidelines and instruction on PA evaluation, scoring, and the use of standard PA scoresheets. The overall goal of this guidance is to assist PA investigators in conducting high-quality assessments that result in correct site screening or further action recommendations on a nationally consistent basis.

This document is structured as follows:

- Section 1, Introduction: Provides background on the purpose and implementation of Superfund legislation, discusses the structure of the Superfund process, and provides specific detail on the purpose and role of the PA in the site assessment process.

- Section 2, Conducting the PA Investigation: Provides a detailed discussion of data gathering for the PA, including types of sites encountered, conducting file searches, gathering additional "desktop" information, and preparing for and conducting site reconnaissance.

- Section 3, Site Evaluation and Scoring: Furnishes factor-by-factor instruction to evaluate the data collected to develop a site score using PA scoresheets, and discusses the role of professional judgment in the site evaluation process.

- Section 4, Reporting Requirements: Discusses the information needs for PA reporting, provides a detailed outline of a standard PA report, and addresses the use of a standard form for recording site characteristics information.

- Section 5, Reviews: Provides guidelines to review the site evaluation and score, discusses critical aspects of the evaluation that may impact site disposition, and provides guidelines to apply analytical data.

\subsection{CERCLA/SARA LEGISLATION}

In 1980, Congress enacted the Comprehensive Environmental Response, Compensation, and Liability Act (CERCLA), commonly known as Superfund, to respond to the threats posed by uncontrolled releases of hazardous substances into the environment. Section 105 of CERCLA required EPA to establish criteria for determining priorities among releases or threatened releases of 
hazardous substances for the purpose of taking remedial action. To meet this requirement, EPA developed the Hazard Ranking System (HRS) (47 FR 31180, July 16, 1982) to evaluate sites for possible inclusion on the National Priorities List (NPL). The NPL includes those sites that appear to pose the most serious threats to public health or the environment, and are eligible for Superfundfinanced remedial action.

The Superfund Amendments and Reauthorization Act of 1986 (SARA) required EPA to revise the HRS to more accurately "assess the relative degree of risk to human health and the environment posed by sites." SARA also required the HRS to take into account recreational use of surface waters, contamination of the human food chain and drinking water supplies, and potential contamination of ambient air. EPA revised the HRS in response to these mandates (55 FR 51532 , December 14, 1990). The revised HRS requires more data than the original HRS, and the site assessment process has been restructured accordingly. Changes to the site assessment process are also the result of balancing the need to accurately assess site conditions with the need to conserve resources.

\subsection{THE SUPERFUND PROCESS}

EPA uses a structured program to determine appropriate response for Superfund sites (Figure 1-1):

- The site assessment phase identifies sites for the NPL.

- The remedial phase determines the extent of contamination and implements cleanup remedies.

The primary objective of the site assessment phase is to obtain the data necessary to identify the highest priority sites posing threats to human health and the environment. The site assessment phase begins with site discovery, or notification to EPA of possible releases of hazardous substances. Sites are discovered by Regional EPA offices, State agencies, and citizens who file a PA petition. Section 105(d) of SARA established the PA petition as a formal mechanism for citizens to report potential hazardous waste sites. Publication 9200.5-301FS, "Preliminary Assessment Petition," by EPA's Office of Emergency and Remedial Response describes the process. Once discovered, sites are entered into the Comprehensive Environmental Response, Compensation, and Liability Information System (CERCLIS), EPA's computerized inventory of potential hazardous waste sites. EPA then evaluates the potential for a release of hazardous substances from a site during two investigative steps:

- Preliminary Assessment: A PA is a limited-scope investigation performed by States and/or EPA on every CERCLIS site. PA investigators collect readily available information and conduct a site and environs reconnaissance. The PA is designed to distinguish between sites that pose little or no threat to human health and the environment and sites that require further investigation. The PA also identifies sites requiring assessment for possible emergency response actions.

- Site Inspection (SI): If the PA recommends further investigation, an SI is performed. SI investigators typically collect waste and environmental samples to determine the substances present at a site and whether they are being released to the environment. The objective of the $\mathrm{SI}$ is to identify which sites have a high probability of qualifying for the NPL. A second objective is to identify sites posing immediate health or environmental threats which require emergency response. 
Figure 1-1

The Superfund Process

\section{SITE ASSESSMENT PHASE}

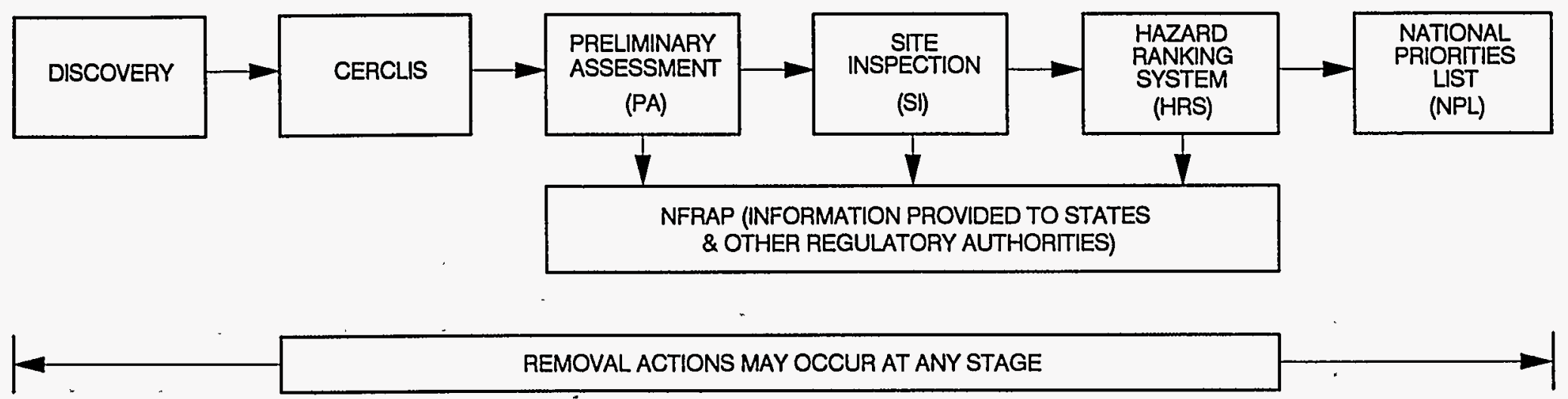

\section{REMEDIAL PHASE}

\begin{tabular}{|c|c|c|c|c|}
\hline $\begin{array}{l}\text { NATIONAL } \\
\text { PRIORITIES } \\
\text { LIST } \\
\text { (NPL) }\end{array}$ & $\begin{array}{l}\text { REMEDIAL } \\
\text { INVESTIGATION/ } \\
\text { FEASIBILITY } \\
\text { STUDY } \\
\text { (RI/FS) }\end{array}$ & $\begin{array}{l}\text { RECORD } \\
\text { OF } \\
\text { DECISION } \\
\text { (ROD) }\end{array}$ & $\begin{array}{c}\text { REMEDIAL } \\
\text { DESIGN/ } \\
\text { REMEDIAL } \\
\text { ACTION } \\
\text { (RD/RA) }\end{array}$ & $\begin{array}{c}\text { OPERATION } \\
\text { AND } \\
\text { MAINTENANCE }\end{array}$ \\
\hline
\end{tabular}

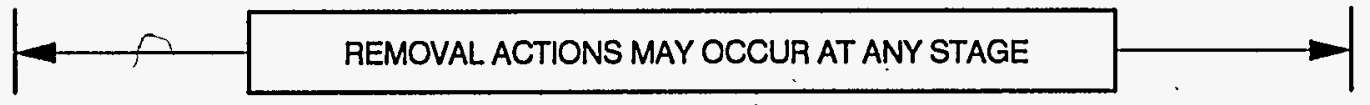


At the end of both the PA and SI, EPA applies the HRS to derive a site score and determine either that further investigation is necessary or that the site should receive a "no further remedial action planned" (NFRAP) recommendation. A NFRAP recommendation means that further action under the Federal Superfund program is not planned; however, such sites may be reexamined later if warranted. File information for NFRAP sites is provided to the State, or other regulatory authorities, which may also take action on their own.

The SI can be conducted in one stage or two. Often, the SI can be structured to test the critical PA conclusions that resulted in the recommendation for an SI; the information developed may be sufficient for EPA to determine either that the site requires no further action or that it is likely to score high enough for NPL consideration. If further investigation is necessary to document an HRS score, an expanded SI can be conducted. A site with an HRS score of 28.50 or greater is eligible for proposal to the NPL, and a formal HRS package may be prepared.

These steps -- discovery, entry into CERCLIS, PA, SI, expanded SI (if warranted), HRS package preparation, and placement on the NPL -- make up the site assessment phase of the Superfund process. An important aspect of this process is its screening function, identifying sites that will not score high enough or are otherwise ineligible for the NPL, and removing them from further consideration. While all sites in CERCLIS undergo a PA, only about 3 out of 5 (historically) have been found to require an SI, and only 1 in about 15 or 20 warrant placement on the NPL.

Decisions made during the site assessment phase determine which sites are addressed during the remedial phase of the Superfund program. The objective of the remedial phase is to implement remedies that eliminate, reduce, or control risks to human health and the environment. Investigations and analyses identify the best cleanup alternative for a site:

- Remedial Investigation (RI): An Rl is conducted at all NPL sites. The Rl is a field investigation to characterize the nature and extent of contamination at a site. The RI supports development, evaluation, and selection of the appropriate response alternative.

- Feasibility Study (FS): Based on the data collected during the RI, options for final remedial actions are developed and evaluated in the FS. The most viable cleanup options are evaluated based on several criteria: ability to protect human health and the environment; long- and short-term effectiveness; ability to comply with applicable State and Federal requirements; ability to reduce waste toxicity, mobility, or volume; implementability; State and community acceptance; and cost.

- Record of Decision (ROD): After all facts about a site have been evaluated, EPA selects a final remedy and prepares a ROD. The ROD supports selection of the final remedy by documenting all facts, analyses, and policy considerations.

- Remedial Design/Remedial Action (RD/RA): The RD/RA stage includes development of the actual design of the selected remedy and implementation of the remedy through construction.

The final steps in the Superfund process include initiating long-term operation and maintenance of the site, where necessary.

\subsection{PURPOSE AND SCOPE OF THE PA}

The purpose of the PA is to differentiate sites that pose little or no potential threat to human health and the environment from sites that warrant further investigation. The PA also supports 
emergency response and removal activities, fulfills public information needs, and generally furnishes appropriate information about the site early in the site assessment process.

The scope of the PA is defined in Section 420 of the National Oil and Hazardous Substances Pollution Contingency Plan (40 CFR Part 300), commonly known as the NCP. As the first stage of investigation conducted for every site in CERCLIS, the PA is a relatively quick, low-cost compilation of existing information about the site and its surrounding area, with an emphasis on obtaining comprehensive information on targets -- that is, people and resources that might be threatened by a release from the site. A PA generally involves a reconnaissance of the site and its environs. Sampling is generally not conducted during a PA. The scope of the PA must be sufficient to complete a number of tasks:

- Review existing information about the site.

- Conduct a site and environs reconnaissance.

- Collect additional information about the site, with an emphasis on target information.

- Evaluate all information and develop a site score.

- Prepare a brief site summary report and site characteristics form.

Developing an HRS score usually requires extensive analytical data along with a large amount of other information about the site and its surroundings. At the PA stage, where the scope of investigation and available hours are limited, it is not generally practical to apply the HRS in its entirety. Consequently, to implement the HRS as a screening tool at the PA stage, EPA has developed a simplified evaluation approach to quantitatively assess a limited number of HRS factors. The selected factors are strong indicators of the potential site score and can be evaluated within the scope of the PA. Other important HRS considerations that are not readily available at the PA are evaluated qualitatively. PA scoresheets (Appendix A) identify and provide instruction for the quantitative and qualitative evaluation of the critical HRS factors. This scoring methodology uses reasonable default values and truncated evaluations for factors not critical to the site score.

The PA described in this document typically requires an average of about 120 hours to complete. Some PAs may require more hours if the site is complex and if additional effort is likely to strengthen the recommendation regarding site disposition, particularly a NFRAP recommendation. On the other hand, fewer hours may be needed for relatively straightforward sites that clearly warrant further investigation, sites with extensive existing file information, or sites ineligible for CERCLA remedial action based on statutory or policy requirements. Based on a pilot study EPA conducted in 1991 (see Figure 1-2), the range of hours required for PA activities at typical sites is estimated as follows:

\begin{tabular}{|l|c|}
\hline \multicolumn{1}{|c|}{ PA Activity } & Typical Range of Hours \\
\hline \hline Collect information & $60-80$ \\
\hline Reconnaissance & $10-20$ \\
\hline Scoring & $5-15$ \\
\hline Reporting & $20-30$ \\
\hline \hline Average total & 120 \\
\hline
\end{tabular}




\section{Figurè 1-2}

PA Pilot Study Results

EPA conducted a pilot study to test the PA approach described in this document. The study included 27 sites in EPA Regions 2, 5, and 10, essentially randomly selected from CERCLIS. The sites were already scheduled for PAs and there were no previous EPA investigations at any of them. Hours to perform the PA were tracked for 22 of the 27 sites and reported in four major categories:

- Data collection

- Site reconnaissance

- Scoring (PA scoresheets)

- Reporting (narrative report and site characteristics data form)

An approximate breakdown of hours is shown in the pie chart below. Significant results of the pilot study include:

- Data collection accounted for more than half of the hours expended; targets identification alone required more than one-third of the total.

- Hours required to complete the PA ranged from 66 to 181.

-- 18 of the 22 sites ranged from 93 to 149 hours.

-- The average total was 116 hours; the median was 113 hours.

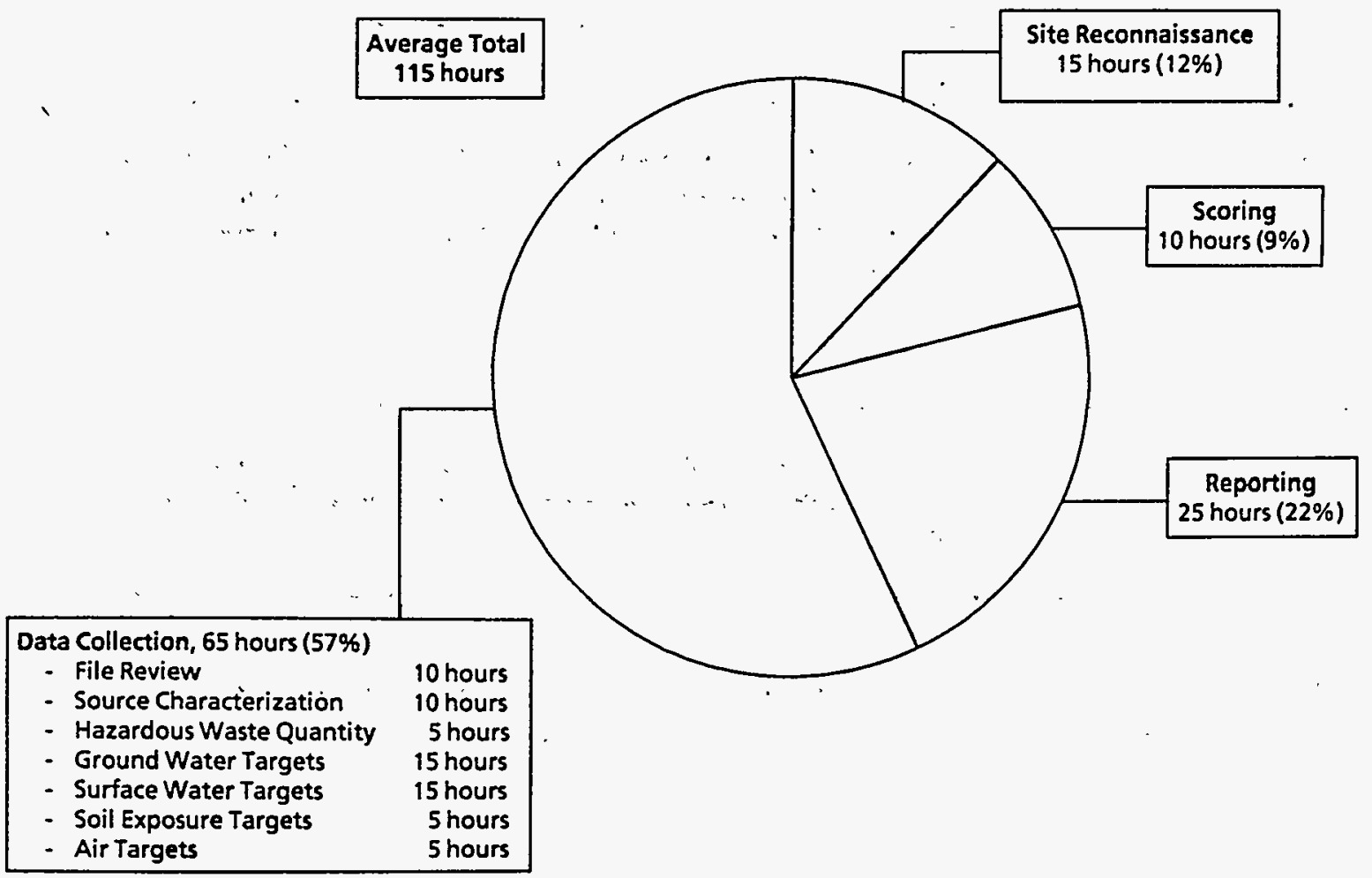


The data and conclusions documented for the PA are the foundation of all future Superfund activity. The PA is a critical stage in the site assessment process; sites must be accurately characterized because incorrect site recommendations could waste resources or even endanger human health and the environment. The PA evaluation approach detailed in this guidance supports this requirement and ensures nationally consistent data collection and documentation, resulting in quantitative, defensible site screening recommendations within a limited budget.

\subsection{S'TRUCTURE OF THE PA}

PA site evaluation follows the structure of the HRS and is divided into four hazardous substance exposure routes called pathways: three migration pathways (ground water, surface water, and air) and one exposure pathway (soil exposure). Each pathway represents a means by which hazardous substances may pose a threat to human health and/or the environment.
Pathway
Accounts for

Ground Water

Hazardous substance migration to and within aquifers; potential thrẹats to drinking water supplies.

Surface Water

Hazardous substance migration to surface water bodies; potential threats to drinking water supplies, the human food chain, and sensitive environments.

Soil Exposure

Potential threat to people on or near the site who may come into contact with exposed wastes or areas of suspected contamination. This includes both soil ingestion and dermal exposure.
Air
Hazardous substance migration, in gaseous or particulate form, through the air; potential threats to people and sensitive environments.

Each pathway consists of three factor categories. The PA investigator collects a variety of information to evaluate these factor categories. 
Likelihood of Release Relative likelihood of a hazardous substance migrating from the site through the specific pathway medium (ground water, surface water, air).

Targets

Presence of people, physical resources (drinking water wells or surface water intakes), and environmental resources (sensitive environments, fisheries) that might be threatened by release of a hazardous substance from the site.

Waste Characteristics

An estimation of the type and quantity of hazardous wastes at the site.

The basic units of site assessment evaluation are called factors. Each factor is assigned a score on the basis of specific data about that factor. Each factor category consists of a set of related factors. Table 1-1 lists the factors requiring explicit PA evaluation, by pathway and factor category.

The PA investigator must collect the necessary information to meet two goals:

- Accurately and completely support a site disposition recommendation, and

- Provide information useful to the SI that may follow.

\subsection{PA TERMINOLOGY}

Some PA terms differ slightly from HRS terms. HRS terms have highly specific meaning and were developed to meet the needs of HRS scoring. PA terminology differs because information available during the PA may be limited, and the principal objective of the PA is to support a recommendation regarding the need for further investigation and possible subsequent HRS scoring.

The glossary beginning on page 161 defines most PA terms in this document. PA scoring factors are also defined in conjunction with factor discussions.in Sections 3.3 through 3.6. Several terms that are not necessarily pathway-specific, but apply broadly throughout the PA evaluation, are defined in the following sections.

\subsubsection{General Terms}

Factor: The basic element of site assessment requiring data collection and evaluation for scoring purposes. 
Table 1-1

PA Factors by Pathway

\begin{tabular}{|c|c|c|c|}
\hline \multirow[b]{2}{*}{ Pathway } & \multicolumn{3}{|c|}{ Factors Within Factor Categories } \\
\hline & Likelihood of Release & Waste Characteristics & Targets \\
\hline Ground Water & $\begin{array}{l}\text { Suspected Release } \\
\text { No Șuspected Release } \\
\text { Depth to Aquifer }\end{array}$ & Hazardous Waste Quantity & $\begin{array}{l}\text { Primary Target Population } \\
\text { Secondary Target Population } \\
\text { Nearest Drinking Water Well } \\
\text { Wellhead Protection Area } \\
\text { Resources }\end{array}$ \\
\hline Surface Water & $\begin{array}{l}\text { Suspected Release } \\
\text { No Suspected Release } \\
\text { Distance to Surface Water } \\
\text { Flood Frequency }\end{array}$ & Hazardous Waste Quantity & $\begin{array}{l}\text { Primary Target Population } \\
\text { Secondary Target Population } \\
\text { Nearest Drinking Water Intake } \\
\text { Resources } \\
\text { Primary Target Fisheries } \\
\text { Secondary Target Fisheries } \\
\text { Primary Target Sensitive Environments } \\
\text { Secondary Target Sensitive Environments }\end{array}$ \\
\hline Soil Exposure & Suspected Contamination & Hazardous Waste Quantity & $\begin{array}{l}\text { Resident Population } \\
\text { Resident Individual } \\
\text { Workers } \\
\text { Terrestrial Sensitive Environments } \\
\text { Resources } \\
\text { Nearby Population }\end{array}$ \\
\hline Air & $\begin{array}{l}\text { Suspected Release } \\
\text { No Suspected Release }\end{array}$ & Hazardous Waste Quantity & $\begin{array}{l}\text { Primary Target Population } \\
\text { Secondary Target Population } \\
\text { Nearest Individual } \\
\text { Primary Target Sensitive Environments } \\
\text { Secondary Target Sensitive Environments } \\
\text { Resources }\end{array}$ \\
\hline
\end{tabular}


Factor category: A set of related factors. Each pathway consists of three factor categories -likelihood of release or exposure, targets, and waste characteristics.

Pathway: The environmental medium through which a hazardous substance may threaten targets. The PA evaluates the migration and threat potential through the ground water, surface water, air, and soil exposure pathways.

Source: An area where a hazardous substance may have been deposited, stored, disposed, or placed. Also, soil that may have become contaminated as a result of hazardous substance migration. In general, however, the volumes of air, ground water, surface water, and surface water sediments that may have become contaminated through migration are not considered sources.

Site: The area consisting of the aggregation of sources, the areas between sources, and areas that may have been contaminated due to migration from sources; site boundaries are independent of property boundaries.

Hazardous substance or hazardous constituent: Material defined as a hazardous substance, pollutant, or contaminant in CERCLA Sections $101(14)$ and 101(33).

Hazardous waste: Any material suspected to contain a hazardous substance, pollutant, or contaminant that is or was in a source.

\subsubsection{Terms Relating to Releases}

Suspected release: A professional judgment conclusion based on site and pathway conditions indicating that a hazardous substance is likely to have been released to the environment. (Suspected release is the PA term analogous to the HRS "observed release.") 
No suspected release: A professional judgment conclusion based on site and pathway conditions indicating that a hazardous substance is not likely to have been released to the environment. (No suspected release is the PA term analogous to the HRS "potential to release."

\subsubsection{Terms Relating to Targets}

Target: A physical or environmental receptor that is within the target distance limit for a particular pathway. Targets may include wells and surface water intakes supplying drinking water, fisheries, sensitive environments, and resources.

Target population: The human population associated with the site and/or its targets. Target populations consist of those people who use target wells or surface water intakes supplying drinking water, consume food chain species taken from target fisheries, or are regularly present on the site or within target distance limits.

Target distance limit: The maximum distance over which targets are evaluated. The target distance limit varies by pathway: ground water and air pathways -- a 4-mile radius around the site; surface water pathway -- 15 miles downstream from the probable point of entry to surface water; soil exposure pathway -- 200 feet (for the resident population threat) and 1 mile (for the nearby population threat) from areas of known or suspected contamination.

Primary target: A target which, based on professional judgment of site and pathway conditions and target characteristics, has a relatively high likelihood of exposure to a hazardous substance. To score a primary target, a suspected release must first be hypothesized; however, a suspected release is not in itself sufficient to score primary targets. (Primary target is the PA term analogous to the HRS target exposed to Level I or Level II actual contamination.)

Secondary target: A target which, based on professional judgment of site and pathway conditions and target characteristics, has a relatively low likelihood of exposure to a hazardous substance. If a release is suspected, there may be both primary targets and secondary targets. However, if no release is suspected, all targets are scored as secondary targets. (Secondary target is the PA term analogous to the HRS target exposed to potential contamination.) 



\section{CONDUCTING THE PA INVESTIGATION}

The investigative portion of the PA primarily involves collecting and reviewing readily available information concerning the site and its surroundings. Figure 2-1 displays a checklist summarizing the type of information needed, divided into general categories that roughly correspond to the structure of the PA. For example, the first type of data to collect and review concerns the general nature of the site -- such things as location, ownership history, type of site operations, whether it is active or inactive, size of the site, setting, and predominant land uses in the vicinity. After collecting this basic information you then examine the site in more detail and review data that concern specific waste sources and potential threats posed through each pathway.

Become familiar with the checklist of information needs before initiating data collection efforts. Knowing the information needs at the outset helps focus attention on those pieces of information that are relevant and necessary to assess the threat to human health and the environment, enhancing the efficiency of completing the task. Figure 2-1 can also be used as a checklist to keep track of data that have been collected and to identify remaining information needs. Two other PA information acquisition tools are available:

- Appendix B of this document provides a general listing of PA information sources with brief descriptions of the types of information each source contains and the particular aspect of the PA that the information supports. In addition, Appendix $B$ contains a cross-referenced listing of data sources organized by PA factors.

- "Site Assessment Information Directory" (available from EPA) contains a much more detailed compilation of PA data sources, including names, addresses, and telephone numbers of agencies that can provide site assessment information.

The scope of the investigative portion of the PA is somewhat limited. Specific components are:

- Verify the site name and location (i.e., ensure that the site exists, and is not a duplicate or "alias" of another site).

- Collect and review readily available file information.

- Determine CERCLA eligibility.

- Collect "desktop" data.

- Conduct site reconnaissance.

- Identify the need for emergency response.

- Collect any additional information needed to develop the PA score.

Section 3 provides more detail on factor-by-factor data collection and evaluation to develop a site score. Reporting PA results is covered in Section 4, and reviewing results is outlined in Section 5. 
Figure 2-1

Checklist of PA Information Needs

\section{GENERAL SITE INFORMATION}
こ Site Name and Locetion
CERCLIS ID Number
$\square$ Type of Facility
$\square$ Type of Ownership
$\square$ Site Status (active/inactive)
$\square$ Years of Operation

Owner/Operator Information

$\square$ Operational History

$\square$ Environmental Setting

$\square$ Approximate Size of Site

$\square$ Latitude/Longitude

$\square$ Site Sketch

\section{SOURCE AND WASTE CHARACTERISTICS}

Source Types and Locations

Size of Sources (dimensions) $\square$ Weste Types and Quantities

$\square$ Hazardous Substances Present

\section{GROUND WATER USE AND CHARACTERISTICS}

$\square$ General Stratigraphy and Hydrogeology

$\square$ Presence of Karst Terrain

$\square$ Depth to Shallowest Aquifer

$\square$ Private Wells Within 4 Miles (locations, populations served) $\square$ Municipal Wells Within 4 Miles (locations, populations served, blended systems)

$\square$ Distance to Nearest Drinking

Water Well

Wellhead Protection Areas

\section{SURFACE WATER USE AND CHARACTERISTICS}

$\square$ Flood Frequency at Site

$\square$ Distance to Nearest Surface Water

$\square$ Surface Water Body Types Within 15 Downstream Miles

$\square$ Surface Water Flow Characteristics Within 15 Downstream Miles

$\square$ Drinking Water Intakes Within 15 Downstream Miles (locations, populations served, blended systems)

$\square$ Fisheries Within 15 Downstream Miles

- Sensitive Environments and Wetlands Within 15 Downstream Miles

SOIL EXPOSURE CHARACTERISTICS

$\square$ Number of People Living Within 200 Feet

$\square$ Schools or Day Care Within 200 Feet (enrollment)

$\square$ Populations Within 1 Mile $\square$ Number of Workers at Facility

$\square$ Locations of Terrestrial Sensitive Environments

\section{AIR PATHWAY CHARACTERISTICS}

Populations Within 4 Miles

Distance to Nearest Individual
Locations of Sensitive Environments

Within 4 Miles

$\square$ Acreage of Wetlands Within 4 Miles 


\subsection{INITIATING THE INVESTIGATION}

As the first step in the site evaluation and screening process, PAs are performed on a wide variety of sites. PA sites may be abandoned or active; they may be large operating facilities or small areas where spills or illegal disposal of hazardous wastes has occurred. Significant amounts of information concerning past operations will be available for some sites; for others, information will be limited: Your may be assigned to perform a PA" on a site that is already under the authority of another environmental statute, or a site whose location you cannot verify. . The structured PA approach described in this document applies to the majority of sites and the types of information typically available.

\subsubsection{CERCLIS}

The NCP requires that a PA be conducted on each site entered into CERCLIS. Potential hazardous waste sites identified by the Superfund program, or reported through citizen complaints or referrals from other agencies, are entered into CERCLIS. As sites progress through the Superfund program -- from PA through remediation -- EPA updates the information in CERCLIS.

CERCLIS contains administrative information and the site name, address, zip code, county code, latitude/longitude coordinates, date discovered, and date and type of any previous site assessment activity. CERCLIS information is updated regularly and is available from hardcopy printouts at EPA Regional and State environmental agency offices.

Verify the physical existence of the site. Because site information is not generally screened before entry into CERCLIS, nonexistent sites or duplicate site names may be ençountered. In the past, a small percentage of sites entered into CERCLIS proved to be "non-sites" upon investigation, when no facility matched the site name and address listed as the site location. In addition, sites may be mistakenly entered into CERCLIS more than once. Therefore, verify the site name and crossreference it against other entries in CERCLIS to ensure it is not a duplicate entry. Be sure to crosscheck using the CERCLIS ID number, not just the site name, because distinct sites can have similar or even the same names. The CERCLIS ID number is a unique identifier for each site. Also verify the address of the site from a local street map. From the map you can begin to get an idea of the șite setting.

Some sites in CERCLIS have also-known-as (aka) designations or "aliases." ' As a site progresses from discovery at the local stage through investigation at the Federal level, its name may be changed to be more descriptive (for example, Longmeadow Dump may be changed to Former Longmeadow Municipal Landfill). Much of your data collection effort will involve accessing State and local agency files, which may list the site under an alternative name. Determining the different names by which a site is known is necessary to complete a comprehensive file search. CERCLIS provides listings of all known aliases for sites entered.

Useful information concerning local geology/hydrology and general site environs (e.g., wetlands, other sensitive environments, local drinking water supply sources) may be obtained from the files of nearby sites previously investigated under CERCLA. Accessing this information may reduce duplication of effort and may also provide names and phone numbers of agencies and individuals you can contact to obtain additional information. CERCLIS can be used to identify nearby sites using zip code; latitude/longitude, or county identifiers. Your office may have additional in-house tracking systems or printouts that list completed investigations. 


\subsubsection{HWDMS}

The Hazardous Waste Data Management System (HWDMS) is another EPA database that lists all known hazardous waste producers in each EPA Region. HWDMS contains general site characteristics information including type of ownership, operational status (i.e., active or inactive), type of facility, Resource Conservation and Recovery Act (RCRA) status, types of permits held, methods of waste disposal, and some waste quantity information. If HWDMS printouts are not available in-house, they are available at EPA Regional offices. The quality of HWDMS data depends on the frequericy of updates. Therefore, supplement any information obtained with additional information from your review of file materials and discussions with EPA personnel (Section 2.3).

\subsection{DETERMINING CERCLA ELIGIBILITY}

The next step in the PA process is to collect and review readily available file information (discussed in Section 2.3) and investigate the site's CERCLA eligibility. Because site screening is not generally performed prior to CERCLIS entry, some sites entered into CERCLIS may be ineligible for CERCLA response for statutory and/or policy reasons. For example, EPA policy has generally been to respond under the RCRA program to sites subject to the corrective action authorities of RCRA Subtitle $C$, thus conserving CERCLA resources. In other cases, CERCLA excludes certain types of releases and wastes.

Hazardous substances, pollutants, and contaminants eligible for CERCLA response are defined in CERCLA Sections 101(14) and 101(33). These include a variety of substances identified in specific sections of the Federal Water Pollution Control Act, the Solid Waste Disposal Act, the Clean Air Act, and the Toxic Substances Control Act, along with any other substance that EPA may designate.

Regional EPA site assessment personnel are responsible for deciding a site's CERCLA eligibility. The PA evaluator is responsible for investigating CERCLA eligibility concerns and must inform EPA site assessment personnel of any findings indicating the site may be ineligible. CERCLA eligibility concerns should be investigated early during the PA process to avoid unnecessary expenditure of resources on sites that should be evaluated under a different program. Note that, should a site be determined ineligible for CERCLA response, the PA may be terminated by your Regional EPA site assessment contact. In such a case, abbreviated PA reporting requirements may apply (see Section 4.4).

Figure 2-2 outlines the process for determining CERCLA eligibility. Each of the categories on the decision tree is discussed in the following subsections.

\subsubsection{RCRA Sites}

EPA's Superfund and RCRA programs overlap. Under certain circumstances and for a variety of policy reasons, EPA will respond under CERCLA to sites that are subject to RCRA Subtitle $C$. See 54 FR 41000, October 4, 1989, for EPA's policy on listing RCRA sites on the NPL. As the PA investigator, you are responsible for identifying sites that may be subject to RCRA Subtitle $C$ corrective action and informing your Regional EPA site assessment contact. Regional EPA site assessment personnel will decide whether to continue CERCLA activities or to address the site under the RCRA program. 
Figure 2-2

CERCLA Eligibility Decision Tree

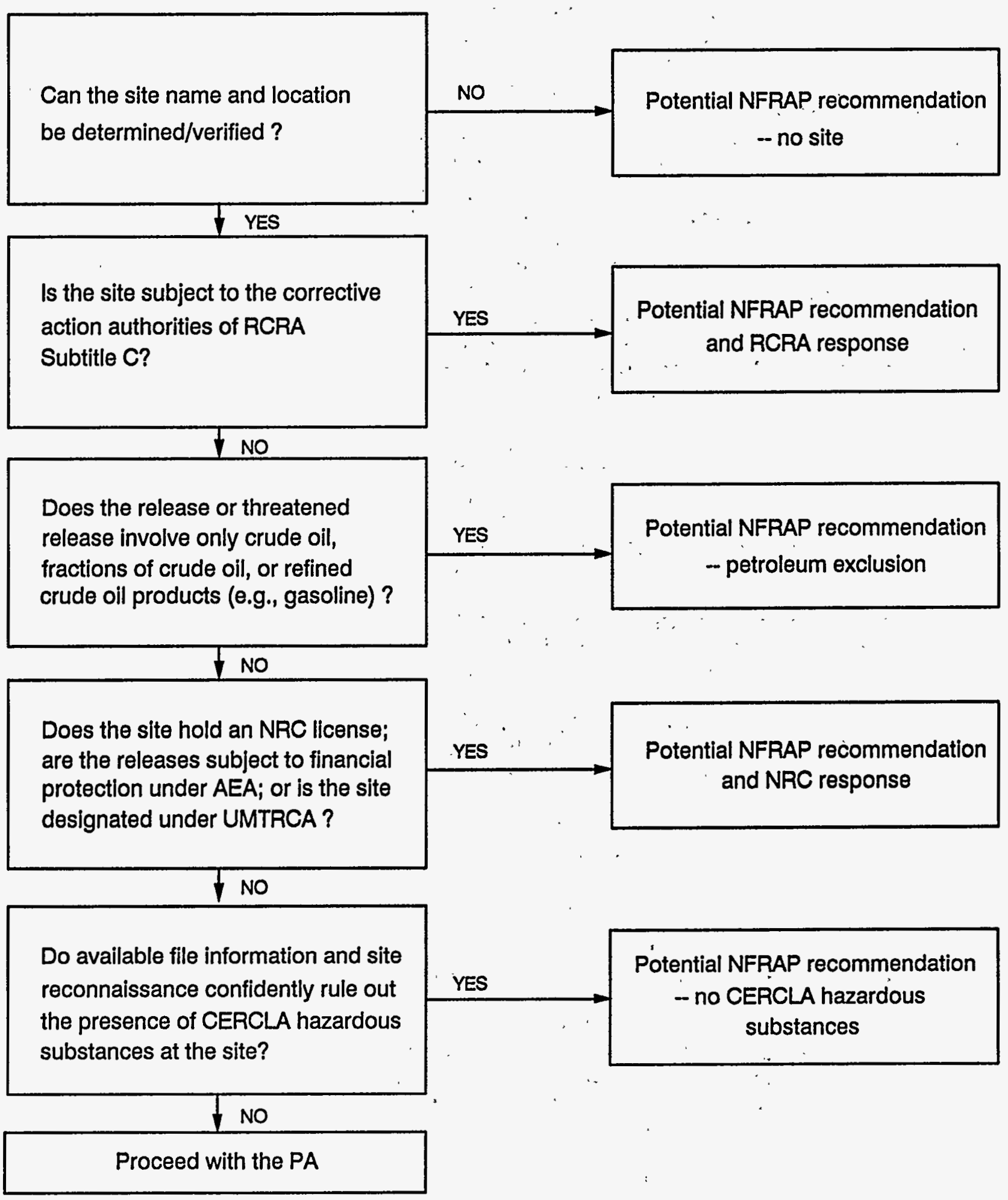


The types of sites subject to the corrective action authorities of RCRA Subtitle C include:

- Currently operating RCRA "Treatment, Storage, or Disposal Fácilities" (TSDFs).

- Former TSDFs that operated as such for a period of time after November 19, 1980.

- RCRA "Converters" that are former "Treatment or Storage Facilities" (TSFs) which have changed their RCRA status to "Generator" or "Non-handler."

- RCRA "Non- or Late Filers."

Sites subject to RCRA Subtitle $C$ include sites handling RCRA-defined hazardous wastes (see 40 CFR Part 261.3, Definition of Hazardous Waste) which are currently, or were for any period of time after November 19, 1980, functioning as TSDFs (see 40 CFR Part 260.10, Definition's): If the site ceased operating before November 19,1980, it is not subject to RCRA Subtitle $C$ and you can proceed with the PA investigation, providing no other eligibility concerns pertain.

All companies handling RCRA-defined hazardous wastes were required to notify EPA of their waste handling practices in 1980 . Those that complied with this requirement were mailed a RCRA Part $A$ Operating Permit Application. Upon submitting the Part A Application, site operators were granted interim RCRA status. Facilities with interim status were authorized to continue operations until EPA requested submittal of a Part B Operating Permit Application. Many TSFs did not pursue full operating permits, but instead changed from TSFs to either "Generator" or "Non-handler" status. These "Converter" sites are still subject to the corrective action authorities of RCRA Subtitle C because they operated as TSFs after November 19, 1980, even though they no longer do.

A second category of sites called "Non- or Late Filers" are facilities that operated as TSDFs for some period after November 19, 1980, but either never notified or delayed notifying EPA of their waste handling practices. These non- or late filers are subject to RCRA Subtitle $C$ corrective action because they were handling hazardous waste after November 19,1980:

A third category of sites, called "Protective Filers", includes facilities that received interim status as a result of filing a Part A Permit Application, but never actually operated as TSDFs. Some companies filed Part A Applications as a precautionary measure to avoid being out of compliance with the new RCRA requirements. These companies later notified EPA that they were not, in fact, TSDFs and had simply filed to protect themselves. Sites which had interim status but have proven that they never operated as TSDFs are considered protective filers and are not subject to the corrective action authorities of RCRA.

Computer printouts available from EPA list the current and past RCRA status of all sites that have identified themselves to EPA as hazardous waste handlers. Consult these printouts to determine if the site being investigated currently has RCRA status. You must also investigate historical RCRA status for facilities that operated after 1980. As discussed above, a site that is currently classified as a "Generator" may have operated for some period of time after November 19, 1980 as a TSF. If so, it is still subject to RCRA corrective action. . Determining CERCLA eligibility for such sites requires additional efforts including review of historical EPA RCRA files (Section 2.3.2) and, possibly, discussions with EPA RCRA personnel. The RCRA status of the site should also be checked in the HWDMS database.

Table 2-1 presents a checklist to evaluate RCRA eligibility. Answering the questions based on your review of database and file information, as well as discussions with EPA personnel, may allow you. to conclude the site's eligibility for RCRA response. :However, determining whether a RCRA site meets EPA's policy for ultimate placement on the NPL may be beyond what can be achieved at the PA stage (for more information, see EPA's "Regional Quality Control Guidance for NPL Candidate 
Sites," OSWER Directive 9345.1-08). If during any stage of the PA investigation you come across information that leads you to believe the site might be eligible for RCRA Subtitle $C$ corrective action, notify your Regional EPA site assessment contact, who will discuss the situation with representatives of the RCRA program and decide whether to proceed with CERCLA investigative activities.

Table 2-1

RCRA Eligibility Checklist

1. Has the facility treated, stored, or disposed any RCRA hazardous waste for any period of time since November 19, 1980 ? (If the facility or site is a known "protective filer," check no.)

Yes $\square$ No

IF THE ANSWER TO QUESTION 1 IS "NO", STOP; SITE IS NOT ELIGIBLE FOR RCRA RESPONSE.

IF YES, CONTINUE WITH CHECKLIST.

2. Does the facility currently have a RCRA Part B Operating Permit or a post-closure permit?

3. Did the facility file a Part A Permit Application?

Yes $\square$ No

3. Did the facility fle a Part A Permit Application?

Yes $\square$ No

. If yes,

- Does the facility currently have interim RCRA status? $\quad \square$ Yes $\square$ No

- Did the facility convert its status from TSF to "Generator" or "Non-handler"?

Yes $\square$ No

If no,

- Is the facility a "Non- or Late Filer"?

Yes

No

IF ANSWERS TO ALL QUESTIONS IN PARTS 2 AND 3 ARE "NO," THE SITE IS NOT ELIGIBLE FOR RCRA RESPONSE. IF THE ANSWER TO ANY QUESTION IS "YES," DISCUSS THE SITE WITH YOUR EPA SITE ASSESSMENT CONTACT.

\subsubsection{CERCLA Petroleum Exclusion}

CERCLA authorized Federal response to releases or threatened releases of "hazardous substances" and "pollutants and contaminants." CERCLA excludes "petroleum, including crude oil or any fraction thereof" from the definition of these terms. . However, . CERCLA does not define the specific types of petroleum products excluded. 
EPA's current interpretation of the petroleum exclusion is that a release or threatened release involving solely crude oil, fractions of crude oil, or refined crude oil products (e.g., gasoline) is not eligible for CERCLA response action. However, release of a CERCLA hazardous substance (e.g., lead, polychlorinated biphenols) mixed with oil through either the addition of the hazardous substance to the oil (e.g., oil-based paint, transformer coolant), or as a result of the use of the oil (e.g., waste oil containing lead as a result of combustion) is subject to CERCLA. In addition, if a CERCLA hazardous substance and oil are commingled to the extent that they cannot be.practicably separated, the entire mixture is subject to CERCLA. Be aware that EPA's interpretation of the petroleum exclusion is currently under review and the policy may change in the future.

If the only type of release or threatened release involves materials that fall under the petroleum exclusion, notify your Regional EPA site assessment contact. EPA will decide whether the investigation should continue or the site should be dropped from CERCLA consideration. Some sites may have several waste sources, some eligible, others ineligible due to the petroleum exclusion. Determining which sources are eligible and ineligible for CERCLA consideration will facilitate an accurate evaluation of targets and waste quantity (discussed in Section 3).

\subsubsection{Other Environmental Statutes}

CERCLA precludes Superfund response actions at particular sites that fall under the jurisdiction of the Atomic Energy Act (AEA) and the Uranium Mill Tailings Radiation Control Act (UMTRCA).

Releases of source, by-product, or special nuclear material defined in AEA Section 68, Statute 923 (e.g., process ore for fresh uranium fuel) from a nuclear incident subject to the financial protection requirements of AEA are excluded from CERCLA response. Typically, this means releases from nuclear power plants licensed by the Nuclear Regulatory Commission (NRC) are the responsibility of NRC (not including facilities licensed by States or other Federal agencies that have been granted licensing authority by NRC).

Releases of source, by-product, or special nuclear material from the 22 processing sites specifically designated in UMTRCA are excluded from CERCLA response.

Also, CERCLA notification and cost recovery provisions may not be applicable to releases associated with the legal application of certain substances regulated under the Federal Insecticide, Fungicide, and Rodenticide Act (FIFRA).

If you conclude after reviewing available background information that response at the site might appropriately occur under any of these statutes, discuss the situation with your Regional EPA site assessment contact.

\subsubsection{Sites With No Hazardous Substances}

Occasionally your review of available file information will yield no evidence or indication that hazardous substances, pollutants, or contaminants were ever handled or disposed at the site. These types of sites pose no CERCLA threat to human health or the environment because they have not released, nor can they release, hazardous substances to the environment.

You must be certain that CERCLA hazardous substances are not now, or have never been, at the site before "no further action" could be recommended on this basis. Many sites have extremely limited information concerning waste sources. Simple lack of information cannot be interpreted to indicate that no hazardous waste is present or has ever been deposited at the site. Such a determination must be supported by convincing evidence, like documentation of a complete removal of all hazardous substances. In addition, you should perform a reconnaissance of the site (Section 2.5) to visually verify the lack of hazardous waste sources. 


\subsection{FILE SEARCHES}

For many sites, a great deal of information may be available from records of State and/or local investigations, Federal and State permit applications, and Federal hazardous waste notification. These can yield information concerning site operations, waste types and quantities, regulatory history, past environmental violations, and citizen complaints. A good deal of this type of information can be obtained by reviewing Regional EPA files and State environmental agency files. Additional information concerning the site area may be obtained by reviewing in-house files for nearby sites that your office has previously investigated.

Before initiating a file search, you should be familiar with the checklist of PA information needs (Figure 2-1), particularly the general site information and source description sections. Also be familiar with the criteria lists in the PA scoresheets (Appendix A) and be aware of the types of questions you need to answer to evaluate the threat of a release from the site and potential impacts on human and environmental targets (Section 3).

\subsubsection{Types of Information}

Information gathered through file searches can be useful in developing professional judgement hypotheses concerning the release of hazardous substances from the site and the exposure of targets to released substances. Collect as much information concerning waste handling practices as possible. This includes information on waste containment and general housekeeping practices.

Documents of particular interest during the file search include site sketches, inspection reports, aerial photographs, permit applications, hazardous waste handling notification forms (RCRA notification forms and CERCLA 103(c) notification forms, filed by facilities to notify EPA of hazardous substances they handled), waste hauling manifests, analytical sampling results, records of citizen complaints, records of violations, and court orders.

Site sketches, maps, and aerial photographs can help identify source types and locations. Permit applications, waste hauling manifests, and Federal hazardous waste notification forms can supply data on the specific types and quantities of waste generated and/or disposed. Previous inspections can provide information on source types, past environmental impacts, and targets. Analytical results of monitoring or inspection activities can provide valuable data concerning the types of hazardous substances found at the site and possible releases. Additionally, citizen complaint reports and court orders may also provide information indicating hazardous substances have been released from the site.

While conducting file searches, always try to obtain copies of source documents. For example, an analytical sampling report prepared by the local board of health after an inspection is better than a letter report prepared at a later date that references the inspection but does not include the actual analytical data. Remember that the PA is the initial step in the site assessment process. Should the site move beyond the PA, data sources used during the PA may carry on to the SI and could eventually be used to support placement on the NPL.

\subsubsection{EPA Regional Files}

Generally, the first files you will access are at Regional EPA offices. In some Regions, the EPA site assessment contact will give you the files when you receive the PA assignment. In other Regions, you may need to coordinate with the contact to gain access to all the necessary files. The PA is the first step in the Superfund site assessment process and, for most sites, you will be initiating the Superfund file for the site. However, you may be assigned a PA on a site that may have been the 
subject of some Federal action such as a removal, regulatory inspection, or permit application. In these instances, Regional files may contain information that will be useful for completing the PA.

First access Regional site assessment files. These may contain useful documents such as CERCLA 103 (c) notification forms, PA petitions, or reports on previous site assessment activities at the site. These documents will likely have information concerning the types of wastes disposed, general site operations, and alleged environmental impacts, possibly including information from State activities.

Next access other Regional Superfund files. For example, the site may have had a Superfund removal action (fencing the site, physical removal of hazardous wastes, closing of wells, supplying alternative drinking water, or other emergency measures). Removal program files may provide useful information concerning waste sources, types and quantities of wastes, and past environmental impacts. Coordinate with your Regional EPA site assessment contact to determine if other Superfund offices have information concerning the site being evaluated and to access those files.

You also need to research EPA offices outside the Superfund program, such as RCRA and the National Pollutant Discharge Elimination System (NPDES) program. They may have permit applications and monitoring results with information on specific waste types and quantities, sources, type of site operations, and operating status. Coordinate with your EPA site assessment contact to access and review files from other Regional programs.

\subsubsection{State Environmental Agency Files}

Historical files of State environmental agencies may provide information about the site, as many sites investigated under Superfund were originally discovered by or identified to a State agency. For State environmental agency personnel conducting PAs, files should be readily available. For others, the process of gaining access to State agency files varies. In some States, you can request file information over the phone and have it sent to your office. Most States, however, require prior arrangements to visit the appropriate State agency offices to review and make copies of the desired file information.

The "Site Assessment Information Directory" (available from EPA) contains the names, locations, and telephone numbers of State agencies that can provide data and information necessary for the $\mathrm{PA}$ investigation. For file search purposes, the principal environmental agency for the State is the best candidate. However, a single division or department within that agency is unlikely to have all of the available information for a site. For example, the State Department of Environmental Protection, as the principal environmental agency, may have a Superfund or solid waste division that has information about the site, and may also have separate RCRA and water resources divisions that have additional information.

As with Federal files, State files may contain information derived from permit applications, previous investigations of the site, or from reported environmental impacts. While reviewing State files, gather information concerning the site's operating history, specifically regarding waste types, quantities, and sources; type of site operations; ownership history; and historical waste handling and disposal practices.

\subsubsection{In-House Files}

Although in-house files generally will not provide information specific to the site, they too can be useful sources of information. Research the possibility that other sites in the vicinity have been investigated by your office. In-house files for such sites can provide data on local geology, hydrology, and other site environs information. In addition, valuable targets information can be 
obtained, such as the locations of public drinking water supply wells or surface water intakes and the extent of municipal supply systems.

Individuals in your office who have performed investigations on sites in the general vicinity of your site are also good resources. These individuals may be able to provide recommendations for sources of information for specific data elements (e.g., the name and telephone number of an individual at the State Fish and Wildlife Department helpful in identifying fisheries and endangered species habitats).

\subsection{OBTAINING "DESKTOP" INFORMATION}

A comprehensive targets survey to identify human populations, sensitive environments, and fisheries potentially affected by the site is a major component of the PA. Much of this information has little to do with waste types or the facility's historical waste handling practices, and will not be found during the file searches discussed in Section 2.3. Preliminary identification of targets and related data gathering may, however, be accomplished without leaving your office (see pathway target discussions in Section 3).

Desktop data sources can provide information concerning geology underlying the site and in the immediate vicinity; location of surface water bodies, fisheries, wetlands, and sensitive environments; location of public drinking water supply wells and surface water intakes; populations served by public water supplies; and residential populations in the vicinity of the site. The following sections present more detailed information on desktop data sources.

\subsubsection{Maps}

Maps provide valuable information on the physical and environmental setting of the site and its associated targets. As a standard practice at the onset of the PA, obtain United States Geological Survey (USGS) 7.5-minute topographic quadrangle maps covering the 4-mile radius around the site, as well as the 15-mile surface water migration route. USGS topographic maps may be available from in-house libraries or map rooms; otherwise, they can be ordered directly from. USGS or purchased from a local map store. It is a good idea to either order multiple copies or make photocopies that you can write on. Once you have received your topographic maps, splice them together (as necessary), outline the site itself, and have a draftsperson draw a series of concentric circles around the site with radii of $1 / 4$ mile, $1 / 2$ mile, 1 mile, 2 miles, 3 miles, and 4 miles. This will be useful to identify and evaluate targets (Section 3).

USGS topographic maps display geographic features of the site and surrounding area. They can be used to identify the surface water migration route, nearby wetlands and sensitive environments, and the nearest resident. Topographic maps can also be used to record various types of data, by highlighting or outlining the surface water migration route, areas served by public and private water supplies, and the locations of the nearest resident and nearest well. In sparsely populated areas, the topographic map can be used to determine the population residing within each of the distance categories, by counting the houses indicated on the map in each distance category and multiplying by the average number of residents per household for the county in which the houses are located (discussed in Section 3).

National Wetlands Inventory Maps, available from the U.S. Fish and Wildlife Service (USF\&WS) or USGS, delineate the boundaries of wetlands and can be used like topographic maps to specify wetlands locations, acreage, and frontage miles. Local city and county street maps can be helpful to identify schools, large office parks and business centers, recreational parks, and other potential targets near the site. Flood Insurance Rate Maps can be obtained from the Federal Emergency Management Agency (FEMA) or from local insurance offices. These maps can be used to determine 
the floodplain in which the site is located. Property maps delineating historical site boundaries may be available from the community or county tax assessor's office. You may want to obtain these maps during the site reconnaissance (discussed in Section 2.5). These maps may be useful to identify areas that were once part of the site, but are not identified as such on current maps. For example, a particular parcel of land that is currently a community baseball field may have previously been owned and operated as a landfill by the facility you are investigating. Such information is valuable for identifying and characterizing sources.

\subsubsection{Geologic Information}

As part of the PA investigation, you need to collect information on the general stratigraphy in the vicinity of the site. Your office may have a collection of geologic references that may include the study area. Otherwise, USGS field offices can provide geologic reference materials. In addition, State geological surveys can provide useful reference documents that typically include detailed technical descriptions, stratigraphic columns, and cross-sections. This type of information can be used to develop the general description of the geologic strata and aquifer(s) underlying and in the vicinity of the site, evaluate depth to the shallowest aquifer, and provide information on the nature and properties of geologic materials between the surface and underlying aquifers.

Other related sources of information on local geology and ground water use include a variety of ground water references published by USGS and State geological surveys. Some States have extensive studies concerning ground water resources. These can provide detailed descriptions of aquifers and their uses in different regions or geographic areas. Some may even include fairly comprehensive well inventories that identify public and private well locations, uses, depths, screened intervals, static water levels, and related information.

The geology departments of local or State universities are another source of information on the geology of the area. University libraries may have studies concerning local geology, and university professors may be experts on local geology. Public water supply utilities and local well drilling companies may also provide information on geology, including depth to shallowest aquifer and composition of geologic strata in the vicinity of the site.

\subsubsection{Databases and Geographic Information Systems}

A variety of databases can provide information about targets. The Geographical Exposure Modeling System (GEMS) is maintained by EPA's Office of Toxic Substances and provides U.S. Bureau of the Census population data for specified distances around a point location. GEMS can be accessed online through a personal computer and modem. Your Regional EPA site assessment contact can provide information on accessing GEMS. As input, GEMS requires the geographic coordinates of the site and the distance categories for which you desire population information. This approach meshes conveniently with the PA evaluation of population in concentric distance categories around the site, out to a distance of four miles. GEMS does, however, have limitations -- particularly for the smaller distances near the site, and for sites in rural areas where populations are typically thinly distributed. Section 3.6.2 discusses the application of GEMS data in more detail.

WELLFAX is a water resource database, maintained by the National Water Well Association (NWWA). WELLFAX contains NWWA's inventory of municipal and community water supplies and provides the number of households served by public water systems, private wells, and other water supply sources. The Federal Reporting Data System (FRDS), maintained by EPA's Office of Drinking Water, contains general information including name, address, and population served by public water supply utilities using ground water, or surface water. 
For surface water, PATHSCAN can provide information concerning both municipal and private drinking water intakes. PATHSCAN is maintained by EPA's Office of Water Regulations and Standards.

Many States also have databases (usually maintained by environmental agencies) that can be used for preliminary identification of public drinking water supplies. Some State geological surveys maintain well log databases that can supply information concerning wells in the vicinity of your site. In addition to supporting drinking water targets evaluations, these databases can be used to compile information on the strata underlying the site and in the general area.

Many of these databases, especially those containing information on drinking water wells, are incomplete. You should not rely exclusively on such databases to determine ground water targets. Always verify information obtained from databases by contacting each community located within the target distance limit to identify drinking water supply sources. At a minimum, databases may provide the names of the different public or private water companies that you need to contact. How to contact public water utilities is discussed in Section 2.4.5. Appendix B provides a general listing of databases that can be used to gather various types of PA information; the "Site Assessment Information Directory" (available from EPA) identifies Regional and State-specific databases.

Another useful tool for gathering PA data is a geographic information system (GIS). Many offices have GIS software that integrates various types of databases to provide information concerning specific geographic areas or point locations. For example, with only the latitude/longitude coordinates for a site, you might be able to use an in-house GIS to gather population information for the area around the site, plot on a map the locations of all public drinking water wells and their service areas, and obtain geologic data. The specific types of data available will depend on the setup and structure of the GIS. The quality of the data depends on the frequency of updating, making follow-up data collection and verification advisable.

\subsubsection{Aerial Photography}

Historical aerial photographs of the site can identify source areas that may not be visible during a routine reconnaissance due to physical changes to the site during the years of operation (e.g., surface impoundments that have since been backfilled and paved over). Current aerial photographs will provide an overall view of the site layout that may not be available from the ground. Aerial photographs can help identify and document the location and distance to various targets, identify the surface water migration route, identify and quantify source areas, and many other applications.

Although aerial photographs can be helpful during the PA, do not expend undue effort or costs to obtain them, as most of the information they provide can be obtained from other sources as well. In certain instances, however, they may be especially helpful. For example, if site access problems prevent you from performing an effective reconnaissance (Section 2.5), or if you have very little information concerning site operations, historical aerial photographs may be able to provide information on waste disposal areas.

Good sources for aerial photographs at the PA stage are local ones, including the local tax assessor's office, local planning or zoning commission, and the State department of highways and transportation. These sources may be able to provide aerial photographs of the site and surrounding area relatively quickly and inexpensively. Other sources of aerial photographs include EPA's Environmental Monitoring Systems Laboratory (EMSL), EPA's Environmental Photographic Interpretation Center (EPIC), the U.S. Army Corps of Engineers (COE), the Soil Conservation Service (SCS) of the U.S. Department of Agriculture (USDA), and the USGS. EMSL and EPIC are the official EPA departments responsible for providing aerial photography; their main services are archival searches for current and historical aerial photographs and interpretive analyses. It is a 
good practice to check turnaround time and delivery schedule for products and interpretive services from any of these sources.

\subsubsection{Telephone Inquiries}

During the PA, you can use the telephone to gather a great deal of information. For the ground water pathway, information concerning drinking water target populations can be obtained from phone conversations with appropriate community officials. For the surface water pathway, flow data can be acquired from USGS. In addition, the locations of sensitive environments for the surface water, air, and soil exposure pathways can be verified by contacting State fish and wildlife services and Natural Heritage Programs. Local emergency response units (e.g., fire department) may be able to provide information on the types of hazardous substances used and stored at active facilities. Before contacting outside agencies, check with your supervisor for the proper procedures and protocols to follow in identifying yourself and your reasons for making the inquiry.

The most direct means of collecting drinking water target population information for both the ground water and surface water pathways is to contact the department of public works or the town hall of each community within the target distance limit to identify the appropriate offices that can provide information on water supplies. Larger communities may have water departments that can be contacted directly. Local water officials can usually supply the necessary information, but to avoid having to repeatedly contact them, prepare a list of questions before you call to ensure collecting all required information.

You first need to determine if the community is served by a centralized water system (public or private water distribution company), private wells or surface water intakes, or a combination. You also need to identify the types (wells or surface water intakes) and locations of drinking water supply sources. The following questions are examples of what to ask water authorities about drinking water supplies:

- Does the community have a centralized drinking water supply system?

- Is it public or private?

- Is the source of drinking water ground water, surface water, or a combination of the two?

- Where are the exact locations of the drinking water supply sources (wells and intakes)?

- What are the names of the drinking water sources (e.g., Wellfield Number 1)?

- For wells:

- How deep are the wells?

- $\quad$ From which aquifer do they withdraw water?

- Is the water system interconnected such that water from any well is capable of reaching any part of the system?

- If so, what percent of the system's output is supplied by each well?

- How many people are served by the drinking water system?

- Does the system supply water to any other community?

- Have there been any problems with ground water contamination in the area?

- Have any wells been closed due to contamination of any kind? If so, request an explanation of the circumstances.

- Has the ground water recently been tested (for what and results)?

- Are there private wells located in the community or the general area?

- What aquifer(s) do these private wells tap?

- $\quad$ Can the water company provide a system distribution map?

- Can the water company mark the location of supply wells and distribution areas on a topographic map?

- Do neighboring communities have drinking water supply systems' (ask for contacts)? 
- For surface water intakes:

- Where is each intake located?

- What is the average flow rate of the water body from which each intake draws?

- How many people are served by the system?

- Is the water supply system interconnected such that water from any intake is capable of reaching any part of the system?

- If so, what percentage of the total system's output is supplied by each intake?

- Is the water treated prior to distribution?

- If so, why and how?

- Has an intake ever been closed or taken out of service due to contamination of any kind? If so, request an explanation of the circumstances.

- Has the surface water recently been tested (for what and results)?

- Are there private intakes located on surface water bodies in the vicinity?

- $\quad$ Can the water company provide a system distribution map?

- Can the water company mark the location of intakes and distribution areas on a topographic map?

- Do neighboring communities have drinking water supply systems (ask for contacts)?

Sensitive environments need to be identified for the surface water, air, and soil exposure pathways. Review the sensitive environment tables in the PA scoresheets (PA Tables 5 and 7) to familiarize yourself with the descriptions of the sensitive environments that qualify for consideration. The USF\&WS and State fish and wildlife services can be contacted to gather information on fisheries and habitats of endangered and threatened species. State Natural Heritage Programs are also good sources of information on sensitive environments (e.g., wetlands and critical habitats). You can contact the heritage program for the State in which the site is located and request information for the surrounding area (see EPA's "Site Assessment Information Directory" for telephone numbers).

Another source of information is the local fire or police department. SARA mandated that all facilities actively handling hazardous materials notify local emergency response units (e.g., fire department, police) of the hazardous materials stored at the facility. Local emergency response authorities may also have information concerning sources and the physical state of wastes (i.e., solids, liquids, or sludges). Such data are helpful in evaluating waste quantity, suspected releases, and targets that may be exposed to hazardous substances.

Information obtained over the telephone needs to be recorded on paper as a means of documenting the source of the information. "Teleconference notes" (telecons) or "records of communication" (ROCs), as these are known, are common references to the PA narrative report (Section 4.2).

Several examples are provided in the sample PA narrative report in Appendix C. Note that telecons need not be typed; legible handwriting is acceptable. Teleçons must document the following:

- Date and time of the conversation.

- Site name.

- Name, affiliation, and telephone number of the person contacted.

- Name and affiliation of the person making the contact.

- Purpose of the call and questions asked.

- Summary of the conversation and pertinent information obtained.

- Action items or follow-up activities, if any.

- Dated signature of the person making the contact.

\subsection{SITE RECONNAISSANCE}

The purpose of a reconnaissance is to visually observe the site and its environs and to collect additional information to assist the PA evaluation. An offsite reconnaissance is generally required; 
an onsite reconnaissance may be performed, as appropriate (NCP, 40 CFR 300.420). Depending on information needs and the type of reconnaissance, activities may inçlude an onsite visit, an offsite perimeter survey, a site environs survey, and collecting additional information from local authorities.

Under some circumstances, a site reconnaissance may not be necessary. If file searches and desktop data collection activities yield sufficient information to indicate that an $\mathrm{SI}$ is necessary, a reconnaissance may not be required to complete the PA; consult with your Regional EPA site assessment contact. It is usually difficult, however, to conclude that no further action is necessary without the benefit of actually observing conditions at and around the site. Exceptions may include sites that are not eligible for response under CERCLA (see Section 2.2 for discussion).

When conducting a reconnaissance, pay particular attention to physical features of the site (e.g., dimensions and locations of sources, buildings) and the surrounding area. Record any observations that differ from descriptions gathered through previous data collection (e.g., a new housing development not shown on the topographic map). Another important aspect of the site reconnaissance is to evaluate the need for a removal action. A removal action could include the stabilization or removal of wastes, fencing the site, or other emergency response activity that eliminates, controls, or otherwise mitigates an imminent and serious threat to the public health or the environment. Emergency response considerations are discussed in Section 2.6.

\subsubsection{Preparing for the Site Reconnaissance}

To prepare for the site reconnaissance, review what is known about the site and what remains unknown after conducting file searches (see the checklist of PA information needs, Figure 2-1). Decide whether to perform an onsite reconnaissance or an offsite reconnaissance, depending on considerations including:

- Regional EPA specifications for performing site reconnaissance during the PA.

- Type of site and operations.

- Amount of information available concerning sources.

- Status of the site (i.e., active or inactive).

- Age and reliability of the data available for review.

- Potential visibility of the site from public access areas.

- Relative ease or difficulty of obtaining site access.

- Health and safety concerns.

Consider whether an onsite reconnaissance is necessary and practical, given the specific situation for each site. Necessity and practicality are often contradictory. For example, an onsite reconnaissance may be deemed necessary for a site that is abandoned, not easily observed from areas of public access, and for which little information is available from file searches and desktop data collection activities. These same circumstances may make an onsite reconnaissance impractical from the perspective of health and safety -- in view of the many unknowns -- and the ability to gain legal access. On the other hand, an onsite visit may be most practical, but not necessary, for an active facility about which much is known, and whose operator cooperates in granting access and providing requested information.

To perform an onsite reconnaissance you must arrange site access and prepare an appropriate health and safety plan. You must obtain legal access to the site from the site owner before conducting an onsite reconnaissance. In some Regions, EPA is solely responsible for obtaining access. In other Regions, State and/or contractor personnel may make access arrangements. Obtain the proper procedure for gaining legal site access from your EPA site assessment contact, or follow your established in-house operating procedures (if available). Finalizing access arrangements 
may take considerable time, so initiate actions to obtain access immediately after determining to conduct an onsite reconnaissance.

You must develop a study plan whether the reconnaissance is onsite or offsite. The study plan should enumerate all reconnaissance activities and identify the specific information to be gathered. In addition to observations of the site itself, these may include contact with local authorities, such as the tax assessor's office to verify ownership and site boundary information or the local water authority to gather water supply information. The study plan should also detail the survey of site surroundings and efforts that will be taken to verify or identify the nearest resident, worker populations, nearest well, and other site environs information.

Preparing for the site reconnaissance also includes gathering necessary materials and equipment, such as a camera to document site conditions, health and safety monitoring equipment (e.g., $\mathrm{HNu}$, OVA, radiation meter), and extra copies of topographic maps to mark target locations, water distribution areas, and other important observations.

You also need a logbook to record observations and activities while in the field. Each PA investigation requires its own logbook, which is a standard reference for the PA narrative report (Section 4.2). Use the logbook to record such things as:

- Visual observations of the site and its surroundings

- Descriptions of photographs taken

- Conversations with site personnel or neighbors

- Visits to local authorities and information obtained

- Housecounts and other observations relating to targets

- Freehand site sketch

Record activities and observations in the logbook as they occur, rather than at the end of the day or when you are back in the office. Also record the time of day for each activity or observation entered. For documentation purposes, the logbook must be completed in waterproof ink, preferably by a single person. Each page of the logbook must be signed and dated after the last entry on the page. Figure 2-3 illustrates a sample logbook page.

\subsubsection{Conducting Onsite Reconnaissance}

The major advantage of an onsite reconnaissance is the opportunity to visually observe the site and the sources. Characterizing the site and sources is a critical task in the site evaluation process. During the onsite reconnaissance, you may be able to estimate or measure source areas or volumes, examine facility files to obtain hazardous waste quantity data, observe waste handling practices, and possibly detect sources and targets (e.g., drum disposal area, onsite residents) not previously identified during file searches and desktop data research.

\section{Source Characterization and Target Identification}

During the onsite reconnaissance, concentrate on characterizing potential hazardous waste sources. Record in your logbook detailed descriptions of each source, including source type, location, dimensions, and evidence of containment. Look for signs of migration of hazardous substances from sources. Record descriptions of observed areas of stained soil or stressed vegetation.

Also identify any wells on the site, the location of any residences, schools or daycare facilities and the populations associated with each, an estimate of the number of workers if the facility is active, and the presence of any onsite sensitive environments. 


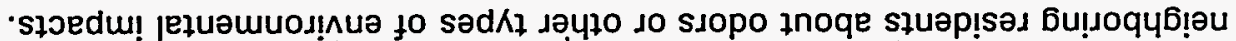

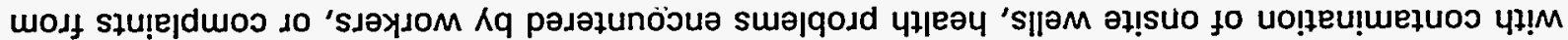

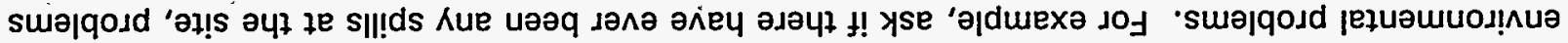

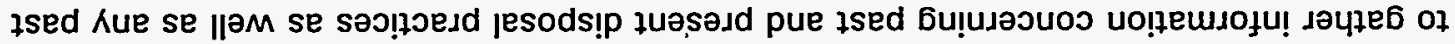

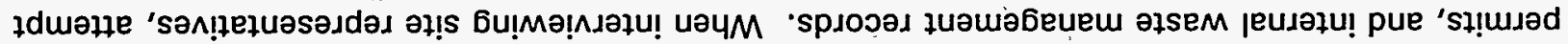

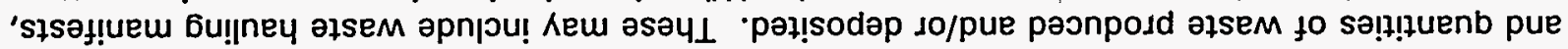

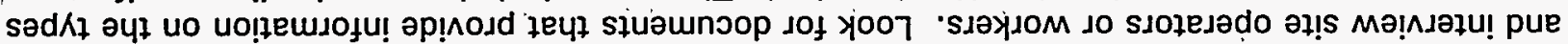

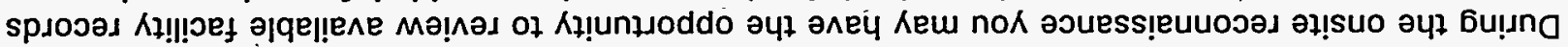

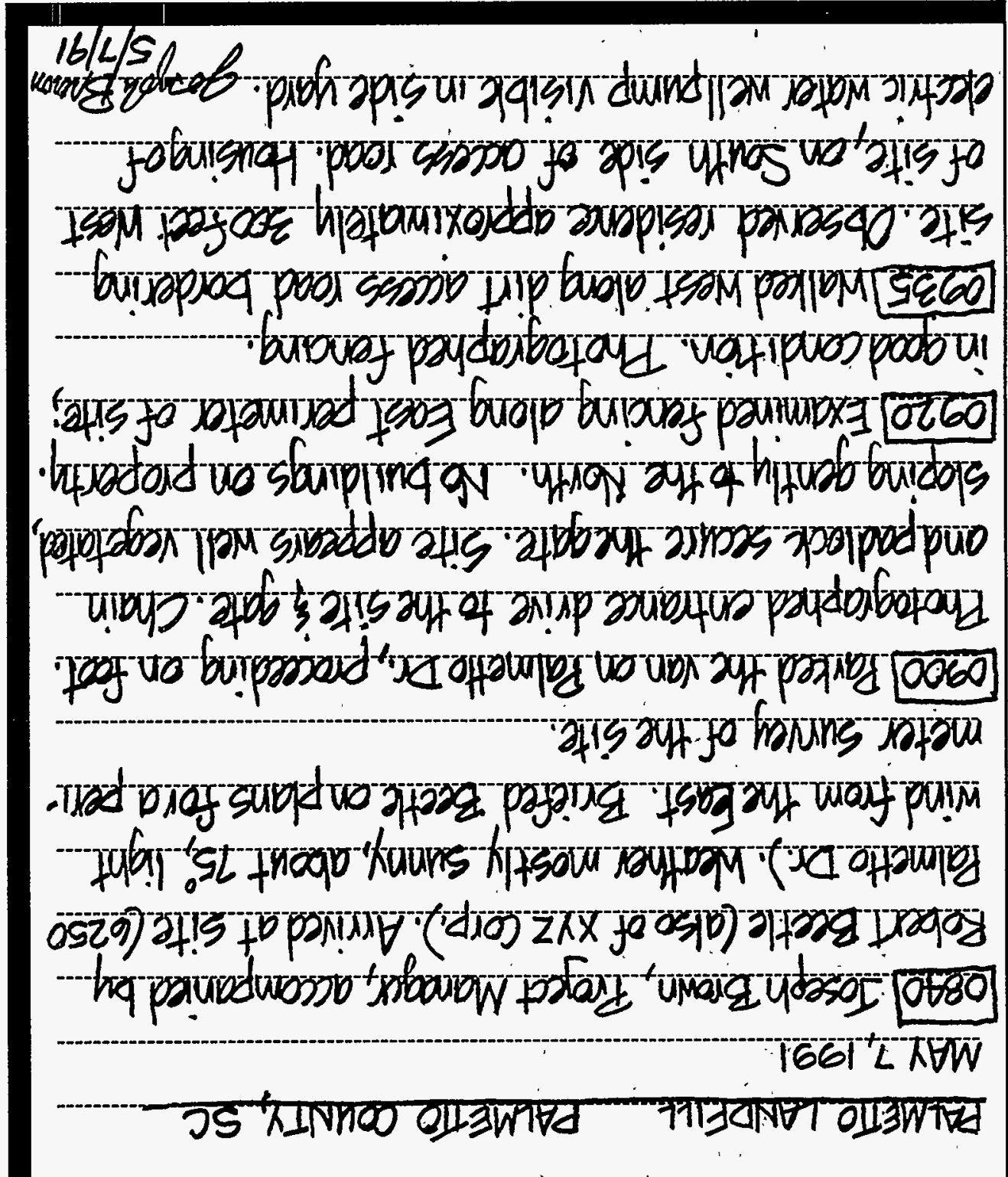

әБеd Yooq60ך әdures

$\varepsilon-\tau$ วגnธ!」 


\section{Site Sketch and Photodocumentation}

Prepare a sketch of the site in the logbook noting all important physical features. A drafted sketch of the site can be made from the hand-drawn site sketch upon returning to the office. Include in the sketch locations and dimensions of all sources, distances from sources to major site structures (e.g., buildings, site boundaries), locations and distances from sources to all targets (e.g., onsite residents, wells, surface water bodies, sensitive environments), significant site features (e.g., railroad beds, roads, parking lots, hills), and the drainage pattern and overland flow route to surface water. Also include a North arrow. Figure 2 in Appendix $C$ shows an example site sketch.

During the reconnaissance, document source areas and any evidence of contamination (e.g., stressed vegetation, stained soil, leaking drums) with color photographs. Also take a series of photographs showing a panoramic view of the entire site. You can also use photographs to document other important aspects of the site such as fencing or proximity of residences and surface water. Print several copies of the photographs so you can include originals with each copy of the narrative report.

All photographs taken during the site reconnaissance need to be documented in sequential order in the logbook. Create a table in the logbook to record photograph information. Include the number of the photograph (e.g., number 12 of 36 on roll \#1), the time taken, and a detailed description; key each photograph to the site sketch. An example entry is provided below (see also Appendix $C$, page $\mathrm{C}-17)$ :

Roll Number 1, 36 photographs available

Number Time Description

10800 hours Leaking drums in drum disposal area located on the far east side of the property. Photo taken while facing north.

\section{Health and Safety Considerations}

At all times during the onsite reconnaissance, you must be cognizant of health and safety concerns. Follow the health and safety plan developed for the reconnaissance and record any readings detected by monitoring equipment. Above-background readings on monitoring equipment may indicate that hazardous substances are being released to the air. Be prepared to go to a higher level of personal protective equipment, or to abandon the reconnaissance. Always be cautious when traversing a potential hazardous waste site.

\subsubsection{Conducting Offsite Reconnaissance}

An offsite reconnaissance should generally be performed at all sites, regardless of whether an onsite reconnaissance is also conducted. An offsite reconnaissance includes a perimeter survey of the facility, a local site environs survey, and collection of additional data from local authorities. In cases where you do not conduct an onsite reconnaissance, examine the site and its sources to the extent practical through a perimeter survey. Other main objectives are to:

- Verify target locations close to the site

- Gather additional information concerning the overland flow route to surface water

- Determine land uses in the vicinity of the site 
A perimeter survey consists of walking or driving around the property, but not actually entering. During the perimeter survey, attempt, to obtain a view of the site from public access areas and record your observations in the field logbook. Be aware of private property rights and restrict your. movements to public areas; do not trespass private property (either the site itself or neighboring properties) unless you receive permission from the property owner (either in writing in advance or verbally at the time of your visit).

The objectives of the perimeter survey are the same as those for the onsite reconnaissance. Concentrate on characterizing potential hazardous waste sources, including source types, dimensions, location, and evidence of poor containment. To the extent practical, estimate the area or volume of sources. Photograph the site and surrounding area for documentation purposes. Record photographs in your logbook according to the procedures discussed in Section 2.5.2. Record information concerning public access. Also look for evidence of hazardous substance migration from the site, including stressed vegetation, areas of visibly stained soil, or possibly an outfall discharging to a surface water body.

\section{Site Environs Survey}

The purpose of the site environs survey is to identify and verify the existence and locations of nearby targets. A windshield survey (i.e., a look around by car) of the surrounding area is useful for this purpose. As part of the windshield survey, perform a house count to obtain population estimates for areas near the site. Identify residential areas near the site that rely on private wells. Verify the overland flow route to the nearest surface water body; if possible, walk along the flow route and look for evidence of hazardous substance migration. Record any features of the surrounding area that may not be indicated on the topographic map, such as new housing, business, or commercial developments. Transcribe all of the information collected during the perimeter and local environs survey onto your local site environs sketch or topographic map.

\section{Additional Data Collection}

During the offsite reconnaissance, you may visit a number of local authorities to collect additional information. Local health departments may have information concerning inspections performed at the site, past complaints from nearby residents (e.g., odors, smoke, unsightly conditions), and health impacts attributed to the site. As discussed in Section 2.4.5, local water authorities may be able to provide water distribution maps or mark the location of public drinking water supply sources and distribution areas on a topographic map. In addition, water officials may provide information on private water wells in the vicinity. The tax assessor's office may have information regarding ownership and boundary history of the site, which may lead to the discovery of other hazardous waste sources not previously identified.

\subsection{EMERGENCY RESPONSE CONSIDERATIONS}

During the site reconnaissance, you must be alert for conditions that may warrant immediate or emergency action, and notify your Regional EPA site assessment contact of such situations. At any time during the site assessment process, a removal may be performed at a site. CERCLA and the NCP (40 CFR 300.415) authorize and generally define removals as actions taken to eliminate, control, or otherwise mitigate a threat posed to the public health or environment due to a release or threatened release of a hazardous substance. Removals are relatively short-term actions, as opposed to the long-term remedial solutions that the NPL addresses. They are designed to respond to situations that require immediate action to eliminate a present threat or to avoid a more serious 
future problem (e.g., containerizing hazardous substances leaking from deteriorating drums may prevent ground water from becoming contaminated).

Removal actions can include, but are not limited to, any of the following (see "Superfund Removal Procedures," OSWER Directive 9360.3-011:

- Fencing the site

- Providing 24-hour security to restrict public access

- Stabilizing waste sources such as leaking drums or overflowing surface impoundments

- Physical removal of hazardous substances

- Capping areas of obvious contamination

- Assessing the need to temporarily relocate populations

- Providing alternative drinking water supplies .

Before EPA initiates a removal action, Emergency Response Division (ERD) personnel perform an assessment to determine if removal action is appropriate. The PA investigator is responsible for identifying sites that may warrant removal assessments; your Regional EPA site assessment contact, in consultation with removal program personnel, will determine whether a removal assessment is necessary.

Site conditions that may require immediate response or emergency action are likely to be obvious. For example, conditions that allow humans to easily come in direct contact with hazardous substances (e.g., unrestricted public access to areas with exposed hazardous substances) may warrant some form of emergency response, as would site conditions that allow continuous releases of hazardous substances into the environment le.g., wet surface impoundments with inadequate overflow controls). Types of conditions that might lead to a removal assessment include, but are not limited to:

\section{- Threat of fire and/or explosion}

- unstable hazardous materials are stored onsite

- reactive materials have been disposed of together

- former military site with unexploded ordinance

\section{- Threat of direct contact with hazardous substances}

- unrestricted public access to exposed hazardous substances

- runoff carries hazardous substances to publicly used surface water bodies

- hazardous substances have migrated onto residential properties

\section{- Threat of a continuing release of hazardous substances}

- $\quad$ sources are poorly contained (e.g., deteriorating drums), possibly threatening ground water by releasing hazardous substances at or below the surface

- $\quad$ surface impoundments with inadequate diking, located on the banks of a river prone to flooding

\section{- Threat of drinking water contamination}

- $\quad$ suspected release to ground water where private residences rely on shallow wells for drinking water

- underground storage tanks may be leaking near a municipal well

- private well users have reported foul-smelling and/or foul-tasting water 
These are just a few examples of site conditions you should be aware of while conducting the PA, and especially during the site reconnaissance. These examples are not inclusive of all site conditions that might indicate the need for a removal assessment. However, not all conditions that pose threats can be addressed effectively by a removal (i.e., some sites can only be addressed with long-term remedial actions). Each site is unique and the need for a removal assessment must be based on site-specific conditions. If during the site reconnaissance you observe conditions that you believe require immediate action to mitigate a threat to public health or the environment, notify your Regional EPA site assessment contact as soon as possible to discuss the situation.

\subsection{POTENTIAL RADIOACTIVE WASTE SITES}

Radioactive waste sites pose special hazards for field investigators, and EPA discourages Superfund personnel from physically approaching such sites during a perimeter survey or onsite reconnaissance. Because of the unique considerations associated with radiation sites and the special skills required to evaluate and minimize radiation exposures, investigation of radiation sites beyond the PA is generally implemented by EPA's Office of Radiation Programs (ORP).

To date, the number of CERCLIS sites that involve radioactive materials has been relatively small; perhaps less than 2 percent. Radioactive materials are most commonly associated with types of sites that include, but are not limited to:

- Department of Energy (DOE) or Department of Defense (DOD) facilities.

- DOE or DOD contractor, supplier, or research facilities.

- Contractor, supplier, or research facilities of DOE predecessor agencies (Atomic Energy Commission, Energy Research and Development Administration).

- Private or public nuclear energy production or research facilities (e.g., power plant, university).

- Aircraft, submarine, or shipbuilding facilities.

- Mining and related facilities (e.g., production, milling, processing).

- Deep well injection facilities.

- Facilities that manufacture, store, dispose, or otherwise handle radiopharmaceuticals.

- Facilities employing industrial radiography.

If you are conducting an onsite reconnaissance or offsite perimeter survey and you encounter any reason to suspect the presence of radioactive materials, health and safety considerations require you to vacate the area immediately and notify your Regional EPA site assessment contact. Examples of reasons to vacate include:

- Above-background readings on a radiation meter.

- Presence of drums, other containers, or areas marked with the radiation symbol.

- Evidence (such as manifests, disposal records, or verbal statements) of radioactive materials handling, storage, or disposal.

You may find information relating to radioactive materials during earlier stages of the PA such as file searches or desktop data collection activities. Such information may include permits, permit 
applications, manifests, materials handling or disposal records, and statements from officials or facility personnel obtained through interviews. If at any time during the PA you obtain information indicating that radioactive materials are or were present at the site, notify your Regional EPA site assessment contact immediately. Your contact will discuss the situation with ORP and determine how you should continue the investigation. 



\section{SITE EVALUATION AND SCORING}

The principal objective of the PA is to evaluate potential hazards to determine if further action at the site is necessary. EPA officials make a decision regarding site disposition and SI priority based on the PA evaluation of the potential threat the site may pose to human health and the environment. This section describes the process and requirements to evaluate and score sites at the PA stage of investigation:

- Section 3.1 discusses the importance of professional judgment to evaluate the likelihood of hazardous substance releases and exposure of targets to released substances, particularly to apply available analytical data.

- Section 3.2 describes the task of site, source, and waste characterization as a fundamental prerequisite to pathway evaluation and site scoring.

- Sections 3.3 through 3.6 provide specific guidance and instruction to evaluate and score the ground water, surface water, soil exposure, and air pathways using standard PA scoresheets.

A copy of the PA scoresheets is provided as Appendix A. The scoresheets package functions as a self-contained workbook providing all the basic tools to apply collected data and develop a PA score. The scoresheets package contains worksheets, factor value tables, scoring forms, and brief instructions. Sections 3.2 through 3.6 provide guidance that directly addresses the scoresheets and also applies to the PA-Score computer program (Section 4.3.2).

\subsection{IMPORTANCE OF PROFESSIONAL JUDGMENT}

Most of the factors that make up the PA are evaluated quantitatively by determining amounts, sizes, distances, and so forth. However, other factors -- those that relate to releases of hazardous substances from the site and the likelihood that specific targets may be exposed to released substances -- must often be evaluated qualitatively during the PA, by applying "professional judgment."

To know whether a release has occurred and whether specific targets have been exposed requires analytical sampling data detecting hazardous substances onsite and showing the presence or absence of hazardous substances in environmental media and at targets. This requires a sufficient number of samples, of sufficient quality, to show that any substances found are present above background levels and are present as a result of activity at the site. However, sampling is not generally performed during the $P A$, and comprehensive sampling data are not usually available from owner/operator or regulatory agency files for PA sites. This poses a dilemma for the PA investigator. Compounding the dilemma is the fact that, due to the structure of HRS and PA factor values, targets exposed to hazardous substances are weighted many times more heavily than targets not exposed, and for targets to be exposed, a hazardous substance must be released from the site.

\subsubsection{Applying Existing Analytical Data}

As an initial site investigation consisting primarily of a review of existing information about the site and a comprehensive study of targets, acquiring site-specific analytical data through environmental sampling is generally not within the scope of the PA. Such data may be available in site files and company records if routine company monitoring, a contracted site investigation, State or local Department of Health investigations, or emergency action has occurred. In most cases, however, 
the site will not have been sampled in the past. When sampling data are available for a PA site, they must be examined carefully with respect to their suitability for drawing conclusions about hazardous substance releases and exposure of targets.

While there can be many advantages to having sample results at the PA to provide specific details about the identity, concentration, and areal distribution of hazardous substances, there are also many pitfalls in relying on such data, because:

- Previous sampling efforts may not have been conducted for purposes that are compatible with Superfund site assessment objectives (i.e., the need to identify hazardous substances, releases, and exposed targets).

- Previous sampling may not have been extensive enough to fully characterize the site and the possibility of a release (e.g., number and placement of sampling locations, depth of monitoring wells).

- Laboratory protocols and standards may not be known (e.g.: QC/QA procedures; limited analysis, rather than full-spectrum Target Compound List (TCL) analysis).

- Conditions may have changed since the site was last sampled (e.g., substances may have been released, migration may have spread, additional waste disposal may have occurred).

For these reasons, existing analytical data for PA sites should be very carefully reviewed to ensure that they do not lead to false negative conclusions. The fundamentals of an appropriate sampling strategy specific to the site, and specific to the needs of the Superfund site assessment program, will be formulated by you for sites that appear to warrant further investigation through an SI.

Interpret analytical data with caution and be aware of their limitations.

Analytical data indicating that hazardous substances are present in environmental media (ground water, surface water, surface water sediments, soil, or air) onsite, directly offsite, or at a particular target can be used to support a hypothesis that hazardous substances have been released from the site and/or that specific targets have been exposed, regardless of considerations relating to data quality, attribution of substances to site operations, or concentrations relative to background levels. In such cases, analytical indications are sufficient to support the hypothesis; it is not necessary to definitively demonstrate that a problem exists.

Analytical data can also be used to support hypotheses that no release has occurred and that targets have not been exposed, but the analytical data themselves should not generally be the sole or principal consideration leading to the hypothesis. For the reasons outlined above, existing analytical data indicating that a particular site, source, target, or sample is "clean" or contains hazardous substances below background levels must be viewed with caution: Applying existing analytical data as the principal support for hypotheses that rule out the occurrence of releases and the exposure of targets requires that the data definitively demonstrate that a problem does not exist; indications alone are not sufficient unless convincingly supported by other evidence.

In some cases, existing analytical data may be sufficiently reliable to confidently rule out the occurrence of releases and exposure of targets, and to confidently characterize the hazardous substances associated with the site. Refer to Section 5.3 for further discussion on how to apply such data.

Summarize any available analytical data on page 2 of the PA scoresheets under "Probable Substances of Concern." In particular, identify the sample media and locations, and list the 
substances detected in source, environmental, and target samples, along with their corresponding maximum concentrations.

\subsubsection{Applying Professional Judgment}

If suitable analytical data are not available during the PA, you must apply professional judgment to evaluate the occurrence of releases and the presence of exposed targets. This is a somewhat intuitive process which relies on accumulated professional expertise and specific knowledge of characteristics and conditions of the site, its surroundings, and targets.

Critical PA professional judgments take the form of hypotheses that: (1) a release of a hazardous substance is or is not suspected to have occurred; and (2) specific targets are or are not suspected to have a relatively high likelihood of exposure to released substances. Targets likely to be exposed are termed "primary targets," while others are called "secondary targets."

Formulating appropriate hypotheses on these points is the essence of professional judgment. To assist in this process, "Criteria Lists" present a series of questions relating to the site, its surroundings, pathway characteristics, and targets. Their purpose is to get you thinking about the types of site-specific characteristics and conditions that may favor the release of hazardous substances and their migration to specific targets. The Criteria Lists are included in the PA scoresheets. Detailed discussion of pathway-specific Criteria Lists and guidance to apply them are presented for each pathway in Sections 3.3 through 3.6.

In general, it is appropriate to hypothesize the presence of primary targets and/or the occurrence of suspected releases when:

- Available analytical data indicate a potential problem.

- In the absence of analytical data, qualitative information indicate a potential problem.

Hypothesizing the absence of primary targets (secondary targets only) and no suspected release is generally appropriate when:

- Analytical data alone demonstrate there is no problem.

- Analytical data coupled with other, qualitative information supports a conclusion that there is no problem.

- In the absence of analytical data, qualitative information supports a conclusion that there is no problem.

When you have completed the PA, you will have a set of hypotheses regarding releases and targets. If the site advances to an $\mathrm{Sl}$, these hypotheses will form the foundation for the $\mathrm{SI}$ sampling plan. Most SI samples will be collected to test these hypotheses; the resulting analytical data will support either accepting or rejecting each hypothesis.

Always remember that when professional judgment is required to formulate hypotheses, it is important not to underestimate the potential threat. While it should be possible to collect sufficient information to support a clear professional judgment about the likelihood of a release and the condition of targets, when in doubt it is best to err on the side of caution and conclude that specific targets are affected and/or that a release has occurred. By not underestimating the potential threat, the worst outcome is that an SI will be conducted, the results of which may show that the threat is, in fact, relatively low and a NFRAP decision is appropriate. On the other hand, if the threat is underestimated at the PA, the worst outcome is that a PA NFRAP decision is made for a site that should have undergone an $\mathrm{Sl}$, that releases have occurred, and that targets land possibly 
human health) have been affected; these facts would remain undetected because the site was prematurely designated as NFRAP.

\subsection{SITE, SOURCE, AND WASTE CHARACTERIZATION}

A fundamental requirement of the PA is to describe the site, both physically and in terms of operational history. The first step is to access CERCLIS to obtain basic descriptive information about the site. CERCLIS can often provide the official site name, site identification number, street address, geographic coordinates, and other basic information (Section 2.1.1). Be aware that, because no field verification occurs prior to CERCLIS entry, information obtained from CERCLIS must be independently verified as part of your investigation. Record basic descriptive information on the cover page of the PA scoresheets and page 1 of the PA data summary form (Appendix D).

Determine the location of the site within the State and obtain the appropriate USGS 7.5-minute quadrangle topographic maps. Geographic coordinates of the site are sometimes lacking from the CERCLIS printout or are accurate only to the nearest minute. Always verify the coordinates obtained from CERCLIS by determining them yourself. Use EPA's standard operating procedure (SOP; Appendix E) to determine latitude and longitude coordinates by linear interpolation from the topographic map to within 0.5 second precision. Attach completed SOP worksheets as a reference to your PA narrative report (Section 4.2).

Suggestions on how to pursue other general descriptive information are offered in the following subsections. Additionally, it is essential to collect qualitative (descriptive) and quantitative (to the extent it can be approximated) information about wastes associated with the site. Technical data about sources and quantity of wastes in each source are critical to site assessment; obtaining this information is also addressed in the following subsections.

Pages 1 through 4 of the PA scoresheets provide space to present general site and source information. Your PA narrative report (Section 4.2) should contain similar summary information. Specific elements include:

- Official site name.

- CERCLIS identification number.

- Location: street address, city, county, State.

- Geographic coordinates: latitude/longitude; township, range, section.

- Owner/operator names, addresses, telephone numbers.

- Type of ownership: Federal, State, Indian, county, municipal, private.

- Years of operation.

- Regulatory involvement: permits, violations.

- Type of facility: 'manufacturing, waste disposal, storage, recycling, etc.

- Description of operations.

- History of methods of hazardous substance disposal, storage, or handling.

- Probable source types.

- Types of wastes present, probable substances of concern.

- Description of prior spills.

- Summary of existing samples and analytical data (if any).

- Reference and summary of manifests or waste records.

- Containment of wastes: secondary structures, procedures, monitoring.

- Mass, volume, or areal size of sources or volume of spills.

- Emergency or removal actions.

- Important resources and environments on or near the site. 


\subsubsection{Site Description and Source Characterization}

A physical and operational description of the site can be obtained through file searches, interviews, and site reconnaissance (see Section 2). Page 2 of the PA scoresheets provides space to summarize this information.

\section{General Site Description}

Definition: Site -- The area consisting of the aggregation of sources, the areas between sources, and areas that may have been contaminated due to migration from sources; site boundaries are independent of property boundaries.

Examine existing file information in the Regional EPA and State environmental agency offices (Section 2.3). Identify the site owner and operator (individual, organization, or company), address, and telephone number. Note that the "owner" and the "operator" may be two different parties. Depending on Regional guidance, you may want to verify this information by contacting a representative of the facility owner or operator.

Files at EPA and State environmental agency offices may yield information about current and previous operator activities, site history, regulatory and permitting actions, etc. By examining files at the facility itself (during an onsite reconnaissance, for example), you may be able to obtain engineering plans or field layout diagrams showing buildings, structures, roads, and waste handling areas on the site. These can be very useful in physically characterizing the site and providing insights into its operational history. For each PA, whether such materials are available or not, you also need to view and photograph the site during your reconnaissance to document current conditions (see Section 2.5).

During the site reconnaissance, measure or estimate dimensions to develop an accurate portrayal of areas where waste disposal activities may have occurred. However, do not attempt to directly measure waste source areas without authorized access, a health and safety plan, and appropriate protective equipment, as discussed in Section 2.5. Determine dimensions in feet and area in square feet or acres. Note that dimensions may have changed over time, as facility operations expanded or declined, or as portions of the property were acquired or sold. Recall the definition of "site" and be careful to delineate as fully as possible any areas that may qualify as part of the site, regardless of current conditions, fences, boundaries, or ownership. In addition, identify any adjacent or nearby property owned or leased by the site owner/operator. Investigate the dates or years of operation, and identify current operational status. If the site is active, determine or estimate the number of workers employed. Identify the type of facility -- manufacturing, mining, coal gasification, retail, landfill, salvage, and so forth -- and the main site activities and operations, both past and present.

\section{Source Identification and Characterization}

Summarize waste treatment, storage, or disposal activities that have or may have occurred both in the past and at present; note if these activities are documented or alleged. It is especially important to identify the specific areas where waste disposal, deposition, storage, or handling may have occurred -- these represent the sources that you evaluate for waste quantity (Section 3.2.2). 
Definition: Source -- An area where a hazardous substance may have been deposited, stored, disposed, or placed. Also, soil that may have become contaminated as a result of hazardous substance migration. In general, however, the volumes of air, ground water, surface water, and surface water sediments that may have become contaminated through migration are not considered sources.

A site may involve one or many types of sources such as surface impoundments, waste piles, municipal landfills, industrial landfills, industrial dumps, open dumps, above ground tanks, underground tanks, land treatment areas, sludge spreading areas, drum and container storage areas, spill areas, burn areas, etc. Identify all potential sources, their types, and dimensions (to the extent they can be measured or estimatedl. Sources are classified by physical structure (e.g., impoundment, landfill, tanks, containers) or by describing how the wastes have come to be deposited (e.g., pile, contaminated soil). If possible, also investigate source containment practices and type, volume, and physical state of wastes. Source types are described in Table 3-1, which includes an "other" source type for sources that clearly do not fit any other description.

Sources can be delineated and characterized through visual inspection during site reconnaissance; interviews with facility representatives, employees, or-neighbors; and file searches (especially those at the facility itself) for disposal records, waste manifests, and waste sampling data. Another useful reference is aerial photography (see Section 2.4.4). Historical air photos may identify sources that are no longer discernible on the ground due to physical changes to the facility or surrounding topography. Manifests listing types and quantities of hazardous waste materials transported or deposited may be available for periods after 1980, when this type of record-keeping became mandatory. Some types of permit applications, including National Pollutant Discharge Elimination System (NPDES) permits, may also contain information about waste composition and quantity.

If information or data exist for previous sampling at the site, prepare a summary table and attach it to the PA scoresheets. For each sample, indicate the medium sampled, sample location, hazardous substances detected, concentrations, and analytical detection limits. On page 2 of the PA scoresheets, under "Probable Substances of Concern," briefly discuss the conclusions of previous sampling episodes and relate these findings to specific hazardous substances or compounds suspected to be present at the site. Discuss whether sampling detected any areas of onsite contamination or evidence of offsite migration via a release to ground water, surface water, or air.

\section{Pathway Considerations}

In addition to site history, physical characteristics of the site, and source characteristics, also identify any significant resources or features pertinent to the ground water, surface water, soil exposure, and air pathways. Note ground water monitoring or drinking water wells on or near the site. Determine if portions of the site are located in surface water. Describe surface water bodies and identify residences, schools, or sensitive environments on or adjacent to the site. 
Table 3-1

Source Type Descriptions

Landfill: an engineered (by excavation or construction) or natural hole in the ground into which wastes have been disposed by backfilling, or by contemporaneous soil deposition with waste disposal, covering wastes from view.

Surface Impoundment: a topographic depression, excavation, or diked area, primarily formed from earthen materials (lined or unlined) and designed to hold accumulated liquid wastes, wastes containing free liquids, or sludges that were not backfilled or otherwise covered during periods of deposition; depression may be dry if deposited liquid has evaporated, volatilized or leached, or wet with exposed liquid; structures that may be more specifically described as lagoon pond, aeration pit, settling pond, tailings pond, sludge pit, etc.; also a surface impoundment that has been covered with soil after the final deposition of waste materials (i.e., buried or backfilled).

Drums: portable containers designed to hold a standard 55-gallon volume of wastes.

Tanks and Non-drum Containers: any stationary device, designed to contain accumulated wastes, constructed primarily of fabricated materials (such as wood, concrete, steel, or plastic) that provide structural support; any portable or mobile device in which waste is stored or otherwise handled.

Contaminated Soil: soil onto which available evidence indicates that a hazardous substance was spilled, spread, disposed, or deposited.

Pile: any non-containerized accumulation above the ground surface of solid, non-flowing wastes; includes open dumps. Some types of piles are: Chemical Waste Pile -- consists primarily of discarded chemical products, by-products, radioactive wastes, or used or unused feedstocks; Scrap Metal or Junk Pile -- consists primarily of scrap metal or discarded durable goods such as appliances, automobiles, auto parts, or batteries, composed of materials suspected to contain or have contained a hazardous substance; Tailings Pile -- consists primarily of any combination of overburden from a mining operation and tailings from a mineral mining, beneficiation, or processing operation; Irash Pile -- consists primarily of paper, garbage, or discarded non-durable goods which are suspected to contain or have contained a hazardous substance.

Land Treatment: landfarming or other land treatment method of waste management in which liquid wastes or sludges are spread over land and tilled, or liquids are injected at shallow depths into soils.

Other: a source that does not fit any of the descriptions given above; examples include contaminated building, ground water plume with no identifiable source, storm drain, dry well, and injection well. 
An example of the type of brief site description to record on page 2 of the PA scoresheets follows:

Site $X$ is an inactive 4.5-acre fabricated metal products manufacturing facility located in an industrial park which has. been developed on former pasture land since the early 1960's. The facility was built in 1966. Through 1979, the main manufacturing process was candlestick electroplațing, which generated lead-based paint sludge, chromium compounds, scrap metals, and various solvents. Wastes were discharged to three surface impoundments. From 1975 through 1979, 2 acres of the facility were also used to salvage and restore chrome automobile bumpers. In 1987, the State Department of Health (DOH) investigated citizen complaints about "suspicious" liquid wastes pooled in impoundments on the abandoned property. Samples of soil near the surface impoundments revealed lead $(231 \mathrm{mg} / \mathrm{kg})$ and $\mathrm{Cr}^{+3}(12,400 \mathrm{mg} / \mathrm{kg})$. According to $D O H$ records, samples for VOC analysis were also collected, but the results could not be found in the file. DOH secured the site with cyclone fencing in 1988.

Surrounding businesses obtain drinking water and process water from a single well that serves all facilities in the park. The well is located approximately 900 feet northwest of the site. The nearest residence is approximately $3 / 4$ mile to the east of the industrial park.

A drainage ditch originates on the site and follows the western perimeter; the ditch passes several other industrial establishments before entering a marshy area approximately 2,000 feet north of the site. Little Creek emerges from the marsh and flows 2.1 miles before entering Big River.

\section{Site Sketch}

Sketch the site on page 3 of the PA scoresheets. Indicate all pertinent features, including all potential waste sources, buildings, dwellings, access roads, parking areas, drainage patterns, ponded water, water bodies, stressed vegetation, barren areas, wells, sensitive environments, and so forth. If necessary, enlarge areas of the sketch to illustrate details of specific conditions. Your sketch should provide sufficient detail to locate critical pathway elements and to reference previous sampling locations (if available for the site). Note significant natural features as well as buildings and other structures. Appendix $C$ includes an example site sketch for the PA narrative report, which may be included in the scoresheets.

\subsubsection{Waste Quantity and Waste Characteristics}

The heart of waste characterization during the PA is an estimation of the quantity of potential wastes associated with all sources at the site. Use the information gathered about historical and current waste handling procedures, potential sources, waste amounts, and source dimensions, to characterize as completely as possible the waste quantities related to the facility.

Due to the limited, scope of the PA, your evaluation of waste characteristics will never be truly complete. Not until further study has identified, characterized, measured, sampled, analyzed, and documented all sources can the quantity and properties of the hazardous wastes at the site be fully known. Consequently, the following assumptions regarding sources and wastes typically apply for the PA: 
- Every potential source is large enough to actually or potentially impact human and environmental resources, regardless of size.

- It is very likely that hazardous substances present in wastes related to the site are extremely toxic, mobile, persistent, and able to accumulate in tissues.

- The total quantity of hazardous wastes associated with the site are eligible for evaluation even if, at any time in the history of the facility, wastes have been removed. (Exceptions to this assumption may occur, on a site-by-site basis, for certain types of qualifying removals. For further details, see EPA publication 9345.103FS, "The Revised Hazard Ranking System: Policy on Evaluating Sites After Waste Removals.")

- The total quantity of waste present produces at least the PA minimum waste characteristics factor category score (discussed later in this section).

\section{Tiered Approach to Evaluate Waste Quantity (WO)}

For each source, waste quantity may be evaluated by one or all of four different measures called "tiers": constituent quantity, wastestream quantity, source volume, source area. PA Table 1a (page 5 of the PA scoresheets) is divided into these four horizontal tiers. The amount and level of detail of the information available determine which tier(s) to use for each source. For each source, evaluate as many of the four tiers as you have data to support and select the result that gives the highest waste characteristics factor category score.

Hazardous constituent quantity refers to the mass of pure hazardous substances present in a source. Detailed disposal records and/or detailed analytical data are necessary to evaluate hazardous constituent quantity; this level of information is not often available for PA sites.

Wastestream quantity refers to the total mass of each particular type of waste present in the source. For example, a trench that received a known number of drums of spent solvent, a known mass of lead batteries, and a known volume of creosote-treated railroad ties could be evaluated on the basis of these three distinct wastestreams by converting each to mass and summing inote that this source would also be evaluated on the basis of volume and area if depth and surface dimensions were known or could be estimated). Detailed disposal records, which are not often available, are needed to properly evaluate wastestream quantity.

If records are available to support hazardous constituent and/or wastestream quantity calculations (in pounds), apply the following conversions:

1 cubic yard $=4$ drums $=200$ gallons $=1$ ton $=2,000$ pounds

Sources are most commonly evaluated at PA sites on the basis of volume or area. Measuring or estimating source dimensions has been previously discussed (Sections 2.3, 2.4, 2.5, and 3.2.1); onsite reconnaissance, owner/operator files, facility maps or engineering plans, and aerial photographs are all good approaches to determine source dimensions. When estimating source dimensions, it is a good practice to extrapolate those dimensions to cover the full area where you suspect hazardous substances may have been deposited and to include the total possible area of soil that may have been contaminated by substances associated with the sources. Recall the definition of "source" and, if you suspect that areas between sources may also be contaminated, evaluate those areas as separate sources as well. 


\section{General Instructions to Score Waste Characteristics (WC)}

Turn to PA Table 1a (page 5 of the PA scoresheets) and note the four horizontal tiers. In the volume and area tiers, the left-most column lists a variety of source types. Moving horizontally across the table for each source type, the next three columns provide volume and area ranges for each source type. Each range corresponds to a waste characteristics factor category score (WC) given at the top of the column $(18,32$, or 100$)$.

For a site with a single source, assign WC for the appropriate size range of the appropriate source type. Evaluate as many tiers as you have data to support, and select the highest resulting WC.

\section{Example: Single-source site}

$\begin{array}{ll}\text { Source type: } & \text { Landfill } \\ \text { Constituent quantity: } & \text { Not available } \\ \text { Wastestream quantity: } & \text { Not available } \\ \text { Volume: } & 7 \text { million } \mathrm{ft}^{3} ; W C=32 \\ \text { Area: } & 250,000 \mathrm{ft}^{2} ; W C=18\end{array}$

Site $W C=32$, the highest result among the tiers evaluated

For a site with multiple sources, convert each source measure to its appropriate units, and divide the result as indicated in the right-most column of PA Table 1a; this yields a waste quantity (WQ) value for each source. Sum the highest WO values, among the tiers evaluated, for all sources. From PA Table 1b, assign WC corresponding to the range into which the summed WO falls.

\section{Example: Multiple-source site}

Source type:

Constituent quantity:

Wastestream quantity:

Volume:

Area:

Source type:

Constituent quantity:

Wastestream quantity:

Volume:

Area:
Landfill

Not available

Not available

7 million $\mathrm{ft}^{3} ; \mathrm{WO}=7$ million $\div 67,500=103.7$

$250,000 \mathrm{ft}^{2} ; \mathrm{WO}=250,000 \div 3,400=73.5$

Drums

Not available

750 drums $\times 50 \mathrm{gal} / \mathrm{drum} \times 10 \mathrm{lb} / \mathrm{gal}=375,000 \mathrm{lb}$

$W O=375,000 \div 5,000=75$

750 drums; $W Q=750 \div 10=7.5$

Not evaluated

Summing the highest WO for each source yields a site WO $=103.7+75=178.7$

From PA Table $1 b$, site $W C=32$

Evaluating constituent quantity and/or wastestream quantity is no different from volume and area evaluations, except that mass (in pounds) is always the unit of measure regardless of source type. 
With that as a brief explanation of the structure and use of PA Tables $1 \mathrm{a}$ and $1 \mathrm{~b}$, general instructions for evaluating $W Q$ and determining WC for sites having a single source and sites with multiple sources are summarized below.

\section{For sites with only one source:}

1. Identify soúrce type (Table $3-1$ ).

2. Examine all waste quantity data available.

3. Estimate the mass or dimensions of the source.

4. Determine which quantity tiers to use based on the source information available (see PA Table $1 \mathrm{a}$ and page 45 of this guidance).

5. Convert source measurements to the appropriate units for each tier evaluated.

6. Identify the range into which the source falls for each tier evaluated (PA Table 1a).

7. Determine the highest waste characteristics factor category score (WC) obtained for any tier $(18,32$, or 100, at the top of PA Table 1a columns).

8. Use this WC for all pathways (exceptions are noted in Sections 3.3.3, 3.4.3, and 3.6.3).

For sites with multiple sources:

1. Identify each source type (Table 3-1).

2. Examine all waste quantity data available for each source.

3. Estimate the mass or dimensions of each source.

4. Determine which quantity tiers to use for each source based on the information available (see PA Table 1a and page 45 of this guidance).

5. Convert source measurements to the appropriate units for each tier evaluated for each source.

6. Divide the measurement for each source as indicated in the right-most column of PA Table 1a. Identify the highest resulting waste quantity value (WO), among the tiers evaluated, for each source. Sum the highest WQs for all sources.

7. Use PA Table $1 \mathrm{~b}$ to assign the waste characteristics factor category score (WC) for the range into which the summed WO falls.

8. Use this WC for all pathways (exceptions are noted in Sections 3.3.3; 3.4.3, and 3.6.3). 


\section{Scoring Waste Characteristics (WC) for Specific Source Types}

Procedures to quantitatively evaluate each source type using PA Tables $1 \mathrm{a}$ and $1 \mathrm{~b}$ follow:

Hazardous Constituent (pure hazardous substance)

Determine mass for each constituent. If necessary, convert volume to pounds. Sum all constituent mass values. If total constituent mass is less than or equal to 100 pounds, assign a waste characteristics factor category score (WC) of 18 . If total constituent mass is greater than 100 and less than 10,000 pounds, assign WC 32; greater than 10,000 pounds, assign WC 100.

Constituent wastes are hazardous substances in pure liquid, solid, or (less commonly) gaseous form. The mass of constituents can be calculated from volume. Some examples of applying constituent data are:

- For 16 25-gallon containers and 20 drums labeled carbon tetrachloride (pure substance), determine the total volume in gallons (assume a 50 -gallon volume for drums not otherwise specified) and convert to mass (10 pounds per gallon). The resulting quantity of hazardous constituent is 14,000 pounds $(((16 \times 25)+(20 \times 50))$ $x 10)$, which yields a PA waste characteristics score of 100 .

- For a single drum of unspecified volume and labeled 30 percent aldicarb (a pesticide), multiply 50 gallons $\times 10$ pounds per gallon $\times 0.3$, yielding 150 pounds for constituent waste quantity.

- 50,000 pounds of sludge with a representative lead concentration of $300 \mathrm{mg} / \mathrm{kg}$ results in a constituent quantity of 15 pounds of lead.

- For 5 million $y d^{3}$ of mine tailings with representative arsenic and copper concentrations of 24.4 and $47.6 \mathrm{mg} / \mathrm{kg}$, respectively, first convert volume to mass: 5 million $\mathrm{yd}^{3} \times 1$ ton $/ \mathrm{yd}^{3}=5$ million tons $=10$ billion $\mathrm{lb}$. Next, convert constituent concentrations to mass: $24.4 \mathrm{mg} / \mathrm{kg}$ in 10 billion $\mathrm{lb}$ of tailings yields $244,000 \mathrm{lb}$ of arsenic; $47.6 \mathrm{mg} / \mathrm{kg}$ in 10 billion lb of tailings yields $476,000 \mathrm{lb}$ of copper. The constituent waste quantity is the sum: $244,000+476,000=720,000 \mathrm{lb}$; $W C$ is 100 .

- A report or manifest showing that 120 pounds of powdered DDT concentrate were transported from an agricultural research facility and disposed at the site could also be used as evidence of constituent quantity.

\section{Hazardous Wastestream (known quantity of a single type of waste)}

Determine mass of each wastestream. If necessary, convert volume to pounds. If there is only one wastestream and the wastestream quantity is less than 500,000 pounds, assign WC 18; if greater than 500,000 and less than 50 million pounds, assign WC 32; if greater than 50 million pounds, assign WC 100.

If there is more than one wastestream, divide each wastestream mass by 5,000 and sum the results to obtain a wastestream WO. Add the wastestream WO to other partial WO values calculated for sources at the site, and assign WC from PA Table $1 \mathrm{~b}$.

Drum Volume (for drums not suspected or labeled as containing pure or undiluted hazardous substances)

For standard 55-gallon drums, assume the volume of each is $\mathbf{5 0}$ gallons (allowing a 5 -gallon headspace). If there are less than 1,000 drums $(50,000$ gallons) at the site, WC is 18 ; if 
greater than 1,000 and less than 100,000 drums 150,000 gallons $<V<5$ million gallons), WC is 32; if more than 100,000 drums, or greater than 5 million gallons, WC is 100 .

If there are other sources, along with drums, divide the total number of drums by 10 to determine the drum WO value. Add the drum WQ to the other source WO values calculated for the site, and assign WC from PA Table $1 \mathrm{~b}$.

\section{Tank and Non-drum Container Volume}

For a source consisting of tanks or containers other than drums, sum the volumes of the containers (in like units of measure) and convert the total volume to gallons. Assign WC a value of 18 if the total volume is less than or equal to 50,000 gallons, WC 32 if volume is greater than 50,000 and less than 5 million gallons, and WC 100 if volume is greater than 5 million gallons.

If there are other sources, along with tanks or containers, divide the total non-drum volume (gallons) by 500 to determine the non-drum volume WQ value. Add the non-drum volume WO to the other source WO values calculated for the site, and assign WC from PA Table $1 \mathrm{~b}$.

$$
\begin{aligned}
& \text { Volume and Area Conversions } \\
& 1 \text { cubic yard }=27 \text { cubic feet } \\
& 1 \text { acre }=43,560 \text { square feet }
\end{aligned}
$$

Landfill Volume (length $x$ width $x$ depth) or (area $x$ depth)

If surface area and depth of excavation for landfilling operations are known or can be estimated, calculate landfill volume in cubic yards. Landfill volume less than or equal to $250,000 \mathrm{yd}^{3}$ receives a WC value of 18; greater than 250,000 and less than 25 million $\mathrm{yd}^{3}$ receives WC 32; and greater than 25 million $y^{3}{ }^{3}$ receives WC 100.

If there are other sources, along with the landfill, divide the landfill volume $\left(y d^{3}\right)$ by 2,500 to determine the landfill volume WQ value. Add the landfill volume WO to the other source WO values calculated for the site, and assign WC from PA Table $1 \mathrm{~b}$.

\section{Landfill Area (length $x$ width)}

Measure or estimate landfill surface area in square feet or acres. If the area is less than or equal to $340,000 \mathrm{ft}^{2}$ (7.8 acres), assign WC 18; if greater than 340,000 and less than 34 million $\mathrm{ft}^{2}\left(780\right.$ acres), assign WC 32; if greater than 34 million $\mathrm{ft}^{2}$ ( 780 acres), assign WC 100 .

If there are other sources, along with the landfill, divide the landfill area $\left(\mathrm{ft}^{2}\right)$ by 3,400 to determine the landfill area WO value. Add the landfill area WO to the other source WO values calculated for the site, and assign WC from PA Table 1b.

\section{Surface Impoundment Volume (length $\mathrm{x}$ width $\mathrm{x}$ depth) or (area $\mathrm{x}$ depth)}

For a surface impoundment, whether wet, dry, buried, or backfilled, if area and depth are known or can be estimated, determine volume of the impoundment in cubic yards. If the volume is less than or equal to $250 \mathrm{yd}^{3}, W C$ is 18 ; if greater than 250 and less than 25,000 $y d^{3}, W C$ is 32; if greater than $25,000 \mathrm{yd}^{3}, W C$ is 100 . 
If there are other sources, along with the surface impoundment, divide the surface impoundment volume $\left(\mathrm{yd}^{3}\right) \cdot$ by 2.5 to determine the surface impoundment volume WO value. Add this WO value to the other source $W O$ values calculated for the site, and assign WC from PA Table 1b.

Surface Impoundment Area (length $x$ width)

Measure or estimate, in square feet, the area of the surface impoundment (whether wet, dry, backfilled, or buried). Assign WC 18 if the surface impoundment area is less than or equal to $1,300 \mathrm{ft}^{2} ; 32$ if area is greater than 1,300 and less than $130,000 \mathrm{ft}^{2}$; and 100 if area is greater than $130,000 \mathrm{ft}^{2}$.

If there are other sources, along with the surface impoundment, divide the surface impoundment area $\left(\mathrm{ft}^{2}\right)$ by 13 to determine the surface impoundment area WQ. Add this WO value to the other source WO values calculated for the site, and assign WC from PA Table $1 \mathrm{~b}$.

Contaminated Soil Volume (length $x$-width $x$ depth) or (area $x$ depth)

If the volume of contaminated soil can be determined by measuring or estimating area and the depth to which hazardous substances are suspected to extend, convert the volume to cubic yards. If contaminated soil is the only source at the site, assign WC values for ranges of volume: 18 if volume is less than or equal to $250,000 \mathrm{yd}^{3} ; 32$ if greater than 250,000 and less than 25 million $\mathrm{yd}^{3}$; and 100 if greater than 25 million $\mathrm{yd}^{3}$.

If there are other sources, along with contaminated soil, divide the contaminated soil.volume $\left(\mathrm{yd}^{3}\right)$ by 2,500 to obtain a contaminated soil volume WO. Add this WQ value to the other source WQ values calculated for the site, and assign WC from PA Table $1 \mathrm{~b}$ :

Contaminated Soil Area (length $x$ width)

Measure or estimate the surface area of contaminated soil (square feet or acres). Assign WC 18 if the area is less than or equal to 3.4 million $\mathrm{ft}^{2}$ (78 acres); 32 if area is greater than 3.4 million and less than 340 million $\mathrm{ft}^{2}(7,800$ acres); and 100 if area is larger still.

If there are other sources, along with contaminated soil, divide the contaminated soil area $\left(\mathrm{ft}^{2}\right)$ by 34,000 to obtain a contaminated soil area WO. Add this WO value to the other source WO values calculated for the site, and assign WC from PA Table $1 \mathrm{~b}$.

Contaminated soil may be the result of spills, leaking containers, or direct disposal of solid or liquid hazardous wastes on the ground. You may hypothesize areas of contaminated soil from. accounts of waste handling procedures, intentional spreading practices (with and without permits), fire records, known or alleged discharges, and similar evidence. You may also use evidence of stained soil, stressed vegetation or areas barren of vegetation, and available analytical data (if any) to estimate' areas of contaminated soil.

Although many sites have contaminated soil, the quantity is rarely great enough to contribute significantly, to the overall site. WC factor category score; because so much'/more than $250,000 \mathrm{yd}^{3}$ or 78 acres) is required to achieve a WC above the PA minimum of 18 . However, it remains important to identify. and to note all areas of contaminated soil, because the distance from sources to targets can be a critical consideration for each pathway -:especially the soil exposure pathway.

\section{Pile Volume}

If you know or can estimate the volume of waste making up a source pile, convert units to cubic yards. Assign WC a value of 18 if the volume is less than or equal to $250 \mathrm{yd}^{3}, W C 32$ if volume is greater than 250 and less than $25,000 \mathrm{yd}^{3}$, and WC 100 if volume is greater than $25,000 \mathrm{yd}^{3}$. 
If there are other sources, along with the pile, divide the pile volume $\left(y d^{3}\right)$ by 2.5 to determine the pile volume $W Q$ value. Add the pile volume $W O$ to the other source $W O$ values calculated for the site, and assign WC from PA Table $1 \mathrm{~b}$.

Pile Area (land surface area under the pile)

Estimate the area under a source pile and express in square feet. Assign WC 18 if area is less than or equal to $1,300 \mathrm{ft}^{2} ; 32$ if area is greater than 1,300 and less than $130,000 \mathrm{ft}^{2}$; and 100 if area is greater than $130,000 \mathrm{ft}^{2}$.

If there are other sources, along with the pile, divide the pile area by 13 to determine the pile area WQ value. Add the pile area WO to the other source $W Q$ values calculated for the site, and assign WC from PA Table $1 \mathrm{~b}$.

\section{Other Volume}

The "other" source type can only be selected for a source that clearly does not fit any of the other source type descriptions in Table 3-1, and can only be evaluated on the basis of volume. If you know or can estimate the volume of the source, convert units to cubic yards. Assign WC a value of 18 if the volume is less than or equal to $250 \mathrm{yd}^{3}$, WC 32 if volume is greater than 250 and less than $25,000 \mathrm{yd}^{3}$, and WC 100 if volume is greater than $25,000 \mathrm{yd}^{3}$.

If there are additional sources, along with the "other" source, divide the "other" source volume $\left(y d^{3}\right)$ by 2.5 to determine the source volume WQ value. Add the volume WO to the additional source WQ values calculated for the site, and assign WC from PA Table $1 \mathrm{~b}$.

\section{Land Treatment Area (length $x$ width)}

Measure or estimate, in square feet, the area of land treatment. Assign WC 18 if the area is less than $27,000 \mathrm{ft}^{2}(0.62$ acres); 32 if area is greater than 27,000 and less than 2.7 million $\mathrm{ft}^{2}$ (62 acres); and 100 if area is greater than 2.7 million $\mathrm{ft}^{2}$.

If there are other sources, along with the land treatment area, divide the land treatment area $\left(\mathrm{ft}^{2}\right)$ by 270 to obtain the land treatment area WO value. Add this WO value to the other source WO values calculated for the site, and assign WC from PA Table $1 \mathrm{~b}$.

\section{Concluding Note}

Identify and describe each source in the space provided on page 4 of the PA scoresheets. Also show all source WO and site WC calculations.

Remember to evaluate WQ for each source under as many tiers as you have data to support. Assign the highest resulting WO to the source. If there is more than one source at the site, sum the assigned WQ values for each source to arrive at the site.WQ. Assign WC on the basis of this total site WQ.

Do not assign any WC score other than 18,32 , or 100 . The PA minimum WC is 18 , which may be assigned if waste quantity information is lacking, incomplete, or minimal. Never assign a zero score to WC; if you can convincingly show that no CERCLA hazardous substances are or ever have been at the site, PA scoring may not be necessary (see Section 2.2.4).

The assigned WC is applied as the waste characteristics factor category score under all four pathways, except if primary targets are present. Sections 3.3.3, 3.4.3, and 3.6.3 discuss these exceptions on a pathway-by-pathway basis. 


\section{GROUND WATER PATHWAY}

\subsection{GROUND WATER PATHWAY}

The PA evaluation of the ground water pathway requires you to consider and assign scores to factors in three factor categories: Likelihood of Release, Targets, and Waste Characteristics.

Evaluating likelihood of release requires you to hypothesize whether hazardous substances are likely to have migrated to ground water. When a release is not suspected, special considerations that enter into your scoring decision include the depth to the shallowest aquifer and the presence of karst terrain.

The principal threat under the ground water pathway is the threat posed to drinking water and to populations relying on ground water as their source of drinking water. Therefore, the targets evaluation is primarily concerned with identifying drinking water wells, and their associated populations, within the 4-mile target distance limit (radius) around the site.

The evaluation and score for the waste characteristics factor category (WC, Section 3.2.2) applies directly to the ground water pathway, as to all other pathways, except if primary targets are identified (Section 3.3.3).

Proper evaluation of the ground water pathway requires a general understanding of the local geology and subsurface conditions. Of particular interest is descriptive information relating to subsurface stratigraphy, aquifers, and ground water use.

Definition: Aquifer -- A saturated subsurface zone from which drinking water is drawn.

Publications of the USGS and State geological surveys are good sources for local and regional geologic information. Other local sources of information may include well drillers, well logs (possibly maintained by local or State government agencies), and university geology departments. Briefly describe the local geology, subsurface stratigraphy, aquifers, and aquifer uses within 4 miles of the site. Record this summary on page 6 of the PA scoresheets. 


\subsubsection{Likelihood of Release}

Evaluating the Likelihood of Release factor category requires a professional judgment, based on site and pathway conditions, as to whether a hazardous substance is likely to have been released to ground water. Likelihood of Release is scored on the basis of one of two scenarios, "Suspected Release" or "No Suspected Release," either of which require you to make this' professional judgment. Your judgment takes the form of a hypothesis that a release has or has not occurred. The formulation of your hypothesis is guided by the "Criteria List" (page 7 of the PA scoresheets).

\section{Criteria List for Suspected Release to the Ground Water Pathway}

The Criteria List helps guide the process of developing hypotheses about two very important aspects of the site: whether a hazardous substance is likely to have been released to ground water; and whether any drinking water wells are likely to be exposed to a hazardous substance as a result of a release. The Criteria List suggests a number of characteristics of the site and its environs to consider in reaching conclusions on these points. Answer the questions in the left-hand column of the Criteria List; which deal with a suspected release; the right-hand column, dealing with primary targets, is evaluated in connection with the Targets factor category (Section 3.3.2) if you conclude that a release to ground water is likely to have occurred.

Carefully consider each element on the Criteria List within the context of the site and its environs. Answers to every question on the list, however, are unlikely to be available for many sites. You need not spend excessive amounts of time trying to develop detailed information to respond to each question -- it is possible to arrive at sound hypotheses about suspected releases and their potential effects on targets without knowing answers to all questions on the list.

Also, keep in mind that because there is an infinite variety of site-specific circumstances, no list of this type could identify every characteristic that might apply to any specific site. The list, therefore, is by no means complete and the criteria making up the list are not prioritized in any way: Instead, these questions are meant to get you thinking about the types of site-specific conditions that need to be considered when formulating hypotheses about releases and the condition of targets. There are likely to be other site-specific criteria that apply to a particular site, and you are encouraged to think along these lines. If such additional considerations enter into your conclusions, identify them at the bottom of the list.

Answer the questions on the list by checking the appropriate box marked "yes, " no," or "unknown." In evaluating each question, rely on the total body of information you have obtained about the site and its environs through the course of your investigation -- file searches, desktop data collection, site reconnaissance, interviews, etc.

Answers to many of the individual questions are likely to be fairly self evident. The difficult part lies in drawing the final conclusion, which amounts to a hypothesis as to whether you suspect a release. This requires professional judgment and is a somewhat intuitive process that relies upon your accumulated professional expertise and specific knowledge of site and target characteristics. Note that the Criteria List is not a tally sheet requiring a majority of "yes" or "no" responses to reach a conclusion. You may hypothesize a suspected release on the basis of one or more characteristics that lead you to believe there is a relatively high likelihood that a hazardous substance has been released to ground water. 


\section{GROUND WATER PATHWAY LIKELIHOOD OF RELEASE}

\section{Suspected Release Considerations}

Each item on the Criteria List for suspected releases to ground water is briefly discussed below.

Are sources poorly contained?

For many types of sources, proper containment to prevent hazardous substances from migrating to ground water requires engineered structures, such as double liners and a leachate collection system, that are inspected regularly and properly maintained. This level of containment for all sources is not often found at CERCLIS hazardous waste sites. Your response may be "yes" if wastes have been:

- Leaked, spilled, or spread on the ground.

- Buried underground.

- Deposited in trenches or impoundments in permeable soils.

- Deposited in sources lacking complete containment.

An example of conditions for a "no" response is: tanks on a well-maintained cement platform inside an intact building, protected from precipitation and run-on, with functioning runoff control should the containers leak or rupture.

Is the source a type likely to contribute to ground water contamination?

Many source types are likely contributors to ground water contamination because they are situated in or on the ground. Examples include underground tanks, landfills, surface impoundments or lagoons, and open dumps. The presence of liquid wastes in a source adds to the likelihood of migration. Sources less likely to contribute to ground water contamination might include sound above-ground tanks, drummed solid wastes, or sources inside buildings.

Is waste quantity particularly large?

Depending on the type of waste and its physical state, "large" is a relative term with respect to the potential for a release to ground water. In this context, a relatively small lagoon containing liquid wastes probably has more importance than a large pile of mine tailings. In general, however, any amount is considered "large" if it produces a waste characteristics factor category score (WC) of 32 or more.

Is precipitation heavy?

Heavy precipitation provides a driving force to carry hazardous substances through the soil to ground water. Total annual precipitation exceeding 40 inches or annual net precipitation exceeding 15 inches might be considered "heavy" precipitation. You can obtain this information from the "Climatic Atlas of the United States," published by the U.S. Department of Commerce, or from local weather stations.

Is the infiltration rate high?

A high infiltration rate means that surface soil conditions favor the rapid downward movement of water. The combination of heavy precipitation and high infiltration rate increases the likelihood of hazardous substances reaching ground water. Infiltration rates range from very high in gravelly and sandy soils to very low in fine silt and clayey soils. You can find out about 
soil types in the area of the site from the County Extension Office of the USDA Soil Conservation Service (SCS), or from soil survey maps published by the SCS for most counties in the nation.

Is the site located in an area of karst terrain?

In karst formations, ground water moves very rapidly through solution channels caused by dissolution of the rock material (usually limestone), which could facilitate migration of hazardous substances. See the discussion of karst conditions on pages 57 to 58 for more information.

Is the subsurface highly permeable or conductive?

Just as high infiltration rates indicate rapid movement of water through surface soils, highly permeable or conductive subsurface materials also favor downward movement of water that may transport hazardous substances. The presence of low-permeability materials or confining layers will impede this movement. Well logs, local geologic literature, or interviews with individuals knowledgeable about the geology of the area will help answer these questions.

Sands and gravels tend to be very conductive, as do highly fractured bedrock environments. The presence of lava tubes or mine drainage tunnels, or conditions of non-karst cavern porosity, also favor the rapid movement of ground water.

Is drinking water drawn from a shallow aquifer?

In the context of the PA, an aquifer is defined as "a saturated subsurface zone from which drinking water is drawn." Note the emphasis on ground water use in the definition. The shallower a source of drinking water, the higher the threat of contamination by hazardous substances. Information on well and aquifer depths can be obtained from well logs and by interviewing local water authorities, well drillers, and private well owners. Geologic literature on the area may also be useful. Determining depth to aquifer is discussed on pages 56 to 57 .

Are suspected contaminants highly mobile in ground water?

The extent to which you can identify the hazardous substances present at a site is variable at the PA. For some sites, specific substances will be identifiable from available analytical data, file searches, or interviews during a site visit. At other sites, the general types of substances present may be inferred from knowledge about site operations. You should be able to generalize about the substances suspected to be present, and their relative mobility in ground water. Metals, for example, do not tend to be very mobile, while most liquids tend to be relatively highly mobile.

Does analytical or circumstantial evidence suggest ground water contamination?

"Circumstantial" implies a level of certainty below that of "proven fact," and this is sufficient for PA purposes. In this context, any condition that you find suspicious, and that indicates a possible contamination problem, can be considered circumstantial evidence. A few examples are:

- Analytical data provide indications of hazardous substances in ground water, regardless of whether you can specifically attribute those substances to the site. 


\section{GROUND WATER PATHWAY}

LIKELIHOOD OF RELEASE

- Monitoring wells are present onsite.

- Nearby wells of any type have been closed for reasons you do or do not know.

- Users of nearby drinking water wells have complained to the Health Department about "funny tasting" water.

After answering these questions, and adding other considerations to the list, indicate your professional judgment as to the likelihood of a release of hazardous substances by checking "yes" or "no" next to the "Suspected Release?" question. Remember that this is a judgment call; you don't need a majority of "yes" responses -- in some cases, a single "yes" may be sufficient to suspect a release. Summarize the rationale for your hypothesis.

\section{Special Considerations When a Release Is Not Suspected}

If your evaluation of the Criteria List leads you to conclude that a release to ground water is not suspected, two specific considerations are important to assign the PA score for Likelihood of Release: depth to aquifer and presence of karst terrain. Both are included in the Criteria List, but are discussed in more detail here due to their importance when a release is not suspected.

\section{Depth to Aquifer}

Definition: Depth to Aquifer -- The vertical distance between the deepest point at which hazardous substances are suspected and the top of the shallowest aquifer that supplies drinking water.

Depth to aquifer can be used as an indicator of the likelihood of release of hazardous substances to ground water. Consider, for example, two hypothetical sites with similar characteristics, except that the depth to aquifer under Site $A$ is relatively small (say, 50 feet), while the depth to aquifer under Site B is relatively great (say, 150 feet). You might expect Site A to have a higher likelihood of hazardous substances migrating to ground water.

Three pieces of information are required to evaluate depth to aquifer:

(1) An estimate of the deepest point at the site at which you suspect hazardous substances may be located.

(2) An estimate of the depth below land surface:(bls) to the top of the shallowest aquifer that supplies drinking water.

(3) Confirmation that the aquifer you are measuring to is used to provide drinking water.

Usually, estimating the deepest point at which hazardous substances are suspected to be located is a function of the types of sources at the site. For example, at a landfill the deepest point of hazardous substances could be estimated as the depth (bls) of the landfill itself. Similarly, the maximum depth of a surface impoundment or lagoon might be used. For waste piles, drum storage areas, or other above-ground sources, the deepest point of hazardous substances might be the ground surface itself. 
If previous site investigations (by a State agency or the site owner, perhaps) involved environmental sampling, the resulting analytical data could be used to estimate the deepest point of hazardous substances. Boreholes, test pits, or other excavations may have revealed subsurface contamination at known depths, or monitoring well samples might indicate hazardous substances in ground water. In the latter case, the deepest point of hazardous substances could be estimated as the top of the well screen. Be aware, howèver, that PA sites with available subsurface analytical data are not common; in most cases, you will have to rely on other types of information.

For sources that extend below the ground surface, but whose actual depth cannot be estimated, you may assume depth of waste deposition to be 6 feet.

Don't get hung up on trying to pinpoint the depth of the deepest hazardous substances. Unless one or more sources are actually deep in the ground (for example, an underground storage tank or an excavated landfill), there's not likely to be a great difference between the true depth of hazardous substances, a default depth of 6 feet, or the ground surface. The depth of the aquifer itself is generally the more important concern.

You can most directly determine the depth to the top of the shallowest aquifer by interviewing local water supply officials. This can be done via telephone from your office, or during a meeting as part of your offsite reconnaissance. Other sources may include the local Health Department, where the County Sanitarian or similar official is responsible for testing the potability of well water, and local well drillers. Since aquifers are usually laterally extensive, and because variations in surface topography affect the below-land-surface depth of the aquifer, use a depth estimate that is local to the site. It need not be the depth specifically under the site, but it shouldn't be a depth from more than 2 miles away. Record the depth to aquifer in the "Pathway Characteristics" box on the ground water pathway scoresheet (page 8 of the PA scoresheets).

Remember that the aquifer whose depth you are evaluating must be the shallowest aquifer that supplies drinking water to wells within the 4-mile target distance limit. Be sure that the people you contact regarding aquifer depths understand this distinction, and that you include confirmation of use in your written documentation.

In addition to interviews as discussed above, other primary sources of information on local hydrogeology, water supply, and aquifer use include the geologic literature published by USGS and similar State agencies. Aquifer depths can also often be determined from well logs filed with local or State agencies, or obtained from a local drilling company.

\section{Karst Terrain}

"Karst" is a kind of terrain with characteristics of relief and drainage arising from a high degree of rock solubility. The majority of karst conditions occur in limestone areas, but karst may also occur in areas of dolomite, gypsum, or salt deposits. Features associated with karst terrain may include irregular topography, abrupt ridges, sinkholes, caverns, abundant springs, and disappearing streams. Well-developed or well-integrated surface drainage systems of streams and tributaries are generally lacking.

The presence of karst is an important aspect of the environment around the site because the PA treats karst areas somewhat differently from non-karst areas. Compared to other geologic formations, karst formations and karst aquifers transmit larger quantities of water and do so much more rapidly. Water in karst aquifers moves through solution channels in rock material; water in other types of aquifers moves through pores or cracks, or along fractures and faults. The 


\section{GROUND WATER PATHWAY LIKELIHOOD OF RELEASE}

comparison is somewhat akin to water movement through a pipe vs. a sponge. Thus, hazardous substances associated with a site located in karst terrain are more likely to reach ground water than substances from a site with similar conditions located in a non-karst area. Once in ground water, hazardous substances in a karst aquifer are also apt to travel farther and less impeded than they might in other rock types.

The PA takes these considerations into account to evaluate ground water likelihood of release and targets. The presence of karst terrain in the vicinity of the site is used as an indicator of a high potential to release at sites where an actual release is not suspected to have occurred. Also, secondary drinking water target populations in karst areas receive higher weighted values than those in non-karst areas.

You can identify karst terrain by the predominant presence of the types of topographic features mentioned above -- irregular topography, abrupt ridges, sinkholes, caverns, abundant springs, disappearing streams, and a general lack of well-developed surface drainage systems. These features are typically evident on topographic maps and/or aerial photographs. Geologic literature about the area can also confirm the occurrence of karst terrain. If in doubt as to whether the area around a site can be considered karst terrain, consult your staff geologist. Local experts at USGS or State geologic agency offices, university geology departments, or well drillers can also be consulted. If you have reason to believe that the area around the site can be described as karst, but remain uncertain, assume that it is karst.

\section{Scoring Likelihood of Release}

After completing your evaluation of the Criteria List for releases to ground water, including depth to aquifer and karst considerations, you should have a hypothesis as to whether you do or do not suspect a release. The following pages explain how to assign a score to the Likelihood of Release factor category, depending on whether your hypothesis is "Suspected Release" or "No Suspected Release." 
Factor: Suspected Release

Definition: A professional judgment conclusion based on site and pathway conditions indicating that a hazardous substance is likely to have been released to ground water.

Evaluation Strategy: In scoring a suspected release, you are stating a hypothesis that a hazardous substance is likely to have been released to ground water. You may hypothesize a suspected release on the basis of available analytical data indicating that a release may have occurred; however, analytical data are not usually available for PA sites. For PA purposes, your professional judgment is usually based on indications -- which is not the same as documented fact.

The Criteria List for releases to ground water (discussed on pages 53 to 56 ) helps guide the process of considering pertinent characteristics of the site and surrounding area that might lead you to suspect a release. You may hypothesize a suspected release on the basis of one or more characteristics of the site, its environs, sources, and type and quantity of wastes thought to be present.

It is not possible to provide comprehensive guidance on what does and does not "qualify" as a suspected release; you must rely on your professional judgment. Two examples of circumstances that might warrant a suspected release hypothesis are:

- Analytical data from a well 1,000 feet from the site indicate high concentrations of benzene and related organics. You may score a suspected release even though background concentrations are not available and you do not know whether the contaminants are specifically attributable to activities at the site.

- Liquid wastes and sludges have been stored outdoors in drums, some of which are rusted, perforated, and lying on the ground surface; areas of stained soil are visible; and the water table is known to be present at depths ranging from 20 to 50 feet within 2 miles of the site.

Scoring Instructions: Hypothesize and score a suspected release when available information leads you to conclude that there is a relatively high likelihood of a hazardous substance having migrated to ground water. Assign a score of 550 to factor \#1 (Suspected Release) on the ground water pathway scoresheet (page 8 of the PA scoresheets); assign the score under Column $A$ and use only Column $A$ for the ground water pathway. Do not assign a score to factor \#2 (No Suspected Release).

If you do not hypothesize a suspected release, score factor \#2 (No Suspected Release). 
Factor: No Suspected Release

Definition: A professional judgment conclusion based on site and pathway conditions indicating that a hazardous substance is not likely to have been released to ground water.

Evaluation Strategy: If you did not hypothesize a suspected release from your evaluation of the Criteria List, then your hypothesis must be that a release is not suspected. You must complete an evaluation of the Criteria List (left-hand column) before concluding that a release is not suspected.

Just as a hypothesis that a release is suspected is based on characteristics of the site, its environs, sources, and type and quantity of wastes thought to be present, so is the hypothesis that a release is not suspected. In this instance, however, available information leads you to conclude that there is a relatively low likelihood of a hazardous substance having been released to ground water.

Scoring Instructions: If you do not suspect a release to ground water, there are two possible scores to assign -- 340 or 500 . To determine the appropriate score, consider the depth to the shallowest aquifer that supplies drinking water within the 4-mile target distance limit and the presence or absence of karst terrain. Both of these considerations appear on the Criteria List and their evaluation is discussed on pages 56 to 58 .

If you do not suspect a release and:

- The site is located in an area of karst terrain, assign a score of 500 to factor \#2 (No Suspected Releiase).

- The depth to aquifer is 70 feet or less, assign a score of 500 to factor \#2.

If neither of these two specific conditions applies, assign a score of 340 to factor $\# 2$.

If No Suspected Release is scored, assign the score to factor \#2 under Column B and use only Column B for the ground water pathway. 


\subsubsection{Targets}

Ground water pathway targets are drinking water supply wells within 4 miles of the site. For every PA site, you must develop a good understanding of the drinking water supply situation within the 4-mile target distance limit, and perform a comprehensive survey of drinking water supply systems and the number of people they serve. Very often, drinking water is supplied by some combination of domestic wells serving individual residences, community wells serving multiple residences, municipal wells serving entire towns or cities, and surface water supplies. For the ground water pathway, you are specifically concerned with private and public drinking water supply wells but, in the course of developing information about water supplies, you must also find out about surface water sources of drinking water (Section 3.4.2).

Your survey, must be comprehensive enough to allow you to identify, on a topographic map, the location of each municipal drinking water well and surface water intake supplying drinking water within the target distance limit. Delineate on the map the specific geographic areas where drinking water is supplied by: municipal wells, municipal intakes, private and community wells, and private and community intakes. Note that, in some areas, private water companies supply drinking water to large numbers of people. These systems also fall within the meaning of a "municipal" system.

\section{Multiple-Aquifer Systems}

In researching the local water supply situation, you may find that drinking water is drawn from more than one aquifer. In many areas, multiple-aquifer systems provide drinking water from different aquifers at different depths. In such situations, the deeper aquifer(s) may or may not be at risk from a release from the site, depending on whether it is hydrogeologically isolated from overlying aquifers. Often, the extent to which one aquifer may be either isolated from or in hydraulic communication with another aquifer is not easily determined and even hydrogeologic experts may disagree. For these reasons, the PA evaluation of populations drinking ground water includes all persons served by all aquifers. Nonetheless, when researching drinking water populations, it is a good practice to develop as much information as possible concerning the populations associated with specific aquifers; such information may be useful to the SI if the site advances to that stage.

\section{Municipal Drinking Water Supplies}

The best place to begin a water supply survey is the local municipal and county water authorities. Bring your topographic map and ask the appropriate officials to locate municipal drinking water wells and intakes, including those that might be designated as "standby" or "backup," and to delineate the municipal distribution system. Very often, the entire system is interconnected -- by way of valves or connecting lines -- so that water drawn from any individual well or intake has the potential to reach any user of the system. This is referred to as a "blended system." In other cases, separate distribution systems function independently and do not have the capability for interconnection with other systems. Identify the specific systems that are blended, and the specific systems that are independent. You also need to know either the number of people served or the number of service connections in each blended and independent system, which wells and intakes supply each system, and the average annual production from each well and intake.

\section{Drinking Water Supplies in Areas Not Served by a Municipal System}

After identifying municipal wells, intakes, and distribution systems, investigate water supplies in areas outside of the municipal systems. People in these areas probably obtain water from private 


\section{GROUND WATER PATHWAY TARGETS}

and community wells and/or intakes. Water authority officials may also be able to provide this information. If not, contact the local Health Department or Water Commission. Often, a permit from such an agency is required to drill or operate a private or community well, and the City or County Sanitarian (or similar official, often in the Health Department) is responsible for ensuring the potability of drinking water. Officials at these agencies are knowledgeable of local water use and can identify areas where domestic and community wells (or intakes) are used.

\section{Identifying the Nearest Drinking Water Well}

In addition to evaluating drinking water populations, the PA considers the proximity of the nearest drinking water well. If the areas around the site are supplied exclusively by municipal systems, the nearest drinking water well (and ground water target population) is easily determined through interviews with local water officials as discussed above. However, if areas around the site (closer than the nearest municipal well) do not have municipal water service, you'll want to have a good understanding of how drinking water is obtained and where the "nearest well" is located. If this still isn't clear after interviewing local officials, you may want to conduct a local survey. This might entail a "windshield" survey in which you drive through selected areas looking for residences with wellheads or pumphouses on the property and note their location on the topographic map. In some instances, a door-to-door survey may be appropriate, in which you briefly interview residents about their source of drinking water. Due to potential community relations concerns, be sure to consult your supervisors before undertaking such a survey. Windshield or door-to-door surveys need not be extensive, but limited to areas where you need to confirm locations of critical wells.

\section{Evaluating Drinking Water Populations Served by Ground Water}

Transcribe all of the well and distribution system locations onto the topographic map. In the PA evaluation of populations using ground water for drinking water, the "weight" given to secondary target populations is a function of how far their drinking water wells are from the site. On the topographic map, draw a series of concentric circles around the site with radii of $1 / 4$ mile, $1 / 2$ mile, 1 mile, 2 miles, 3 miles, and 4 miles. Evaluate drinking water populations according to the location of wells within these distance categories. Note that it is the location of the well that is important, not the location of the population served by that well.

The specific number of people served by a well or a municipal system is seldom known. Instead, water authorities are more likely to provide information on the number of service connections associated with the well or the distribution system. You then estimate the population by multiplying the number of service connections by the average number of persons per household for the county, using data from the U.S. Bureau of the Census. Likewise, assume each residence served by a private well represents the county average number of persons per household.

\section{Populations Served by "Blended" Municipal Systems}

A blended system is defined as "a drinking water supply system that can or does combine le.g., via connecting valves) water from more than one well or surface water intake, or from a combination of wells and intakes." For PA purposes, it is the capability for interconnection that defines a blended system; for example, connecting lines between different parts of a distribution system may exist to allow uninterrupted service to the entire system in case of well failure or other emergency in one part of the system. Even if this capability has never actually been placed in service, the system is still considered a blended system. 
From interviews with local water officials, you should know whether any of the local systems are blended. If any systems are blended, you may need to apportion the drinking water population to individual wells (and intakes, if any).

Apportion populations when a blended system uses a combination of wells and intakes. For a blended system served solely by wells, apportionment is not necessary if any well serving the system is suspected to be a primary target (discussed on pages 65 to 70); in such a case, the entire drinking water population associated with the system is considered a primary target population. If all wells serving the system are secondary targets, apportionment is only necessary if the wells are located in more than one distance category, because secondary target populations are weighted according to the distance of their wells from the site. For example, a blended system served by four secondary target wells at distances ranging from 1.1 to 1.6 miles from the site would not require apportioning the drinking water population to individual wells because all four wells are located in the same distance category (1 to 2 miles). In contrast, a blended system served by four secondary target wells, one located 0.7 miles and the other three between 1.1 and 1.6 miles from the site, would require apportioning the population because the four wells are in two distance categories ( $1 / 2$ to 1 mile, and 1 to 2 miles).

Local water officials can provide information on the number of people or connections served by each blended system, and the average annual production or production capacity of each well (and intake). If any single well in the system can or does contribute more than 40 percent of the total output of the system, apportion populations to each well (and intake) on the basis of their relative contributions to the total. Do this on the basis of average annual production. If those data are not available, use production capacity instead. For example, consider a blended system drawing a total of 8.2 billion gallons of water annually from three wells serving a population of 120,000 :

\begin{tabular}{|c|c|c|c|c|}
\hline $\begin{array}{c}\text { Well } \\
\text { No. }\end{array}$ & $\begin{array}{c}\text { Avg. Annual } \\
\text { Production (gal) }\end{array}$ & $\begin{array}{c}\% \text { Total } \\
\text { Production }\end{array}$ & $\begin{array}{c}\% \text { Total } \\
\text { Population }\end{array}$ & $\begin{array}{c}\text { Apportioned } \\
\text { Population }\end{array}$ \\
\hline \hline 1 & 2.4 billion & $29.3 \%$ & $29.3 \%$ & 35,160 \\
\hline 2 & 3.8 billion & $46.3 \%$ & $46.3 \%$ & 55,560 \\
\hline 3 & 2.0 billion & $24.4 \%$ & $24.4 \%$ & 29,280 \\
\hline \hline & 8.2 billion & $100.0 \%$ & $100.0 \%$ & 120,000 \\
\hline
\end{tabular}

Use the same process to apportion populations for a blended system involving a combination of wells and surface water intakes; the population associated with intakes is scored in your evaluation of surface water pathway targets (Section 3.4.2).

If no well in a blended system can or does contribute more than 40 percent of the total system output, simply divide the total population equally among each well (and intake). For example: 


\section{GROUND WATER PATHWAY}

\section{TARGETS}

\begin{tabular}{|c|c|c|c|c|}
\hline $\begin{array}{c}\text { Well } \\
\text { No. }\end{array}$ & $\begin{array}{c}\text { Avg. Annual } \\
\text { Production (gal) }\end{array}$ & $\begin{array}{c}\% \text { Total } \\
\text { Production }\end{array}$ & $\begin{array}{c}\% \text { Total } \\
\text { Population }\end{array}$ & $\begin{array}{c}\text { Apportioned } \\
\text { Population }\end{array}$ \\
\hline \hline 1 & 3.1 billion & $37.8 \%$ & $33.3 \%$ & 40,000 \\
\hline 2 & 2.4 billion & $29.3 \%$ & $33.3 \%$ & 40,000 \\
\hline 3 & 2.7 billion & $32.9 \%$ & $33.3 \%$ & 40,000 \\
\hline \hline & 8.2 billion & $100.0 \%$ & $100.0 \%$ & 120,000 \\
\hline
\end{tabular}

If neither average ànnual production nor production capacity data are available, apportion the population equally among each well (and intake) as a default measure.

When one or more wells in a blended system are backup or standby wells, apportioning populations becomes somewhat complicated. Backup wells may either be included in the apportionment or excluded:

\begin{tabular}{|c|c|c|c|c|}
\hline & & & \multicolumn{2}{|c|}{ Population Apportionment } \\
\cline { 4 - 5 } $\begin{array}{c}\text { Well } \\
\text { No. }\end{array}$ & $\begin{array}{c}\text { Avg. Annual } \\
\text { Production (gal) }\end{array}$ & \multirow{2}{*}{$\begin{array}{c}\text { Total } \\
\text { Production }\end{array}$} & $\begin{array}{c}\text { Including } \\
\text { Backup }\end{array}$ & $\begin{array}{c}\text { Excluding } \\
\text { Backup }\end{array}$ \\
\hline \hline 1 & 2.5 billion & $30.5 \%$ & $25.0 \%$ & $33.3 \%$ \\
\hline 2 & 2.4 billion & $29.3 \%$ & $25.0 \%$ & $33.3 \%$ \\
\hline 3 & 2.7 billion & $32.9 \%$ & $25.0 \%$ & $33.3 \%$ \\
\hline $\begin{array}{c}4 \\
\text { bkup }\end{array}$ & 0.6 billion & $7.3 \%$ & $25.0 \%$ & - \\
\hline \hline
\end{tabular}

In determining whether to include or exclude backup wells, select the approach that results in the highest population factor value. In general, this means selecting the approach that results in larger close-in populations, because secondary drinking water target populations served by wells closer to the site are weighted more heavily than those served by wells farther from the site. If backup wells are included, apportion populations to them just as you would to "regular" wells (on the basis of average annual production when such wells are actually in use, or production capacity).

If the blended system being evaluated also includes backup or standby surface water intakes, apportion populations to them only in connection with your evaluation of surface water pathway targets (Section 3.4.2).

\section{Populations Served by Other Municipal Systems}

For blended systems that do not require apportioning populations (e.g., all wells serving the system are secondary targets in the same distance category), simply multiply the number of service 
connections by the county average number of persons per household. Use the same approach for systems served by an individual well.

\section{Populations Served by Private Domestic or Community Wells}

Your water supply survey may identify areas within the target distance limit that are not served by municipal drinking water. Interviews with local water officials and windshield surveys should be used to confirm the areas where private domestic or community wells provide drinking water. To estimate populations, perform a "house count" from the USGS topographic map on which you have delineated the municipal water-supply systems; count only those residences located outside of municipal service areas. Multiply the number of counted residences by the county average number of persons per household.

House counts from outdated topographic maps should be verified by a windshield survey. However, due to the time required, the lower influence of more distant secondary target populations (see PA Table 2, page 9 of the PA scoresheets), and the wide population ranges used to assign factor values (PA Table 2), a windshield survey should generally not extend beyond 1 mile from the site. While conducting a windshield survey, be particularly alert for circumstances where a single community well might serve dozens of residences -- for example, a trailer park or new residential development.

\section{Worker and Student Populations}

Drinking water populations should include all people served by a given water supply system -whether at home, in schools, or the work place. Water authorities commonly report the number of service connections, rather than the number of people drinking water from the system. Drinking water populations estimated by multiplying the number connections by the county average number of persons per residence generally do not accurately represent student and worker populations.

In some instances, it may be useful to pursue worker and student drinking water populations. If schools are present nearby and the local water authorities can confirm that they are served by ground water (as, for example, through the municipal system), student populations can be determined by telephone calls to school administrative offices. The drinking water supply of a major industrial installation (which may have its own well, or may be served by the municipal system) may be similarly investigated. However, due to the lower influence of more distant populations, time-consuming inquiries should generally be limited to distances less than 1 mile from the site. Unique exceptions to investigate beyond 1 mile are large institutions (e.g., university, large business complex) where thousands of students or workers drink ground water; also, any well that you suspect may be a primary target should be evaluated for drinking water population regardless of distance from the site.

\section{Criteria List for Primary Target Wells}

Identify which, if any, drinking water wells you consider to be primary targets and which you consider to be secondary. Identifying a primary target well represents a professional judgment, based on site, pathway, and target characteristics, that the well in question has a relatively high likelihood of exposure to a hazardous substance. Secondary targets have a relatively low likelihood of exposure.

The Criteria List can help guide the process of developing hypotheses about wells that might be considered primary targets. The right-hand column of the Criteria List identifies a number of target 


\section{GROUND WATER PATHWAY \\ TARGETS}

characteristics to consider. Carefully consider each element on the Criteria List for primary targets within the context of the site and its particular targets. Answers to every question on the list, however, are unlikely to be available for many sites. You need not spend excessive amounts of time to develop detailed information to respond to each question -- it is possible to arrive at sound hypotheses about primary targets without knowing the answers to all questions on the list.

Also, keep in mind that there is an infinite variety of conditions that might lead you to identify a primary target, and no list of this type could identify them all. There are likely to be other considerations that may apply to a particular target, and you are encouraged to think along these lines. If such additional considerations enter into your conclusions, identify them at the bottom of the list.

Answer all questions on the list by checking the appropriate box marked "yes," "no," or "unknown." In evaluating each question, rely on all of the information you have obtained about the site and its targets through the course of your investigation -- file searches, desktop data collection, site reconnaissance, interviews, etc.

Answers to many of the questions are likely to be fairly self evident. The difficult part lies in drawing the final conclusion, which amounts to a hypothesis as to whether a particular well is a primary target. This requires professional judgment and is a somewhat intuitive process that relies on your accumulated professional expertise and specific knowledge of site and target characteristics. Answer the bottom question "yes" or "no" regarding your conclusion whether a specific target may be affected by a release. Note that the Criteria List is not a tally sheet requiring a majority of "yes" or "no" responses to reach a conclusion. You may hypothesize that a particular well is a primary target on the basis of one or more target conditions or site characteristics that lead you to believe there is a relatively high likelihood of a hazardous substance having migrated to the target.

\section{Primary Target Well Considerations}

Each item on the Criteria List for primary target wells is briefly discussed below.

Is any drinking water well nearby?

If a release to ground water is suspected, proximity of wells to the site is a significant consideration; the closer the well, the higher the likelihood that it may be exposed to hazardous substances. Just what qualifies as "nearby" depends on circumstances specific to the site and its environs. Generally, any well within $1 / 8$ mile is considered "nearby" and likely to be affected by a release of hazardous substances to ground water. Wells at greater distances up to $1 / 4$ mile (or more) might also be considered "nearby," depending on what you know or suspect about the depth to aquifer, depth of the screened interval, permeability of the subsurface, presence of karst conditions, mobility of hazardous substances suspected to be associated with the site, and other circumstances.

Has any nearby drinking water well been closed?

You may encounter cases where a drinking water well on or near the site has been closed or abandoned. There are any number of reasons why this might have occurred, and it may not be possible to find out why. If you have reason to suspect that a well was abandoned due to water quality problems or concerns about the site, it is appropriate to evaluate that well as if it were still functioning and consider it a primary target. If you don't know why the well was 
abandoned, it is best to assume the closure was associated with concerns about contamination and evaluate it as a primary target. On the other hand, if the closure resulted from a problem that could not possibly be related to the site (for example, a domestic well was abandoned because municipal water service became available, or because the residence burned down and the owners moved away), it would not be appropriate to consider that well a primary target.

Has any nearby drinking water user reported foul-tasting or foul-smelling water?

If you have learned about water quality problems from the local Health Department or any. other source during your investigation, it may be appropriate to suspect that these problems are associated with the site and to evaluate the affected wells as primary targets. Reference any accounts of suspicious, foul-tasting, foul-smelling, or off-colored drinking water.

Does any nearby well have a large drawdown or high production rate?

High-production wells may create a "cone of depression" that draws down the water table in the vicinity of the well as large quantities of water are "sucked" to the well. The result is an influence on local ground water flow gradients that could speed the movement of hazardous substances through the aquifer and directly to the well, thus increasing the likelihood of exposure.

Is any drinking water well located between the site and other wells that are suspected to be exposed to a hazardous substance?

If any well has been identified as a suspected primary target, and there are other wells located between it and the site, it is appropriate to assume that those other wells are also likely to be affected and to evaluate them as primary targets. Similarly, other wells that are near a primary target well, but not necessarily between it and the site, might also be evaluated as primary targets.

Does analytical or circumstantial evidence suggest contamination at a drinking water well?

The distinction between "ground water" and "drinking water" is that, while all drinking water drawn from wells is ground water, all ground water is not necessarily drinking water. Likewise, not all wells are necessarily drinking water wells. If there is reason to suspect contamination of a well which supplies irrigation water or contamination of a monitoring well, it would be appropriate to consider nearby drinking water wells as primary targets.

Does any drinking water well warrant sampling?

Perhaps the most straightforward test to identify primary targets. is to ask yourself the question "Given what I know and suspect about this site, would I recommend that this well be sampled (during an $\mathrm{SI}$, for example) with the expectation of detecting hazardous substances there?" If the answer to this question is "yes," you have come to a professional judgment identifying a primary target.

After answering these questions, and adding any other considerations to the list, indicate your professional judgment as to the occurrence of primary targets by checking the appropriate box next to the "Primary Target(s) Identified?" question. 
To score any well as a primary target, you must first score a suspected release; a release is a precondition to a conclusion that a particular well has a relatively high likelihood of exposure to a hazardous substance. If your evaluation of the Criteria List leads you to believe that one or more wells should be considered primary targets, yet your earlier evaluation of likelihood-of release led you to the No Suspected Release hypothesis, you should revisit the Criteria List for suspected releases and reconsider your judgment regarding the likelihood of release.

If your evaluation of the Criteria List leads you to conclude that some wells should be considered primary targets, summarize your rationale and identify the wells. 
Factor: Primary Target Population

Definition: The human population served by drinking water drawn from primary target wells.

Evaluation Strategy: Identifying a primary target well represents a professional judgment based on site, pathway, and target characteristics indicating a relatively high likelihood that a hazardous substance has migrated to the well. A primary target may be hypothesized on the basis of available analytical data indicating that the well may be exposed to hazardous substances; however, analytical data are not usually available for PA sites. For PA purposes, your professional judgment is usually based on indications -- which is not the same as documented fact. You may hypothesize a primary target well on the basis of one or more characteristics of the site and its environs, sources, and types and quantity of wastes thought to be present, coupled with the proximity and physical characteristics of the well itself.

Use the Criteria List for primary targets to help guide the process of considering pertinent characteristics that might lead you to identify a primary target well. The application of the Criteria List is discussed on pages 65 to 68 .

It is not possible to provide comprehensive guidance on what does and does not "qualify" as a primary target; you must rely on your professional judgment. A few example scenarios are given below:

- Analytical data from a drinking water well 1,000 feet from the site indicate high concentrations of benzene and related organics. A suspected release has been hypothesized, even though background concentrations are not available and you cannot attribute the contaminants specifically to activities at the site. In this case, evaluate the well as a primary target, since the condition of the well contributed to the judgment that a release is suspected.

- Liquid wastes and sludges have been stored outdoors in drums, some of which are rusted, perforated, and lying on the ground surface; areas of stained soil are visible; the water table in the area is 20 to 50 feet deep; and a suspected release has been scored on these considerations. No analytical data are available, but a drinking water well (depth unknown) is 1,000 feet from the site. In this case, the well may be evaluated as a primary target on the basis of proximity to a suspected release. 


\section{GROUND WATER PATHWAY TARGETS}

- Conditions are as described above, except the well is known to be screened at a depth of 300 to 350 feet. In this case, even though a suspected release is scored, the well might not be evaluated as a primary target, due to its depth.

- Conditions are as described above, except it is known that drinking water within 4 miles is obtained only from aquifers below 300 feet and no release is suspected to impact that aquifer depth. In this case, the well would not be evaluated as a primary target.

Remember that, in order to evaluate any well as a primary target, a suspected release to ground water must first be scored. In such cases, you may identify both primary-and secondary targets. If a release is not suspected, there, can be no primary targets.

Scoring Instructions: Evaluate a drinking water well as a primary target when available information leads you to hypothesize that there is a relatively high likelihood that a hazardous substance has migrated to the well.

Determine the population served by each primary target well as discussed on pages 61 to 65 . Briefly:

- For each private domestic well, count the number of persons in households or assign a population equal to the average number of persons per household in the county using U.S. Bureau of the Census data (round up to the next integer for each household).

- For a well serving more than one residence (community or municipal wells), determine the number of people served by the well and assign that population. If the specific number of people served is not available from the operating authority, determine the number of service connections associated with the well. Multiply this number by the county average number of persons per household (round up to the next integer before multiplying) and assign the resulting.population to the well. Apportion populations if blended systems are served by multiple wells or a combination of wells and intakes, and show your calculations on page 6 of the PA scoresheets.

- For a well serving a distinct non-residential population (a business, industrial park, school, or university, for example), determine the population served by interviewing the well owner/operator or facility administrator and assign this population to the well.

Sum the populations served by each primary target well, regardless of distance from the site. Enter the total primary target population on the blank for factor \#3 (Primary Target Population) on the ground water pathway scoresheet (page 8 of the PA scoresheets). Multiply this total by 10 and enter the resulting factor score.under Column $A$.

If your evaluation of the Criteria List led you to conclude that there are no primary target wells, assign a zero score to factor \#3. 
Factor: Secondary Target Population

Definition: The human population served by drinking water drawn from secondary target wells.

Evaluation Strategy: Just as the identification of primary target wells represents a professional judgment based on site, pathway, and target characteristics, so is the identification of secondary target wells. In this instance, however, available information leads you to conclude that the wells in question have a relatively low likelihood of exposure to a hazardous substance. You base this determination on one or more characteristics of the site and its environs, sources, and types and quantity of wastes thought to be present, coupled with the proximity and physical characteristics of the wells.

Note that, if a release is suspected, some targets may be evaluated as primary targets and some as secondary targets. However, if no release is suspected, all targets are evaluated as secondary targets.

After completing your ground water targets survey and applying the Criteria List, you will have a set of hypotheses identifying the wells that you believe are secondary targets. Application of the Criteria List is discussed on pages 65 to 68 .

Assign populations to each secondary target well and develop separate secondary target population totals for each distance category around the site: less than $1 / 4$ mile, $1 / 4$ to $1 / 2$ mile, $1 / 2$ to 1 mile, 1 to 2 miles, 2 to 3 miles, and 3 to 4 miles. Secondary target populations are determined and summed for each distance category because different weights are applied to populations according to distance from the site in order to account for the dispersion of substances that may enter ground water. The weights are built into PA Table 2 and become smaller with distance from the site to reflect greater dispersion with distance.

When you have completed your target survey and transcribed the locations of municipal and community wells onto the topographic map, and also delineated the areas served by municipal, community, and domestic wells, determining secondary target populations is relatively straightforward. Completing a targets survey, evaluating target populations associated with each well, and apportioning populations in blended systems are discussed on pages 61 to 65 . 


\section{GROUND WATER PATHWAY}

\section{TARGETS}

Scoring Instructions: Evaluate a drinking water well as a secondary target when available information leads you to conclude that there is a relatively low likelihood of a hazardous substance having migrated to the well.

Draw the six distance categories on the topographic map in order to clearly delineate and identify the wells whose associated populations will be summed for each category, and to see which categories include areas relying on domestic wells. Determine the population served by each secondary target well as discussed on pages 61 to 65 . Briefly:

- For each private domestic well, assign a population equal to the average number of persons per household for the county using data from the U.S. Bureau of the Census (for secondary target populations, do not round the average up to the next integer).

- For a well serving more than one residence (community or municipal well), determine the number of people served by the well and assign that population to the well. If the specific number of people served is not available from the authority operating the well, determine the number of service connections associated with the well. Multiply this number by the county average number of persons per household (do not round the average up to the next integer) and assign the resulting population to the well. If necessary, apportion populations.

- For wells serving a distinct non-residential population la business, industrial park, or university, for example), determine the population served by interviewing the well owner/operator or facility administrator and assign that population to the well.

For each distance category, sum the population served by secondary target wells. Score a nonkarst aquifer using PA Table 2a (page 9 of the PA scoresheets); score a karst aquifer using PA Table $2 b$. For each distance category, using the appropriate table:

1) Enter the secondary target population for the distance category in the "Population" column.

2) Working horizontally across the table, circle the value in the same row that represents the range that the distance-category population falls into.

3) Record the circled value in the same row of the "Population Value" column.

Sum the population values in the far-right column. Record this total at the bottom of the column and in one of the blanks for factor \#4 (Secondary Target Population) on the ground water pathway scoresheet. Use the blank under Column A if you scored a suspected release; use the blank under Column B if you scored "No Suspected Release.". Mark your response to the question "Are any wells part of a blended system?". If you have apportioned populations, show your calculations on page 6 of the PA scoresheets. 
Factor: Nearest Well

Definition: The drinking water well closest to any source at the site.

Evaluation Strategy: In addition to evaluating both primary and secondary target populations, the PA also evaluates the distance to the nearest drinking water well. This distance is an indicator of the magnitude of the threat the site may pose to ground water users. All other considerations being equal, the closer a drinking water well is to the site, the higher the threat that the well might be exposed to a hazardous substance. If you have identified any primary target well you have, in effect, hypothesized that the threat or likelihood of exposure is relatively high. For this reason, whenever a primary target well is present, assign a score of 50 to the Nearest Well factor, regardless of distance.

If there are no primary target wells, identify the nearest secondary target well and assign a distance-weighted factor score using PA Table 2. Estimate the straight-line distance between that well and the nearest source at the site. After completing your ground water target survey and transcribing this information onto a topographic map, use a ruler or pair of dividers to identify the secondary target well nearest to any source on the site and convert that map distance to feet using the map scale. If the nearest well is so close that map measurement is not practical, estimate the distance through visual observation during the site reconnaissance. Annotate the topographic map to identify the well. Record the distance in the "Pathway Characteristics" box on the ground water pathway scoresheet. Record an absolute number (e.g., "800 feet"), not a range (e.g., "800-900 feet" or "less than 900 feet"), accurate within a margin of \pm 100 feet.

Scoring Instructions: If you have identified any primary target well within the target distance limit, assign a score of 50 to factor \#5 (Nearest Well); assign the score under Column A.

Otherwise, identify the nearest secondary target well on the topographic map: Enter the distance to this well in the "Pathway Characteristics" box on the ground water pathway scoresheet. Using either PA Table $2 a$ or $2 b$ (page 9 of the PA scoresheets) for non-karst or karst aquifers, as appropriate, select the distance category in which the nearest secondary target well is located (left-hand column). Circle the value on the same line in the column labeled "Nearest Well." Record this circled value in one of the blanks for factor \#5 (Nearest Well) on the ground water pathway scoresheet. Use the blank under Column A if you scored "Suspected Release" for the Likelihood of Release factor category; use the blank under Column B if you scored "No Suspected Release." 


\section{GROUND WATER PATHWAY \\ TARGETS}

Factor: Wellhead Protection Area

Definition: A State-designated area restricting certain land uses and industrial practices around drinking water wells that might be susceptible to adverse impacts.

Evaluation Strategy: Wellhead protection areas (WHPAs) are designated by State authorities under Section 1428 of the Federal Safe Drinking Water Act: WHPAs protect principal drinking water supplies from contamination that might otherwise result from unrestricted waste disposal or other industrial practices. The importance of protecting such water supplies is reflected in the PA by the Wellhead Protection Area factor. State environmental agencies and local water authorities can provide information about the locations of WHPAs.

Scoring Instructions: If any source associated with the site lies within or above a designated WHPA, or if you have identified any primary target well within a WHPA, assign a score of 20 to factor \#6 (Wellhead Protection Area). If neither of these conditions apply, but any part of a designated WHPA is within 4 miles of the site, assign 5 . If no portion of a designated WHPA lies within 4 miles of the site, assign a zero score. Use the blank under Column A if you scored a "Suspected Release" for the Likelihood' of Release factor category; use the blank under Column B if you scored "No Suspected Release." 
Factor: Resources

Definition: Use of ground water for purposes other than drinking water.

Evaluation Strategy: In addition to providing drinking water, ground water is often used for other purposes that could affect human health:

- Irrigation (5 acre minimum) of commercial food crops or commercial forage crops.

- Watering of commercial livestock.

- Ingredient in commercial food preparation (e.g., canning plant).

- Supply for commercial aquaculture (e.g., hydroponic greenhouse, catfish farm).

- Supply (other than drinking water supply) for a major or designated water recreation area (e.g., municipal swimming pool).

- Potential usability as drinking water supply, though the resource is not currently used for drinking water.

The PA accounts for such use through the resources factor, which is assigned a value of 5 if any of the above resource uses are present within 4 ,miles; a zero value is assigned if there is no resource use.

Since ground water often has some beneficial use, the resources factor can generally be assigned 5 points as a default measure. This approach is conservative from the scoring perspective (as the maximum value is assigned), has little impact on the pathway and site score, and can potentially save you many hours of research trying to determine crop acreage,

"commercial" uses, "major or designated" areas, and "usability."

Scoring Instructions: If, within 4 miles of the site, ground water is used for any of the purposes itemized above, assign a score of 5 to one of the blanks for factor \#7 (Resources) on the ground water pathway scoresheet; otherwise, assign a zero value. Alternatively, simply assign the 5 point value as a default measure. Use the blank under Column A if you scored a "Suspected Release" for the Likelihood of Release factor category; use the blank under Column B if you scored "No Suspected Release."

Total Targets: Calculate the Targets factor category score by summing the scores assigned to factors \#3 through 7. Factor scores should appear in only one of the two columns (A or B) depending on whether you scored a suspected release. 


\section{GROUND WATER PATHWAY WASTE CHARACTERISTICS \\ AND \\ PATHWAY SCORE}

\subsubsection{Waste Characteristics}

The evaluation of the:Waste Characteristics factor category is discussed in Section 3.2.2.

If you have identified any primary target well, assign either the waste characteristics score (WC) that you calculated using PA Table 1 (Section 3.2.2, and page 4 of the PA scoresheets) or a score of 32 -- whichever is greater -- to factor \#8a. Assign this score under Column A. Do not evaluate factor \#8b.

If you have not identified any primary target well, assign the waste characteristics score (WC) that you calculated using PA Table 1 (Section 3.2.2, and page 4 of the PA scoresheets) to factor \#8b. Assign the score under Column A if you scored "Suspected Release" for Likelihood of Release; under Column B if you scored "No Suspected Release." Do not evaluate factor \#8a:

\subsubsection{Calculating'the Ground Water Pathway Score}

The ground water pathway scoresheet is organized by the three factor categories: Likelihood of Release (LR), Targets (T), and Waste Characteristics. (WC). Enter the score for either Suspected Release (factor \#1) or No Suspected Release (factor \#2) into the box labeled "LR." Sum the Target scores (factors \#3 through 7) down the appropriate column and record the sum in the box labeled "T." Enter the Waste-Characteristics score (factor \#8a or $8 \mathrm{~b}$ ) into the box labeled "WC." All scores should appear in either Column A or Column B, depending on your evaluation of Likelihood of Release.

Multiply LR $\times$ T $\times$ WC; divide the product by 82,500 ; round to the nearest integer; and record the result, subject to a maximum of 100 , as the ground water pathway score at the bottom of the page. If your calculated score exceeds 100 , assign 100 as the pathway score. 


\subsection{SURFACE WATER PATHWAY}

The PA evaluation of the surface water pathway requires you to consider and assign scores to factors in three factor categories: Likelihood of Release, Targets, and Waste Characteristics.

Evaluating likelihood of release requires you to hypothesize whether hazardous substances are likely to have migrated to surface water. When a release is not suspected, special considerations that enter into your scoring decision include the distance to surface water and the flood potential at the site.

Definition: Surface Water -- A naturally-occurring, perennial water body; also, some artificiallymade and/or intermittently-flowing water bodies.

Surface waters include streams and rivers, lakes, coastal tidal waters; and oceans. The glossary provides detailed definitions for each type. Note that certain ditches and intermittently-flowing waters are included in the "streams and rivers" water body type. Specifically, ditches qualify as surface water if they perennially flow into other surface water. In areas where mean annual precipitation is less than 20 inches, intermittently-flowing waters and contiguous intermittentlyflowing streams and ditches also qualify as surface water.

If there is no surface water within an overland flow distance of 2 miles from the site, do not evaluate the surface water pathway for that site. Do, however, identify the nearest surface water body and its distance from the site, and record this information on the PA scoresheet as your reason for not evaluating the pathway.

Release of a hazardous substance to surface water could threaten drinking water supplies, human food chain organisms, and sensitive environments. The targets portion of the surface water pathway is thus divided into these three separate threat evaluations. You must identify and evaluate intakes supplying drinking water, fisheries, and surface water sensitive environments within a 15-mile target distance limit.

The evaluation and score for the waste characteristics factor category (WC, Section 3.2.2) applies directly to the surface water pathway, as to all other pathways, except if primary targets are identified for any of the three threats (Section 3.4.3). 


\subsubsection{Likelihood of Release}

Evaluating the Likelihood of Release factor category requires a professional judgment, based on site and pathway conditions, as to whether a hazardous substance is likely to have been released to surface water. Likelihood of Release is scored on the basis of one of two scenarios, "Suspected Release" or "No Suspected Release," either of which require you to make this professional judgment. Your judgment takes the form of a hypothesis that a release has or has not occurred. The formulation of your hypothesis is guided by the "Criteria List" (page 11 of the PA scoresheets).

\section{Criteria List for Suspected Release to the Surface Water. Pathway}

The Criteria List helps guide the process of developing hypotheses about two very important aspects of the site: whether a hazardous substance is likely to have been released to surface water; and whether any targets (intakes supplying drinking water, fisheries, sensitive environments) are likely to be exposed to a hazardous substance as a result of a release. The Criteria List suggests a number of characteristics of the site and its environs to consider in reaching conclusions on these points. Answer the questions in the left-hand column of the Criteria List, which deal with a suspected release; the right-hand column, dealing with primary targets, is evaluated in connection with the Targets factor category (Section 3.4.2) if you conclude that a release to surface water is likely to have occurred.

Carefully consider each element on the Criteria List within the context of the site and its environs. Answers to every question on the list, however, are unlikely to be available for many sites. You need not spend excessive amounts of time trying to develop detailed information to respond to each question - - it is possible to arrive at sound hypotheses about suspected releases and their potential effects on targets without knowing the answers to all questions on the list.

Also, keep in mind that because there is an infinite variety of site-specific circumstances, no list of this type could identify every characteristic that might apply to any specific site. The list, therefore, is by no means complete and the criteria making up the list are not prioritized in any way. Instead, these questions are meant to get you thinking about the types of site-specific conditions that need to be considered when formulating hypotheses about releases and the condition of targets. There are likely to be other site-specific criteria that apply to a particular site, and you are encouraged to think along these lines. If such additional considerations enter into your conclusions, identify them at the bottom of the list.

Answer the questions on the list by checking the appropriate box marked "yes," "no," or "unknown." In evaluating each question, rely on the total body of information you have obtained about the site and its environs through the course of your investigation -- file searches, desktop data collection, site reconnaissance, interviews; etc. " . .

Answers to many of the individual questions are likely to be fairly self evident. The difficult part lies in drawing the final conclusion, which amounts to a hypothesis as to whether you suspect a release. This requires professional judgment and is a somewhat intuitive process that relies upon your accumulated professional expertise and specific knowledge of site and target characteristics. Note that the Criteria List is not a tally sheet requiring a majority of "yes" or "no" responses to reach a conclusion. You may hypothesize a suspected release on the basis of one or more characteristics that lead you to believe there is a relatively high likelihood that a hazardous substances has been released to surface water. 


\section{Suspected Release Considerations}

Each item on the Criteria List for suspected releases to surface water is briefly discussed below.

Is surface water nearby?

Proximity is directly related to the ease with which hazardous substances can migrate to 'surface water. In general, the nearer the site is to surface water, the higher the likelihood of a release. Just what constitutes "nearby" depends on site-specific conditions. If the surrounding terrain is flat, precipitation is low, and soils are sandy (high infiltration), a couple of hundred feet might be considered "nearby"; if a drainage channel runs past the site and annual precipitation or occasional rainfall events are high, $3 / 4$ mile might still be considered "nearby." Note that sites where the overland flow distance to the nearest surface water is more than 2 miles are not evaluated for the surface water pathway:

Is waste quantity particularly large?

Depending on the type of waste, its physical state, and its location, "large" is a relative term with respect to the potential for a release to surface water. In this context, a relatively small quantity of liquid wastes spilled on the ground surface probably has more importance than a relatively large quantity of solid wastes deposited in a landfill. In general, however, any amount is considered "large" if it produces a waste characteristics factor category score (WC) of 32 or more.

Is the drainage area large?

"Drainage area" refers to the area of the site itself plus the area upgradient of the site that produces runoff flowing over the site: Larger drainage areas generally produce more runoff that could potentially carry hazardous substances overland to surface water. Note that, in urban areas, curbed streets and storm sewers may effectively limit the drainage area to the area of the site itself.

Is rainfall heavy?

If the site and surrounding areas are flat, the combination of heavy rainfall and low infiltration rate may cause rainwater to pool on the site. Otherwise, these characteristics will contribute to generating runoff that may carry hazardous substances overland to surface water:

Total annual rainfall exceeding 40 inches, or 2-year, 24-hour rainfall exceeding 2 inches might be considered "heavy." You can obtain this information from the "Climatic Atlas of the United States," published by the U.S. Department of Commerce, or from local weather stations.

Is the infiltration rate low?

Infiltration rates range from very high in gravelly and sandy soils to very low in fine silt and clayey soils. You can find out about soil types in the area of the site from the County Extension Office of the USDA Soil Conservation Service, or from soil survey maps published by the SCS for most counties in the nation. Paved sites, of course, prevent infiltration and generate runoff. 


\section{SURFACE WATER PATHWAY LIKELIHOOD OF RELEASE}

Are sources poorly contained or prone to runoff or flooding?

For many types of sources, proper containment that would prevent hazardous substances from migrating to surface water requires engineered structures such as dikes, berms, run-on and runoff control systems, and spill collection and removal systems. Such controls would have to be designed to meet the specific requirements of containing the contents of the source against migration to surface water, and would have to be regularly inspected and properly maintained. This level of containment for all sources is not often found at CERCLIS hazardous waste sites.

In general, sources that may be prone to releasing hazardous substances via runoff are those over which drainage might flow: sources resulting from leaks, spills, or intentional deposition or disposal of hazardous wastes on the ground surface. Sources not prone to runoff include underground tanks, above-ground tanks, and containers stored in a building.

Any source on a site prone to flooding has a likelihood of releasing hazardous substances to surface water that is directly related to flood frequency, which is discussed later in this section.

Is a runoff route well defined?

The runoff route is the downgradient path that runoff follows from the site to surface water. A runoff route may be engineered (e.g., storm drains, drainage ditch) or natural. In general, in the case of a natural overland route, the closer the site is to surface water and the steeper the terrain is, the easier it will be to identify the route. A well defined runoff route will more likely contribute to migration to surface water than a poorly defined one.

Is vegetation stressed along the probable runoff route?

Once you have identified the runoff route, examine the condition of vegetation on and adjacent to it. Vegetation that is dead, dying, stunted, discolored, or otherwise distressed may indicate that hazardous substances have been carried overland by runoff.

Are sediments or water unnaturally discolored?

An unnatural color to ponded water or sediments along the runoff route, or to sediments or water in the water body itself, may indicate that hazardous substances have migrated from the site.

Is wildlife unnaturally absent?

An unnatural absence of wildlife (terrestrial or aquatic), a decline in populations, a fishkill, or similar adverse environmental effects in or around a water body may also indicate that hazardous substances have migrated to surface water. Local fish and game officials may have such information.

Has deposition of waste into surface water been observed?

Visual (or alleged) evidence of direct deposition of what you suspect may be hazardous waste could include an outfall pipe from the site direct to surface water or to a ditch (or gully, swale, etc.) leading to surface water, presence of a plume in surface water, or presence of a drum in a river bank or creek bed. 


\section{SURFACE WATER PATHWAY}

LIKELIHOOD OF RELEASE

Is ground water discharge to surface water likely?

If there is no apparent overland runoff route to surface water land even in cases where there is), consider the potential for hazardous substances to reach surface water by migrating through ground water. This could be a concern in karst areas (see Section 3.3.1), in cases where surface water is nearby and a steep hydraulic gradient is known to exist between the site and surface water, or when available evidence strongly suggests that ground water is contaminated (not merely suspected to be contaminated). Note that in order to score a suspected release to surface water via ground water, you must also score a suspected release to ground water.

Does analytical or circumstantial evidence suggest surface water contamination?

"Circumstantial" implies a level of certainty well below that of "proven fact," and this is sufficient for PA purposes. In this context, any condition that you find suspicious, and that indicates a possible contamination problem, can be considered circumstantial evidence. A few examples are:

- Analytical data provide indications of hazardous substances in surface water, regardless of whether you can attribute those substances specifically to the site.

- The surface water body has been sampled by State, local, or site officials, whether or not you know the results.

- Fishing or recreational use of the surface water body has been curtailed for health or other reasons that may be associated with the site.

After answering these questions, and adding other considerations to the list, indicate your professional judgment as to the likelihood of a release of hazardous,substances by checking "yes" or "no" next to the "Release Suspected?" question. Remember that this is a judgment call; you don't need a majority of "yes" responses -- in some cases, a single "yes" may be sufficient to suspect a release. Summarize the rationale for your hypothesis.

\section{Special Considerations When a Release is Not Suspected}

If your evaluation of the Criteria List leads you to conclude that a release to surface water is not suspected, two specific considerations are important to asșign the PA score for Likelihood of Release: distance to surface water and flood frequency. Both are included in the Criteria List, but are discussed in more detail here due to their importance when a release is not suspected.

\section{Distance to Surface Water}

Definition: Distance to Surface Water -- The shortest distance that runoff would follow from a source to surface water.

Distance to surface water can be used as an indicator of the likelihood of release of hazardous substances to surface water. Given two sites with similar characteristics, except that Site $A$ is 


\section{SURFACE WATER PATHWAY LIKELIHOOD OF RELEASE}

located closer to surface water than Site B, you might expect Site $A$ to have a higher likelihood of. releasing hazardous substances to surface water.

To evaluate distance to surface water, identify the shortest runoff route from the site to the probable point of entry (PPE) to a surface water; body. Note that this is a downgradient distance and is unlikely to be a straight line.

Definition: Probable Point of Entry -- The point at which runoff from the site most likely enters surface water.

As part of your site reconnaissance (Section 2.5), identify the drainage patterns on and flowing from the site. To the extent that it is easily accomplished, you may want to physically follow the runoff route to the PPE. This may be possible if surface water is near the site, the runoff route is well defined, and following it doesn't require trespassing on private property. If these conditions do not apply, follow the runoff route to a landmark identifiable on a topographic map. Using the elevation contours, you can then map the runoff route to the PPE. Do this by drawing the shortest probable route, between the landmark and the P.PE, that crosses each intervening contour line at a right angle.

If there is more than one runoff route to one or more surface water bodies, identify the shortest distance among the various possibilities.

Estimate distances using a map wheel or calibrated string; if the distance is short and measurement from a map is not practical, estimate the distance by visual observation during the site reconnaissance. For tidally-influenced water bodies, estimate the distance to the mean high water level; for other water bodies, estimate to the mean water level. Record the distance in the "Pathway Characteristics" box on the surface water pathway scoresheet (page 12 of the PA scoresheets). The distance you record must be an absolute number (e.g.; "1,800 feet"), not a range (e.g.; "1,000 - 2,000 feet" or "less than $1 / 2$ mile"), and should be accurate within a margin of \pm 100 feet.

If it is too difficult to reasonably approximate a runoff route, as a default measure you may use the shortest straight-line distance from the site to the surface water body.

In urban areas, the runoff route may not follow the apparent gradient because curbed roads direct drainage to storm sewers that carry it to an outfall to surface water (perhaps passing through a wastewater treatment plant along the way). In these cases, you could determine the runoff route by obtaining the storm sewer layout plans from the local highway or public works department, but this approach is not recommended because it is time consuming. Instead, ask the highway or public works department to locate storm sewer outfalls on your topographic map, and measure the straight-line distance from the site to the nearest outfall.

Sketch the runoff route(s), as part of the larger surface water migration route sketch, on page 10 of the PA scoresheets. 


\section{Flood Frequency}

The location of the site with respect to surface water floodplains is a second indicator of likelihood of release and is also directly related to distance from surface water. Floodplains are delineated on the basis of statistical analysis of long-term records of stream flow. The Federal Emergency Management Agency (FEMA) publishes "Flood Insurance Rate Maps." Local planning departments or zoning commissions generally have these maps, or you can obtain them directly from FEMA. Homeowner insurance companies may also be able to provide flood frequency maps for areas where FEMA maps may not be available.

FEMA Flood Insurance Rate Maps delineate 100-year and 500-year floodplains. Maps produced by local planning commissions and similar authorities may be more detailed and also delineate the annual and 10-year floodplains. Areas located in the annual floodplain can typically be expected to flood about once every year. The 100-year floodplain includes the annual floodplain, 10-year floodplain, 50-year floodplain, and so forth -- areas that can be expected to suffer flooding at least once over a 100-year period. Similarly, the 500-year floodplain includes the annual floodplain, the 100 -year floodplain, and other areas subject to flooding at least once over a 500-year period. Areas beyond the 500-year floodplain are not expected to flood except under the most extreme of circumstances -- circumstances that are expected to occur less frequently than once in a 500-year period.

Locate the site on a floodplain map. Record the flood frequency in the "Pathway Characteristics" box on the surface water scoresheet; this should be the most frequent flood event appropriate to the site. For example, while it is true that a site located in the 10 -year floodplain could also be said to be in the 100-year and 500-year floodplains, record the flood frequency for this site as 10 years.

\section{Scoring Likelihood of Release}

After completing your evaluation of the Criteria List for releases to surface water, including distance to surface water and flood frequency, you should have a hypothesis as to whether you do or do not suspect a release. The following pages explain how to assign a score to the Likelihood of Release factor category, depending on whether your hypothesis is "Suspected Release" or "No Suspected Release." 
Factor: Suspected Release

Definition: A professional judgment conclusion based on site and pathway conditions indicating that a hazardous substance is likely to have been released to surface water.

Evaluation Strategy: - In scoring a suspected release, you are stating a hypothesis that a hazardous substance is likely to have been released to surface water. You may hypothesize a suspected release on the basis of available analytical data indicating that a release may have occurred; however, analytical data are not usually available for PA sites. For PA purposes, your professional judgment is usually based on indications -- which is not the same as documented fact.

The Criteria List for releases to surface water (discussed on pages 78 to 81 ) helps guide the process of considering pertinent characteristics of the site and surrounding area that might lead you to suspect a release. You may hypothesize a suspected release on the basis of one or more characteristics of the site, its environs, sources, and type and quantity of wastes thought to be present.

It is not possible to provide comprehensive guidance on what does and does not "qualify" as a suspected release. You must rely on your professional judgment. Two examples of circumstances that might warrant a suspected release hypothesis are:

- Several surface impoundments containing liquid and sludge are present onsite, some or all of which show evidence of having overflowed. The ground surface is stained and vegetation is absent in the overflow area; vegetation elsewhere on the site appears stressed. Drainage patterns are difficult to discern because the site itself is basically flat, but there is a boggy area adjacent to the site and about 600 feet from the nearest impoundment. A small creek originates from the bog.

- Sources are as described above, but much of the site has a discernible slope that appears to define a runoff route to a ditch bordering the site. The ditch is dry for 1,200 feet downgradient of the site, where perennial flow appears to begin; the ditch then flows an additional 900 feet before emptying to a creek.

Scoring Instructions: Hypothesize and score a suspected release when available information leads you to conclude that there is a relatively high likelihood of a hazardous substance having migrated to surface water. Assign a score of 550 to factor \#1 (Suspected Release) on the surface water pathway scoresheet (page 12 of the PA scoresheets); assign the score under Column $A$ and use only Column $A$ for the surface water pathway. Do not assign a score to factor \#2 (No Suspected Release).

If you do not hypothesize a suspected release, score factor \#2 (No Suspected Release). 
Factor: No Suspected Release

Definition: A professional judgment conclusion based on site and pathway conditions indicating that a hazardous substance is not likely to have been released to surface water.

Evaluation Strategy: If you did not hypothesize a suspected release from your evaluation of the Criteria List, then your hypothesis must be that a release is not suspected. You must complete an evaluation of the Criteria List (left-hand column) before concluding that a release is not suspected.

Just as a hypothesis that a release is suspected is based on characteristics of the site, its. environs, sources, and type and quantity of wastes thought to be present, so is the hypothesis that a release is not suspected. In this instance, however, available information leads you to conclude that there is a relatively low likelihood of a hazardous substance having been released to surface water.

Scoring Instructions: If you do not suspect a release to surface water, evaluate likelihood of release on the basis of two conditions -- distance to surface water and flood frequency. Both of these considerations appear on the Criteria List and their evaluation is discussed on pages 81 to 83.

If distance to surface water is 2,500 feet or less, assign a score of 500 .

If distance to surface water is greater than 2,500 feet, assign a score based on flood frequency:

$\begin{array}{lr}\text { Site in annual or 10-year floodplain } & 500 \\ \text { Site in 100-year floodplain } & 400 \\ \text { Site in 500-year floodplain } & 300 \\ \text { Site outside 500-year floodplain } & 100\end{array}$

If any source or any part of the site lies within the annual floodplain, or if the site is known to have flooded during the period when hazardous wastes were present, you should review your conclusion of No Suspected Release and consider scoring the site on the basis of a Suspected Release instead.

If No Suspected Release is scored, assign the score to factor \#2 under Column B and use only Column B for the surface water pathway. 


\section{SURFACE WATER PATHWAY}

\section{TARGETS}

\subsubsection{Targets}

Surface water pathway targets include intakes that supply drinking water, fisheries, and sensitive environments. Each is evaluated separately. The result is separate scores for three separate threats: Drinking Water Threat, Human Food Chain Threat, and Environmental Threat.

\section{Target Distance Limit}

Targets are identified and evaluated over a 15-mile target distance limit; which defines the "inwater segment" of the surface water migration route (in contrast to the "overland segment" which is the runoff route from the site to surface water).

Begin measuring the in-water segment at the probable point of entry (PPE) to surface water, and continue downstream for 15 miles.

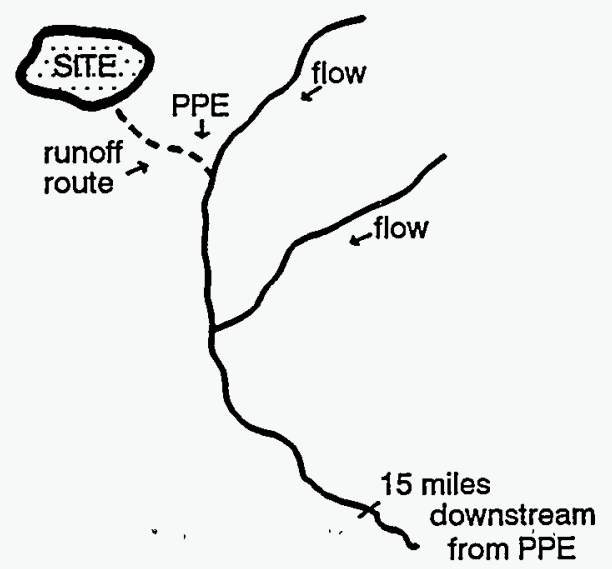

If the 15-mile distance ends in a lake, coastal tidal waters, or ocean, measure the portion of the in-water segment in that water body as an arc from the mouth of the discharging water body and extending to the shores of the receiving water body.

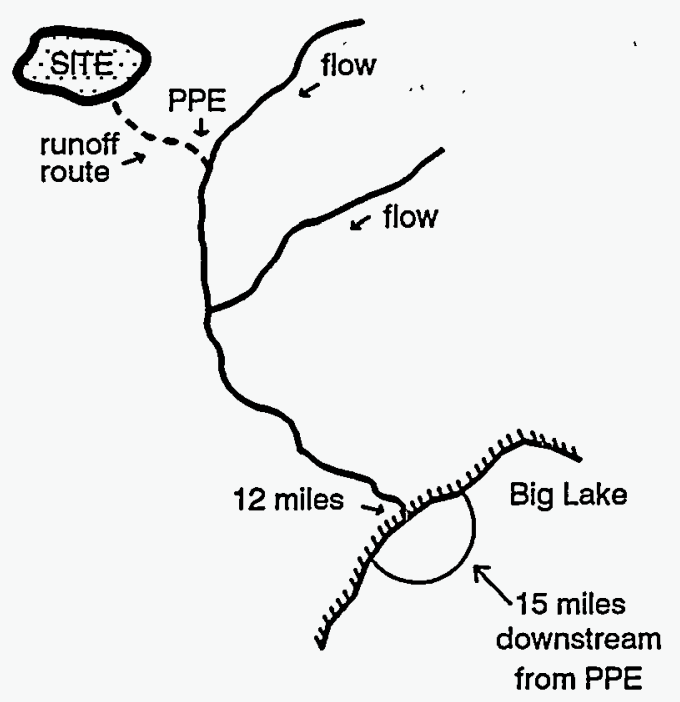


If the PPE is to a tidally-influenced water body (e.g., an estuary), the in-water segment extends 15 miles downstream and also extends upstream as far as the tidal run could be expected to carry hazardous substances released from the site (up to a maximum distance of an additional 15 miles).
If runoff from the site enters more than one surface water body, evaluate targets along each in-water segment, out to the target distance limit (as discussed above) measured from each PPE. This may result in two (or more) in-water segments that eventually join and run coincidently to the target distance limit. In this case, evaluate and score all identified targets to obtain the drinking water, human food chain, and environmental threat scores for the site.

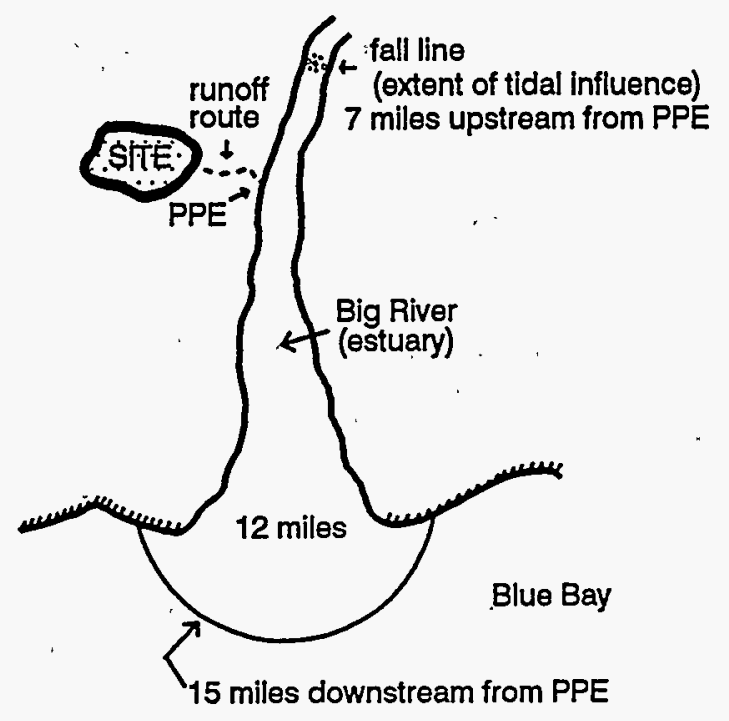

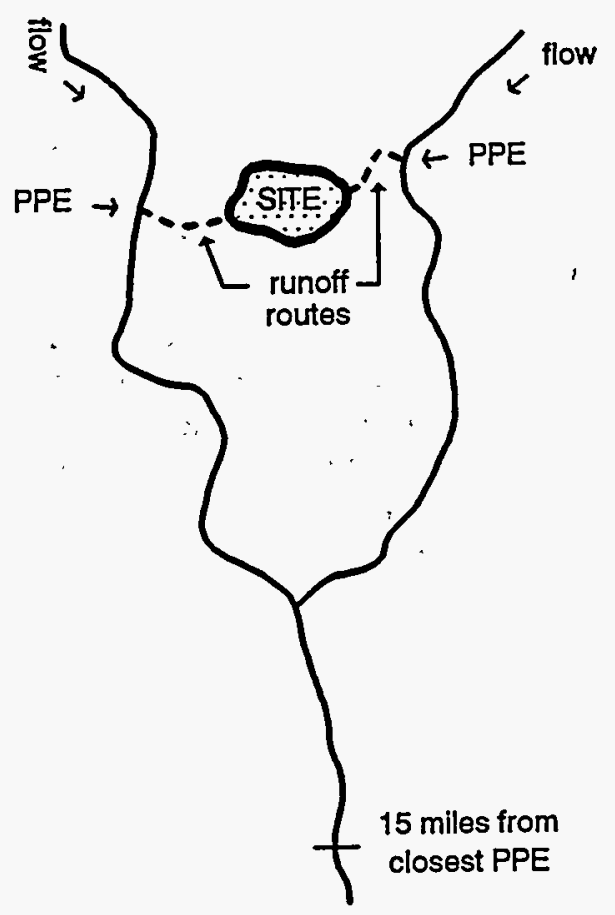


Other cases where runoff from the site enters more than one surface water body result in:

- Two or more entirely different in-water segments that do not join within the target distance limit.

- Two or more in-water segments that run coincidentally for part of the distance and diverge for part of the distance, but end the distance divergent (i.e., at the 15-mile point, all in-water segments are not coincident).

In either case, the divergent in-water segments are said to be in different watersheds. Targets associated with each watershed are evaluated separately to arrive at drinking water, human food chain, and environmental threat scores for each watershed. The surface water pathway score is calculated for each watershed, and the highest result is used to score the site.

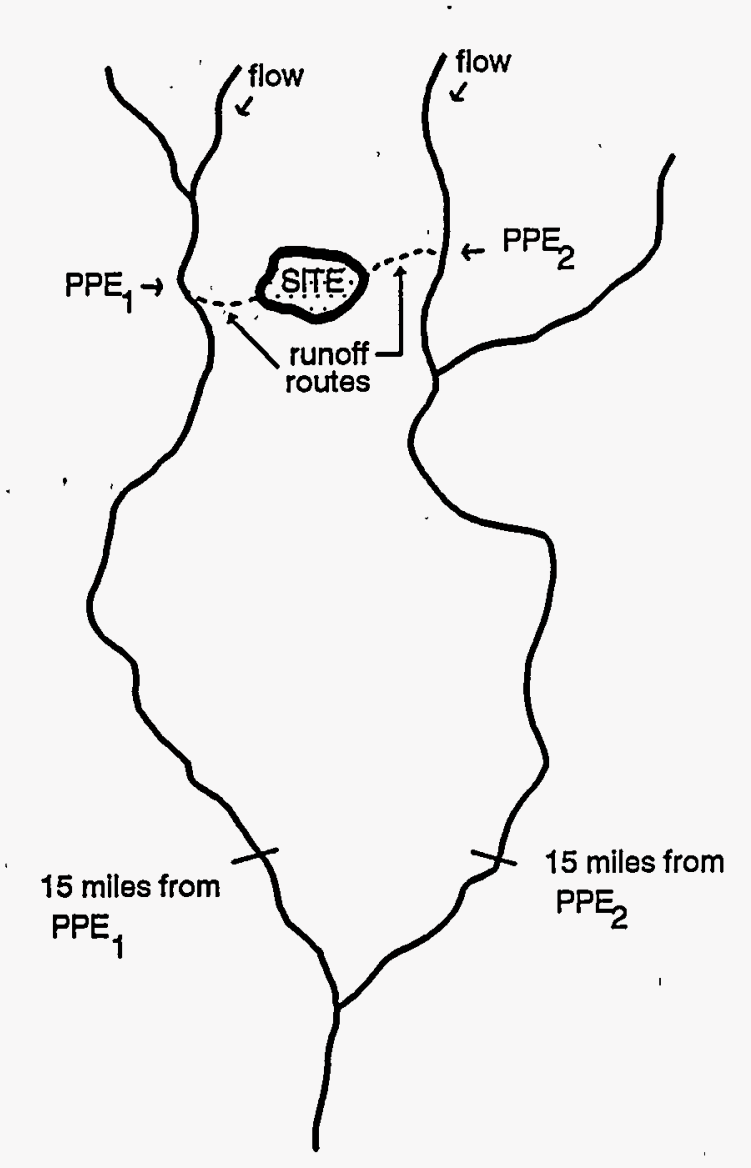

\section{Drinking Water Threat Targets}

Surface water intakes that supply drinking water are targets under the Drinking Water. Threat. Identify target intakes, mark the location and extent of the service area of each on a topographic map, determine the flow rate at each intake, and determine the population served by each.

\section{Identifying Drinking Water Intakes}

Identify drinking water intakes drawing from water bodies along the in-water segment of the surface water migration route in conjunction with your survey of water supply systems in the vicinity of the site. Section 3.3.2 discusses such a survey in the context of identifying drinking water wells. Except for the target distance limit, the approach to identify drinking water intakes is similar.

Drinking water intakes may serve municipal systems or, less commonly, community systems or individual residences. Identify municipal intakes by telephoning or visiting the municipal water authorities for the communities located along the in-water segment. These officials, or the County 
Sanitarian or similar Health Department official, can probably also provide information on areas where private community or domestic intakes are used.

Municipal intakes are sometimes identified on topographic maps. Both private and municipal intakes are catalogued in electronic databases such as PATHSCAN, which is maintained by EPA's Office of Water Regulations and Standards (Section 2.4.3). Be aware, however, that sources such as these may be incomplete. Always verify information obtained from databases, especially for completeness, by interviewing knowledgeable local officials.

Transcribe onto the topographic map the locations of all municipal drinking water intakes along the in-water segment and the extent of all distribution systems served by each intake. Also indicate areas on the map where domestic or community intakes are used.

\section{Flow at Target Intakes}

Obtain the average flow rate of the stream or lake at the location of each drinking water intake. Flow is expressed in units of cubic feet per second (cfs); average flow is generally calculated over a period of many years. Local water authorities can probably provide you with average flow at or near their own intakes, and may also be able to estimate the flow at or near private intakes.

The USGS operates a nationwide network of gauging stations that record flow on many thousands of water bodies. These data are reported in serialized "Water-Data Reports" published annually by USGS, on a State-by-State basis, and entitled "Water Resources Data, <State name>, Water Year $19\langle x x\rangle$." Long-term average flow is reported as "average discharge." A gaging station need not be located right by the target intake for published data to be useful. Upstream or downstream gauging stations can be used to approximate flow at the target.

For an intake located on a lake with in-flowing streams, determine flow by summing the average flows of all streams discharging into the lake. For an out-flowing lake without in-flowing streams, sum the flows of all streams leaving the lake. For a closed lake with neither in-flowing nor outflowing streams, assume a flow rate less than $10 \mathrm{cfs}$.

Flow is important because secondary target populations are evaluated according to volume of flow available to dilute hazardous substances that may be released from the site. This "dilution weighting" is built into PA Table 3 (page 13 of the PA scoresheets). Note from PA Table 3 that the flow categories increment by orders of magnitude. While it is preferable to obtain actual flow values if they are readily available, in the absence of such data you should be able to estimate average flow within the indicated order-of-magnitude ranges. PA Table 4 lists qualitative descriptions of the different water body types, corresponding to flow rates, that may be useful for estimation purposes.

The "mixing zone" flow category in PA Tables 3 and 4 refers to "quiet-flowing" streams or rivers, as opposed to turbulent flow, with an average flow rate of at least $10 \mathrm{cfs}$. From PA Table 3, note that this category produces higher dilution-weighted population values than any other category with flow greater than $10 \mathrm{cfs}$, because quiet-flowing streams or rivers provide less-rapid dispersion and dilution than turbulent flow does. An intake may be evaluated under the mixing zone flow category only if:

(1) It is located on a quiet-flowing stream or river with a flow rate greater than $10 \mathrm{cfs}$,

(2) It is not more than 3 miles from the PPE, and

(3) The entire reach between the PPE and the intake is quiet-flowing. 


\section{SURFACE WATER PATHWAY \\ TARGETS}

\section{Evaluating Drinking Water Populations}

Establish a drinking water population associated with each intake in the same way as explained in Section 3.3.2 for the ground water pathway. Briefly:

- If a municipal water authority cannot provide population figures for its system, multiply the number..of service connections by the county, average number of persons per household using U.S. Bureau of the Census data.

- If any municipal system served by surface water intakes "blends" water from more than one intake, or from a combination of intakes and wells, apportion populations to each intake and well. The same rules of apportionment apply to intakes as to wells (Section 3.3.2), except that "standby" or "backup" wells are not included when evaluating surface water drinking water population (just as standby or backup intakes are not included when evaluating ground water drinking water population).

- Evaluate standby or backup intakes for the surface water pathway as discussed for standby or backup wells on page 64; that is, you may either include or exclude them in population apportionment. Select the approach that results in the highest population factor value. In doing so, note that secondary surface water drinking water populations are evaluated on the basis of dilution weighting lin contrast to the distance weighting employed for ground water drinking water populations). In general, this means selecting the approach that results in the largest populations served by intakes drawing from water bodies with the lowest flow rates.

- In areas supplied by domestic or community intakes, estimate populations by performing a house count and multiplying the number of counted residences by the county average number of persons per household. Residences may be counted from topographic maps or aerial photographs, or by conducting a windshield survey.

- As in the ground water pathway, worker and student populations should always be evaluated in cases where the intake serving such a population is suspected to be exposed to a hazardous substance released from the site (i.e., it is a primary target intake). It is generally not time-efficient, however, to pursue the identification and evaluation of secondary target intakes serving workers or students. Note from PA Table 3 that intakes on water bodies where flow is less than $10 \mathrm{cfs}$, or in the mixing zone of quiet-flowing streams and rivers with flow rate of at least $10 \mathrm{cfs}$, begin to achieve large population values when populations served exceed 1,000 . For intakes on water bodies in all other flow categories, populations served must exceed 10,000 (for 10 to $100 \mathrm{cfs}$ ), 100,000 (for $>100$ to $1,000 \mathrm{cfs}$ ), or $1,000,000$ (for $>1,000 \mathrm{cfs}$ ) before significant population values are assigned. Other than municipal water supply, few (if any) intakes will be found that serve such large populations. Consequently, a secondary target intake serving workers or students need not be evaluated unless you believe that it meets the following two requirements:

(1) It is located on a water body with average flow rate less than $10 \mathrm{cfs}$, or in the mixing zone of a quiet-flowing stream or river with average flow rate of at least 10 cfs, and

(2) You suspect that the intake serves more than 1,000 people. 


\section{Human Food Chain Threat Targets}

Fisheries are targets under the Human Food Chain Threat. Identify each fishery, and the water body type and flow rate at each fishery, within the target distance limit.

Definition: Fishery -- An area of a surface water body from which food chain organisms are taken or could be taken for human consumption on a subsistence, sporting, or commercial basis. Food chain species include fish, shellfish, crustaceans, amphibians, and amphibious reptiles.

The definition of fishery is intentionally broad and is meant to include any portion of a body of water that does or could provide at least one trout; clam, lobster, frog, or alligator (to name one of each type of animal specified in the definition) for human consumption. In practice, then, water bodies that qualify as fisheries are extremely common. There are some exceptions. Identifying some types of ditches as fisheries, even though they may technically qualify as surface water (see the definition of "stream or river" in the glossaryl, would defy logic; for example, the ditch may be only intermittently flowing; or may be a perennially-flowing highway drainage ditch. Other examples of "non-fisheries" include water bodies that are sterile for reasons unassociated with the site, and water bodies that are closed to fishing for reasons unassociated with the site (e.g., bacterial or sewage contamination, red tide, contamination from other facilities).

Beginning at the PPE, delineate separate fisheries along the 15-mile in-water segment. One fishery ends and another begins wherever the water body type changes or the water body flow characteristics of a stream or river change. Water body types include:

- Streams and rivers

- Lakes

- Coastal tidal waters

- Oceans (includes the Great Lakes)

Each of these water body types are defined in the glossary. Within the "streams and rivers" water body type, flow characteristics are defined by orders of magnitude (see also PA Tables 3 and 4 in the PA scoresheets):

\begin{tabular}{|c|c|}
\hline Stream and River Types & Flow Characteristics \\
\hline \hline Minimal Stream & $<10 \mathrm{cfs}$ \\
Small to Moderate Stream & 10 to $100 \mathrm{cfs}$ \\
Moderate to Large Stream & $>100$ to $1,000 \mathrm{cfs}$ \\
Large Stream to River & $>1,000$ to $10,000 \mathrm{cfs}$ \\
Large River & $>10,000 \mathrm{cfs}$ \\
"Quiet-flowing" Mixing Zone & $10 \mathrm{cfs}$ or greater \\
\hline
\end{tabular}




\section{SURFACE WATER PATHWAY TARGETS}

Delineating fisheries by water body type is straightforward and can be done by examining the inwater segment on a topographic map. Delineating fisheries by flow characteristics within the "streams and rivers" water body type is more difficult because average flow data are necessary. While actual average flow will often be available at intakes, the data may be less common for fisheries. Lacking actual data from published (USGS) sources or from municipal water authorities, contact local fish and game officials. Obtaining an estimated average flow at any point along the in-water segment will be helpful, as you can use that datum as a starting point for estimating flow in other reaches. If actual flow values cannot be determined, it should be possible to at least estimate within the order-of-magnitude ranges. In fact, you need not expend undue effort trying to obtain flow data because careful estimation is acceptable. Obtaining flow data, for lakes as well as streams and rivers, is discussed on page 89 in conjunction with identifying drinking water intakes.

\section{Environmental Threat Targets}

Sensitive environments are targets requiring identification and evaluation under the Environmental Threat. Sensitive environments may be either terrestrial or aquatic but, for surface water pathway purposes, they must lie either in or adjacent to the in-water segment.

Definition: Sensitive Environment -- A terrestrial or aquatic resource, fragile natural setting, or other area with unique or highly-valued environmental or cultural features.

Typically, areas that fall within the definition of "sensitive environment" are established and/or protected by State or Federal law. Examples include National Parks, National Monuments, habitats of threatened or endangered species, and wildlife refuges. A complete list of qualifying sensitive environments is given in PA Table 5 (page 16 of the PA scoresheets).

Identify all sensitive environments in or adjacent to the in-water segment. Many types of sensitive environments are identified and labeled on topographic maps, and this is the best place to begin your survey. Telephone interviews of local fish and game officials, and parks and recreation officials, can also be fruitful. Many States also fund a Natural Heritage Program that inventories and provides information on sensitive environments, recreational areas, natural resources, and so forth. These can be excellent sources of information, but should not be your only source. The Natural Heritage Program is usually housed in the Department of Natural Resources, or similar State agency.

PA Table 5 lists several types of habitat used by State- or Federally-designated endangered or threatened species. Very often, Natural Heritage Programs and other authorities report habitats on a county-wide basis. You may find that a more specific location to answer the question "Does it occur in or adjacent to the in-water segment within the target distance limit?" is not available. Under such circumstances, assume that it does occur along the in-water segment, and score it accordingly.

The soil exposure and air pathways also require you to identify and evaluate sensitive environments, so a comprehensive survey to meet the scoring needs of each pathway should be conducted as a unified task.

Probably the most common type of sensitive environment is the wetland. 40 CFR $230.3(t)$ provides EPA's wetland definition: 
Definition: Wetland -- An area that is sufficiently inundated or saturated by surface or ground water to support vegetation adapted for life in saturated soil conditions. Wetlands generally include swamps, marshes, bogs, and similar areas.

Many wetlands are identified on topographic maps by the "swamp symbol," "but the maps may not show all wetlands. It is a good practice to supplement the topographic map with Wetlands Inventory Maps, which are produced by the U.S. Fish \& Wildlife Service (USF\&WS) and are available either directly from them or from the State or local agency with fish and wildlife responsibilities. The U.S. Army Corps of Engineers (COE), which has responsibilities pertaining to issuing permits to dredge or fill wetlands and waterways, can also be helpful in identifying wetlands.

For each sensitive environment, identify the water body type that the environment is in or adjacent to, and either obtain or estimate the flow at that environment. Refer to the discussions above (drinking water and food chain threats) for details on obtaining or estimating flow, and remember that order-of-magnitude estimates are acceptable.

With the exception of wetlands, each sensitive environment is assigned a value as indicated in PA Table 5.

For wetlands, measure the total frontage (that portion of the in-water segment that is in contact with wetlands) in each water body type; for the "streams and rivers" water body type, measure the total frontage in each flow characteristics category. Assign a wetlands frontage value from PA Table 6 for each of these frontage totals; for scoring purposes, each of these frontage totals represents a separate environment. In cases where wetlands occur on both sides of a stream or river, measure and sum the total frontage on both sides.

You may encounter situations where two or more sensitive environments overlap. For example, the in-water segment for a particular site passes a 3-mile-long wetland located in a State Wildlife Refuge in a county designated as a critical habitat for the Federally-designated endangered snail darter. In this example, three sensitive environments overlap: the wetland (75 points, PA Table 6), the refuge (75 points, PA Table 5), and the critical habitat (100 points, PA Table 5). If, rather than a county-wide designation, the wetland itself is specifically designated as a critical habitat for the snail darter, the wetland would be assigned 175 points and the refuge 75 points. If the wetland is also a habitat used by bald eagles (another Federally-designated endangered species), it receives an additional 100 . points, for a total of 275 , while the refuge retains a 75 -point value.

\section{Criteria List for Primary Targets.}

After you have identified all drinking water intakes, fisheries, and sensitive environments located in or adjacent to the in-water segment, and transcribed their locations onto a topographic map, determine which (if any) you consider to be primary targets and which you consider to be secondary.

Identifying a primary target represents a professional judgment, based on site, pathway, and target characteristics, that the target in question has a relatively high likelihood of exposure to a hazardous substance. Secondary targets have a relatively low likelihood of exposure. 


\section{SURFACE WATER PATHWAY TARGETS}

The Criteria List can help guide the process of developing hypotheses about targets that might be considered primary targets. The right-hand column of the Criteria List identifies a number of target characteristics to consider. Carefully consider each element on the Criteria List for primary targets within the context of the site and its particular targets. Answers to every question on the list, however, are unlikely to be available for many sites. You need not spend excessive amounts of time to develop detailed information to respond to each question -- it is possible to arrive at sound hypotheses about primary targets without knowing the answers to all questions on the list.

Also, keep in mind that there is an infinite variety of conditions that might lead you to identify a primary target, and no list of this type could identify them all. There are likely to be other considerations that may apply to a particular target, and you are encouraged to think along these lines. If such additional considerations enter into your conclusions, identify them at the bottom of the list.

Answer all questions on the list by checking the appropriate box marked "yes," "no," or "unknown." In evaluating each question, rely on all of the information that you have obtained about the site and its. targets through the course of your investigation -- file searches, desktop data development, site reconnaissance, interviews, etc.

Answers to many of the questions are likely to be fairly self evident. The difficult part lies in drawing the final conclusion, which amounts to a hypothesis as to whether a particular intake, fishery, or environment is a primary target. This requires professional judgment and is a somewhat intuitive process that relies on your accumulated professional expertise and specific knowledge of site and target characteristics. Answer each of the bottom three questions "yes" or "no" regarding your conclusion whether any specific target may be affected by a release. Note that the Criteria List is not a tally sheet requiring a majority of "yes" or "no". responses to reach a conclusion. You may hypothesize that a particular intake, fishery, or environment is a primary target on the basis of one or more target conditions or site characteristics that lead you to believe there is a relatively high likelihood of a hazardous substance having migrated to the target.

\section{Primary Target Considerations}

Each item on the Criteria List for primary targets is briefly discussed below.

Is any target nearby? (If yes, check "drinking water intake," "fishery," and/or "sensitive environment.")

If a release to surface water is suspected, proximity of targets to the site is a significant consideration; the closer the target, the higher the likelihood that it may be exposed to a hazardous substance. Just what qualifies as "nearby" depends on circumstances specific to the site and the water body. Of particular importance are water body type, flow characteristics, and the relative persistence of the hazardous substances you suspect may be associated with the site.

Fast-flowing water bodies can carry hazardous substances further in a shorter period of time than slower-flowing water bodies, so released substances have a greater chance of reaching more distant targets. High-volume flows tend to disperse and dilute contaminants more quickly than low-volume flows, making analytical detection of hazardous substances (during * the SI) less likely. The same is true of turbulent flow. This interplay of velocity and volume is further complicated by the persistence of substances that might degrade more or less quickly. 
These complex interactions mean that little guidance can' be given as to what is "nearby" and what is not. You should consider these parameters and make a case-by-case professional judgment as to the likelihood of a particular target being exposed to released substances. It may be helpful to keep in mind that the "proof" of exposure results from analytical sampling that would occur at the SI, and ask yourself if sampling at a particular target would likely reveal contaminants.

Has any intake, fishery, or recreational area been closed?

If water use at or near a target has been curtailed or restricted due to contamination, this could be a strong indicator that it is a primary target -- particularly if there is reason to suspect that the problem is in some way associated with the site. If the reason is unknown, it is best to assume that the problem is associated with the site and evaluate the target accordingly. Exceptions would include conditions such as closure due to bacterial or sewage contamination, red tide, or other problems known to be related to an incident not connected to the site.

Although recreation areas are not specifically evaluated as a separate class of targets, a closed recreation area could provide circumstantial evidence that contamination may exist at nearby intakes, fisheries, or sensitive environments.

Does analytical or circumstantial evidence suggest surface water contamination at or downstream of a target?

"Circumstantial" implies a level of certainty well below that of "proven fact," and this is sufficient for PA purposes. In this context, any condition that you find suspicious, and that indicates a possible contamination problem at or near a target, can be considered "circumstantial evidence." A couple of examples are:

- Analytical data indicate a hazardous substance in surface water at or near a target.

- The surface water body on which the target is located has been sampled by State, local, or site officials, whether or not you know the results.

- A plume, or discolored water or sediment, is present at or near the target.

Does any target warrant sampling? (If yes, check "drinking water intake," "fishery," and/or "sensitive environment.")

Perhaps the most straightforward test to identify primary targets is to ask yourself the question "Given what I know and suspect about this site, would I recommend that this target be sampled (during an $\mathrm{SI}$, for example) with the expectation of detecting hazardous substances there?" If the answer to this question is "yes," you have come to a professional judgment identifying a primary target.

After answering these questions and adding any other considerations to the list, indicate your professional judgment as to the occurrence of primary targets by checking the appropriate box next to each of the three questions at the bottom of the list asking if any primary target(s) have been identified.

To score any target as a primary target, you must first score a suspected release; a release is a precondition to a conclusion that a particular target has a relatively high likelihood of exposure to a 
TARGETS

hazardous substance. If your evaluation of the Criteria List leads you to believe that one or more targets should be considered primary targets, yet your earlier evaluation of likelihood of release led you to the No Suspected Release hypothesis, you should revisit the Criteria List for suspected releases and reconsider your judgment regarding the likelihood of release.

If your evaluation of the Criteria List leads you to conclude that some targets should be considered primary targets, summarize your rationale and identify the targets. 
Definition: The human population served by drinking water drawn from primary target intakes.

Evaluation Strategy: Identifying a primary target intake represents a professional judgment based on site, pathway, and target characteristics indicating a relatively high likelihood that a hazardous substance has migrated to the intake. A primary target may be hypothesized on the basis of available analytical data indicating that the intake may be exposed to hazardous substances; however, analytical data are not usually available for PA sites. For PA purposes, your professional judgment is usually based on indications -- which is not the same as documented fact. You may hypothesize a primary target intake on the basis of one or more characteristics of the site and its environs, sources, and types and quantity of wastes thought to be present, coupled with the proximity of the target and the flow characteristics of the water body on which it is located.

Use the Criteria List for primary targets to guide the process of considering pertinent characteristics that might lead you to identify a primary target intake. The application of the Criteria List is discussed on pages 93 to 96.

It is not possible to provide comprehensive guidance on what does and does not "qualify" as a primary target; you must rely on your professional judgment. Of particular importance in formulating this judgment are the proximity of the intake to the PPE, the flow characteristics (volume, velocity, turbulence) in the interval between the PPE and the intake, and the relative persistence of substances suspected to be associated with the site.

Remember that, in order to evaluate any target as a primary target, a suspected release to surface water must first be scored. In such cases, you may identify both primary and secondary targets. If a release is not suspected, there can be no primary targets. 
Scoring Instructions: Identify each drinking water intake within the target distance limit, the water body type on which each intake is located, and the flow rate of each water body. Enter this information in the box on the drinking water threat scoresheet (page 12 of the PA scoresheets).

Evaluate a drinking water intake as a primary target when available information leads you to hypothesize that there is a relatively high likelihood that a hazardous substance has migrated to the intake.

Determine the population served by each primary target intake as discussed on page 90 and as further described in conjunction with the ground water drinking water population (Section 3.3.2). Briefly:

- For each private domestic intake, count the number of persons in households or assign a population equal to the county average number of persons per household using U.S. Bureau of the Census data (round up to the next integer for each household).

- For an intake serving more than one residence (community or municipal intakes), determine the number of people served by the intake and assign that population. If the specific number of people served is not available from the operating authority; determine the number of service connections associated with the intake. Multiply this number by the county average number of persons per household (round up to the next integer before multiplying) and assign the resulting population to the intake. Apportion populations if blended systems are served by more than one intake or a combination of wells and intakes, and attach a page to the PA scoresheets to show your calculations.

- For an intake serving a distinct non-residential population (a business, industrial park, school, or university, for example), determine the population served by interviewing the intake owner/operator or facility administrator and assign this population to the intake.

Enter the population served by each intake (primary and secondary) in the box under question \#3 on the drinking water threat scoresheet (page 12 of the PA scoresheets). Sum the populations served by each primary target intake. Enter the total primary target population on the blank for factor \#4 (Primary Target Population). Multiply this total by 10 and enter the resulting factor score under Column $A$.

If your evaluation of the Criteria List led you to conclude that there are no primary target intakes, assign a zero score to factor \#4. 
Definition: The human population served by drinking water drawn from secondary target intakes.

Evaluation Strategy: Just as the identification of primary target intakes represents a professional judgment based on site, pathway, and target characteristics, so is the identification of secondary target intakes. In this instance, however, available information leads you to conclude that the intakes in question have a relatively low likelihood of exposure to a hazardous substance. You base this determination on one or more characteristics of the site and its environs, sources, and types and quantity of wastes thought to be present, coupled with the proximity of the target and the flow characteristics of the water body on which it is located.

Note that, if a release is suspected, some targets may be evaluated as primary targets and some as secondary targets. However, if no release is suspected, all targets are evaluated as secondary targets.

After completing your surface water targets survey and applying the Criteria List, you will have a set of hypotheses identifying the intakes that you believe are secondary targets. Application of the Criteria List is discussed on pages 93 to 96.

Develop separate secondary target population totals for all intakes drawing from water bodies in each flow characteristics category: $<10 \mathrm{cfs} ; 10$ to $100 \mathrm{cfs}$; $>100$ to $1,000 \mathrm{cfs} ;>1,000$ to $10,000 \mathrm{cfs} ;>10,000 \mathrm{cfs}$ (include intakes on the Great Lakes in this category), and mixing zones of quiet-flowing streams and rivers with flow rates of at least $10 \mathrm{cfs}$. Determine and sum secondary target populations within each flow characteristics category because different weights are applied to populations according to volume of flow to account for the dispersion and dilution of substances that may enter surface water: The weights become smaller with increasing flow rate and water body size to reflect greater dispersion and dilution. This dilution weighting is built into PA Table 3.

When you have completed your target survey and transcribed the locations of municipal and community intakes onto the topographic map, delineated the areas served by municipal, community, and domestic intakes, and obtained or estimated the flow rate at each intake, determining secondary target populations is relatively straightforward. Completing a targets survey, evaluating target populations associated with each intake, apportioning populations in blended systems, and obtaining average flow rates are discussed on pages 88 to 90 . 


\section{SURFACE WATER PATHWAY DRINKING WATER THREAT TARGETS}

Scoring Instructions: Evaluate a drinking water intake as a secondary target when available information leads you to conclude that there is a relatively low likelihood of a hazardous substance having migrated to the intake.

Determine the population served by each secondary target intake as discussed on page 90 . Briefly:

- For each private domestic intake, assign a population equal to the average number of persons per household for the county using data from the U.S. Bureau of the Census (for secondary target populations, do not round the average up to the next integer).

- For an intake serving more than one residence (community or municipal intake), determine the number of people served by the intake and assign that population to the intake. If the specific number of people served is not available from the authority " operating the intake, determine the number of service connections associated with the intake. Multiply this number by the county average number of persons per household (do not round the average up to the next integer) and assign the resulting population to the intake. Apportion populations if necessary.

- For intakes serving a distinct non-residential population (a business, industrial park, or. university, for example), determine the population served by interviewing the intake owner/operator or facility administrator and assign that population to the intake. Recall the discussion of dilution weighting of secondary target populations (pages 89 and 90) and PA Table 3; you need not pursue the identification and evaluation of private or community intakes serving residences, workers, or students unless you believe that a particular intake is located on a water body with average flow rate less than $10 \mathrm{cfs}$, or in the mixing zone of a quiet-flowing stream or river with average flow rate greater than 10 cfs, and you suspect that the intake serves more than 1,000 people.

For each flow characteristics category, sum the population served by secondary target intakes. Using PA Table 3 (page 13 of the PA scoresheets) for each flow category with secondary target intakes:

1) Enter the secondary target population for the flow, category in the "Population" column.

2) Working horizontally across the table, circle the value in the same row that represents the range into which the flow-category population falls.

3) Record the circled value in the same row of the "Population Value" column.

Sum the population values in the far-right column. Record this total at the bottom of the column and in one of the blanks for factor \#5 (Secondary Target Population) on the drinking water threat scoresheet. Use the blank under Column A if "Suspected Release" was scored for the Likelihood of Release factor category; use the blank under Column B if "No Suspected Release" was scored. Mark your response to the question "Are any intakes part of a blended system?". If you have apportioned populations, attach a page to the PA scoresheets to show your calculations. 
Factor: Nearest Intake

Definition: The drinking water intake closest to the probable point of entry to surface water.

Evaluation Strategy: In addition to evaluating both primary and secondary target populations, the PA also evaluates the distance to the nearest drinking water intake. This distance is an indicator of the magnitude of the threat the site may pose to surface water users. All other considerations being equal, the closer an intake is to the site and the lower the water body flow at the intake, the higher the threat the intake might be exposed to a hazardous substance.

Annotate the topographic map to identify the nearest target intake. A map wheel or calibrated string can be used to determine the distance between that intake and the PPE; record this distance in the "Pathway Characteristics" box at the top of the drinking water threat scoresheet. The number you record should be an absolute number, not a range, and accurate to the nearest 0.1 mile. Determine the flow rate at the intake; flow rates are discussed on page 89 and are determined as part of the surface water pathway targets survey.

Scoring Instructions: If you have identified any primary target intake you have, in effect, hypothesized that the threat or likelihood of exposure is relatively high. For this reason, whenever a primary target intake is present, assign a score of 50 to the Nearest Intake factor under Column A, regardless of distance or flow rate.

Otherwise, from PA Table 3 (page 13 of the PA scoresheets), select the flow characteristics category in which the nearest secondary target intake is located (far-left column). Circle the value on the same line in the column labeled "Nearest Intake." Record the selected value in one of the blanks for factor \#6 (Nearest Intake) on the drinking water threat scoresheet. Use the blank under Column A if you scored "Suspected Release" for the Likelihood of Release factor category; use the blank under Column B if you scored "No Suspected Release." 


\section{SURFACE WATER PATHWAY \\ DRINKING WATER THREAT \\ TARGETS}

Factor: Resources

Definition: Use of surface water for purposes other than drinking water.

Evaluation Strategy: In addition to providing drinking water, surface water. is often used for other purposes that could affect human health:

- Irrigation (5 acre minimum) of commercial food crops or commercial forage crops.

- Watering of commercial livestock.

- Ingredient in commercial food preparation (e.g., canning plant).

- Major or designated water recreation area (e.g., boat ramp, marina).

- Potential usability as drinking water supply, though the resource is not currently used for drinking water.

The PA accounts for such use through the resources factor, which is. assigned a value of 5 if any of the above resource uses are present within the 15-mile in-water segment; a zero value is assigned if there is no resource use.

Since surface, water often has some beneficial use, the resources factor can generally be assigned 5 points as a default measure. This approach is conservative from the scoring perspective (as the maximum value is assigned), has little impact on the pathway and site score, and can potentially save you many hours of research trying to define crop acreage, "commercial" uses, "major or designated" areas, and "usability."

Scoring Instructions: If, within the target distance limit, surface water is used for any of the purposes itemized above, assign a score of 5 to one of the blanks for factor \#7 (Resources) on the surface water pathway scoresheet; otherwise, assign a zero value. Alternatively, simply assign the 5 point value as a default measure. Use the blank under Column $A$ if you scored a "Suspected Release" for the Likelihood of Release factor category; use the blank under Column $B$ if you scored "No Suspected Release."

Total Drinking Water Threat Targets: Calculate the Drinking Water Threat Targets factor category score by summing the scores assigned to factors \#4 through 7. Factor scores should appear in only one of the two columns (A or B) depending on whether you scored a suspected release. 
Factor: Primary Target Fisheries

Definition: Fisheries suspected to be exposed to a hazardous substance released from the site.

Evaluation Strategy: The identification of primary target fisheries is analogous to that for primary target intakes; refer to the "Evaluation Strategy" for primary target population on page 97.

Scoring Instructions: Delineate each fishery (primary and secondary) within the target distance limit (see pages 91 to 92). For each, enter a fishery name, its water body type, and flow rate in the box on the human food chain threat scoresheet (page 14 of the PA scoresheets). If there is no fishery (primary or secondary), assign a zero score for human food chain threat targets at the bottom of the page.

Evaluate a fishery as a primary target when available information leads you to conclude that there is a relatively high likelihood that a hazardou's substance has migrated to the fishery. If you have identified one or more primary target fisheries, list them under factor \#9 (Primary Fisheries) and assign a single score of 300 to the factor under Column A. Carry this score to the bottom of the page as the Human Food Chain Threat Targets score (do not evaluate factor $\# 10$, Secondary Fisheries).

If you identified no primary target fisheries, assign a zero score to factor \#9. 


\section{SURFACE WATER PATHWAY HUMAN FOOD CHÄIN THREAT TARGETS}

Factor: Secondary Target Fisheries

Definition: Fisheries not suspected to be exposed to hazardous substances released from the site.

Evaluation Strategy: This factor need only be evaluated if you have not identified a primary target fishery. The identification of secondary target fisheries is analogous to that for secondary target intakes; review the first three paragraphs of the "Evaluation Strategy" for secondary target population on page 99.

Unless a release is suspected, secondary target fisheries are scored on the basis of flow rate. Because low-flow water bodies have less ability to disperse and dilute hazardous substances than do high-flow water bodies, this factor is scored on the basis of the fishery with the lowest flow rate.

Scoring Instructions: Delineate each fishery (primary and secondary) within the target distance limit (see pages 91 to 92). For each, enter a fishery name, its water body type, and flow rate in the box on the human food chain threat scoresheet (page 14 of the PA scoresheets). If there is no fishery (primary or secondary) within the target distance limit, assign a zero score for human food chain threat targets at the bottom of the page.

Evaluate a fishery as a secondary target when available information leads you to conclude that there is a relatively low likelihood that a hazardous substance has migrated to the fishery.

If you suspect a release to surface water, but do not suspect that a hazardous substance has migrated to any fishery (i.e., you have identified one or more secondary target fisheries but have not identified any primary target fishery), assign a score of 210 to factor \#10a (Secondary Fisheries). Assign the score under Column $A$ and carry it to the bottom of the page as the Human Food Chain Threat Targets score.

If you do not suspect a release to surface water, identify the fishery with the lowest flow rate. Assign a single score to factor \#10b from the table on the human food chain threat scoresheet. Assign a score of 210 if the lowest flow rate is less than $10 \mathrm{cfs} ; 30$ if between 10 and $100 \mathrm{cfs}$; or 12 if greater than $100 \mathrm{cfs,}$ or if fisheries are only located in coastal tidal waters, oceans, or the Great Lakes. Assign the score under Column B and carry it to the bottom of the page as the Human Food Chain Threat Targets score. 
Factor: Primary Target Sensitive Environments

Definition: Sensitive environments suspected to be exposed to a hazardous substance released from the site.

Evaluation Strategy: The identification of primary target sensitive environments is analogous to that for primary target intakes; refer to the "Evaluation Strategy" for primary target population on page 97.

Scoring Instructions: Identify each sensitive environment (primary and secondary) in or adjacent to the in-water segment within the target distance limit (see pages 92 to 93 and PA Table 5, page 16 of the PA scoresheets). For each, enter an environment name, its water body type, and flow rate in the box under item \#11 on the environmental threat scoresheet (page 15 of the PA scoresheets). If there are no sensitive environments (primary or secondary), assign a zero score for environmental threat targets at the bottom of the page.

Evaluate a sensitive environment as a primary target when available information leads you to conclude that there is a relatively high likelihood that a hazardous substance has migrated to that environment. If you have identified one or more primary target sensitive environments, list them on the blanks provided by factor \#12 (Primary Sensitive Environments) and assign a single score of $\mathbf{3 0 0}$ to the factor under Column A. Carry this score to the bottom of the page as the Environmental Threat Targets score (do not evaluate factor \#13, Secondary Sensitive Environments).

If you identified no primary target sensitive environments, assign a zero score to factor \#12. 
SURFACE WATER PATHWAY

ENVIRONMENTAL THREAT

TARGETS

Factor: Secondary Target Sensitive Environments

Definition: Sensitive environments not suspected to be exposed to hazardous substances released from the site.

Evaluation Strategy: This factor need only be evaluated if you have not identified a primary target sensitive environment. The identification of secondary target sensitive environments is analogous to that for secondary target intakes; review the first three paragraphs of the "Evaluation Strategy" for secondary target population on page 99.

Secondary target sensitive environments are scored on the basis of flow rate, because low-flow water bodies have less ability to disperse and dilute hazardous substances than do high-flow water bodies. Possible scoring scenarios include: situations where some or all of the surface water pathway secondary sensitive environments are located in or adjacent to water bodies with flow rates of $100 \mathrm{cfs}$ or less; and situations where all surface water pathway sensitive environments are located in or adjacent to water bodies with flow rates exceeding $100 \mathrm{cfs}$.

Scoring Instructions: Identify each sensitive environment (primary and secondary) in or adjacent to the in-water segment within the target distance limit (see pages 92 to 93 and PA Table 5, page 16 of the PA scoresheets). For each, enter an environment name, its water body type, and flow rate in the box under item \#11 on the environmental threat scoresheet (page 15 of the PA scoresheets). If there are no sensitive environments (primary or secondary), assign a zero score for environmental threat targets at the bottom of the page.

Evaluate a sensitive environment as a secondary target when available information leads you to conclude that there is a relatively low likelihood that a hazardous substance has migrated to that environment.

For each surface water pathway sensitive environment associated with a water body having a flow rate of $100 \mathrm{cfs}$ or less, identify the environment type, its point value (PA Tables 5 and 6, page 16 of the PA scoresheets), and its flow rate. Enter this information in the box under factor \#13a. For each such environment, use PA Table 4 (page 13 of the PA scoresheets) to obtain a dilution weight corresponding to its flow category (1 or 0.1 , as appropriate). Enter the dilution weight for each environment in the box under factor \#13a. For each environment, multiply its assigned point value by the appropriate dilution weight, and enter the product in the box under the column labeled "Total." Sum the products for each environment, round the sum to the nearest integer, and enter the result as the score for factor \#13a (Secondary Sensitive Environments). Assign the score under Column A if you scored a suspected release; under Column B if you did not. Do not evaluate factor \#13b. 


\section{SURFACE WATER PATHWAY}

ENVIRONMENTAL THREAT

\section{TARGETS}

If all surface water pathway sensitive environments are associated with water bodies having flow rates greater than $100 \mathrm{cfs}$, do not evaluate factor \#13a. Instead, assign a single score of 10 to factor \#13b. Assign the score under Column A if you scored a suspected release; under Column $B$ if you did not. 


\subsubsection{Waste Characteristics}

The evaluation of the Waste Characteristics factor category is discussed in Section 3.2.2.

If you have identified any primary target drinking water intake, fishery, or sensitive environment, assign either the waste characteristics score (WC) that you calculated using PA Table 1 (Section 3.2.2, and page 4 of the PA scoresheets) or a score of 32 -- whichever is greater -- to factor \#14a. Assign this score under Column A. Do not evaluate factor \#14b.

If you have not identified any primary target, assign the waste characteristics score (WC) that you calculated using PA Table 1 (Section 3.2.2, and page 4 of the PA scoresheets) to factor \#14b. Assign the score under Column A if you scored "Suspected Release" for likelihood of release; under Column B if you scored "No Suspected Release." Do not evaluate factor \#14a.

\subsubsection{Calculating Surface Water Threat and Pathway Scores}

Calculate separate scores for the drinking water, human food chain, and environmental threats, then combine them to obtain the surface water pathway score.

Fill in the matrix on page 17 of the PA scoresheets with the appropriate values for likelihood of release (LR), targets (T), and waste characteristics (WC) for each threat. Note that LR and WC are the same for all threats; only $T$ may differ for each threat. Calculate the score for each threat and enter it in the far-right column of the matrix: multiply $L R \times T \times W C$, divide the product by 82,500 , and round to the nearest integer. The drinking water and food chain threats are each subject to a maximum score of 100; if the score you calculate exceeds 100 , assign 100 as the threat score. The environmental threat is subject to a maximum score of 60 ; if the score you calculate exceeds 60 , assign 60 as the threat score.

Sum the drinking water, human food chain, and environmental threat scores. Record the result as the surface water pathway score at the bottom of the page. If your calculated score exceeds 100 , assign 100 as the pathway score. 


\subsection{SOIL EXPOSURE PATHWAY}

The soil exposure pathway assesses the threat to human health and the environment by direct exposure to hazardous substances and areas of suspected contamination. This pathway differs. from the three migration pathways in that it accounts for contact with in-place hazardous substances at the site, rather than migration of substances' from the site.

The PA evaluation of the soil exposure pathway requires you to consider and assign scores to factors in three factor categories. The first, Likelihood of Exposure, is analogous to Likelihood of Release in the other pathways. Targets are evaluated under two threat categories: The resident population threat deals with human, environmental, and resource targets located on or very near the site. The nearby population threat accounts for the likelihood of residents within the surrounding area coming into contact with contamination related to the site. The evaluation and score for the Waste Characteristics factor category (WC, Section 3.2.2) applies directly to the soil exposure pathway, without exceptions. 


\section{SOIL EXPOSURE PATHWAY}

LIKELIHOOD OF EXPOSURE

\subsubsection{Likelihood of Exposure}

The Likelihood of Exposure factor category is concerned with areas of suspected contamination. While this evaluation occurs in the context of the soil exposure pathway, areas of suspected contamination are not limited to soils; any sources, areas of contamination, or other material on the surface is considered (e.g., gravel fill, waste pile, plank flooring, concrete, asphalt paving).

Areas of suspected contamination are defined by the presence of hazardous substances. Thus, in general, most sources (including in-ground sources such as surface impoundments and landfills, onground sources such as contaminated soil and piles, and above-ground sources such as drums and tanks) are considered areas of suspected contamination. There are two types of exceptions:

- Sources with more than 2 feet of cover.

- Sources with an impenetrable cover (e.g., asphalt paving), regardless of thickness.

The evaluation of this factor category functions as an "on/off" switch. A score of 550 is assigned if you know or suspect that ân area of contamination is present; a zero score is assigned if there are no areas of contamination. Areas of suspected contamination are present at most CERCLA sites. Occasionally, however, you may encounter sites with no areas of contamination. Examples may include:

- A ground water plume site with no identifiable source

- A closed landfill with a 3-foot-thick clean fill cover

- A site that has been completely paved with 4 inches of asphalt

- A site where the only source is inside a building

Even with sites such as these, it may be difficult to rule out the presence of areas of suspected contamination with information available during a PA. For example:

- For a plume site, while a source may not be visually identifiable, one may be revealed through surface sampling.

- For a site involving clean cover material greater than 2 feet thick, uneven distribution of the material, subsequent erosion, or leachate breakouts could result in areas of suspected contamination.

- For a paved site, areas of suspected contamination may be present atop the pavement itself. Or, prior to paving, runoff may have carried hazardous substances onto adjoining areas that have not been paved.

- For a source inside a building, areas of suspected contamination may exist on the flooring.

To confidently rule out the presence of areas of suspected contamination, appropriate quality analytical data demonstrating the absence of hazardous substances are generally necessary. For this reason, and because areas of contamination are present at most CERCLA sites, you may generally assume this to be the case and assign a value of 550 for Likelihood of Exposure. To assign the alternative zero value, which effectively eliminates the soil exposure pathway from further consideration, you generally need analytical data that confidently demonstrate the absence of areas of contamination. Review Section 3.1 for a discussion of potential limitations in applying available analytical data. Also refer to-Section 5.3 for a discussion of evaluating available analytical data to determine whether they meet the test of appropriate quality. 
Factor: Suspected Contamination

Definition: Known or suspected areas of contamination; that is, areas containing hazardous substances not covered by either an essentially impenetrable cover or more than 2 feet of cover material.

Evaluation Strategy: Because areas of suspected contamination are usually present at CERCLA hazardous waste sites, a Likelihood of Exposure score of $\mathbf{5 5 0}$ is generally appropriate and you may assign this value as a default measure. Assign the alternative zero value only in cases where the presence of areas of contamination can be confidently ruled out. To do this, appropriate quality analytical data are usually necessary. Refer to Sections 3.1 and 5.3 for discussions regarding available analytical data and the conditions under which such data may be considered appropriate quality.

Scoring Instructions: If available analytical data confidently rule out the presence of areas of suspected contamination, assign a zero score to factor \#1 (Suspected Contamination) on the soil exposure pathway scoresheet (page 19 of the PA scoresheets). Due to the multiplicative algorithm for pathway scoring (Likelihood of Exposure $\times$ Targets $x$ Waste Characteristics), this effectively eliminates further consideration of the soil exposure pathway; therefore, assign zero as the pathway score at the bottom of the page.

Otherwise, or as a default measure, assign a score of 550 to factor \#1. 


\section{SOIL EXPOSURE PATHWAY \\ TARGETS}

\subsubsection{Targets}

Soil exposure pathway targets involve two separate threats:

- The resident population threat evaluates targets located on or within 200 feet of areas of suspected contamination. Factors include resident population, resident individual, workers, terrestrial sensitive environments, and resources.

- The nearby population threat represents a separate threat to the population in the surrounding vicinity.

Keep these targets in mind as you investigate the site and its environs during the site reconnaissance (Section 2.5). For many of these target factors, first-hand observation will likely prove more fruitful and accurate than site file records, existing photographs, and topographic maps. During the reconnaissance, observe and verify the current use of the site property, and the location of onsite buildings and nearby homes, residential developments, schools, and daycare facilities.

Resident population, resident individual, workers, and terrestrial sensitive environments are identified and evaluated on the basis of their presence on, or their distance from, areas of suspected contamination. The key to identifying and evaluating these targets, then, is to delineate sources completely and thoroughly.

Recall the definition of the term "source."

Definition: Source -- An area where a hazardous substance may have been deposited, stored, disposed, or placed. Also, soil that may have become contaminated as a result of hazardous substance migration.

By carefully identifying and delineating sources, you define the maximum extent of suspected contamination; targets are evaluated on the basis of their distance from these areas. Refer to "Source Identification and Characterization" in Section 3.2.1 for further discussion, and remember that the extent of suspected contamination is not limited by facility property boundaries.

\section{Identifying Resident Population}

The resident population factor represents the human population with the highest risk of exposure to hazardous substances at the site. This population is potentially exposed on an essentially daily basis because they either live or attend school or daycare in areas where hazardous substances may be present. This "resident population" is analogous to "primary targets" in the three migration pathways. Resident population targets meet either of the following conditions:

- A person who resides on or within 200 feet of an area of suspected contamination.

- A person who attends school or daycare on or within 200 feet of an area of suspected contamination.

Areas of suspected contamination are not limited to the property boundaries of the facility itself -they may occupy less than the total area of the facility, or may extend onto adjacent and other 
nearby properties. Hazardous substances may have spread from the facility to other properties via air migration, overland runoff, or mechanical means such as tracking by vehicles.

Investigate whether the facility property previously encompassed a greater area than the current area of operations or property boundaries. Sources of information include facility operating files, former employees, and historical aerial photographs. The local tax assessor's office will have a complete historical record of the sale, acquisition, and transfer of all real estate; this is an excellent and reliable source of detailed information including dates of property transfer and real estate development activities. If surrounding properties include residences or schools, find out from the tax assessor when they were built. By comparing these dates to the operating history of the site, you may find, for example, that houses have been built on former waste disposal areas that are no longer discernible because they have been developed. People living in those houses would be considered resident population.

When identifying schools and daycare facilities whose attendees may be considered resident population, include all types of public and private institutions. In addition to nursery schools, elementary and secondary schools, and colleges and universities, also consider adult daycare facilities, adult education centers, driving schools, and so forth.

\section{Criteria List for Resident Population}

After delineating the full extent of areas of suspected contamination, identify nearby residences and schools on or within 200 feet of suspected contämination.

Review the Soil Exposure Pathway Criteria List (page 18 of the PA scoresheets). The Criteria List can help guide the process of developing hypotheses about the extent of suspected contamination and the presence of resident population targets. The Criteria List identifies conditions to consider in reaching these conclusions, but other conditions may apply to a particular site that might lead you to identify a resident population, and you are encouraged to think along these lines. If such additional considerations enter into your conclusions, identify them at the bottom of the list.

Answer all questions on the list by checking the appropriate box marked "yes," "no," or "unknown." In evaluating each question, rely on all of the information you have obtained about the site and its targets through the course of your investigation -- file searches, desktop data collection, site reconnaissance, interviews, etc. Answer the bottom question "yes" or "no" regarding your conclusion whether a specific target may be on or within 200 feet of an area of suspected contamination.

\section{Resident Population Considerations}

Each item on the Criteria List for resident population targets is briefly discussed below.

Is any residence, school, or daycare facility on or within 200 feet of an area of suspected contamination?

Identifying areas of suspected contamination is the key to identifying resident populations. This requires a thorough delineation of sources -- which includes areas that you suspect may be contaminated as a result of hazardous substance migration.

Do not rely solely on topographic maps to identify houses and school buildings because they 1 may not be up to date. During your site reconnaissance, look for homes, residential 


\section{SOIL EXPOSURE PATHWAY \\ TARGETS}

developments, trailer parks, apartment buildings, schools, daycare facilities, and other new development that may not be indicated on your maps. Persons who live or attend school or daycare on or within 200 feet of areas of suspected contamination qualify as resident population targets.

Is any residence, school, or daycare facility located on adjacent land previously owned or leased by the site owner/operator?

Over time, portions of the original facility property may have been sold, or adjacent property might at one time have been leased for facility operations. If so, hazardous substances may be present on those properties. You need not expend undue effort to definitively conclude that hazardous substances were handled on, or migrated to, those areas; it may be enough to know or suspect that these properties could have been involved in facility operations or that contamination could have been tracked or migrated there.

Is there a migration route that might spread hazardous substances near residences, schools, or daycare facilities?

Consider whether a runoff route from the site could result in soil or sediment contamination on or near residential or school property. Also consider windblown transport -- especially if your evaluation of the air pathway likelihood of release led to a hypothesis that an air release is suspected (Section 3.6.1). In addition, consider whether waste hauling vehicles may have traversed properties that are now occupied by residences, schools, or daycare facilities. Related considerations include any reports or observations of stained. soil or stressed vegetation on nearby properties.

Have onsite or adjacent residents or students reported any adverse health effects, exclusive of apparent drinking water or air contamination problems?

The local Health Department or other authorities may have reports of adverse health effects -such as skin burns or rashes after yard work or outdoor play - that might be associated with contact with hazardous wastes or contaminated soil related to the site.

\section{Does any neighboring property warrant sampling?}

Perhaps the most straightforward test to identify potential resident population targets is to ask yourself the question "Given what I know and suspect about the sources and the history of this site, would I recommend that this neighboring property be sampled (during an $\mathrm{SI}$, for example) with the expectation that I might find hazardous substances there?" If the answer to this question is "yes," you have come to a professional judgment and you may have identified resident population targets if schools, daycare facilities, or residences are within 200 feet of the area of suspected contamination.

\section{Other criteria?}

There may be other criteria that support the identification of areas of suspected contamination and the presence of resident population targets. These might include consideration of releases via the migration pathways if, for example, releases are suspected to have resulted in soil contamination on adjacent or nearby offsite properties. Has the site flooded, or have sources (such as surface impoundments) overflowed onto adjacent properties? Might windblown substances released from the site have been deposited on nearby properties? These additional 
questions may not apply to all sites; likewise, there may be other considerations specific to the site you are evaluating.

After answering these questions and adding any other considerations to the list, indicate your professional judgment as to the occurrence of resident population targets by checking the appropriate box next to the "Resident Population' Identified?" question.

If your evaluation of the Criteria List leads you to conclude that any residence, school, or daycare facility should be evaluated for resident population, summarize your rationale and identify the specific targets.

\section{Evaluating Resident Populations}

Determine the number of persons occupying residences that qualify as resident population targets. If possible, obtain a count of residents by conducting a door-to-door survey. Be aware of potential community relations concerns and do not undertake a door-to-door survey without first consulting your supervisors. Alternatively, obtain the county average number of persons per household from the U.S. Bureau of the Census. Round up to the next whole number of persons for each residence, and multiply the number of households considered resident population targets by the county average. Houses that are used as seasonal residences (for example, summer cottages, winter homes, lake or beach houses) should be evaluated just as year-round places of residence are.

For apartments or condominiums, contact the building superintendent or leasing/sales agent to obtain the number of residential units in the building. Multiply the number of units by the county average number of persons per household, first rounding the average up to the next integer.

Determine the enrollment or attendance at schools and daycare facilities regarded as resident population targets by contacting the facility administrator. Remember to consider all types of educational institutions.

\section{Identifying and Evaluating Workers}

The resident population threat includes an evaluation of workers on the facility property and workers on the property of nearby facilities where you also suspect contamination related to the site. This addresses the threat to workers who may be exposed to hazardous substances by virtue of being present at the workplace. If some workers also reside on the facility property, or on neighboring properties where you suspect contamination, count them under both the worker category and the resident population category. Do not be concerned about "double counting," for that is the intent -- such persons are doubly exposed.

Include both full-time and part-time workers in the count. If the facility is engaged in shift work, count all workers on all shifts.

If the site is active, you may be able to determine the number of workers through file searches, or by interviewing a facility representative, or present or former employees. If you cannot determine the number of workers by these means, estimate a reasonable number for a facility of this size and type.

Note from page 19 of the PA scoresheets that workers are scored in ranges of 0,1 to 100,101 to 1,000 , and greater than 1,000. In the absence of an exact figure, careful estimation within these ranges is acceptable. You may be able to make an estimate based on your site reconnaissance. 


\section{SOIL EXPOSURE PATHWAY TARGETS}

Counting the number of employee parking spaces is an acceptable means of approximating the right range. Aerial photographs may also indicate personal vehicles in employee parking lots, which you may count, if feasible. However, do not evaluate the number of workers that might have been employed at the facility in the past, unless this number is also a good approximation of the number currently employed.

\section{Identifying and Evaluating Terrestrial Sensitive Environments}

As with the resident population factor, identifying sensitive environments for the soil exposure pathway requires a clear delineation of land areas where you suspect contamination by site-related hazardous substances. You then evaluate the presence of terrestrial sensitive environments on those areas of suspected contamination. Because, under the soil exposure pathway, some portion of a sensitive environment must occur on an area of suspected contamination, qualifying environments are analogous to primary sensitive environments under the surface water and air pathways:

Definition: Terrestrial Sensitive Environment -- A terrestrial resource, fragile natural setting, or other area with unique or highly-valued environmental or cultural features.

Typically, areas that fall within the definition of "terrestrial sensitive environment" are established and/or protected by State or Federal law. Examples include National Parks, National Monuments, habitats of threatened or endangered species, and wildlife refuges. Note that, while your evaluation of sensitive environments under the surface water and air pathways includes both terrestrial and aquatic environments, the soil exposure pathway evaluation is limited to terrestrial sensitive environments. PA Table 7 (page 20 of the PA scoresheets) lists sensitive environments applicable to the soil exposure pathway.

Identify terrestrial sensitive environments as part of a unified task to identify sensitive environments for the surface water, soil exposure, and air pathways. Many types of sensitive environments are identified and labeled on topographic maps, and this is the best place to begin your survey. Telephone interviews of local fish and game officials, and parks and recreation officials, can also be fruitful. Many States also fund a Natural Heritage Program that inventories and provides information on sensitive environments, recreational areas, natural resources, and so forth. These can be excellent sources of information, but should not be your only source. The Natural Heritage Program is usually housed in the State Department of Natural Resources, or similar State agency.

PA Table 7 lists several types of habitat used by State- or Federally-designated endangered or threatened species. . Very often, Natural Heritage Programs and other authorities that inventory such habitats report their occurrence on a county-by-county basis. You may find that a more specific location to answer the question "Does it occur on an area of suspected contamination associated with the site?" is not available. Under such circumstances, it is best to assume that it does occur on an area of suspected contamination and score it accordingly.

Consider the following example: You find from the State Department of Natural Resources that the county in which the site is located is specified as terrestrial habitat used by the State-designated threatened snowshoe hare and spotted groundhog. You wonder if the "entire county" designation is specific enough to indicate that the habitats are likely to be on the site itself. A colleague 


\section{SOIL EXPOSURE PATHWAY \\ TARGETS}

remembers that, in the past, the office consensus was to score this environment only if you observed and photographed the threatened species during site assessment field activities.

However, your site reconnaissance occurred on a snowy January day, during which you could not see a snowshoe hare because of its natural coloration, and the groundhog was still hibernating (Groundhog Day is February 2). For PA purposes, the county-wide designation is sufficient to assign 50 points (PA Table 7) for the snowshoe hare and 50 points for the spotted groundhog, obtaining a score of 100 . This example also illustrates that, as with sensitive environments under the surface water and air pathways, the score for soil exposure terrestrial sensitive environments is cumulative for multiple designations. 
Factor: Resident Population

Definition: Persons living or attending school or daycare on or within 200 feet of suspected contamination.

Evaluation Strategy: Resident population consists of those people likely to be most highly exposed to hazardous substances in areas of suspected contamination. They are subject to exposure because they live, or attend school or daycare, on or very near areas of suspected contamination.

The evaluation of resident population requires careful identification and delineation of sources. Do this in conjunction with your evaluation of waste quantity and waste characteristics (Section 3.2.2). Identifying sources and delineating areas of suspected contamination involves a combination of quantitative evidence and professional judgment. Remember that areas of suspected contamination include areas to which hazardous substances may have migrated -- this may be less than the total area of the facility property itself, or may extend onto neighboring properties.

With all areas of suspected contamination delineated, resident populations are identified on the basis of distance from those areas of suspected contamination. Resident population includes:

- Any person who resides on or within 200 feet of an area of suspected contamination.

- Any person who attends school or daycare on or within 200 feet of an area of suspected contamination.

You may hypothesize a resident population on the basis of available analytical data indicating that people live or attend school or daycare on or within 200 feet of hazardous substances; however, analytical data are not usually available for PA sites. For PA purposes, your professional judgment is usually based on indications -- which is not the same as documented fact. Fully documented areal distribution of contamination usually cannot be achieved at the PA.

When delineating areas of suspected contamination and identifying resident population targets, consider characteristics of the sources at the facility, the capability for migration to neighboring properties, and the proximity of the target itself. When available information leads to the conclusion that there is a relatively high likelihood of a hazardous substance within 200 feet of a residence, school, or daycare facility, you have identified a resident population.

Use the Criteria List for resident population targets to guide the process of considering pertinent characteristics that might lead you to suspect a resident population. The application of the Criteria List is discussed on pages 113 to 115. 
Scoring Instructions: Determine the number of people occupying residences that qualify as resident population targets. Obtain a count by conducting a door-to-door survey if community relations considerations allow and if your supervisors concur. Alternatively, obtain the county average population per household from the U.S. Bureau of the Census, round this average up to the next integer, and multiply the result by the number of residences identified as resident population targets.

For apartment and condominium buildings, multiply the number of residential units by the county average as described above.

For schools or daycare, obtain an enrollment figure from the facility's administration office. Remember to consider all types of educational institutions.

Sum the number of persons determined as discussed above. Enter the total population on the blank by factor \#2 (Resident Population) on the soil exposure pathway scoresheet (page 19 of the PA scoresheets). Multiply this total population by 10 and enter the resulting factor score.

If your evaluation of the Criteria List led you to conclude that there is no resident population, assign a zero score to factor \#2 (Resident Population) and factor \#3 (Resident Individual). 
SOIL EXPOSURE PATHWAY

TARGETS

Factor: Resident Individual

Definition: Any resident population target.

Evaluation Strategy: The resident individual factor reflects the fact that the simple presence of a resident population means that at least one person is potentially threatened by proximity to hazardous substances in areas of suspected contamination. This factor is analogous to the nearest well, intake, and individual factors of the other three pathways. Because resident populations are analogous to primary targets under the other three pathways, the resident individual factor receives the maximum score if a resident population is present; it scores zero otherwise.

Scoring Instructions: If you have identified any resident population (factor \#2), assign a score of 50 to the resident individual factor (factor \#3). If there is no resident population, assign a score of zero. 
Factor: Workers

Definition: Full- or part-time employees.

Evaluation Strategy: This factor addresses the threat to workers who may be exposed to hazardous substances because they are present at the workplace. If the facility is active, determine the number of workers by contacting a facility representative, interviewing present or former employees, or through file information. Lacking an exact number, make a reasonable estimate for a facility of this size and type. If the facility involves shift work, count all workers on all shifts. Count the workers at neighboring facilities only if you suspect that hazardous substances have migrated there.

Scoring instructions: Assign a score to factor \#4 (Workers) from the table printed on the soil exposure pathway scoresheet. Assign the score that corresponds to the total number of workers at the facility (and at affected neighboring facilities, if appropriate). Do not evaluate workers who might have been employed at the facility in the past. 
SOIL EXPOSURE PATHWAY

TARGETS

Factor: Terrestrial Sensitive Environments

Definition: Terrestrial resources, fragile natural settings, or other areas with unique or highlyvalued environmental or cultural features.

Evaluation Strategy: Like the resident population factor, identifying terrestrial sensitive environments for the soil exposure pathway first requires carefully identifying sources and delineating areas of suspected contamination. Generally, to score this factor, some portion of a terrestrial sensitive environment must be on an area of suspected contamination related to the site. The exceptions are habitats of threatened or endangered species, which might be designated on a county-wide basis.

PA Table 7 (page 20 of the PA scoresheets) lists terrestrial sensitive environments for the soil exposure pathway. Identify sensitive environments as part of a unified research task for the surface water, soil exposure, and air pathways. Topographic maps, State Natural Heritage Program offices, and interviews with local officials (fish and game, parks and recreation) are all good sources of information.

Scoring Instructions: For each qualifying terrestrial sensitive environment, assign a value for environment type from PA Table 7. Qualifying environments must (1) appear in PA Table 7, and (2) occur on an area of suspected contamination that is related to the site (except in the case of county-wide habitat designations).

Note that a single environment can be evaluated for multiple designations. For example, a midnight dumping site in a State-designated Natural Area (25 points, PA Table 7) that is also a habitat used by the State-designated threatened snowshoe hare (50 points) and spotted groundhog (50 points), would receive 125 points for the terrestrial sensitive environments factor.

Sum the values for all qualifying environments. Assign the sum as the score for factor \#5 (Terrestrial Sensitive Environments) on the soil exposure pathway scoresheet. 
Factor: Resources

Definition: Use of the resource (land) for commercial agriculture, commercial silviculture, or commercial livestock production or grazing.

Evaluation Strategy: The resources factor accounts for land uses impacted by suspected contamination:

- Commercial agriculture.

- Commercial silviculture (e.g., tree farming, timber production, logging).

- Commercial livestock production or grazing.

The resources factor is assigned a value of 5 if any of the above resource uses are present on an area of suspected contamination associated with the site; otherwise, a zero value is assigned.

Often, extensive analytical data are required to reliably determine whether any of the specified resource uses occur on an area of contamination. Because such data are not usually available at the PA, the resources factor can generally be assigned 5 points as a default measure. This approach is conservative from the scoring perspective (as the maximum value is assigned), has little impact on the pathway and site score, and can potentially save you many hours of research trying to determine whether a particular use qualifies as "commercial."

Scoring Instructions: If any of the resource uses itemized above occurs on an area of suspected contamination associated with the site, assign a score of 5 to factor \#6 (Resources) on the soil exposure pathway scoresheet; otherwise, assign a zero value: Alternatively, simply assign the 5 point value as a default measure.

Total Resident Population Threat Targets: Calculate the Resident Population Threat Targets factor category score by summing the scores assigned to factors \#2 through 6 . Factor scores should appear in only one of the two columns (A or B) depending on whether you scored a suspected release. 


\section{THREAT AND PATHWAY SCORES}

\subsubsection{Waste Characteristics}

The evaluation of the Waste Characteristics factor category is discussed in Section 3.2.2. The waste characteristics score (WC) that you calculated using PA Table 1 (Section 3.2.2, and page 4 of the PA scoresheets) is applied to the soil exposure pathway without modification. Assign the WC score to factor \#7 on the soil exposure pathway scoresheet.

\subsubsection{Calculating Soil Exposure Threat and Pathway Scores}

Sum the scores assigned to factors \#2 through 6 to arrive at the Resident Population Threat Targets score; enter this sum in the box labeled "T." Multiply the scores in the Likelihood of Exposure (LE), Targets (T), and Waste Characteristics (WC) boxes; divide by 82,500; round to the nearest integer; and record the result, subject to a maximum of 100 , as the Resident Population Threat score. If your calculated score exceeds 100 , assign 100 as the Resident Population Threat score.

The Nearby Population Threat acknowledges that there are likely to be nearby residents who do not qualify as resident population but may, nevertheless, come in contact with areas of contamination and exposed or accessible wastes by traveling to the site. Do not assign a score to the Nearby Population Threat if you gave a zero score to Likelihood of Exposure. Otherwise, score the Nearby Population Threat on the basis of the population within a 1-mile radius of the site. Use the same 1mile radius total population you evaluated for air pathway population targets (Section 3.6.2), and assign the threat score according to the following table:

\begin{tabular}{|c|c|}
\hline $\begin{array}{c}\text { Population Within } \\
\text { One Mile }\end{array}$ & $\begin{array}{c}\text { Nearby Population } \\
\text { Threat Score }\end{array}$ \\
\hline \hline$<10,000$ & 1 \\
\hline 10,000 to 50,000 & 2 \\
\hline$>50,000$ & 4 \\
\hline
\end{tabular}

Sum the Resident Population Threat Score and the Nearby Population Threat score. Record the result, subject to a maximum of 100 , as the soil exposure pathway score at the bottom of the page. If your calculated score exceeds 100 , assign 100 as the pathway score. 


\subsection{AIR PATHWAY}

The PA evaluation of the air pathway requires you to consider and assign scores to factors in three factor categories: Likelihood of Release, Targets, and Waste Characteristics.

Evaluating likelihood of release requires you to hypothesize whether hazardous substances are likely to be migrating from the site to the air.

The principal threat under the air pathway is the threat of airborne releases of hazardous substances. The targets evaluation is primarily concerned with identifying and evaluating the human population within the 4-mile target distance limit (radius) around the site, and sensitive environments within $1 / 2$ mile.

The evaluation and score for the waste characteristics factor category (WC, Section 3.2.2) applies directly to the air pathway, as to all other pathways, except if primary targets are identified (Section 3.6.3). 


\subsubsection{Likelihood of Release}

Evaluating the Likelihood of Release factor category requires a professional judgment, based on site and pathway conditions, as to whether it is likely that release of a hazardous substance to the air could be detected. This differs somewhat from the way you evaluate Likelihood of Release for the ground water and surface water migration pathways, where you make a professional judgment as to whether a release is likely to have occurred.

As with releases to the other migration pathways, a PA hypothesis of a suspected air release is tested through analytical sampling of environmental media for sites that progress to an SI. However, air releases are fundamentally different from releases to ground water or surface water. Hazardous substances released to ground water may be detected in samples taken long after the release occurred. Likewise, hazardous substances released to surface water may adsorb to sediments and thus remain detectable for long periods. In contrast, because. of the rapid dispersion of released substances in the atmosphere, air releases can usually be detected only while the release is occurring. In this sense, the detectability of an air release is transient. Even if the likelihood that a release has occurred is very high, for this pathway it is the likelihood that the release can be detected during $\mathrm{SI}$ sampling that is more important.

Likelihood of Release is scored on the basis of one of two scenarios, "Suspected Release" or "No Suspected Release," either of which require you to make a professional judgement as to whether a release is or is not likely to be detected.

\section{Criteria List for Suspected Release to the Air Pathway}

The Criteria List suggests a number of characteristics of the site and its environs to consider in developing a hypothesis as to whether an air release might be detected. Answer the questions in the left-hand column of the Criteria List, which deal with a suspected release. Unlike the other. migration pathways, a suspected release to the air is sufficient, in itself, to identify primary targets. Consequently, there is no Criteria List for air pathway primary targets.

Carefully consider each element on the Criteria List within the context of the site and its environs. Answers to every question on the list, however, are unlikely to be available for many sites. You need not spend excessive amounts of time trying to develop detailed information to respond to each question -- it is possible to arrive at a sound hypothesis about suspected releases without knowing answers to all questions on the list.

Also, keep in mind that because there is an infinite variety of site-specific circumstances, no list of this type could identify every characteristic that might apply to any specific site. The list, therefore, is by no means complete and the criteria making up the list are not prioritized in any way. Instead, these questions are meant to get you thinking about the types of site-specific conditions that need to be considered when formulating a hypothesis about a suspected release. There are likely to be other site-specific criteria that apply to a particular site, and you are encouraged to think along these lines. If such additional considerations enter into your conclusions, identify them at the bottom of the list.

Answer the questions on the list by checking the appropriate box marked "yes," "no," or "unknown." In evaluating each question, rely on the total body of information you have obtained about the site and its environs through the course of your investigation -- file searches, desktop data collection, site reconnaissance, interview's, etc. 


\section{AIR PATHWAY \\ LIKELIHOOD OF RELEASE}

Answers to many of the individual questions are likely to be fairly self evident. The difficult part lies in drawing the final conclusion, which amounts to a hypothesis as to whether you suspect a release, and whether that release is likely to be detectable during an SI. This requires professional judgment, and is a somewhat intuitive process that relies upon your accumulated professional expertise and specific knowledge of site conditions and characteristics. Note that the Criteria List is not a tally sheet requiring a majority of "yes" or "no" answers to come to a particular conclusion. You may hypothesize a suspected release on the basis of one or more considerations that lead you to believe there is a relatively high likelihood of detecting hazardous substances released to the air.

\section{Suspected Release Considerations}

Each item on the Criteria List for suspected release to the air is briefly discussed below.

Are odors currently reported?

Reports of odors from the site may indicate that hazardous substances are being released to the air. Such reports may come from employees, if the site is active, or from nearby residents. The local Department of Health may have received complaints of odors, or you may obtain such reports while interviewing site representatives and neighbors. Be aware of odors yourself during your site reconnaissance. If you undertake an onsite reconnaissance, health and safety rules require you to conduct continuous air monitoring with $\mathrm{HNu}$, OVA, or similar instrumentation; abnormal readings from these instruments, even if you don't smell anything, could also be indicative of a release. When evaluating odors, keep in mind the characteristics and operational history of the site itself. Some sites -- landfills, for example -- typically smell unpleasant, and odor alone may not be sufficient cause to suspect a release of hazardous substances.

Has release of a hazardous substances to the air been directly observed?

Direct observation of a release to the air might occur under circumstances where hazardous substances are suspected to be present in particulate form (e.g., mine tailings, waste pile) or adsorbed to particulates (e.g., contaminated soil), and site conditions (e.g., dry, dusty, windy) favor air transport. For example, facility employees or neighbors may report dust clouds from the site when the wind is high, or you may observe such a condition during your reconnaissance.

Are there reports of adverse health effects potentially resulting from migration of hazardous substances through the air?

The local Health Department, facility employees, or neighbors may have reported health effects such as headaches, nausea, or dizziness that could lead to a hypothesis that releases are occurring. Should you experience such symptoms yourself during the site reconnaissance, health and safety considerations require you to leave the area immediately. Such an experience would be a strong reason to hypothesize a release.

Does analytical or circumstantial evidence suggest a release to the air?

Other evidence of release to the air might include conditions such as dead or stressed vegetation that doesn't appear to have been affected by direct deposition or overland migration of hazardous substances, reports from neighbors of any type of airborne particulate 


\section{AIR PATHWAY \\ LIKELIHOOD OF RELEASE}

"fallout" that might have originated at the site, faded paint or etched glass on the automobiles in the facility's parking lot, and so forth.

After answering these questions, and adding other considerations to the list, indicate your professional judgment as to the likelihood of detecting a release of hazardous substances to the air by checking "yes" or "no" next to the "Release Suspected?" question. Remember that this is a judgment call; you don't need a majority of "yes", responses -- in some cases, a single "yes" may be sufficient to suspect a release. 'Summarize the rationale for your hypothesis.

\section{Scoring Likelihood of Release}

After completing your evaluation of the Criteria List for releases to the air, you should have a hypothesis as to whether you do or do not suspect that a release may be detectable. The following pages explain how to assign a score to the Likelihood of Release factor category, depending on whether your hypothesis is "Suspected Release" or "No Suspected Release." 
Factor: Suspected Release

Definition: A professional judgment conclusion basèd on site and pathway conditions indicating that release of a hazardous substance to the air is likely to be detected.

Evaluation Strategy: In scoring a suspected releăse, you are stating a hypothesis that is likely that a hazardous substance from the site could be detected in a release to the air. For PA purposes, your professional judgment is usually based on indications -- which is not the same as documented fact. Remember, however, that detecting an air releașe with environmental samples during an $\mathrm{SI}$ is often more difficult than detecting a release to ground water or surface water. Your judgment regarding a suspected air releasë must include consideration of the ability to detect such a release.

The Criteria List for air releases (discussed on pages 126 to 128 ) heelps guide the process of considering pertinent conditions that might lead you to suspect a release.

Scoring Instructions: Hypothesize and score a suspected release when available information leads you to conclude that there is a relatively high likelihoód of detecting a hazardous substance released to the air. Assign a score of 550 to factor \# 1 (Suspected Release) on the air pathway scoresheet (page 22 of the PA scoresheets); assign the score under Column A, and use only Column $A$ for the air pathway. Do not assigni a score to factor \#2 (No Suspected Release).

If you do not hypothesize a suspected release, score factor \#2 (No Suspected Release). 


\section{AIR PATHWAY \\ LIKELIHOOD OF RELEASE}

Factor: No Suspected Release

Definition: A professional judgment conclusion based on site and pathway conditions indicating that release of a hazardous substance to the air is not likely to be detected.

Evaluation Strategy: If you did not hypothesize a suspected release from your evaluation of the Criteria List, then your hypothesis must be that a release is not suspected. You must complete an evaluation of the Criteria List before concluding that no release is suspected.

Just as a hypothesis that a release is suspected is based on conditions at and around the site, so is the hypothesis that a release is not suspected. In this instance, however, available information leads you to conclude that there is a relatively low likelihood that a hazardous substance is being released to the air, or that any releases that may occur are so transient or rapidly dispersed that it is unlikely that a release could be detected through sampling during an SI.

Scoring Instructions: If you do not suspect a release to air, assign a score of 500 to factor \#2 (No Suspected Release) on the air pathway scoresheet. Assign the score under Column B and use only Column $B$ for the air pathway. 


\subsubsection{Targets}

Target populations under the air pathway consist of people who reside, work, or go to school within the 4-mile target distance limit around the site. PA air pathway targets also include sensitive environments and resources.

Targets are evaluated on the basis of their distance from the site. To assist in this evaluation, draw a series of concentric circles on your topographic map with radii of $1 / 4$ mile, $1 / 2$ mile, 1 mile, 2 miles, 3 miles, and 4 miles from the site.

\section{Residential Populations}

Identify the residential population onsite and in each of the six distance categories around the site. Automated electronic databases are very useful for this purpose. The Graphical Exposure Modeling System (GEMS) is one such database. GEMS was developed for, and is maintained by, EPA's Office of Toxic Substances. If direct access to GEMS is not available through your office, contact the EPA Regional office to arrange access and to find out about other databases of population information.

GEMS works with U.S. Bureau of the Census population data. You provide, as input, the latitude and longitude coordinates for the site, and specify the six distance radii (in kilometers). GEMS returns the residential population in each distance category.

National Planning Data Corporation (NPDC, Ithaca, NY) maintains a similar database that uses U.S.' Census data updated to account for population growth and new development. For a fee, NPDC can also provide population data.

The Bureau of the Census has developed Topographically Integrated Geographic Encoding and Referencing (TIGER) data files for use as a base map for the 1990 census. These may be available for access late in 1991 and will constitute the most accurate and authoritative of electronic population databases.

GEMS and NPDC data are based on populations within "census tracts," which are irregular in size, depending on local population density. Populations are assigned to the centroid of each tract. Thus, if the population centroid for a given tract lies within one of the specified distance categories, GEMS or NPDC reports the entire population of that tract as being in that distance category, even if the census tract itself falls only partially in that distance category. Consequently, populations for specific distance categories may be over- or underestimated. This is of particular concern for the smaller, close-in distance categories -- especially in non-urban, sparsely populated areas. The more distant categories cover much larger areas which are less sensitive to over- or underestimation; population totals reported by GEMS or NPDC for these categories are subject to less error than the areally smaller distance categories.

Populations reported by GEMS or NPDC for distance categories beyond $1 / 2$ mile can usually be accepted as sufficiently accurate for PA purposes. There may be occasional instances where the population reported by the database clearly doesn't "fit" with your existing knowledge of the area around the site and, in these cases, you may feel it appropriate to obtain an alternative estimate from other sources. However, note from PA Table 8 (page 23 of the PA scoresheets) that, for distance categories of $1 / 2$ to 1 mile and beyond, large populations are required to score significant secondary target population points, and the population ranges used for scoring purposes are quite wide. The large numbers and wide ranges work to smooth errors in estimation. Consequently, the 


\section{AIR PATHWAY \\ TARGETS}

populations reported by GEMS or similar databases for these distance categories should be adequate, and it may not be time-efficient to pursue alternative estimates.

For the close-in distance categories -- onsite, 0 to $1 / 4$ mile, and $1 / 4$ to $1 / 2$ mile -- it is a good practice to supplement the information received from databases with house counts from topographic maps, aerial photographs, a windshield survey, or some combination of these methods. For apartments or condominiums, contact the building superintendent or leasing/sales agent to obtain the number of residential units in the building. Obtain the county average figure for persons per household (from U.S. Bureau of the Census data) and multiply this average by the number of counted residences. to obtain the population total. For primary target populations, round the average up to the next integer before multiplying; for secondary target populations, round up to the next integer only after multiplying. For onsite residences, count houses during the site reconnaissance and, if your supervisors concur, interview residents to obtain an exact population.

\section{Worker and Student Populations}

Because available electronic databases do not provide worker and student populations, identifying these populations is inherently more difficult. Any attempt to fully identify such populations throughout the target distance limit would be time consuming. For these reasons, it is usually best to limit your evaluation of workers and students to readily available information.

From PA Table 8 , note the population values assigned to the indicated population ranges according to distance category. For distances beyond $1 / 2$ mile, very large populations are required to achieve significant point values. For this reason, it is usually not time-efficient to evaluate workers and . students in these distance categories unless there are specific, readily-identifiable institutions (e.g., major industrial facility, large university) that may, individually, account for thousands of workers or students.

For distances less than $1 / 2$ mile, you may want to perform a somewhat more comprehensive survey of workers and students. Most types of schools are identified on topographic maps and local street maps. School enrollment figures can be obtained by contacting school administrators. You may want to obtain worker counts from specific, large businesses, but a complete canvass of employers within $1 / 2$ mile would not usually be reasonable. In the interest of time-efficiency, again let the population values in PA Table 8 guide the amount of effort to expend.

\section{Sensitive Environments}

Identify all sensitive environments, both terrestrial and aquatic, on the site, within $1 / 4$ mile of the site, and between $1 / 4$ and $1 / 2$ mile of the site. During the PA, it is not usually necessary to evaluate sensitive environments between $1 / 2$ mile and the 4-mile target distance limit because distance weights render their contribution to the site score minimal. Be aware that the surface water and soil exposure pathways also require you to identify and evaluate sensitive environments, so a comprehensive survey to meet the scoring needs of each pathway should be conducted as a unified task.

Definition: Sensitive Environment -- A terrestrial or aquatic resource, fragile natural setting, or other area with unique or highly-valued environmental or cultural features. 
Typically, areas that fall within the definition of "sensitive environment" are established and/or protected by State or Federal law. Examples include National Parks, National Monuments, habitats of threatened or endangered species, and wildlife refuges. PA Table 5 (page 16 of the PA scoresheets) lists qualifying sensitive environments.

Many types of sensitive environments are identified and labeled on topographic maps, and this is the best place to begin your survey. Telephone interviews with local fish and game officials, and parks and recreation officials, can also be fruitful. Many States also fund a Natural Heritage Program that inventories and provides information on sensitive environments, recreational areas, natural resources, and so forth. These can be excellent sources of information, but should not be your only source. The Natural Heritage Program is usually housed in the State Department of Natural Resources, or similar State agency.

Some sensitive environments cover large areas (e.g., State Wildlife Refuge) and may span, for example, both the 0 to $1 / 4$-mile and $1 / 4$ - to $1 / 2$-mile distance categories. In these cases (except for wetlands, which are discussed separately below), evaluate the environment only for its closest occurrence to the site; in the example given here, evaluate the refuge only for its occurrence in the 0 to $1 / 4$-mile category.

PA Table 5 lists several types of habitat used by State- or Federally-designated endangered or threatened species. Very often, Natural Heritage Programs and other authorities report habitats on a county-wide basis. You may find that a more specific location to answer the question "Is it present on the site, within $1 / 4$ mile of the site, or within $1 / 2$ mile of the site?" is not available. Under such circumstances, it is best to assume that it is present in all three categories, and score it accordingly; that is, score it as present on the site, but not for its presence in the $1 / 4-$ or $1 / 2$-mile distance categories.

Probably the most common type of sensitive environment is the wetland. 40 CFR $230.3(t)$ provides EPA's wetland definition:

Definition: Wetland -- An area that is sufficiently inundated or saturated by surface or ground water to support vegetation adapted for life in saturated soil conditions. Wetlands generally include swamps, marshes, bogs, and similar areas.

Many wetlands are identified on topographic maps by the "swamp symbol," but the maps may not show all wetlands. It is a good practice to supplement the topographic map with Wetlands Inventory Maps, which are produced by the U.S. Fish \& Wildlife Service and are available either directly from them or from the State or local agency with fish and wildlife responsibilities. The U.S. Army Corps of Engineers, which has responsibilities pertaining to issuing permits to dredge or fill wetlands and waterways, can also be helpful in identifying wetlands.

Measure the total wetlands acreage in each of the following three categories: onsite, 0 to $1 / 4$ mile from the site, and $1 / 4$ to $1 / 2$ mile from the site. Assign a wetlands area value from PA Table 9 (page 23 of the PA scoresheets) to each of these acreage totals; for scoring purposes, each of these acreage totals represents a separate environment.

You may encounter situations where two or more sensitive environments overlap to various degrees. Consider, for example, a 10-acre wetland 2,000 feet from the site, located in a State 


\section{AIR PATHWAY \\ TARGETS}

Wildlife Refuge, in a county that is designated as critical habitat for the Federally-designated endangered northern spotted owl. In this example, three sensitive environments overlap: the wetland (25 points, PA Table 9), the refuge (75 points, PA Table 5), and the critical habitat (100 points, PA Table 5). If, rather than a county-wide designation, the refuge itself is specifically designated as critical habitat for the owl, the refuge would be assigned a total of 175 points (75 for being a State Wildlife Refuge, plus 100 for being a specifically-designated critical habitat), and the wetland 25 points.

\section{Primary Targets}

Like the other migration pathways, a release must be suspected in order to score primary targets for the air pathway. Releases to the air pathway, however, are fundamentally different from releases to the other migration pathways. Depending on the wind, air releases may disperse in any direction. During an SI, primary target hypotheses are tested via analytical sampling, and all populations and sensitive environments out to and including the furthest distance category in which the release can be documented are evaluated as-primary targets.

For these reasons, there is no Criteria List for air pathway primary targets (page 21 of the PA scoresheets). Instead, when a release is suspected during the $P A$, all populations and sensitive environments out to and including the $1 / 4$-mile distance category are evaluated-and scored as primary targets. Because air releases are usually quickly diluted in the atmosphere, targets beyond the $1 / 4$-mile distance are evaluated as secondary targets:

As with the other migration pathways, when a release is not suspected, all targets are evaluated as secondary targets. 
Factor: Primary Target Population

Definition: The human population most likely subject to exposure from release of a hazardous substance to the air.

Evaluation Strategy: If you suspect a release to the air, those persons closest to the site are most likely to be affected and are evaluated as primary targets. When you suspect a release to the air, evaluate and score the residential, student, and worker population within $1 / 4$ mile as the primary target population.

Scoring Instructions: Evaluate air pathway primary target population only when you suspect a release to the air. If your evaluation of the Criteria List for air releases led you to conclude that a release is not suspected, assign a zero score to factor \#3 (Primary Target Population). Otherwise, determine the population within $1 / 4$ mile as described on pages 131 to 132 . GEMS, or a similar electronic database, may be used as a starting point but may not be accurate enough for population evaluations in the close-in distance categories. Database populations should be supplemented by a house count within $1 / 4$ mile of the site.

During your site reconnaissance, determine the number of people regularly present on the site as residents, students, or workers. Perform a house count within the $1 / 4$-mile distance category by examining topographic maps and/or aerial photographs, if they are up to date. Otherwise, conduct a windshield survey as part of your site reconnaissance. The windshield survey will also help identify large apartment or condominium buildings or complexes; obtain the number of units in each by interviewing building superintendents or leasing/sales agents. Determine total residential population by multiplying the number of counted residences by the U.S. Bureau of the Census average number of people per household in the county (round the average up to the next integer before multiplying). The windshield survey, coupled with examining topographic and local street maps, will also identify schools and specific large businesses that may warrant evaluation for student or worker populations (see page 132 for more discussion).

Sum the number of residents, students, and workers identified onsite and within $1 / 4$ mile of the site. Enter this total on the blank by factor \#3 (Primary Target Population) on the air pathway scoresheet (page 22 of the PA scoresheets). Multiply the total by 10, and record the resulting factor score under Column $A$. 
AIR PATHWAY

TARGETS

Factor: Secondary Target Population

Definition: The human population less likely to be subject to exposure from release of a hazardous substance to the air.

Evaluation Strategy: If you suspect a release to the air, the residential, student, and worker population onsite and within $1 / 4$ mile of the site is evaluated as the primary target population; the residential, student, and worker population between $1 / 4$ mile and 4 miles is evaluated as the secondary target population. If you do not suspect a release, the residential, student, and worker population within the entire 4-mile target distance limit is evaluated as the secondary target population.

Scoring Instructions: Identify residential, student, and worker population as discussed on pages 131 to 132 and in conjunction with the "Evaluation Strategy" for primary target population (page 135). Use GEMS or other electronic databases as a starting point. GEMS or similar data for distances beyond $1 / 2$ mile are usually acceptable. However, you should supplement the database populations with house counts within $1 / 2$ mile of the site. Use topographic maps, local street maps, and a windshield survey to perform and/or supplement the house count, and to identify specific large business or educational institutions where worker or student populations may be sufficiently large to warrant investigation.

Sum the residential, student, and worker populations to obtain individual totals for the following distance categories: onsite, 0 to $1 / 4$ mile, $1 / 4$ to $1 / 2$ mile, $1 / 2$ to 1 mile, 1 to 2 miles, 2 to 3 miles, 3 to 4 miles. From PA Table 8 (page 23 of the PA scoresheets), for each distance category:

1) Enter the total secondary target population for the distance category in the "Population" column.

2) Working horizontally across the table, circle the value in the same row that represents the range that the distance-category population falls in.

3) Record the circled value in the same row of the "Population Value" column.

Sum the population values in the right-hand column. Record this total at the bottom of the column and in one of the blanks for factor \#4 (Secondary Target Population) on the air pathway scoresheet. Use the blank under Column A if you scored a suspected release for the Likelihood of Release factor category; use Column $B$ if not. 
Factor: Nearest Individual

Definition: The person closest to any source at the site.

Evaluation Strategy: The distance to the nearest individual is an indicator of the magnitude of the threat the site poses to the person most likely to be exposed to hazardous substances that may be released from the site. All other considerations being equal, the closer a person is to the site, the higher the threat that the person might be exposed to hazardous substances.

The nearest individual is represented by the nearest regularly occupied building -- you need not locate or obtain the identity of an actual person. The nearest regularly occupied building could be a building on the site itself, or it could be a nearby residence, workplace, school, church, etc.

Annotate the topographic map to identify the nearest regularly occupied building. Use a ruler or pair of dividers to determine the shortest straight-line distance between it and any source at the site. If the distance is so short as to make map measurement impractical, estimate the distance through visual observation during the site reconnaissance. Record this distance in the "Pathway Characteristics" box on the air pathway scoresheet; record an absolute number, not a range, accurate within a margin of \pm 100 feet.

Scoring Instructions: If you have identified any primary target population you have, in effect, hypothesized that the threat or likelihood of exposure is relatively high. For this reason, whenever a primary target population is present, assign a score of $\mathbf{5 0}$ to the Nearest Individual factor, regardless of distance. Assign the score under Column A.

Otherwise, from PA Table 8 (page 23 of the PA scoresheets), select the distance category in which the nearest regularly occupied building is located (far-left column). Circle the value on the same line in the column labeled "Nearest Individual." Record the selected value in one of the blanks for factor \#5 (Nearest Individual) on the air pathway scoresheet. Use the blank under Column A if you scored "Suspected Release" for the Likelihood of Release factor category; use the blank under Column B if you scored "No Suspected Release." 


\section{AIR PATHWAY \\ TARGETS}

Factor: Primary Target Sensitive Environments

Definition: Sensitive environments most likely subject to exposure from release of a hazardous substance to the air.

Evaluation Strategy: Identify all sensitive environments on and within $1 / 2$ mile of the site (pages 132 to 134 ) as part of a unified task to identify sensitive environments for the air, soil exposure, and surface water pathways.

If you suspect a release to the air, those sensitive environments closest to the site are most likely to be affected and are evaluated as primary targets. Therefore, if you suspect a release to the air, evaluate and score all sensitive environments on or within $1 / 4$ mile of the site as primary sensitive environments.

Scoring Instructions: Evaluate air pathway primary target sensitive environments only when you suspect a release to the air. In the box under factor \#6 (Primary Sensitive Environments) on the air pathway scoresheet, list all sensitive environments on or within $1 / 4$ mile of the site. From PA Table 5 (page 16 of the PA scoresheets), assign values for each environment type. In the case of wetlands, assign values for wetland area (PA Table 9, page 23 of the PA scoresheets). Sum these values and record the result as the factor score for primary target sensitive environments. Record the score under Column A.

If your evaluation of the Criteria List for air releases led you to conclude that a release is not suspected, assign a zero. score to factor \#6. 
Factor: Secondary Target Sensitive Environments

Definition: Sensitive environments less likely subject to exposure from release of a hazardous substance to the air.

Evaluation Strategy: Identify all sensitive environments on and within $1 / 2$ mile of the site (pages 132 to 134 ) as part of a unified task to identify sensitive environments for the air, soil exposure, and surface water pathways.

If you suspect a release to the air, all sensitive environments on or within $1 / 4$ : mile of the site are scored as primary sensitive environments; those between $1 / 4$ and $1 / 2$ mile are scored as secondary sensitive environments. If a release is not suspected, all sensitive environments on or within $1 / 2$ mile of the site are scored as secondary sensitive environments.

Scoring Instructions: From PA Tables 5 and 9 (pages 16 and 23 of the PA scoresheets) assign a value for each secondary sensitive environment. Turn to PA.Table 10 (page 23 of the PA scoresheets) and list each environment by distance category, along with its associated value. Remember that, except for wetlands, sensitive environments that span two or more distance categories are evaluated only for their closest occurrence to the site. For wetlands, the acreage occurring in each distance category is evaluated separately. Multiply each environments' value by the distance weight given in PA Table 10, and record the product in the right-hand column. Sum the values in the right-hand column; record the total at the bottom of the column and as the score for factor \#7 (Secondary Sensitive Environments) on the air pathway scoresheet. Record the score under Column $A$ if you scored a suspected release for the Likelihood of Release factor category; under Column $B$ if you did not. 


\section{AIR PATHWAY \\ TARGETS}

Factor: Resources

Definition: Use of land around the site for commercial agriculture, commercial silviculture, or recreation.

4:

Evaluation Strategy: The resources factor accounts for land uses around the site that may be impacted by a release to the air:

- Commercial agriculture.

- Commercial silviculture (e.g., tree farming, timber production, logging).

- Major or designated recreation area (e.g., municipal swimming pool, campground, park).

The resources factor is assigned a value of 5 if any of the above resource uses are present within $1 / 2$ mile of any source at the site; otherwise, a zero value is assigned.

Because agriculture, silviculture, or recreation uses are often present, the resources factor can generally be assigned 5 points as a default measure. This approach is conservative from the scoring perspective (as the maximum value is assigned), has little impact on the pathway and site score, and can potentially save you many hours of research trying to determine whether a particular use qualifies às "commercial" or "major or designated:" .

$\because \because .$.

Scoring Instructions: If any of the resource uses itemized above are present within $1 / 2$ mile of any source at the site, assign a score of 5 to one of the blanks for factor \#8 (Resources) on the air pathway scoresheet; otherwise, assign a zero value. Alternatively, simply assign the 5 point value as a default measure. Use the blank under Column A if you scored a "Suspected Release" for the Likelihood of Release factor category; use the blank under Column B if you scored "No Suspected Release."

Total Targets: Calculate the Targets factor category score by summing the scores assigned to factors \#3 through 8. Factor scores should appear in only one of the two columns (A or B) depending on whether you scored a suspected release. 


\section{AIR PATHWAY \\ WASTE CHARACTERISTICS \\ AND \\ PATHWAY SCORE}

\subsubsection{Waste Characteristics}

The evaluation of the waste characteristics factor category is discussed in section 3.2.2.

If you have identified any primary target population or primary target sensitive environment, assign either the waste characteristics score (WC) that you calculated using PA Table 1 (Section 3.2.2, and page 4 of the PA scoresheets) or a score of 32 -- whichever is greater -- to factor \#9a. Assign this score under Column A. Do not evaluate factor \#9b.

If you have not identified any primary target population or primary target sensitive environment, assign the waste characteristics score (WC) that you calculated using PA Table 1 (Section 3.2.2, and page 4 of the PA scoresheets) to factor \#9b. Assign the score under Column A if you scored "Suspected Release" for likelihood of release; under Column B if you scored "No Suspected Release." Do not evaluate factor \#9a.

\subsubsection{Calculating the Air Pathway Score}

The air pathway scoresheet is organized by the three factor categories: Likelihood of Release (LR), Targets (T), and Waste Characteristics (WC). Enter the score for either Suspected Release (factor \#1) or No Suspected Release (factor \#2) into the box labeled "LR." Sum the Target scores (factors \#3 through 8) down the appropriate column and record the sum in the box labeled "T." Enter the Waste Characteristics score (factor \#9a or 9b) into the box labeled "WC." All scores should appear in either Column A or Column B, depending on your evaluation of Likelihood of Release.

Multiply LR $\times T \times W C$; divide the product by 82,500 ; round to the nearest integer; and record the result, subject to a maximum of 100 , as the air pathway score at the bottom of the page. If your calculated score exceeds 100, assign 100 as the pathway score. 


\subsection{SITE SCORE AND SUMMARY}

Calculate the site score by filling in the matrix at the top of page 24 of the PA scoresheets. Record each pathway score in the appropriate box under the column labeled "S." Square each pathway score, and record the result in the appropriate box under the column labeled " $S^{2}$." Sum the four $S^{2}$ values; divide the sum by 4 , take the square root of the result, round to the nearest integer, and record the result as the site score.

Answer the questions on page 24, of the PA scoresheets; these summarize important conclusions of the PA.

The questions ask for a qualitative evaluation of the relative risk of targets being exposed to hazardous substances from the site. You may find your responses to these questions a good cross-check against the way you scored the individual pathways. For example, if you scored the ground water pathway on the basis of no suspected release and secondary targets only, yet your response to question \#1 is "yes," this presents apparently conflicting conclusions that you need to reconsider and resolve. Answers to the questions on page 24 should be consistent with your evaluations elsewhere in the PA scoresheets package.

For affirmative responses regarding high risk to targets, the questions also ask you to identify specific targets. This information will be useful for next-step planning purposes. Attach additional pages if necessary. 


\section{REPORTING REQUIREMENTS}

In general, PA deliverables consist of three ẅwork products: data summary form, narrative report, and scoresheets.

\subsection{PA DATA AND SITE CHARACTERISTICS FORM}

A completed data' and site characteristics form, "Potential Hàzardous Waste Site Preliminary Assessment Form" (see Appendix D), is a standard product of every PA. The data form:

- Identifies and provides a place to record technical data to evaluate the site. " $"$

- Records administrative information to update and maintain CERCLIS.

- Records descriptive site information to update and maintain EPA's electronic database of characteristics of all CERCLIS sites (the CERCLIS Characterization Database).

The form can also function as a data collection tool, identifying all of the basic raw data required to score a PA. In addition, the form serves as a four-page summary of the PA scioresheets and narrative report, and as a mechanism to organize the information in a format compatible with data entry needs for CERCLIS and the CERCLIS Characterization Databàse.

Responses on the form need not be typed; legible handwriting is acceptable. When pröoduced by PA-Score, EPA's computerized version of the scoresheets (Section 4.3.2), completion of the form can be simplified. PA-Score can print the data form and draw on the data entered during site scoring to automatically transcribe most of the required information. After printing the form, users then manually transcribe the missing data elements.

\subsection{NARRATIVE REPORT}

A narrative report is a standard product of every PA. The report should summarize what is known about the site and what is inferred or assumed, the activities conducted during the PA, and all information researched. Following Regional EPA guidelines, the report may be a letter report or may stand alone, transmitted under a cover letter. Factual statements in the report should be keyed, by number, to a supporting reference. References not generally available to the public should be attached to the report. As one of the references, include worksheets showing the determination of site latitude and longitude coordinates according to EPA's standard operating procedure (Appendix E).

The narrative portion of the report should be brief and written in plain English. Avoid using HRS terminology. Certain PA terminology, however, is acceptable. For example:

\section{Consider using:}

suspected release primary target

secondary target aquifer in use

4-mile radius

15-mile downstream distance
Instead of:

observed release

actual contamination

potential contamination aquifer of concern target distance limit in-water segment

Table 4-1 presents an annotated outline of the PA report. Depending on the complexity of the site and the amount of information presented, typical narratives may range from 3 to 4 pages up to 8 
to 10 pages in length (excluding attachments and references). The main body of the report is structured like the PA itself, beginning with site and source characterization, and moving logically through an examination of the threats and targets associated with each pathway. The "Summary and Conclusions" section should summarize the most important characteristics of the site, and identify major pathways and targets of concern.

To foster national consistency in the content of PA narratives and to aid the successful application of the national QC/QA program, both the structure and content of each PA report should follow the outline given in Table 4-1 as a minimum requirement. At Regional EPA discretion, additional information not identified in the outline may also be included. Appendix $C$ presents an example PA narrative report for a fictitious site.

The narrative report plays a particularly important role as a vehicle for public information about the site and about this PA thầt was conducted. It.is therefore important that it contain sufficient information and documentation to support EPA's decision-making process for site disposition. For a NFRAP site, this means convincingly demonstrating that further Superfund activity is not necessary. For a further action site, this means showing sufficient indications of a need for response -- which may take the form of emergency removal or an SI; in either case, the PA narrative provides the basis for next-step planning.

Note, however, that PA narratives should be restricted to factual statements. PA scores and site disposition recommendations, which EPA considers deliberative and potentially protected from disclosure, should not be stated in narrative reports. PA investigators should check with Regional EPA personnel to ensure that PA reports are consistent with current EPA policy on release of PA information. 
Table 4-1

PA Narrative Report, Outline of Contents

\section{INTRODUCTION}

- State that a PA was performed, name the agency or organization performing it, and state the authority under which it was conducted (i.e., CERCLA as amended by SARA, and EPA contract or cooperative agreement). Include the site name, CERCLIS identification number, and location (street address, city, county, stațe).

- Briefly state the purpose of the PA (i.e., to assess the immediate or potential threat wastes at the site pose to human health and the environment and to collect information to support a decision regarding the need for further action under CERCLA/ȘARA) and the scope of the investigation (e.g., research and review file information, comprehensive target survey, and an offsite or onsite reconnaissance).

\section{SITE DESCRIPTION, OPERATIONAL HISTORY, AND WASTE CHARACTERISTICS}

- State brief directions to the site. Provide latitude/longitude coordinates. Identify the type of site (e.g., plating facility, chemical plant), whether it is active or inactive, and years of operation. Describe its physical characteristics (e.g., dimensions, size, structures, buildings, borders, drainage patterns), and setting (e.g., topography, local land uses). Include a USGS 7.5-minute base map locating the site and showing a 1-mile radius. On the map, identify the surface water drainage route; nearest well, intake, and residence; wetlands and other sensitive environments. Include a drafted site sketch showing features on and around the site.

- Provide an operational history of the site. Identify current and former owners and operators, and describe site activities. Identify and describe wastes generated, quantities, disposal practices, and source areas." Indicate source areas on the sketch. Describe any removals, whether conducted by facility operators or regulatory authiorities.

- Describe past regulatory activities including permits, violations, and inspections by local, state, or Federal authorities. Present available analytical data in a table and discuss.

\section{PATHWAY AND ENVIRONMENTAL HAZARD ASSESSMENT}

\section{Ground Water}

- Describe the local geologic and hydrogeologic setting (e.g., stratigraphy, formations, aquifers, karst features, depth and permeability to the shallowest aquifer).

- On the basis of the site description, operational history, local geology and hydrogeology, and any available analytical data, state whether release of a hazardous substance from the site to ground water is suspected. If analytical data, are available, summarize them in a table.

- Discuss ground water use within a 4-mile radius. Identify the nearest drinking water well and state the distance to it. 'Quantify' drinking water populations served by wells within 4 miles. Differentiate between populations served by private wells and those served by municipal wells; identify blended systems. Identify drinking water wells suspected to be primary targets and quantify the populations associated with each. 
Table 4-1 (continued)

PA Narrative Report, Outline of Contents

\section{PATHWAY AND ENVIRONMENTAL HAZARD ASSESSMENT (continued)}

\section{Surface Water}

- Describe the local hydrologic setting, including site location with respect to floodplains, and the overland and downstream portions of the surface water migration path. State the distance from the site to the probable point of entry (PPE) to surface water. Identify the water bodies within a 15-mile downstream distance, and state the length of reach and flow characteristics of each. Include a drafted sketch of the surface water migration path.

- On the basis of the site description and operational.history, local hydrology, and any available analytical data, state whether release of a hazardous substance from the site to surface water is suspected. If analytical data are available, summarize them in a table.

- Indicate whether surface water within a 15-mile downstream distance supplies drinking. water. Identify each drinking water intake and state the distance from the PPE to the nearest intake. Quantify the drinking water population served by surface water and identify blended systems. Identify surface water intakes suspected to be primary targets and quantify the populations served by each.

- Indicate whether surface water along a 15-mile downstream distance supports fisheries. Identify each fishery and sțate the distance from the PPE to the nearest fishery; identify the fishery with the lowest flow characteristics. Identify fisheries suspected to be primary targets.

- Indicate whether sensitive environments are present in or adjacent to the surface water migration path (overland and along a 15-mile downstream distance). Identify each sensitive environment and state the distance from the PPE to the nearest; identify the sensitive environment with the lowest flow characteristics. Identify sensitive; environments suspected to be primary targets.

\section{Soil Exposure and Air}

- Indicate the number of onsite workers and the number of people who live onsite or within $\mathbf{2 0 0}$ feet of areas of known or suspected contamination. Identify schools and day care facilities onsite or within 200 feet of areas of known or suspected contamination, and state the number of attendees. Quantify the populations (residents, students, and workers) within 4 miles of the site; state the distance to the nearest regularly occupied onsite or offsite building. Identify sensitive environments onsite and within 4 miles of the site. Discuss the likelihood of a hazardous substance being released to the air. If analytical data are available, summarize them in a table. 
Table 4-1 (concludèd)

PA Narrative Report, Outline of Contents

\section{SUMMARY AND CONCLUSION}

- Briefly summarize the major aspects of the site and its history that relate to the potential for releases of hazardous substances and the exposure of targets. Identify principal pathways and targets of concern. Discuss additional qualitative considerations or unusual circumstances that should be brought to the attention of Regional EPA site assessment personnel.

\section{PHOTODOCUMENTATION LOG}

- As an attachment, provide original photographs of the site and pertinent site features (e.g., waste source areas, stained soil, stressed vegetation, drainage paths) taken during the site reconnaissance. Provide a written description on the back of each photo, in captions, or in an accompanying text: Key each photo to its location on the site sketch.

\section{REFERENCES}

- Provide a numbered list, in bibliographic citation format, of all references cited in the PA report.

- Attach copies of references cited in the.PA report. Include complete copies of sitespecific references (e.g., USGS topographic quads, records of communication, drinking water population apportionment and calculation worksheets, GEMS and other database printouts, waste handling records or shipping manifests). Include only the title page and pertinent excerpts of general references (e.g., geologic reports, census reports, other publicly available documents).

\subsection{PA SCORING}

Section 3 provides detailed instructions to complete a standard set of PA scoresheets to promote national consistency in PA evaluations. A copy of the scoresheets is provided as Appendix A. A computerized scoring tool, "PA-Score," is also available from EPA ("PA-Score Software, Users Manual \& Tutorial, Version 1," OSWER Directive 9345.1-111.

The PA scoresheets (and the PA-Score computer program) provide space to record reference numbers for each factor. The references and corresponding numbers should be the same as those cited in the PA narrative report (Section 4.2). Copies of the references are attached to the narrative and need not be included with the scoresheets.

To score analytical data from applicable sampling results (as a result of the site review, Section 5.3), complete the SI worksheets (see "Guidance for Performing Site Inspections Under CERCLA, Interim FY 1992"; OSWER Directive 9345.1-05). If the site review leads to the more detailed evaluation of ground water pathway potential to release (Section 5.4), include worksheets explaining the evaluation along with additional ground water pathway and site summary scoresheets. 


\subsubsection{Scoresheets}

The PA scoresheets contain checklists, worksheets, factor value tables, scoring forms, and brief instructions. The package functions as a self-contained workbook providing all of the basic tools to apply collected data and develop a PA score. Right-hand (numbered) pages contain the scoresheets, worksheets, and tables; left-hand (unnumbered) pages contain corresponding instructions. When photocopy duplicating scoresheets for multiple deliverable or file copies, it is only necessary to copy the right-hand pages.

PA scoresheets are available from EPA. Regional guidelines may recommend the use of other scoring materials. The standard PA scoresheets are considered the minimum scoring requirement; Regions, however, may require additional evaluations.

\subsubsection{PA-Score}

EPA developed the PA-Score computer program to automate PA evaluations. PA-Score facilitates scoring by assigning values from tables, performing calculations, and producing PA documentation. PA-Score shares the same basic design and structure as PREscore, EPA's software to calculate HRS scores during the SI. PA-Score requires no specialized computer experience or equipment beyond an IBM (or compatible) personal computer. From the data PA investigators provide on the data entry screens (which resemble the PA scoresheets), PA-Score performs all factor value table look-ups and mathematical calculations. A companion program, PA-Print, prints PA scoresheets, a reference log, and the PA data and site characteristics form. Users of PA-Score should submit a floppy diskette, along with hardcopy printout, as a deliverable.

\subsection{ABBREVIATED REPORTING}

Sites determined ineligible for CERCLA response by Regional EPA site assessment personnel, and purported sites that are determined not to actually exist, do not undergo a complete PA (see Section 2.2). For such sites, the typical PA reporting requirements are abbreviated.

A narrative report remains a requirement. The report, however, may be limited to the "Introduction," "Site Description, Operational History, and Waste Characteristics," and "Summary and Conclusions" sections outlined in Table 4-1. The narrative should present and fully support all of the information that led to.EPA's decision to cease PA investigation at the site. As with a full PA report, factual statements within the narrative must be documented, and appropriate references or excerpts must be attached.

Only the first two pages of the PA data and site characteristics form (Appendix D) are required for abbreviated PA sites. These pages provide necessary administrative information and general descriptive information about the site and associated wastes (if any).

PA scoresheets (Appendix A) or computerized PA-Score site scoring need not be completed for abbreviated PA sites.

Note that these abbreviated reporting requirements apply only to "non-sites" that are determined to be nonexistent, and sites determined ineligible for CERCLA response. Lack of targets is not an acceptable reason to abbreviate either the PA investigation or the standard reporting requirements. Sites lacking targets must be fully documented by a complete narrative report, fully evaluated using either the PA scoresheets or PA-Score software, and summarized by a completed data and site characteristics form. 


\section{REVIEWS}

The PA investigator should conduct a detailed review of the PA report and scoresheets, particularly for internal consistency, as a quality control mechanism. A second reviewer with considerable site assessment experience should then examine the package to assure consistency, and to provide an independent evaluation of PA hypotheses. The reviewer should also evaluate the package to determine if special circumstances exist where detailed analytical data and/or ground water: potential to release factors could be applied to reduce the number of further action siterecommendations ("false positives").

The site review assures an appropriate site disposition recommendation.' For a site receiving a NFRAP recommendation, this means assuring that the judgments and data reasonably support the conclusion that the site poses little threat, or that EPA's policy is to address the site under other statutory authority. For a site receiving a further action recommendation, the review assures that the PA evaluation reasonably supports the need for further investigation. In some cases, the review may identify an opportunity to apply additional information that could result in a NFRAP recommendation.

\subsection{REVIEW FOR INTERNAL CONSISTENCY}

Both the PA investigator and a second independent reviewer should review the PA written products to assure internal consistency in the information and hypotheses recorded in the report and on the data summary form and scoresheets.

An important quality assurance objective is to find and correct errors of consistency. For example, primary targets are targets suspected to be exposed to contamination by a hazardous substance; also, a release must be hypothesized to score primary targets, because a target cannot be exposed to contamination unless a hazardous substance has migrated. A scenario in which the PA. investigator scored primary targets without also scoring a suspected release would represent a . significant inconsistency indicating either an error or a flawed conclusion. In either case, a discrepancy such as this, if undetected, could contribute to an inappropriate site disposition recommendation. Identifying such a discrepancy directs the PA investigator and site reviewer to reexamine the evaluation and resolve the apparent conflict.

The PA scoresheets contain several mechanisms that can assist the review for internal consistency:

- Criteria Lists (pages 7, 11, 18, 21) summarize considerations and rationale leading to hypotheses regarding suspected releases and exposure of targets. Scores assigned to likelihood of release and targets for each pathway should be consistent with conclusions drawn from the Criteria Lists.

- Pathway Characteristics boxes (pages $8,12,19,22$ ) summarize information for key factors to evaluate each pathway. Factor scores should be consistent with the information in the Pathway Characteristics box.

- Scoring Columns "A" and "B" for Suspected Release and No Suspected Release are designed to prevent assigning scores to factors that do not apply. For example, there can be no primary targets when "No Suspected Release" (Column $B$ ) is scored; therefore, the primary target boxes are shaded to restrict scoring in Column B. For each pathway, scores must appear in only one column. 
- Waste characteristics and targets scoring tables (PA Tables 1 through 10) provide for immediate cross-checking of assigned factor values against the values and evaluations recorded in each table.

- The summary questions (page 24) ask for qualitative evaluations of the relative risk of targets being exposed to hazardous substances associated with the site. The identification of targets as primary or secondary should be consistent with responses to these questions.

Table 5-1 provides examples of how these mechanisms can be used to review release and target evaluations for each pathway (page numbers refer to PA scoresheets page numbers).

\subsection{REVIEW OF PA HYPOTHESES}

Regional EPA site assessment personnel conclude a site disposition decision based primarily on the. site score. In general, sites that score $\mathbf{2 8 . 5 0}$ or greater receive a further action recommendation, while sites that score less than 28.50 receive a NFRAP recommendation. . The PA score is most sensitive to targets values. In particular, primary targets are weighted heavily. During the PA, however, analytical data to definitively support or reject the occurrence of releases and exposure of targets may not be available; PA investigators rely on available information and professional judgment to form hypotheses on these points. As these hypotheses strongly influence the PA score, it is particularly important that they be reasonable and well-founded, both in fact and in necessary conservatism when facts are limited.

The review for internal consistency (Section 5.1) may identify inconsistencies that could question the validity of a particular hypothesis or conclusion. This review alone, however, is not sufficient. The reviewer must also evaluate the validity of each hypothesis.

The pathway-specific Criteria Lists guide the formulation of PA hypotheses. Investigators answer each question on the list and, when releases or primary targets are suspected, provide a brief statement summarizing the rationale for their hypothesis. The reviewer's function is to examine these responses and summary statements, in view of all that is known about the site, to assure that appropriate conclusions have been drawn.

Under some circumstances, experienced investigators may have differing interpretations of site conditions and make differing conclusions or hypotheses regarding the likelihood of a release and exposure of targets. Any such differences must be resolved during the review. If the reviewer's interpretations contradict the PA investigator's, the two should discuss the situation and reach a consensus. This aspect of the review identifies significant points about the site evaluation that may need detailed explanation in the PA narrative report (Section 4.2 ) to fully support the conclusions. Throughout the review, the PA investigator and site reviewer must keep in mind the need for conservative judgments in the absence of definitive proof to. avoid underestimating the potential threat -- which could lead to an inappropriate NFRAP recommendation. 


\section{Table 5-1 \\ Checklist for Internal Consistency}

Instructions: The PA scoresheets contain several mechanisms to aid review for internal consistency. The items listed beneath each factor or factor category heading identify questions on the PA scoresheets which support the evaluation of that factor or factor category. The reviewer should check for agreement between all responses. All page numbers refer to PA scoresheet page numbers.

\section{Ground Water Pathway}

\section{Likelihood of release}

Page 7, Criteria List, suspected release?

Page 8, Pathway Characteristics, suspected release question

口 Page 8, Likelihood of Release, item 1 or 2

$\square$ Page 8, Column A or B

If No Suspected Release is scored (all items listed above and the following):

Page 8, Pathway Characteristics, karst terrain and depth to aquifer

Page 8, Likelihood of Release, item 2

Primary targets

口 Page 7, Criteria List, primary targets identified?

- Page 8, Likelihood of Release, item 1

ㅁ Page 8, Targets, item 3

Page 8, Targets, item 5

口 Page 8, Waste Characteristics, item $8 \mathrm{a}$ or $8 \mathrm{~b}$

$\square$ Page 24, Summary question 1

Secondary targets

1] Page 8, Pathway Characteristics, distance to nearest well

Page 8, Pathway Characteristics, karst terrain

口 Page 8, Targets, item 4

ㅁage 8, Targets, item 5

$\square$ Page 9, PA Table $2 a$ or $2 b$

\section{Surface Water Pathway}

\section{Likelihood of release}

Page 11, Criteria List, suspected release?

口 Page 12, Pathway Characteristics, suspected release question

$\square$ Page 12, Likelihood of Release, item 1 or 2

ㅁ Pages 12,14, 15, and 17, Column A or B

If No Suspected Release is scored (all items listed above and the following):

Page 12, Pathway Characteristics, distance to surface water and flood frequency

Page 12, Likelihood of Release, item 2 


\section{Table 5-1 (concluded) \\ Checklist for Internal Consistency}

\section{Surface Water Pathway (concluded)}

\section{Primary targets}

Page 11, Criteria List, primary intake/fishery/sensitive environment identified?

$\square$ Page 12, Likelihood of Release, item 1

$\square$ Page 12, Drinking Water Threat Targets, item 4

$\square$ Page 12, Drinking Water Threat Targets, item 6

$\square$ Page 14, Human Food Chain Threat Targets, item 9

$\square$ Page 15, Environmental Threat Targets, item 12

$\square$ Page 17, Waste Characteristics, item $14 \mathrm{a}$ or $14 \mathrm{~b}$

$\square$ Page 24, Summary question 2

\section{Secondary targets}

$\square$ Page 12, Drinking Water Threat Targets, item 5

$\square$ Page 12, Drinking Water Threat Targets, item 6

Page 13, PA Table 3

$\square$ Page 14, Human Food Chain Threat Targets, item 10

$\square$ Page 15, Environmental Threat Targets, item 13

\section{Soil Exposure Pathway}

\section{Resident population}

Page 18, Criteria List, resident population identified?

Page 19, Pathway Characteristics, residents question

口 Page 19, Pathway Characteristics, students question

$\square$ Page 19, Resident Population Threat Targets, item 2

Page 19, Resident Population Threat Targets, item 3

$\square$ Page 24, Summary question 3

\section{Workers}

Page 19, Pathway Characteristics, active facility question

Page 19, Resident Population Threat Targets, item 4

\section{Air Pathway}

\section{Likelihood of release}

$\square$ Page 21, Criteria List, suspected release?

- Page 22, Pathway Characteristics, suspected release question

$\square$ Page 22, Likelihood of Release, item 1 or 2

$\square$ Page 22, Column A or B

Primary targets

Page 22, Likelihood of Release, item 1

$\square$ Page 22, Targets, item 3

$\square$ Page 22, Targets, item 5

$\square$ Page 22, Waste Characteristics, item 9a or 9b

Secondary targets

Page 22, Pathway Characteristics, distance to nearest individual

$\square$ Page 22, Targets, item 4

$\square$ Page 22, Targets, item 5

Page 23, PA Table 8 


\subsection{REVIEW OF AVAILABLE ANALYTICAL DATA}

This guidance document has emphasized the need to exercise conservative judgments in the absence of definitive proof during the PA. Section 3.1 discusses limitations and potential pitfalls that may be associated with analytical data available to the PA. In general, whether analytical data are available or not, investigators should follow the guidelines in Section 3.1. However, comprehensive and reliable analytical data may be available for some sites. Upon completing the PA scoresheets, review available data to determine whether a more detailed approach can be employed. In brief, this can occur when the following two conditions hold:

(1) The available data are equivalent in quality and comprehensiveness to data that would be obtained from an EPA-sponsored SI sampling program; and

(2) The approach followed in Section 3.1 results in a further action recommendation that could be reversed by applying analytical data in place of standard PA conservative assumptions.

\subsubsection{Rationale for the Standard PA Approach to Analytical Data}

Three major areas of the HRS directly apply analytical data: substantiating or ruling out observed releases; substantiating or ruling out actual contamination of specific targets and differentiating between Level I or Level II; and determining substance-specific hazardous waste characteristics (e.g., toxicity, mobility, persistence, bioaccumulation potential). Recognizing that quality analytical data that definitively support these determinations are often not available at the PA, and consistent with streamlining the HRS for PA evaluations, the standard PA:

- Makes use of professional judgments to identify suspected releases and targets suspected to be exposed to actual contamination, and

- Builds in assumptions for waste characteristics and level of target contamination.

Releases and Target Contamination

Section 3.1 advises that PA investigators may always use analytical data indicating the presence of hazardous substances in environmental media or at specific targets to support hypotheses of suspected releases and primary targets. For PA purposes, such indications are sufficient to warrant a conservative judgment that a problem likely exists; documentation to HRS levels of certainty is not necessary.

Conversely, PA investigators may also always use analytical data in combination with qualitative knowledge of the site, site environs, and target characteristics, to support hypotheses that releases have not occurred and that there are no primary targets. However, PA investigators should not rely on analytical data alone to rule out the occurrence of releases or actual contamination of targets, unless those data are equivalent in quality and comprehensiveness to data that would be obtained from an EPA-sponsored SI (Section 5.3.2).

\section{Differentiating Levels of Target Contamination}

Caution is advisable when attempting to apply analytical data to differentiate between Level I and Level II actual contamination. The standard PA builds in an assumption that primary targets are contaminated at Level I. Even when analytical data are available, differentiating levels of contamination on the basis of a one-time sampling event may not be prudent if, for example, a determination of Level II contamination results in a NFRAP recommendation while Level I contamination would result in a further action recommendation (this can be a problem for Sls as 
well as PAs). In such a case, conservative PA scoring at Level I is appropriate regardless of available analytical data, as further sampling may substantiate the higher level of contamination.

\section{Waste Characteristics}

In most cases it is prudent to assume maximum contaminant chemical properties and not evaluate specific substances and their. associated characteristics. This conservative approach is often .: appropriate even when analytical data or qualitative knowledge of the hazardous substances likely. to be associated with a site indicates otherwise. Ruling out the possibility of a hazardous substance with maximum contaminant properties implies that the site and its sources have been adequately sampled, and those samples have been adequately analyzed, to identify all hazardous substances associated with the site. Further, substance speciation, metabolites, degradation products, and impurities could be present that may be neither suspected by the PA investigator nor analyzed for by the laboratory. For example:

- The PA investigator may suspect that a dry cleaning or solvent recycling facility may have only handled solvents such as tetrachloroethane (PCA), tetrachloroethene (PCE), trichloroethane (TCA), and trichloroethene (TCE), which have HRS-assigned toxicity values ranging from 10 to 1,000 . However, vinyl chloride, a degradation product of TCE, may also be present. Vinyl chloride has an HRS-assigned toxicity value of 10,000 , the maximum (U.S. Environmental Protection Agency, 1991. Superfund Chemical Data Matrix (SCDM), May 10).

- File information and pre-existing analytical data may indicate that a particular wood treating site used pentachlorophenol (PCP), with an HRS-assigned toxicity value of 100, as its sole preservative agent. However, various forms of dioxin (with. HRS-assigned toxicity values as high as 10,000 ) may also be present as impurities associated with the manufacture of PCP.

\subsubsection{Assessing the Applicability of Available Analytical Data}

Some available analytical data may be appropriate to allow more detailed evaluation to:

- Rule out the occurrence of a release

- Rule out actual contamination of specific targets

- Differentiate Level I and Level II contamination of targets

- Rule out the presence of a hazardous substance. with maximum contaminant characteristics

An advantage to applying such data is the potential to screen out sites that do not warrant further investigation. Properly applied, the conservative approach of the standard PA will not result in inappropriate NFRAP recommendations (i.e., "false negatives"). However, it can result in some sites receiving further action recommendations that are later screened out of the Superfund process with the collection of quality analytical data. In some cases, the application of SI quality analytical data can demonstrate that a significant problem does not exist, thus obviating the need for an SI and permitting a confident NFRAP recommendation. Determining whether available data for a particular site are of sufficient quality and confidence to be applied as SI-generated data requires . the professional judgment of an experienced reviewer.

The strategic approach to develop an SI sampling plan is discussed in EPA's "Guidance for Performing Site Inspections Under CERCLA, Interim FY 92" (OSWER Directive 9345.1-05); the site reviewer should be thoroughly familiar with this guidance. In brief, the sampling objectives of the $\mathrm{SI}$ are designed to answer the questions that the standard PA typically addresses via assumptions and professional judgment: 
- What hazardous substances are associated with the site?

- Have releases occurred?

- Are specific targets contaminated by hazardous substances released from the site and, if so, what is the level of contamination?

For Superfund site assessment purposes, analytical data generated during an SI must confidently answer these questions. Analytical data available at the PA must also be sufficient to confidently answer these questions, if those data are applied to override the conservative assumptions of the standard PA approach. To be considered SI quality, existing analytical data must meet the following tests:

- Strategic value. The design of the sampling program must be similar to that for an $\mathrm{SI}$, which typically includes sources, environmental media, and targets. It would be difficult to confidently evaluate hazardous substance contaminant characteristics if sources were not sampled; to confidently rule out the occurrence of a release if appropriate environmental media were not sampled; or to confidently rule out actual contamination of targets and differentiate between Level I and Level II if targets were not sampled.

- Comprehensiveness. Mere availability of analytical data, including source, environmental media, and target samples is not, in itself, sufficient. The extent of samples and sample locations: also must be considered and must be compatible with an EPA-sponsored SI sampling plan for the site. Even if dozens of samples were collected, the site reviewer must consider, for example, whether:

- Sources have been adequately sampled to confidently identify all hazardous substances or show'no hazardous substances present.

- The number and placement of environmental media samples are appropriate and adequate (e.g., depth of monitoring wells, probable points of entry to surface water, areas of evident surficial contamination) to detect or rule out the occurrence of a release.

- Targets selected for sampling are appropriately identified as the most likely to be exposed to released substances.

- Analytical confidence. Analytical and QA/QC procedures employed by the laboratory must be known. Limited, rather than full-spectrum, analyses may not be adequate to identify all hazardous substances that may be present. Detection limits of laboratory equipment and methods, and the QA/OC procedures to validate the results, must also be of a sufficient level of confidence.

- Representativeness. The age of the data must be knowri and the site reviewer must consider whether the data are representative of current conditions. In the time since the site was sampled, releases may have occurred and hazardous substances may have migrated to targets.

\subsubsection{Applying Analytical Data}

If the site reviewer concludes that available analytical data are of SI quality, those data may be applied to override the standard PA evaluations of waste characteristics, releases, and target contamination. : Note that, if the data do not meet all tests, their application may be limited and they may not necessarily be useful in all three categories. Also, remember that the standard PA approach is conservative; therefore it is not necessary to apply the more detailed scoring 
evaluation if the data support the PA assumption of maximum waste characteristics and/or PA hypotheses of suspected releases and primary targets. Key questions are:

- Do the data rule out maximum waste characteristics?

- Do the data rule out a release?

- Do the data rule out actual contamination of targets?

- If the data support actual contamination of targets, do they rule out Level I contamination?

If the answer to one or more of these questions is "yes," applying the data in the same way as SI scoring could screen the site from further action. To do this, use the SI worksheets contained in EPA's "Guidance for Performing Site Inspections Under CERCLA, Interim FY 92" (OSWER Directive 9345.1-05).

Use SI worksheets and tables to record and evaluate anaiytical data regarding hazardous substance identification and contaminant characteristics, releases, and contamination of targets. Otherwise, the information requirements of the SI worksheets are the same as the PA scoresheets. Thus, aside from analytical data, the SI worksheets require no additional information beyond the standard PA scoresheets. The SI worksheets and tables are discussed in EPA's "Guidance for Performing Site Inspections Under CERCLA, Interim FY 92" (OSWER Directive 9345.1-05).

\subsection{REVIEW OF GROUND WATER PATHWAY POTENTIAL TO RELEASE}

A PA hypothesis of "no suspected release" is analogous to an HRS evaluation of potential to release. When a release to ground water is not suspected, the standard PA assigns a potential to release value on the basis of depth to aquifer. If depth to aquifer is 70 feet or less, a value of 500 is assigned; if greater than 70 feet, a value of 340 is assigned. In cases where the depth to aquifer is considerably greater than 70 feet, the assigned value of 340 may be too conservative and could result in an unnecessary recommendation for further investigation, whereas a more detailed evaluation could lead to a confident NFRAP recommendation.

The PA review should examine the ground water pathway evaluation to determine if a more detailed approach to potential to release is appropriate. Figure 5-1 presents a decision tree for the review process. The more detailed potential to release evaluation will only be useful when all four questions are answered with a "yes":

- Is the site score $\geq 28.50$ ? If the PA score is less than 28.50 , the site receives a NFRAP recommendation and there is no benefit in pursuing a more accurate -- but lower -- potential to release value.

- Is the site score < 28.50 without consideration of the ground water pathway? Calculate the PA site score using only the surface water, soil exposure, and air pathway scores. If the result is $\mathbf{2 8 . 5 0}$ or greater without considering the ground water pathway, a refined evaluation of ground water potential to release will not screen the site from further action.

- Is ground water evaluated on the basis of "no suspected release"? Because a "no -suspected releasen evaluation is analogous to HRS potential to release, further evaluation of potential to release can only occur for sites where a release is not suspected. If, instead, the site investigator scored a suspected release for the ground water pathway, the question of potential to release is moot. 
Figure 5-1

Decision Tree for Review of Ground Water Pathway Potential to Release

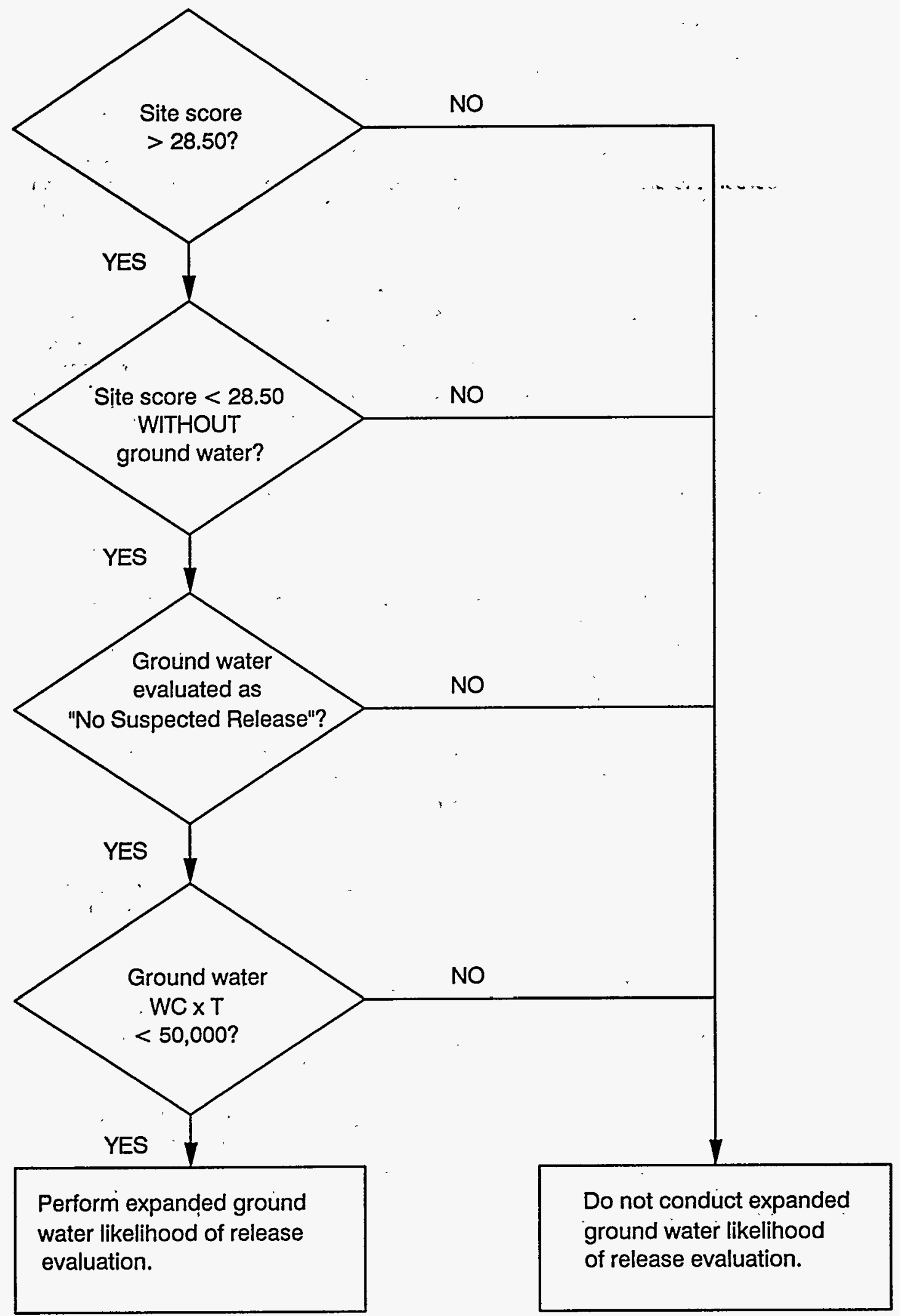


- Is the product of waste characteristics and targets (WC $\times$ T) less than 50,000? A refined evaluation of potential to release will only lower the pathway score sufficiently to result in a NFRAP recommendation if the product of waste characteristics and targets factor category scores is less than a minimum threshold. A product greater than 50,000 results in a NFRAP recommendation only if the potential to release score is less than 100. EPA's empirical analyses of HRS field test sites indicate that such low potential to release scores are very unusual; therefore, pursuing the more detailed evaluation of potential to release is not recommended unless the product of waste characteristics and targets is less than 50,000 .

The more detailed evaluation of potential to release for sites that meet these conditions departs from the standard PA approach of a streamlined HRS evaluation and requires complete evaluation of all HRS potential to release factors for the ground water pathway -- with the exception of source containment. Containment need not be evaluated because very few CERCLIS sites consist entirely of perfectly contained sources.

For sites that meet the four conditions listed above, the PA investigator may evaluate potential to release factors according to Section 3.1.2 of the HRS (55 FR 51595, December 14, 1990). These factors are:

- Net precipitation

- Depth to aquifer

- Travel time, based on hydraulic conductivity and thickness of the layer of lowest hydraulic conductivity

The site investigator should also complete the standard PA scoresheets when applying this more detailed evaluation of ground water potential to release. As an attachment, include worksheets detailing the evaluation of the HRS potential to release factors. Also include a second completed ground water pathway scoresheet (page 8 of the. PA scoresheets), inserting the calculated potential to release value, and a second completed site score calculation (page 24 of the PA scoresheets). 


\section{REFERENCES}

U.S. Congress, 1976. Resource Conservation and Recovery Act of 1976: Public Law 94-580.

U.S. Congress, 1980. Comprehensive Environmental Response, Compensation, and Liability Act of 1980. Public Law 96-510.

U.S. Congress, 1984. Hazardous and Solid Waste Amendments Act of 1984. Public Law 98-616.

U.S. Congress, 1986. Superfund Amendments and Reauthorization Act of 1986. Public Law 99499.

U.S. Environmental Protection Agency, 1987. Section 404(b)(1) Guidelines for Specification of Disposal Sites for Dredged or Fill Material; Definitions. 40 CFR 230.3(t).

U.S. Environmental Protection Agency, 1987. Hazardous Waste Management System: General; Definitions. 40 CFR 260.10.

U.S. Environmental Protection Agency, 1987. Identification and Listing of Hazardous Waste; Definition of Hazardous Waste. 40 CFR 261.3.

U.S. Environmental Protection Agency, 1988. Preliminary Assessment Petition. Office of Emergency and Remedial Response. Publication 9200.5-301FS.

U.S. Environmental Protection Agency, 1989. National Priorities List for Uncontrolled Hazardous Waste Sites -- Final Rule Covering Sites Subject to the Subtitle $\mathrm{C}$ Corrective Action Authorities of the Resource Conservation and Recovery Act. 54 FR 41000, October 4, 1989.

U.S. Environmental Protection Agency, 1990. Hazard Ranking System; Final Rule. 55 FR 51532 , December 14, 1990.

U.S. Environmental Protection Agency, 1990. National Oil and Hazardous Substances Pollution Contingency Plan. 40 CFR Part 300. 55 FR 8666, March 8, 1990.

U.S. Environmental Protection Agency, 1990. Superfund Removal Procedures. Office of Solid Waste and Emergency Response. Directive 9360.3-01.

U.S. Environmental Protection Agency, 1991. Guidance for Performing Site Inspections Under CERCLA, Interim FY 92. Office of Solid Waste and Emergency Response. Directive 9345.1-05 (in development).

U.S. Environmental Protection Agency, 1991. Hazard Ranking System (HRS) Guidance Manual. Office of Solid Waste and Emergency Response. Directive 9345.1-07 (in development).

U.S. Environmental Protection Agency, 1991. PA-Score Software, Users Manual \& Tutorial, Version 1.0. Office of Solid Waste and Emergency Response. Directive 9345.1-11.

U.S. Environmental Protection Agency, 1991. PREscore Software, Users Manual \& Tutorial, Version 1.0. Office of Solid Waste and Emergency Response. Directive 9345.1-04.

U.S. Environmental Protection Agency, 1991. Regional Quality Control Guidance for NPL Candidate Sites. Office of Solid Waste and Emergency Response. Directive 9345.1-08. 
U.S. Environmental Protection Agency, 1991. The Revised Hazard Ranking System: Policy on Evaluating Sites After Waste Removal. Office of Solid Waste and Emergency Response.

Publication 9345.103FS.

U.S. Environmental Protection Agency, 1991. Site Assessment Information Directory. Site Assessment Branch, Hazardous Site Evaluation Division, Office of Emergency and Remedial Response.

U.S. Environmental Protection Agency, 1991. Superfund Chemical Data Matrix (SCDM). May 10. 


\section{GLOSSARY}

Apportioned population: In the evaluation of drinking water target populations associated with a blended system, that portion of the population evaluated as being served by an individual well or intake within the system.

Aquifer: A saturated subsurface zone from which drinking water is drawn.

Blended system: A drinking water supply system which can or does combine (e.g., via connecting valves) water from more than one well or surface water intake, or from a combination of wells and intakes.

CERCLA: Comprehensive Environmental Response, Compensation, and Liability Act of 1980.

CERCLA Information System: CERCLIS, EPA's computerized inventory and tracking system for potential hazardous waste sites.

CERCLIS: CERCLA Information System.

Coastal tidal waters: Surface water body type that includes embayments, harbors, sounds, estuaries, back bays, etc. Such water bodies are in the interval seaward from the mouths of rivers and landward from the 12-mile baseline marking the transition to the ocean water body type.

Comprehensive Environmental Response, Compensation, and Liability Act of 1980: Legislation that established the Federal Superfund for response to uncontrolled releases of hazardous substances to the environment.

Contaminated soil: Soil onto which available evidence indicates that a hazardous substance was spilled, spread, disposed, or deposited.

Depth to aquifer: The vertical distance between the deepest point at which hazardous substances are suspected and the top of the shallowest aquifer that supplies drinking water.

Distance to surface water: The shortest distance that runoff would follow from a source to surface water.

Drinking water population: The number of residents, workers, and students who drink water drawn from wells or surface water intakes located within target distance limits,

Drums: Portable containers designed to hold a standard 55-gallon volume of wastes.

Emergency response: See "removal."

Factor: The basic element of site assessment requiring data collection and evaluation for scoring purposes.

Factor category: A set of related factors. Each pathway consists of three factor categories -likelihood of release or exposure, targets, and waste characteristics.

Federal Register: Daily publication of the Government Printing Office; contains public notices, rules, and regulations issued by the Federal Government. Cited as "<volume > FR <page >." 
FEMA: Federal Emergency Management Agency.

Fishery: An area of a surface water body from which food chain organisms are taken or could be taken for human consumption on a subsistence, sporting, or commercial basis. Food chain organisms include fish, shellfish, crustaceans, amphibians, and amphibious reptiles.

\section{FR: Federal Register.}

GEMS: Geographical Exposure Modeling System.

Geographical Exposure Modeling System: Population database maintained by EPA's Office of Toxic Substances; provides residential populations in specified distance rings around a point location.

Hazard Ranking System: EPA's principal mechanism for placing sites on the NPL.

Hazardous constituent: Hazardous substance.

Hazardous substance: Material defined as a hazardous substance, pollutant, or contaminant in CERCLA Sections 101(14) and 101(33).

Hazardous waste: Any material suspected to contain a hazardous substance, pollutant, or contaminant that is or was in a source.

HRS: Hazard Ranking System.

Karst: A kind of terrain with characteristics of relief and drainage arising from a high degree of rock solubility. The majority of karst conditions occur in limestone areas, but karst may also occur in areas of dolomite, gypsum, or salt deposits. Features associated with karst terrain may include irregular topography, abrupt ridges, sinkholes, caverns, abundant springs, disappearing streams, and a general lack of a well-developed surface drainage system of tributaries and streams.

Lake: A type of surface water body which includes:

- Natural and artificially-made lakes or ponds that lie along rivers or streams (but excluding the Great Lakes):

- Isolated but perennial lakes, ponds, and wetlands.

- Static water channels or oxbow lakes contiguous to streams or rivers.

- Streams or small rivers, without diking, that merge into surrounding perennially-inundated wetlands.

- Wetlands contiguous to water bodies defined as lakes are considered to be part of the lake.

Landfill: An engineered (by excavation or construction) or natural hole in the ground into which wastes have been disposed by backfilling, or by contemporaneous soil deposition with waste disposal, covering wastes from view.

Land treatment: Landfarming or other land treatment method of waste management in which liquid wastes or sludges are spread over land and tilled, or liquids are injected at shallow depths into soils. 
National Contingency Plan: Regulation that establishes roles, responsibilities, and authorities for responding to hazardous substance releases. The NCP established the HRS as the principal mechanism for placing sites on the NPL.

National Priorities List: Under the Superfund program, the list of releases and potential releases of hazardous substances, pollutants, and contaminants that appear to pose the greatest threat to public health, welfare, and the environment.

NCP: National Oil and Hazardous Substances Pollution Contingency Plan, commonly known as the National Contingency Plan.

NFRAP: No further remedial action planned; site disposition decision that further response under the Federal Superfund is not necessary.

No suspected release: A professional judgement conclusion based on site and pathway conditions indicating that a hazardous substance is not likely to have been released to the environment. (No suspected release is the PA term analogous to the HRS "potential to release.")

NPL: National Priorities List.

Ocean: A type of surface water body which includes:

- Ocean areas seaward from a baseline distance of 12 miles from shore.

- The Great Lakes, along with wetlands contiguous to them.

PA: Preliminary assessment.

PA-Score: EPA's computer program that automates PA site scoring.

Pathway: The environmental medium through which a hazardous substance may threaten targets. The PA evaluates the migration and threat potential through the ground water, surface water, air, and soil exposure pathways.

Pile: Any non-containerized accumulation above the ground surface of solid, non-flowing wastes; includes open dumps. Some types of piles are: Chemical Waste Pile -- consists primarily of discarded chemical products, by-products, radioactive wastes, or used or unused feedstocks; Scrap Metal or Junk Pile -- consists primarily of scrap metal or discarded durable goads such as appliances, automobiles, auto parts, or batteries, composed of materials suspected to contain or have contained a hazardous substance; Tailings Pile -- consists primarily of any combination of overburden from a mining operation and tailings from a mineral mining, beneficiation, or processing operation; Trash Pile -- consists primarily of paper, garbage, or discarded non-durable goods which are suspected to contain or have contained a hazardous substance.

PPE: Probable point of entry.

Preliminary assessment: Initial stage of site assessment under Superfund; designed to distinguish between sites that pose little or no threat to human health and the environment and sites that require further investigation.

PREscore: EPA's computer program that automates site scoring with the Hazard Ranking System. 
Primary target: A target which, based on professional judgement of site and pathway conditions and target characteristics, has a relatively high likelihood of exposure to a hazardous substance. (Primary target is the PA term analogous to the HRS target exposed to Level l.or Level II actual contamination.)

Probable point of entry: The point at which runoff from the site most likely enters surface water.

\section{RCRA: Resource Conservation and Recovery Act of 1976.}

Removal: An action taken to eliminate, control, or otherwise mitigate a threat posed to the public health or environment due to release or threatened release of a hazardous substance. Removals are relatively short-term actions to respond to situations requiring immediate action.

Resident: A person whose place of residence (full- or part-time) is within the target distance limit.

Resident individual: Under the soil exposure pathway, a resident or student within 200 feet of any area of suspected contamination associated with the site.

Resident population: Under the soil exposure pathway, the number of residents and students within 200 feet of any area of suspected contamination associated with the site.

Resource Conservation and Recovery Act of 1976: Legislation that established cradle-to-grave accountability for hazardous wastes, from point of generation to point of ultimate disposal.

SARA: Superfund Amendments and Reauthorization Act of 1986.

Secondary target: A target which, based on professional judgement of site and pathway conditions and target characteristics, has a relatively low likelihood of exposure to a hazardous substance. (Secondary target is the PA term analogous to the HRS target exposed to potential contamination.)

Sensitive environment: A terrestrial or aquatic resource, fragile natural setting, or other area with unique or highly-valued environmental or cultural features.

SI: Site inspection.

Site: The area consisting of the aggregation of sources, the areas between sources, and areas that may have been contaminated due to migration from sources; site boundaries are independent of property boundaries.

Site inspection: Second stage of site assessment under Superfund, conducted on sites that receive a further action recommendation after the PA; builds on PA information and typically includes sampling to identify hazardous substances, releases, and contaminated targets; identifies sites that pose the greatest threats to human health and the environment.

Source: An area where a hazardous substance may have been deposited, stored, disposed, or placed. Also, soil that may have become contaminated as a result of hazardous substance migration. In general, however, the volumes of air, ground water, surface water, and surface water sediments that may have become contaminated through migration are not considered sources.

Stream flow: The average rate of flow of a water body, expressed in cubic feet per second (cfs). 
Stream or river: A type of surface water body which includes:

- Perennially-flowing waters from point of origin to the ocean or to coastal tidal waters, whichever comes first, and wetlands contiguous to these flowing waters.

- Aboveground portions of disappearing rivers.

- Artificially-made ditches only insofar as they perennially flow into other surface water.

- Intermittently-flowing waters and contiguous intermittently-flowing ditches in areas where mean annual precipitation is less than 20 inches.

Student: A full- or part-time attendee of a daycare facility or educational institution located within the target distance limit.

Superfund Amendments and Reauthorization Act of 1986: Legislation which extended the Federal Superfund program and mandated revisions to the HRS.

Surface impoundment: A topographic depression, excavation, or diked area, primarily formed from earthen materials (lined or unlined) and designed to hold accumulated liquid wastes; wastes containing free liquids, or sludges that were not backfilled or otherwise covered during periods of deposition; depression may be dry if deposited liquid has evaporated, volatilized or leached, or wet with exposed liquid; structures that may be more specifically described as lagoon pond, aeration pit, settling pond, tailings pond, sludge pit, etc.; also a surface impoundment that has been covered with soil after the final deposition of waste materials (i.e., buried or backfilled).

Surface water: A naturally-occurring, perennial water body; also, some artificially-made and/or intermittently-flowing water bodies. See "water body type" and subsequent definitions for more detail.

Suspected release: A professional judgement conclusion based on site and pathway conditions indicating that a hazardous substance is likely to have been released to the environment. (Suspected release is the PA term analogous to the HRS "observed release.")

Tanks and non-drum containers: Any stationary device, designed to contain accumulated wastes, constructed primarily of fabricated materials (such as wood, concrete, steel, or plastic) that provide structural support; any portable or mobile device in which waste is stored or otherwise handled.

Target: A physical or environmental receptor that is within the target distance limit for a particular pathway. Targets may include wells and surface water intakes supplying drinking water, fisheries, sensitive environments, and resources.

Target distance limit: The maximum distance over which targets are evaluated. The target distance limit varies by pathway: ground water and air pathways -- a 4-mile radius around the site; surface water pathway - 15 miles downstream from the probable point of entry to surface water; soil exposure pathway -- 200 feet (for the resident population threat) and 1 mile (for the nearby population threat) from areas of known or suspected contamination.

Target population: The human population associated with the site and/or its targets. Target populations consist of those people who use target wells or surface water intakes supplying drinking water, consume food chain species taken from target fisheries, or are regularly present on the site or within target distance limits. 
Terrestrial sensitive environment: A terrestrial resource, fragile natural setting, or other area with unique or highly-valued environmental or cultural features.

USF\&WS: U.S. Fish and Wildlife Service.

USGS: U.S. Geological Survey.

Water body type: Classification of a surface water body. Water body types include: streams and rivers; lakes; oceans (includes the Great Lakes); and coastal tidal waters. See the specific definition of each water body type for more detail.

Wetland: A type of sensitive environment characterized as an area that is sufficiently inundated or saturated by surface or ground water to support vegetation adapted for life in saturated soil conditions. Wetlands generally include swamps, marshes, bogs, and similar areas.

Worker: Under the soil exposure pathway, a person who is employed on a full- or part-time basis on the property on which the site is located.' Under all other pathways, a person whose place of full- or part-time employment is within the target distance limit. 


\section{APPENDIX A}

OMB Approval Number: 2050-0095

Approved for Use Through: 1/92

\section{PA Scoresheets}

Site Name:

CERCLIS ID No.:

Street Address:

City/State/Zip:
Investigator:

Agency/Organization:

StreetAddress:

City/State/Zip:

Date: 


\section{INSTRUCTIONS FOR SCORESHEETS}

\section{Introduction}

This scoresheets package functions as a self-contained workbook providing all of the basic tools to apply collected data and calculate a PA score. Note that a computerized scoring tool, "PA-Score," is also available from EPA (Office of Solid Waste and Emergency Response, Directive 9345.1-11). The scoresheets provide space to:

- Record information collected during the PA

- Indicate references to support information

- Select and assign values ("scores") for factors

- Calculate pathway scores

- Calculate the site score

Do not enter values or scores in shaded areas of the scoresheets. You are encouraged to write notes on the scoresheets and especially on the Criteria Lists. On scoresheets with a reference column, indicate a number corresponding to attached sources of information or pages containing rationale for hypotheses; attach to the scoresheets a numbered list of these references. Evaluate all four pathways. Complete all Criteria Lists, scoresheets, and tables. Show calculations, as appropriate. If scoresheets are photocopy reproduced, copy and submit the numbered pages (right-side pages) only.

\section{GENERAL INFORMATION}

Site Description and Operational History: Briefly describe the site and its operating history. Provide the site name, owner/operator, type of facility and operations, size of property, active or inactive status, and years of waste generation. Summarize waste treatment, storage, or disposal activities that have or may have occurred at the site; note also if these activities are documented or alleged. Identify probable source types and prior spills. Summarize highlights of previous investigations.

Probable Substances of Concern: List hazardous substances that have or may have been stored, handled, or disposed at the site, based on your knowledge of site operations. Identify the sources to which the substances may be related. Summarize any existing analytical data concerning hazardous substances detected onsite, in releases from the site, or at targets. 
2

GENERAL INFORMATION

Site Description and Operational History:

Probable Substances of Concern:

(Previous investigations, analytical data)

$\because \cdots$

A-3 


\section{GENERAL INFORMATION (continued)}

Site Sketch: Prepare a sketch of the site (freehand is acceptable). Indicate all pertinent features. of the site and nearby environs, including: waste sources, buildings, residences, access roads, parking areas, drainage patterns, water bodies, vegetation, wells, sensitive environments, etc. 
GENERAL INFORMATION (continued)

Site Sketch:

(Show all pertinent features, indicate sources and closest targets, indicate north)

$:-$

A.5 


\section{SOURCE EVALUATION}

- Number and name each sōurce (e.g., 1. East Drum Storage Area, 2. Sludge Lagoon, 3. Battery Pile).

- Identify source type according to the list below.

- Describe the physical character of each source le.g., dimensions, contents, waste types, containment, operating history).

- Show waste quantity (WQ) calculations for each source for appropriate tiers. Refer to instructions opposite page 5 and PA Tables $1 \mathrm{a}$ and $1 \mathrm{~b}$. Identify waste quantity tier and waste characteristics (WC) factor category score (for a site with a single source, according to PA Table 1a). Determine WC from PA Table 1b for the sum of source WOs for a multiple-source site.

- Attach additional sheets if necessary.

- Determine the site WC factor category score and record at the bottom of the page.

Source Type Descriptions

Landfill: an engineered (by excavation or construction) or natural hole in the ground into which wastes have been disposed by backfilling, or by contemporaneous soil deposition with waste disposal, covering wastes from view.

Surface Impoundment: a topographic depression, excavation, or diked area, primarily formed from earthen materials (lined or unlined) and designed to hold accumulated liquid wastes, wastes containing free liquids, or sludges that were not backfilled or otherwise covered during periods of deposition; depression may be dry if deposited liquid has eveporated, volatilized or leached, or wet with exposed liquid; structures that may be more specifically described as lagoon pond, aeration pit, settling pond, tailings pond, sludge pit, etc.; also a surface impoundment that has been covered with soil after the final deposition of waste materials (i.e., buried or backfilled).

Drums: portable containers designed to hold a standard 55-gallon volume of wastes.

Tanks and Non-Drum Containers: any stationary device, designed to contain accumulated wastes, constructed primarily of fabricated materials (such as wood, concrete, steel, or plastic) that provide structural support; any portable or mobile device in which waste is stored or otherwise handled.

Contaminated Soil: soil onto which available evidence indicates that a hazardous substance was spilled, spread, disposed, or deposited.

Pile: any non-containerized accumulation above the ground surface of solid, non-flowing wastes; includes open dumps. Some types of piles are: Chemical Waste Pile -- consists primarily of discarded chemical products, byproducts, radioactive wastes, or used or unused feedstocks; Scrap Metal or Junk Pile -- consists primarily of scrap metal or discarded durable goods such as appliances, automobiles, auto parts, or batteries, composed of materials suspected to contain or have contained a hazardous substance; Tailings Pile -- consists primarily of any combination of overburden from a mining operation and tailings from a mineral mining, beneficiation, or processing operation; Trash Pile -- consists primarily of paper, garbage, or discarded non-durable goods which are suspected to contain or have contained a hazardous substance.

Land Treatment: landfarming or other land treatment method of waste management in which liquid wastes or sludges are spread over land and tilled, or liquids are injected at shallow depths into soils.

Other: a source that does not fit any of the descriptions above; examples include contaminated building, ground water plume with no identifiable source, storm drain, dry well, and injection well. 
SOURCE EVALUATION

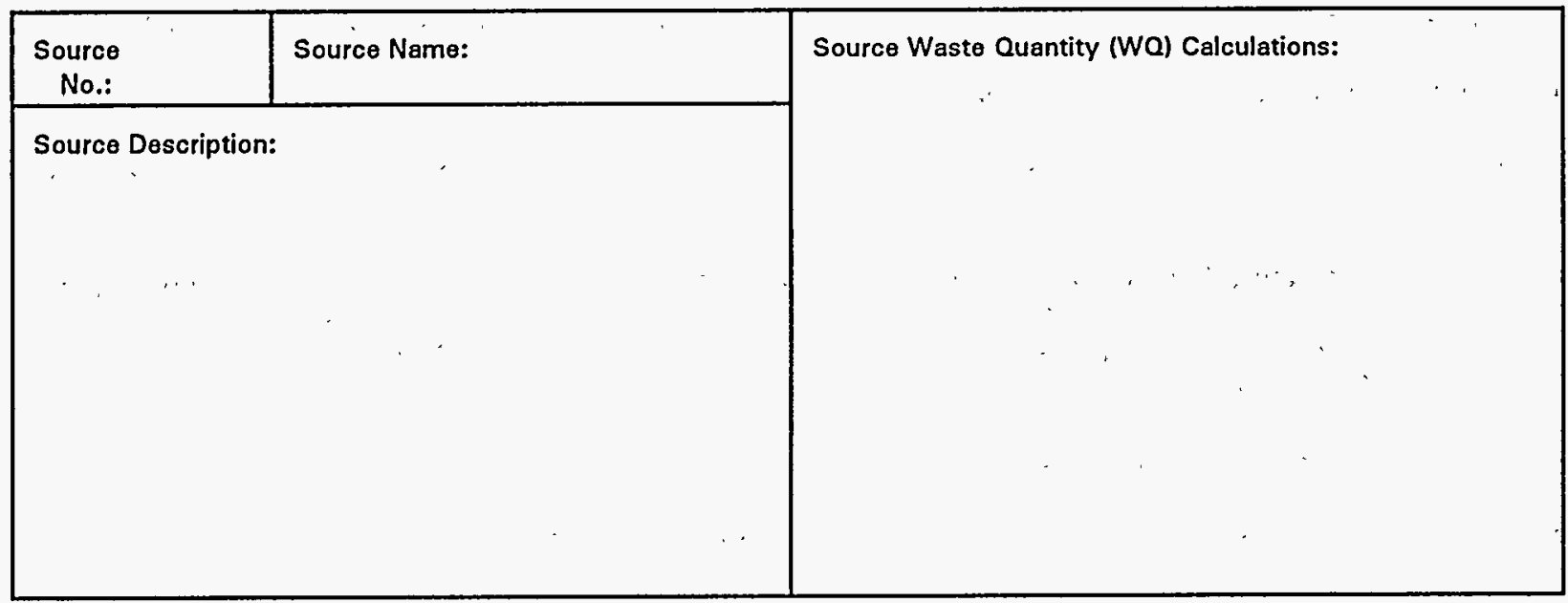
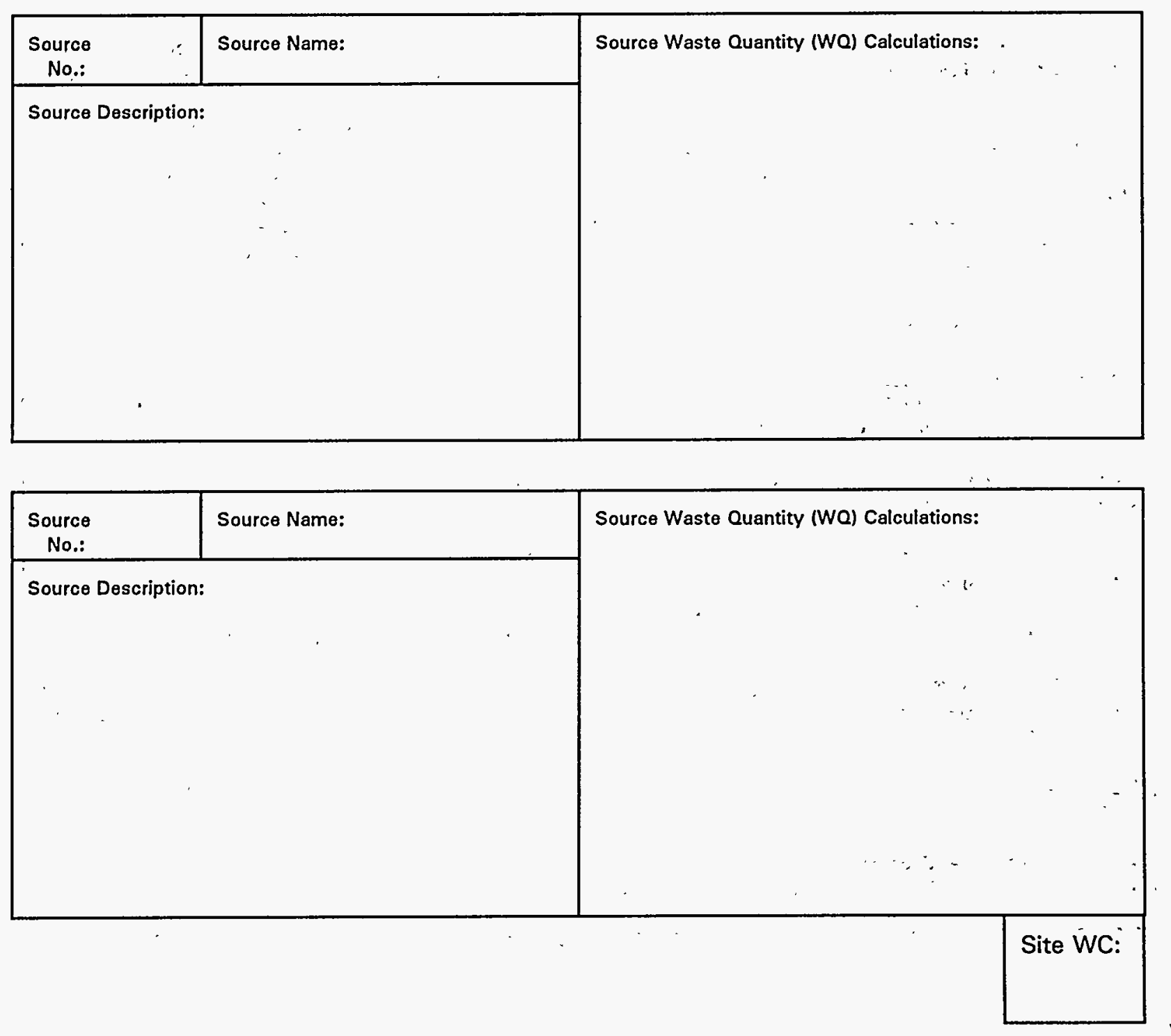

A-7 


\section{WASTE CHARACTERISTICS (WC) SCORES}

WC, based on waste quantity, may be determined by one or all of four measures called "tiers": constituent quantity, wastestream quantity, source volume, and source area. PA Table 1a (page 5) is divided into these four tiers. The amount and detail of information available determine which tier(s) to use for each source. For each source, evaluate waste quantity by as many of the tiers as you have information to support, and select the result that gives you the highest WC score. If minimal, incomplete, or no information is available regarding waste quantity, assign a WC score of 18 (minimum).

PA Table 1a has 6 columns: column 1 indicates the quantity tier; column 2 lists source types for the four tiers; columns 3,4 , and 5 provide ranges of waste amount for sites with only one source, which correspond to WC scores at the top of the columns $(18,32$, or 100$)$; column 6 provides formulas to obtain source waste quantity (WO) values at sites with multiple sources.

To determine WC for sites with only one source:

1. Identify source type (see descriptions opposite page 4).

2. Examine all waste quantity data available.

3. Estimate the mass and/or dimensions of the source.

4. Determine which quantity tiers to use based on available source information.

5. Convert source measurements to appropriate units for each tier you can evaluate for the source.

6. Identify the range into which the total quantity falls for each tier evaluated (PA Table 1a).

7. Determine the highest WC score obtained for any tier 118,32 , or 100, at top of PA Table 1a columns 3, 4, and 5, respectively).

8. Use this WC score for all pathways. *

To determine WC for sites with multiple sources:

1. Identify each source type (see descriptions opposite page 4).

2. Examine all waste quantity data available for each source.

3. Estimate the mass and/or dimensions of each source.

4. Determine which quantity tiers to use for each source based on the available information.

5. Convert source measurements to appropriate units for each tier you can evaluate for each source.

6. For each source, use the formulas in column 6 of PA Table 1a to determine the Wa value for each tier that can be evaluated. The highest WQ value obtained for any tier is the WQ value for the source.

7. Sum the WQ values for all sources to get the site WQ total.

8. Use the site WQ total from step 7 to assign the WC score from PA Table $7 b$.

9. Use this WC score for all pathways.

- The WC score is considered in all four pathways. However, if a primary target is identified for the ground water, surface water, or air migration pathway, assign the determined WC or a score of 32 , whichever is greater, as the WC score for that pathway. 
PA TABLE 1: WASTE CHARACTERISTICS (WCI SCORES

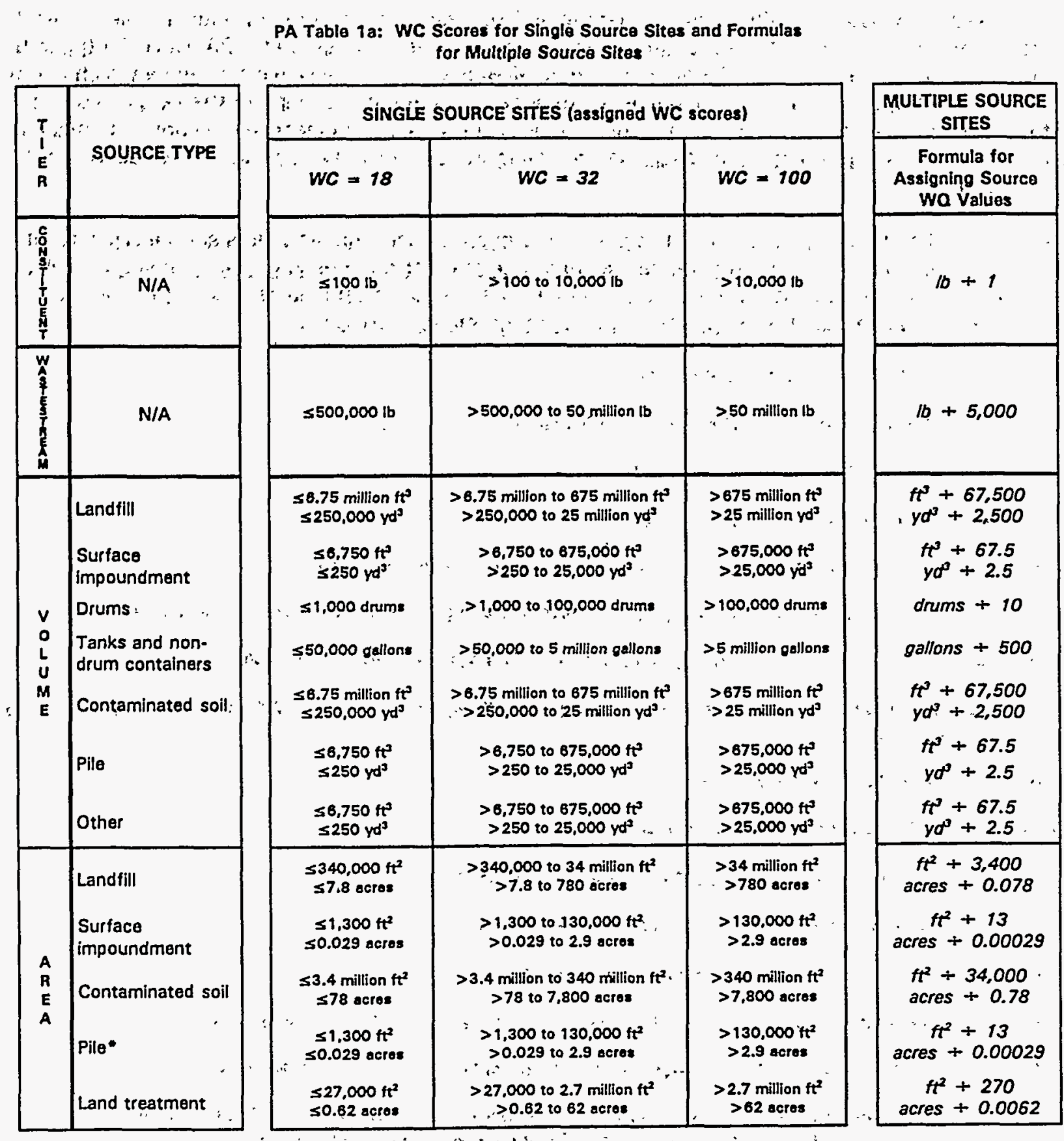

1 ton $=2,000 \mathrm{ib}=1 \mathrm{yd}^{3}=4$ drums $\cong 200$ odlons

- Use area of land surface under pile, not surface aroa of pile.

PA Table 1b: WC Scores for Multiple Source Sites

\begin{tabular}{|c|c|}
\hline wa Toew & wí score \\
\hline$>0$ to 100 & 18 \\
$>100$ to 10,000 & 32 \\
$>10,000$ & 100 \\
\hline
\end{tabular}


Ground Water Use Description: Provide information on ground water use in the vicinity. Present the general stratigraphy, aquifers used, and distribution of private and municipal wells.

Calculations for Drinking Water Populations Served by Ground Water: Provide populations from private wells and municipal supply systems in each distanice category. Show apportionment calculations for blended supply systems. 
6

GROUND WATER PATHWAY

GROUND WATER USE DESCRIPTION

Describe Ground Water Use Within 4-miles of the Site:

(Describe stratigraphy, information on aquifers, municipal and/or private wells)

Calculations for Drinking Water Populations Served by Ground Water:

A-11 
This "Criteria List" helps guide the process of developing hypotheses concerning the occurrence of a suspected release and the exposure of specific targets to a hazardous substance. The check-boxes record your professional judgment in evaluating these factors. Answers to all of the listed questions may not be available during the PA. Also, the list-is not all-inclusive; if other criteria help shape your hypotheses, list them at the bottom of the page or attach an additional pàge:

The "Suspected Release" section identifies several site, source, and. pathway conditions that could provide insight as to whether a release from the site is likely to have occurred. "If a release is suspected, use the "Primary Tàrgets" section to evaluate conditions that may help identify targets likely to be exposed to a hazardous substance. Record responses for the well that you feel has the highest probability of being exposed to a hazardous substance. You may use this section of the chart more than once, depending on the number of targets you feel may be considered "primary."

Check the boxes to indicate a "ye's," "no," or "unknown" answer to each question. If you check the "Suspected Release" box as "yes," make sure you assign a Likelihood" of Release value of 550 for the pathway. 


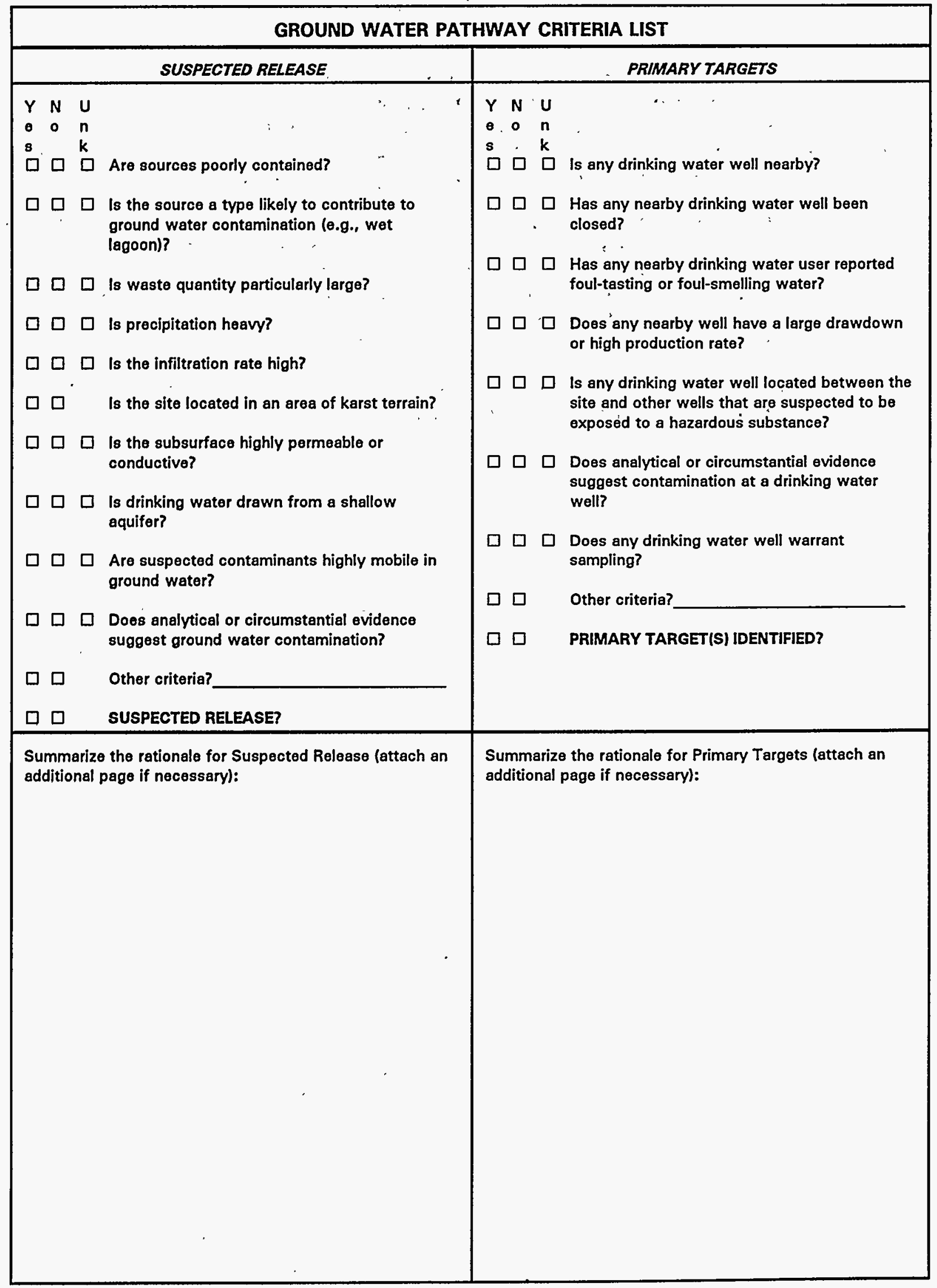




\section{GROUND WATER PATHWAY SCORESHEET}

\section{Pathway Characteristics}

Answer the questions at the top of the page. Refer to the Ground Water Pathway Criteria List (page 7) to hypothesize whether you suspect that a hazardous substance associated with the site has been released to ground water. Record depth to aquifer (in feet): the difference between the deepest occurrence of a hazardous substance and the depth of the top of the shallowest aquifer at (or as near as possible) to the site. Note whether the site is in karst terrain (characterized by abrupt ridges, sink holes, caverns, springs, disappearing streams). Record the distance (in feet) from any source to the nearest well used for drinking water.

\section{Likelihood of Release. (LR)}

1. Suspected Release: Hypothesize based on professional judgment guided by the Ground Water Pathway Criteria List (page 7). If you suspect a release to ground water, use only Column A for this pathway and do not evaluate factor 2.

2. No Suspected Release: if you do not suspect a release, determine score based on depth to aquifer or whether the site is in an area of karst terrain. If you do not suspect a release to ground water, use only Column $B$ to score this pathway.

\section{Targets (T) .}

This factor category evaluates the threat to populations obtaining drinking water from ground water. To apportion populations served by blended drinking water supply systems, determine the percentage of population served by each well based on its production.

3. Primary Target Population: Evaluate populations served by all drinking water wells that you suspect have been exposed to a hazardous substance released from the site. Use professional judgment guided by the Ground Water Pathway Criteria List (page 7) to make this determination. In the space provided, enter the population served by any wells you suspect have been exposed to a hazardous substance from the site. If only the number of residences is known, use the average county residents per household (rounded up to the next integer) to determine population served. Multiply the population by 10 to determine the Primary Target Population score. Note that if you do not suspect a release, there can be no primary target population.

4. Secondary Target Population: Evaluate populations served by all drinking water wells within 4 miles that you do not suspect have been exposed to a hazardous substance. Use PA Table $2 a$ or $2 b$ (for wells drawing from non-karst and karst aquifers, respectfully) (page 9). If only the number of residences is known, use the average county residents per household (rounded to the nearest integer) to determine population served. Circle the assigned value for the population in each distance category and enter it in the column on the far-right side of the table. Sum the far-right column and enter the total as the Secondary Target Population factor score.

5. Nearest Well represents the threat posed to the drinking water well that is most likely to be exposed to a hazardous substance. If you have identified a primary target population, enter 50 . Otherwise, assign the score from PA Table $2 a$ or $2 b$ for the closest distance category with a drinking water well population.

6. Wellhead Protection Area (WHPA): WHPAs are special areas designated by States for protection under Section 1428 of the Safe Drinking Water Act. Local/State and EPA Regional water officials can provide information regarding the location of WHPAs.

7. Resources: A score of 5 can generally be assigned as a default measure. Assign zero only if ground water within 4 miles has no resource use.

Sum the target scores in Column A (Suspected Release) or Column B (No Suspected Release).

Waste Characteristics. (WC)

8. Waste Characteristics: Score is assigned from page 4. However, if you have identified any primary target for ground water, assign either the score calculated on page 4 or a score of 32 , whichever is greater.

Ground Water Pathway Score: Multiply the scores for LR, T, and WC. Divide the product by 82,500 . Round the result to the nearest integer. If the result is greater than 100, assign 100 . 
GROUND WATER PATHWAY SCORESHEET

\begin{tabular}{l}
\hline \multicolumn{1}{|c|}{ Pethway Charactariatics } \\
Do you suspect a release (see Ground Water Pathway Criteria List, page 7)? \\
Is the site located in karst terrain? \\
Depth to aquifer:
\end{tabular}

A $\quad$ B

LIKELIHOOD OF RELEASE

1. SUSPECTED RELEASE: If you suspect a release to ground water (see page 7), assign a score of 550 . Use only column A for this pathway.

2. NO SUSPECTED RELEASE: If you do not suspect a release to ground water, and the site is in karst terrain or the depth to aquifer is 70 feet or less, assign a score of 500; otherwise, assign a score of 340. Use only column B for this pathway.

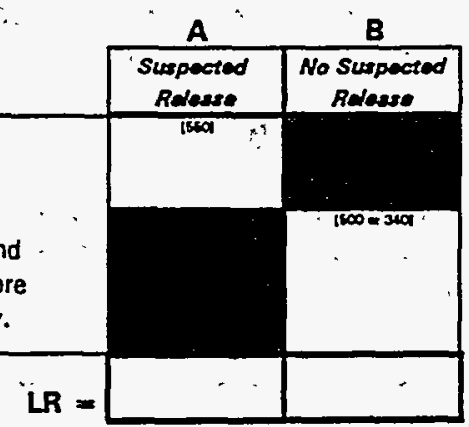

\section{TARGETS}

3. PRIMARY TARGET POPULATION: Determine the number of people served by drinking water wells that you suspect have been exposed to a hazardous substance from the site (see Ground Water Pathway Criteria List., page 7).

people $\times 10$

4. SECONDARY TARGET POPULATION: Determine the number of people served by drinking water wells that you do NOT suspect have been exposed to a hazardous substance from the site, and assign the total population score from PA Table 2.

Are any wells part of a blended system? Yes ___ No

If yes, attach a page to show apportionment calculations.

5. NEAREST WELL: If you have identified a primary target population for ground water, assign a score of 50; otherwise, assign the Nearest Well score from PA Table 2. If no drinking water wells exist within 4 miles, assign a score of zero.

6. WELLHEAD PROTECTION AREA (WHPA): If any source lies within or above a WHPA, or if you have identified any primary target well within a WHPA, assign a score of 20; assign 5 if neither condition holds but a WHPA is present within 4 miles; otherwise assign zero.

7. RESOURCES

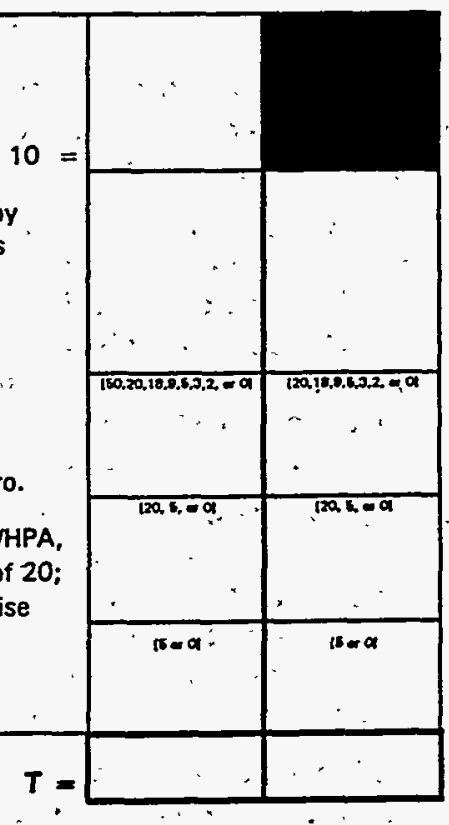

\section{WASTE CHARACTERISTICS}

8. A. If you have identified any primary target for ground water, assign the waste characteristics score calculated on page 4 , or a score of 32 , whichever is GREATER; do not evaluate part $B$ of this factor.

B. If you have NOT identified any primary target for ground water, assign the waste characteristics score calculated on page 4.

GROUND WATER PATHWAY SCORE:

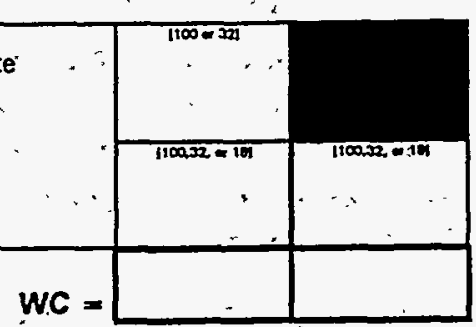

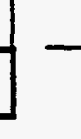

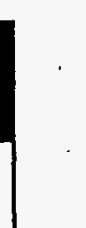

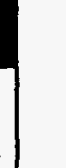



PA TABLE 2: VALUES FOR SECONDARY GROUND WATER TARGET POPULATIONS

PA Table 2a: Non-Karst Aquifers

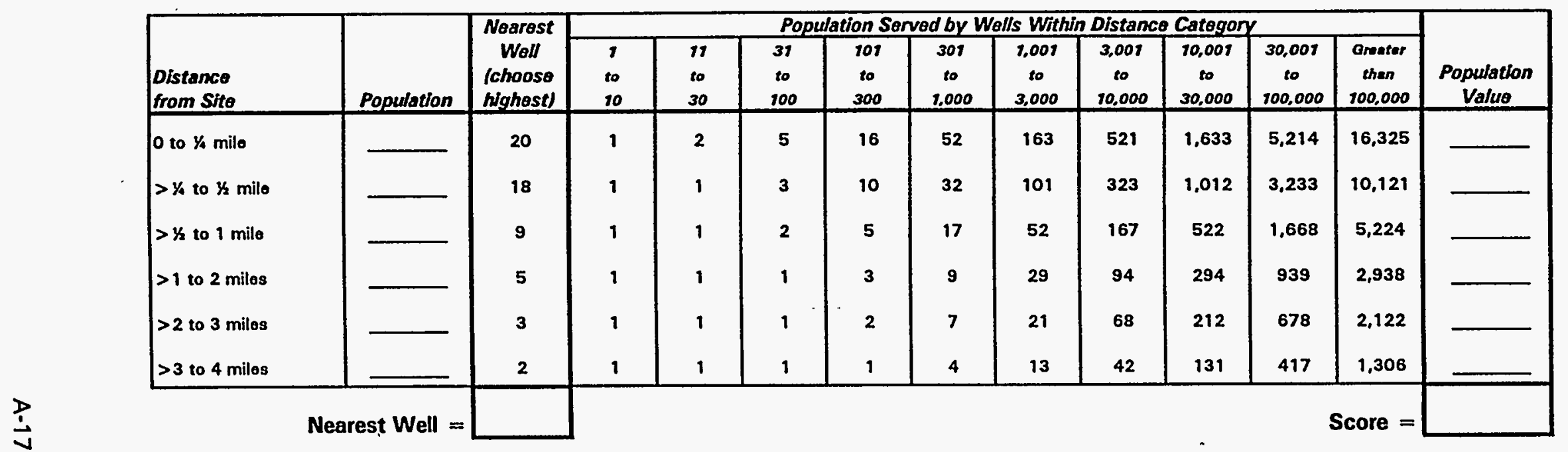

PA Table 2b: Karst Aquifers

\begin{tabular}{|c|c|c|c|c|c|c|c|c|c|c|c|c|c|}
\hline \multirow[b]{2}{*}{$\begin{array}{l}\text { Distance } \\
\text { from Site }\end{array}$} & \multirow[b]{2}{*}{ Population } & \multirow{2}{*}{$\begin{array}{c}\text { Nearest } \\
\text { Woll } \\
\text { (uso } 20 \\
\text { for karst) }\end{array}$} & \multicolumn{10}{|c|}{ Population Served by Wells Within Distance Category } & \multirow[b]{2}{*}{$\begin{array}{c}\text { Population } \\
\text { Value }\end{array}$} \\
\hline & & & $\begin{array}{c}1 \\
10 \\
10 \\
\end{array}$ & $\begin{array}{l}11 \\
\text { to } \\
30 \\
\end{array}$ & $\begin{array}{l}31 \\
20 \\
100 \\
\end{array}$ & $\begin{array}{c}101 \\
t 0 \\
300 \\
\end{array}$ & $\begin{array}{r}301 \\
t 0 \\
1,000 \\
\end{array}$ & $\begin{array}{r}1,001 \\
10 \\
3,000 \\
\end{array}$ & $\begin{array}{c}3,001 \\
10 \\
10,000 \\
\end{array}$ & $\begin{array}{c}10,001 \\
10 \\
30,000 \\
\end{array}$ & $\begin{array}{c}30,001 \\
t 0 \\
100,000 \\
\end{array}$ & $\begin{array}{c}\text { Orantar } \\
\text { than } \\
100,000\end{array}$ & \\
\hline 0 to $y_{4}$ milo & & 20 & 1 & 2 & 5 & 16 & 52 & 163 & 521 & 1.633 & 5,214 & 16,325 & \\
\hline$>y_{4}$ to $\%$ milo & & 20 & 1 & 1 & 3 & 10 & 32 & 101 & 323 & 1,012 & 3,233 & 10,121 & \\
\hline$>$ x to 1 milo & & 20 & 1 & 1 & 3 & 8 & 26 & 82 & 261 & 816 & 2,607 & 8,162 & \\
\hline$>1$ to 2 milos & & 20 & 1 & 1 & 3 & 8 & 26 & 82 & 261 & 816 & 2,607 & 8,162 & \\
\hline$>2$ to 3 milos & & 20 & 1 & 1 & 3 & 8 & 26 & 82 & 261 & 816 & 2,607 & 8,162 & \\
\hline$>3$ to 4 milos & & 20 & 1 & 1 & 3 & 8 & 26 & 82 & 261 & 816 & 2,607 & 8,162 & \\
\hline
\end{tabular}


Migration Route Sketch: Sketch the surface water migration pathway (freehand is acceptable) illustrating the drainage route and identifying water bodies, probable point of entry, flows, and targets. 
10

SURFACE WATER PATHWAY

MIGRATION ROUTE SKETCH

Suface Water Migration Route Sketch:

(include runoff route, probable point of entry, 15-mile target distance limit, intakes, fisheries, and sensitive environments)

A-19 


\section{SURFACE WATER PATHWAY CRITERIÁ LIST}

This "Criteria List" helps guide the process of developing hypotheses concerning the occurrence of a suspected release and the exposure of specific targets to a hazardous substance. The check-boxes record your professional judgment in evaluating these factors. Answers to all of the listed questions may not be available during the PA. Also, the list is not all-inclusive; if other criteria help shape your hypotheses, list them at the bottom of the page or attach an additional page.

The "Suspected Release" section identifies several site, source, and pathway conditions that could provide insight as to whether a release from the site is likely to have occurred. If a release is suspected, use the "Primary Targets" section to guide you through evaluation of some conditions that may help identify targets likely to be exposed to a hazardous substance. Record responses for the target that you feel has the highest probability of being exposed to a hazardous substance. You may use this section of the chart more than once; depending on the number of targets you feel may be considered "primary."

Check the boxes to indicate a "yes," "no," or "unknown" answer to each question. If you check the "Suspected Release" box as "yes," make sure you assign a Likelihood of Release value of 550 for the pathway.

If the distance to surface water is greater than 2 miles, do not evaluate the surface water migration pathway. Document the source of information in the text boxes below the surface water criteria list. 


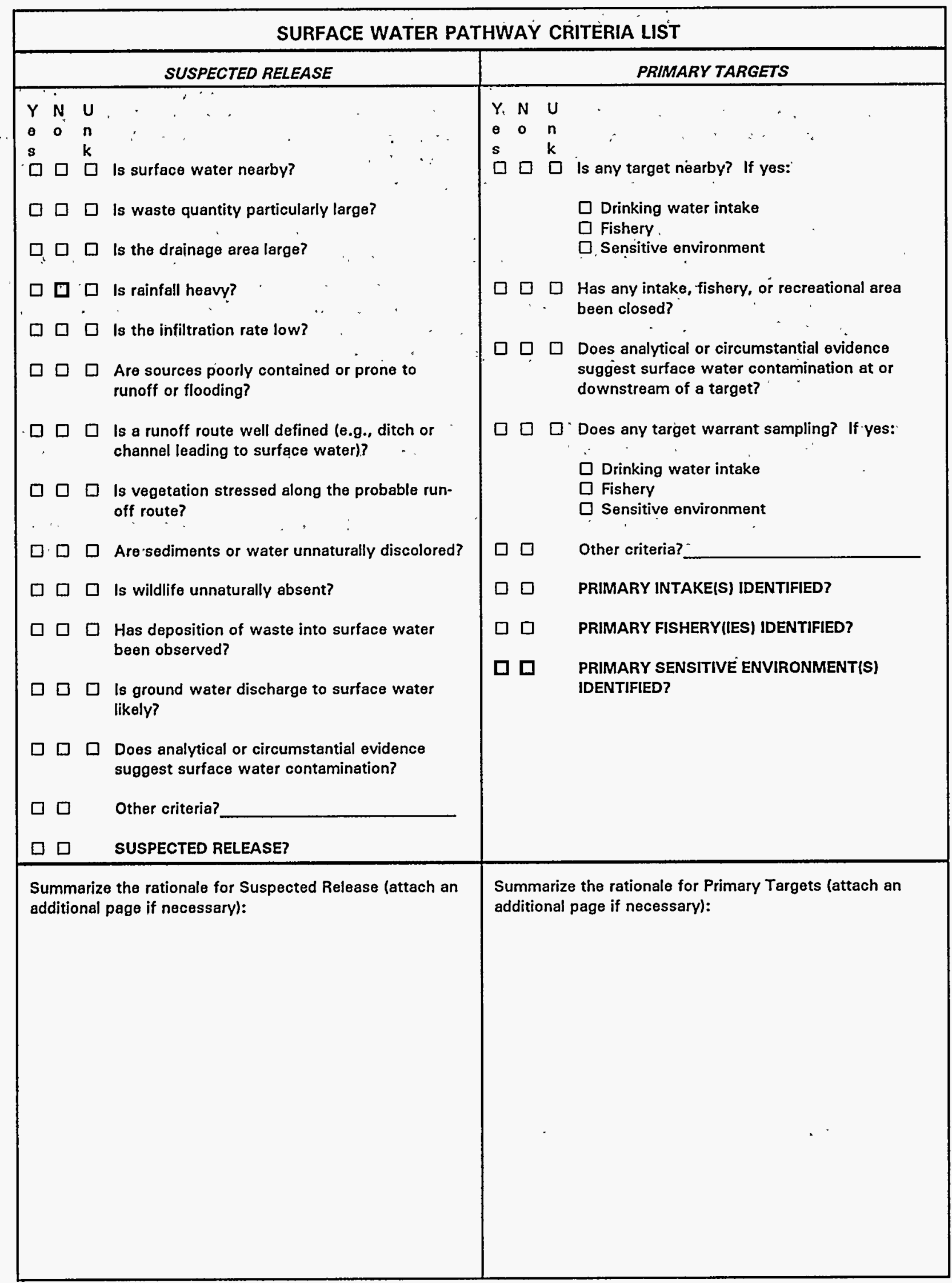




\section{SURFACE WATER PATHWAY LIKELIHOOD OF RELEASE AND DRINKING WATER THREAT SCORESHEET}

\section{Pathway Characteristics}

The surface water pathway includes three threats: Drinking Water Threat, Human Food Chain Threat, and Environmental Threat. Answer the questions at the top of the page. Refer to the Surface Water Pathway Criteria List (page 11 ) to hypothesize whether you suspect that a hazardous substance associated with the site has been released to surface water. Record the distance to surface water (the shortest overland drainage distance from a source to a surface water body). Record the flood frequency at the site (e.g., 100-yr, 200-yr). If the site is located in more than one floodplain, use the most frequent flooding event. Identify surface water use(s) along the surface water migration path and their distance(s) from the site.

\section{Likelihood of Release (LR)}

1. Suspected Release: Hypothesize based on professional judgment guided by the Surface Water Pathway Criteria List (page 11). If you suspect a release to surface water, use only Column A for this pathway and do not evaluate factor 2.

2. No Suspected Release: If you do not suspect a release, determine score based on the shortest overland drainage distance from a source to a surface water body. If distance to surface water is $2,500^{\circ}$ feet or less, assign a score of 500 . If distance to surface water is greater than 2,500 feet, determine score based on flood frequency. If you do not suspect a release to surface water, use only Column B to score this pathway.

\section{Drinking Water Threat Targets (T)}

3. List all drinking water intakes on downstream surface water bodies along the surface water migration path. Record the intake name, the type of water body on which the intake is located, the flow of the water body, and the number of people served by the intake (apportion the population if part of a blended system).

4. Primary Target Population: Evaluate populations served by all drinking water intakes that you suspect have been exposed to a hazardous substance released from the site. Use professional judgment guided by the Surface Water Pathway Criteria List (page 11) to make this determination. In the space provided, enter the population served by all intakes you suspect have been exposed to a hazardous substance from the site. If only the number of residences is known, use the average county residents per household (rounded up to the next integer) to determine population served. Multiply by 10 to determine the Primary Target Population score. Remember, if you do not suspect a release, there can be no primary target population.

5. Secondary Target Population: Evaluate populations șerved by all drinking water intakes within the target distance limit that you do not suspect have been exposed to a hazardous substance. Use PA Table 3 (page 13) and enter the population served by intakes for each flow category. If only the number of residences is known, use the average county residents per household (rounded to the nearest integer) to determine population served. Circle the assigned value for the population in each flow category and enter it in the column on the far-right side of the table. Sum the far-right column and enter the total as the Secondary Target Population factor score.

Gauging station data for many surface water bodies are available from USGS or other sources. In the absence of gauging station data, estimate flow using the list of surface water body types and associated flow categories in PA Table 4 (page 13). The flow for lakes is determined by the sum of flows of streams entering or leaving the lake. Note that the flow category "mixing zone of quiet flowing rivers" is limited to 3 miles from the probable point of entry.

6. Nearest Intake represents the threat posed to the drinking water intake that is most likely to be exposed to a hazardous substance. If you have identified a primary target population, enter 50 . Otherwise, assign the score from PA Table 3 (page 13) for the lowest-flowing water body on which there is an intake.

7. Resources: A score of 5 can generally be assigned as a default measure. Assign zero only if surface water within the target distance limit has no resource use.

Sum the target scores in Column A (Suspected Release) or Column B (No Suspected Release). 
SURFACE WATER PATHWAY

LIKELIHOOD OF RELEASE AND DRINKING WATER THREAT SCORESHEET

\begin{tabular}{l}
\hline Po you suspect a release (see Surface Water Pathway Criteria List, page 111 ? \\
Distance to surface water: \\
Flood frequency: \\
What is the downstream distance to the nearest drinking water intake? \\
Nearest fishery?
\end{tabular}

\section{LIKELIHOOD OF RELEASE}

1. SUSPECTED RELEASE: If you suspect a release to surface water (see page 11), assign a score of $\mathbf{5 5 0}$. Use only column $A$ for this pathway.

2. NO SUSPECTED RELEASE: If you do not suspect a release to surface water, use the table below to assign a score based on distance to surface water and flood frequency. Use only column B for this pathway.

\begin{tabular}{|c|c|}
\hline Distance to surface water $\leq 2,500$ feet & 500 \\
\hline Distance to surface water $>2,500$ feet, and & \\
\hline Site in annual or 10-year floodplain & 500 \\
\hline Site in 100-year floodplain & 400 \\
\hline Site in 500-year floodplain & 300 \\
\hline Site outside 500-year floodplain & 100 \\
\hline
\end{tabular}

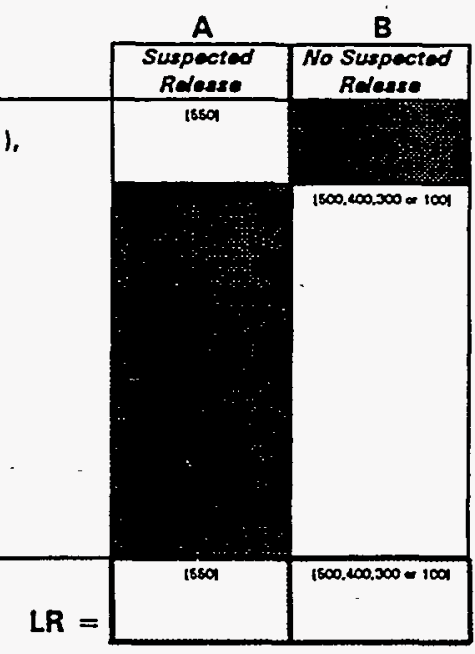

\section{DRINKING WATER THREAT TARGETS}

3. Record the water body type, flow (if applicable), and number of people served by each drinking water intake within the target distance limit. If there is no drinking water intake within the target distance limit, factors 4, 5, and 6 each receive zero scores.

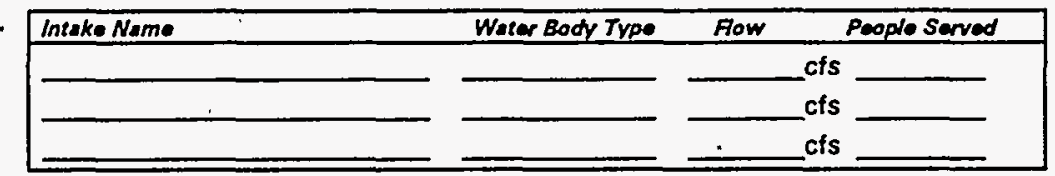

4. PRIMARY TARGET POPULATION: If You suspect any drinking water intake listed above has been exposed to a hazardous substance from the site (see Surface Water Pathway Criteria List, page 11), list the intake name(s) and calculate the factor score based on the total population served.

people $\times 10$

5. SECONDARY TARGET POPULATION: Determine the number of people served by drinking water intakes that you do NOT suspect have been exposed to a hazardous substance from the site, and assign the total population score from PA Table 3.

Are any intakes part of a blended system? Yes __ No

If yes, attach a page to show apportionment calculations.

6. NEAREST INTAKE: If you have identified a primary target population for the drinking water threat (factor 4), assign a score of 50; otherwise, assign the Nearest Intake score from PA Table 3. If no drinking water intake exists within the target distance limit, assign a score of zero.

7. RESOURCES

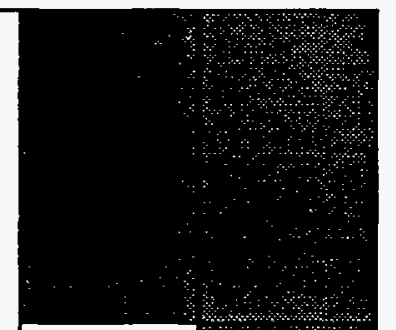

References

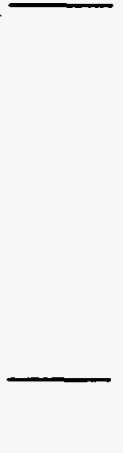



PA TABLE 3: VALUES FOR SECONDARY SURFACE WATER TARGET POPULATIONS

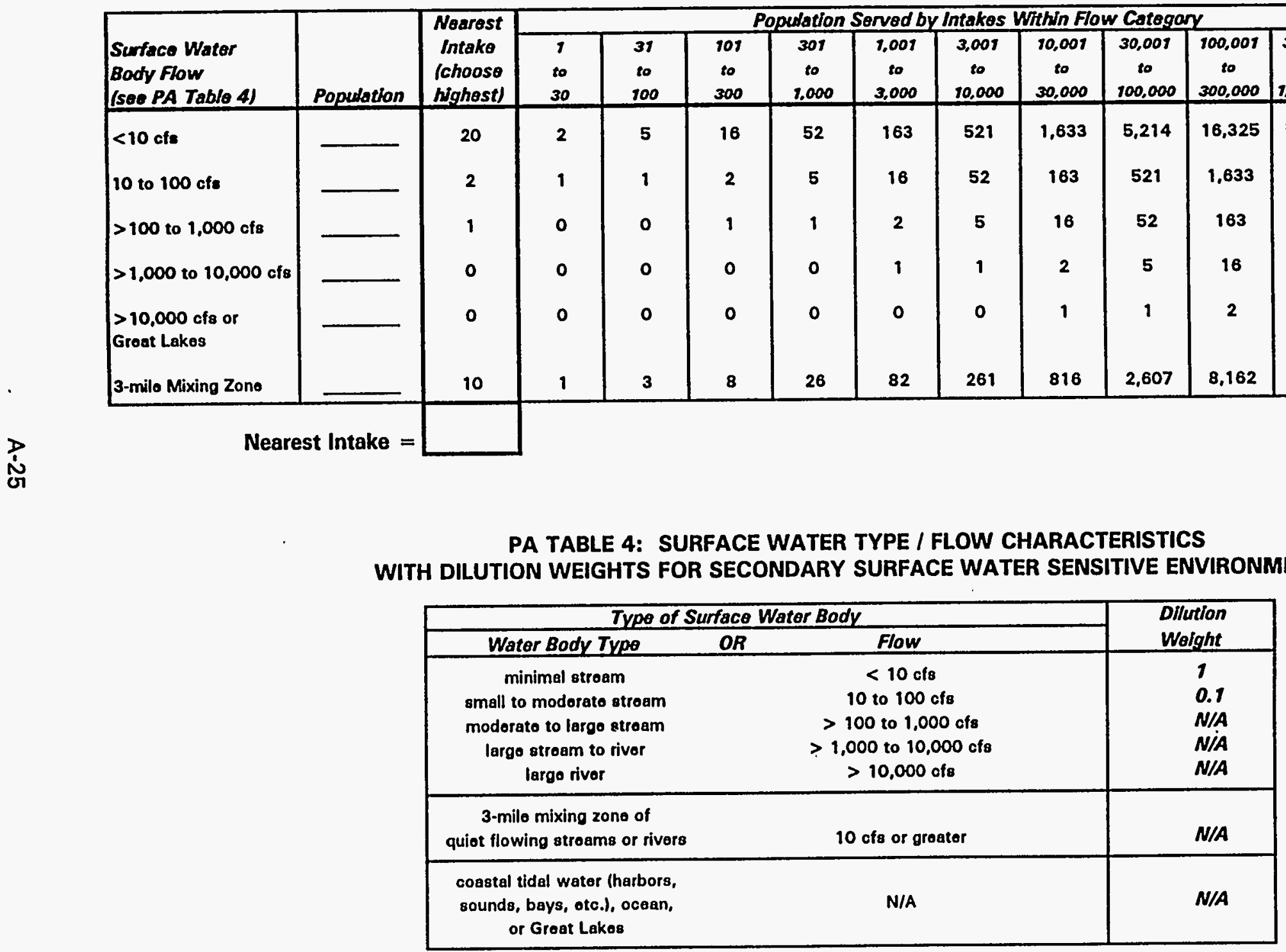




\section{SURFACE WATER PATHWAY HUMAN FOOD CHAIN THREAT SCORESHEET}

\section{Likelihood of Release (LR)}

LR is the same for all surface water pathway threats. Enter LR score from page 12.

\section{Human Food Chain Threat Targets (T)}

8. The only human food chain targets are fisheries. A fishery is an area of a surface water body from which food chain organisms are taken or could be taken for human consumption on a subsistence, sporting, or commercial basis. Food chain organisms include fish, shellfish, crustaceans, amphibians, and amphibious reptiles. Fisheries are delineated by changes in surface water body type (i.e., streams and rivers, lakes; coastal tidal waters, and oceans/Great Lakes) and whenever the flow characteristics of a stream or river change.

In the space provided, identify all fisheries within the target distance limit. Indicate the surface water body type and flow for each fishery. Gauging station flow data are available for many surface water bodies from USGS or other sources. In the absence of gauging station data, estimate flow using the list of surface water body types and associated flow categories in PA Table 4 (page 13). The flow for lakes is determined by the sum of flows of streams entering or leaving the lake. Note that, if there are no fisheries within the target distance limit, the Human Food Chain Threat Targets score is zero.

9. Primary fisheries are any fisheries within the target distance limit that you suspect have been exposed to a hazardous substance released from the site. Use professional judgment guided by the Surface Water Pathway Criteria List (page 11 ) to make this determination. If you identify any primary fisheries, list them in the space provided, enter 300 as the Primary Fisheries factor score, and do not evaluate Secondary Fisheries. Note that if you do not suspect a release, there can be no primary fisheries.

10. Secondary fisheries are fisheries that you do not suspect have been exposed to a hazardous substance. Evaluate this factor only if fisheries are present within the target distance limit, but none is considered a primary fishery.

A. If you suspect a release to surface water and have identified a secondary fishery but no primary fishery, assign a score of 210 .

B. If you do not suspect a release, evaluate this factor based on flow. In the absence of gauging station flow data, estimate flow using the list of surface water body types and associated flow categories in PA Table 4 (page 13). Assign a Secondary Fisheries score from the table on the scoresheet using the lowest flow at any fishery within the target distance limit. (Dilution weight multiplier does not apply to PA evaluation of this factor.)

Sum the target scores in Column A (Suspected Release) or Column B (No Suspected Release). 
SURFACE WATER PATHWAY (continued) HUMAN FOOD CHAIN THREAT SCORESHEET

\begin{tabular}{|c|c|c|c|}
\hline \multirow{2}{*}{\multicolumn{2}{|c|}{ LIKELIHOOD OF RELEASE }} & A & B \\
\hline & & $\begin{array}{l}\text { Suspocted } \\
\text { Redesese }\end{array}$ & $\begin{array}{l}\text { No Suspectod } \\
\text { Relesese }\end{array}$ \\
\hline Enter Surface Water Likelihood of Release score from page 12. & $\mathbf{L R}=$ & issot & $1800,400,5000=1001$ \\
\hline
\end{tabular}

\section{HUMAN FOOD CHAIN THREAT TARGETS}

8. Record the water body type and flow (if applicable) for each fishery within the target distance limit. If there is no fishery within the target distance limit, assign a Targets score of 0 at the bottom of the page.

\begin{tabular}{|c|c|c|}
\hline Flshery Name & Woter Body Type & Fow \\
\hline & & cfs \\
\hline & & _cfs \\
\hline & & _cfs \\
\hline & & _cfs \\
\hline & & _cfs \\
\hline
\end{tabular}

9. PRIMARY FISHERIES: If you sUsDect any fishery listed above has been exposed to a hazardous substance from the site (see Surface Water Criteria List, page 11), assign a score of 300 and do not evaluate Factor 10. List the primary fisheries:

\section{SECONDARY FISHERIES}

A. If you suspect a release to surface water and have identified a secondary fishery but no primary fishery, assign a score of 210 .

B. If you do not suspect a release, assign a Secondary Fisheries score from the table below using the lowest flow at any fishery within the target distance limit.

\begin{tabular}{|l|c|}
\hline Lowest Fow & Secondery Fisherios Score \\
\hline$<10$ cfs & 210 \\
\hline 10 to 100 cfs & 30 \\
\hline $\begin{array}{l}>100 \text { cfs, coastal } \\
\text { tidal waters, oceans, } \\
\text { or Great Lakes }\end{array}$ & 12 \\
\hline
\end{tabular}
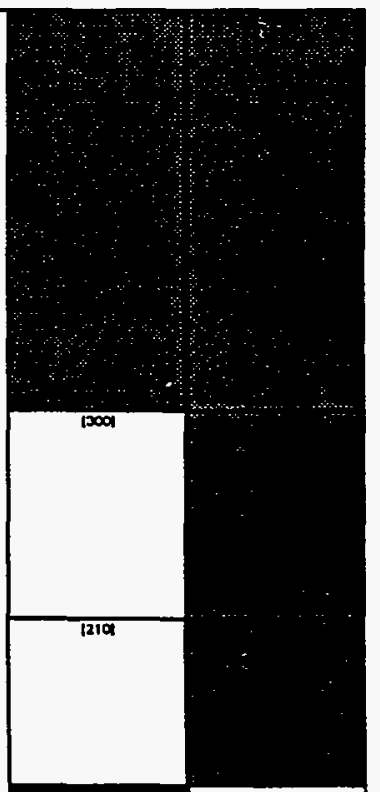

$1210 x a=12 a$

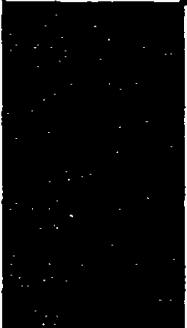




\section{SURFACE WATER PATHWAY ENVIRONMENTAL THREAT SCORESHEET}

\section{Likelihood of Release (LR)}

LR is the same for all surface. water pathway threats. Enter LR score from page 12.

\section{Environmental Threat Targets (T)}

11. PA Table 5 (page 16) lists sensitive environments for the Surface Water Pathway Environmental Threat. In the space provided, identify all sensitive environments located within the target distance limit. Indicate the surface water body type and flow at each sensitive environment. Gauging station flow data for many surface water bodies are available from USGS or other sources. In the absence of gauging station data, estimate flow using the list of surface water body types and associated flow categories in PA Table 4 (page 13). The flow for lakes is determined by the sum of flows of streams entering or leaving the lake. Note that if there are no sensitive environments within the target distance limit, the Environmental Threat Targets score is zero.

12. Primary sensitive environments are surface water sensitive environments within the target distance limit that you suspect have been exposed to a hazardous substance released from the site. Use professional judgment guided by the Surface Water Pathway Criteria List (page 11) to make this determination. If you identify any primary sensitive environments, list them in the space provided, enter 300 as the Primary Sensitive Environments factor score, and do not evaluate Secondary Sensitive Environments. Note that if you do not suspect a release, there can be no primary sensitive environments.

13. Secondary sensitive environments aré surface water sensitive environments that you do not suspect have been exposed to a hazardous substance. Evaluate this factor only if surface water sensitive environments are present within the target distance limit, but none is considered a primary sensitive environment. Evaluate secondary sensitive environments based on flow.

- In the table provided, list all secondary sensitive enivironments on surface water bodies with flow of $100 \mathrm{cfs}$ or less.

1) Use PA Table 4 (page 13) to determine the appropriate dilution weight for each.

2) Use PA Tables 5 and 6 (page 16) to determine the appropriate value for each sensitive environment type and for wetlands frontage.

3) For a sensitive environment that falls into more than one of the categories in PA Table 5, sum the values for each type to determine the environment value (e.g., a wetland with 1.5 miles frontage (value of 50 ) that is also a critical habitat for a Federally designated endangered species (value of 100 ) would receive a total value of 150 ).

4) For each sensitive environment, multiply the dilution weight by the environment type (or length of wetlands) value and record the product in the far-right column.

5) Sum the values in the far-right.column and enter the total as the Secondary Sensitive Environments score. Do not evaluate part $B$ of this factor.

- If all secondary sensitive environments are on surface water bodies with flows greater than 100 cfs, assign 10 as the Secondary Sensitive Environments score.

Sum the target scores in Column A (Suspected Release) or Column B (No Suspected Release). 
SURFACE WATER PATHWAY (continued) ENVIRONMENTAL THREAT SCORESHEET

\begin{tabular}{|c|c|c|c|c|}
\hline & & A & $\mathbf{B}$ & \\
\hline LIKELIHOOD OF RELEASE & & $\begin{array}{l}\text { Suspected } \\
\text { Rotense }\end{array}$ & $\begin{array}{l}\text { No Sumpected } \\
\text { Rabeses }\end{array}$ & Roferences: \\
\hline Enter Surface Water Likelihood of Release score from page 12. & $\mathbf{L R}=$ & 1069 & 1000,0000000100 & \\
\hline
\end{tabular}

\section{ENVIRONMENTAL THREAT TARGETS}

11. Record the water body type and flow (if applicable) for each surface water " sensitive environment within the target distance limit (see PA Tables 4 and 5). If there is no sensitive environment within the target distance limit, assign a Targets score of 0 at the bottom of the page.

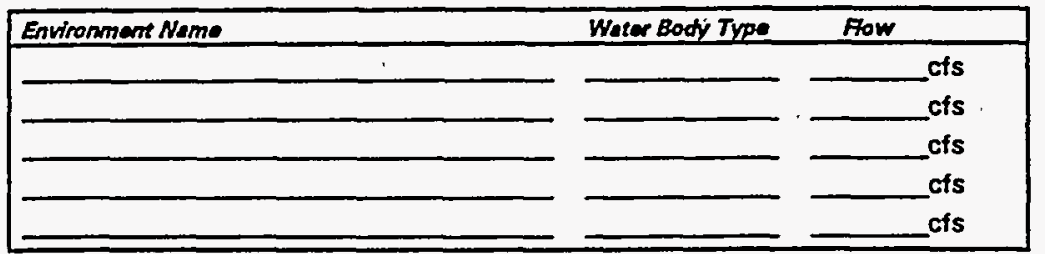

12. PRIMARY SENSITIVE ENVIRONMENTS: If you suspect any sensitive environment listed above has been exposed to a hazardous substance from the site (see Surface Water Criteria List, page 11), assign a score of 300 and do not evaluate factor 13. List the primary sensitive environments:

13. SECONDARY SENSITIVE ENVIRONMENTS: If sensitive environments are present, but none is a primary sensitive environment, evaluate Secondary Sensitive Environments based on flow.

A. For secondary sensitive environments on surface water bodies with flows of $100 \mathrm{cfs}$ or less, assign scores as follows, and do not evaluate part B of this factor:

\begin{tabular}{|c|c|c|c|}
\hline How & $\begin{array}{l}\text { Diverton Waght } \\
\text { (PA Table A) }\end{array}$ & $\begin{array}{l}\text { Environment Type and Value } \\
\text { (PA Tables } 5 \text { and 6) }\end{array}$ & Tota \\
\hline cfs & $x$ & $=$ & \\
\hline cfs & $x$ & $=$ & \\
\hline cfs & $x$ & $=$ & \\
\hline cfs & $x$ & $=$ & \\
\hline cfs & $x$ & $=$ & \\
\hline
\end{tabular}

B. If all secondary sensitive environments are located on surface water bodies with flows > 100 cfs, assign a score of 10 .
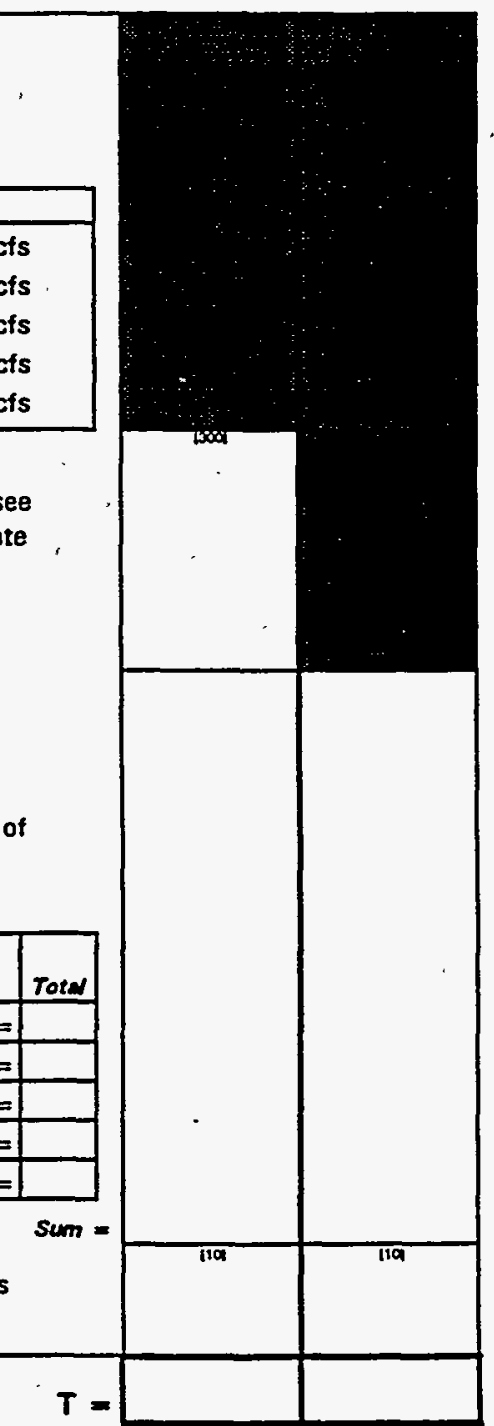


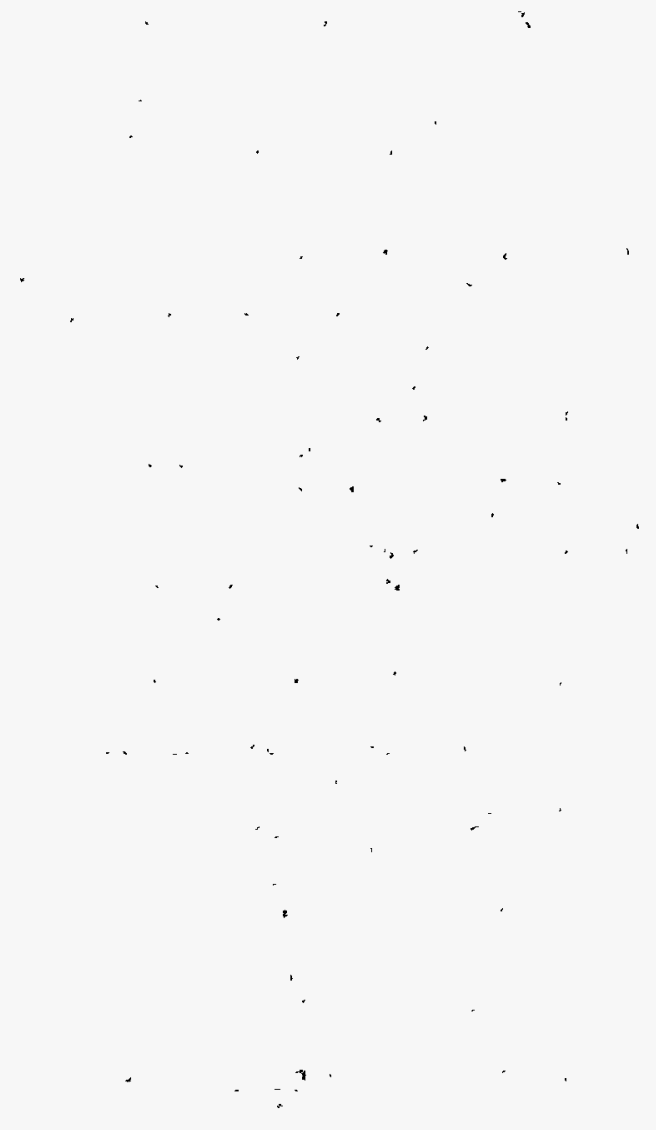


PA TABLE 5: SURFACE WATER AND AIR PATHWAY SENSITIVE ENVIRONMENTS VALUES

Sensitive Environment Assigned Value

Critical habitat for Foderally designated endangered or threatened species

Marino Sanctuary

National Park

Designated Foderal Wilderness Area

Ecologically importent aress identified under the Coastal Zone Wilderness Act

Sensitive Aroas identified under the National Estuary Program or Near Coastal Water Program of the Cloan Wator Act

Critical Aroas Identified under the Clean Lakes Program of the Clean Water Act (subareas in lakes or ontiro small lakes)

National Monumont (air pathway only)

Netional Soashoro Recreation Aroa

National Lakeshore Recreation Area

Habitat known to bo used by Foderally designated or proposed endangered or threatened species

National Proservo

National or State Wildifo Rofugo

Unit of Coastal Barrier Rosourcos System

Federal land designated for the protection of natural ecosystoms

Administrativoly Proposed Foderal Wilderness Area

Spawning areas critical for the maintenance of fish/shellfish spocies within a rivor systom, bay, or estuary

Migratory pathways and fooding areas critical for the maintenance of anedromous fish species in a river system

Torrestrial areas utilized for brooding by large or dense aggregations of vertebrate animals (air pathway) or

semi-aquatic foragers (surface water pathway)

National river roach designeted as Recrostional

Hebitat known to bo usod by Stato designated endangered or threatened species

Habitat known to bo used by a spocies under roviow as to its Foderal endangered or throatenod status

Cosstal Barrior (partially dovelopod)

Foderally dogignated Scenic or Wild River

State land designated for wildlifo or gamo managemont

state designated Scenic or Wild River

Stete designatod Natural Area

Particular aroas, relotivoly small in size, important to maintenance of unique biotic communities

Stato designated areas for protection/maintenance of aquatic lifo under tho Cloan Water Act

See PA Table 6 (Surface Water Pathway)

Wotlands

or

PA Tablo 9 (Air Pathway)

\section{PA TABLE 6: SURFACE WATER PATHWAY WETLANDS FRONTAGE VALUES}

\begin{tabular}{|lc|}
\hline Total Length of Wetlands & Assigned Value \\
\hline Less than 0.1 mile & 0 \\
0.1 to 1 mile & 25 \\
Greater then 1 to 2 miles & 50 \\
Greater then 2 to 3 miles & 75 \\
Greater than 3 to 4 miles & 100 \\
Greater than 4 to 8 miles & 150 \\
Greater than 8 to 12 miles & 250 \\
Greater than 12 to 16 miles & 350 \\
Greater than 16 to 20 miles & 450 \\
Greater than 20 miles & 500 \\
\hline
\end{tabular}




\section{SURFACE WATER PATHWAY WASTE CHARACTERISTICS; THREAT, AND PATHWAY SCORES}

\section{Waste Characteristics (WC)}

14. Waste Characteristics: Score is assigned from page 4. However, if a primary target has been identified for any surface water threat, assign either the score calculated on page-4 or a score of 32 , whichever is greater.

\section{Surface. Water Pathway Threat Scores}

Fill in the matrix with the appropriate scores from the previous pages. To calculate the score for each threat: multiply the scores for LR, T, and WC; divide the product by 82,500 ; and round the result to the nearest integer. The Drinking Water Threat and Human Food Chain Threat are each subject to a maximum of 100 . The Environmental Threat is subject to a maximum of 60 . Enter the rounded threat scores in the far-right column.

\section{Surface Water Pathway Score}

Sum the individual threat scores to determine the Surface Water Pathway Score. If the sum is greater than 100 , assign 100 . 
". , , SURFACE WATER'PATHWAY'(concluded)

WASTE CHARACTERISTICS, THREAT, AND PATHWAY SCORE SUMMARY

A

B

WASTE CHARACTERISTIĊS

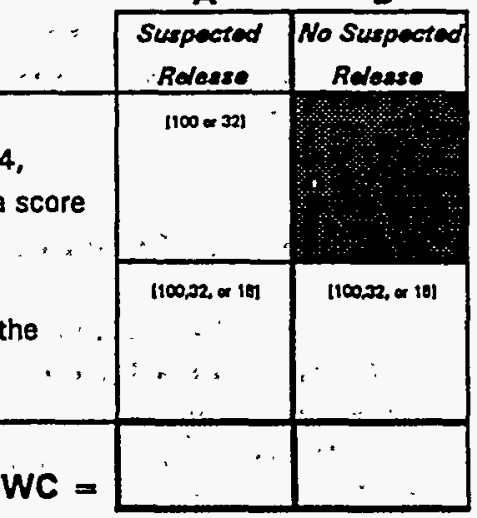

14. A. If you have identified any primary target for surface water lpages 12, 14, or 15), assign the waste characteristics score calculated on page 4; or a score of 32 , whichever is GREATER; do not evaluate part $B$ of this factor.

B. If you have NOT identified any primary target for surface water, assign the waste characteristics score calculated on page 4.

$\therefore \quad$

WC $=$

SURFACE WATER PATHWAY THREAT SCORES

\begin{tabular}{|c|c|c|c|c|}
\hline Threat & $\begin{array}{c}\text { Ukelihood of } \\
\text { Reloses (LR) Score } \\
\text { (from puge i2)' }\end{array}$ & $\begin{array}{l}\text { Targets }(T) \text { Score } \\
\text { (pages 12, 14, 15) }\end{array}$ & $\begin{array}{l}\text { Pathway Waste } \\
\text { Cheractaristios (WC) Score } \\
\text { (dotermined above) }\end{array}$ & $\begin{array}{c}\text { Thraet Score } \\
\angle A \times T \times W C \\
\angle 82.500\end{array}$ \\
\hline Drinking Water & & & & 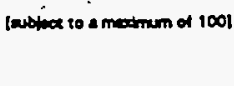 \\
\hline Human Food Chain & & & & twothex to o mestrom of 1001 \\
\hline Environmental & & & & 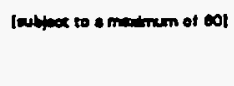 \\
\hline
\end{tabular}

SURFACE WATER PATHWAY SCORE

(Drinking Water Threat + Human Food Chain Threat + Environmental Threat)

Imothax to a motrum of 100 I 


\section{SOIL EXPOSURE PATHWAY CRITERIA LIST}

Areas of surficial contamination can generally be assumed. This "Criteria List" helps guide the process of developing a hypothesis concerning the exposure of specific targets to a hazardous substance at the site. Use the "Resident Population" section to evaluate site and source conditions that may help identify targets likely to be exposed to a hazardous substance. The check-boxes record your professional judgment. Answers to all of the listed questions may not be available during the PA. Also, the list is not all-inclusive; if other criteria help shape your hypothesis, list them at the bottom of the page or attach an additional page.

Check the boxes to indicate a "yes," "no," or "unknown" answer to each question. 


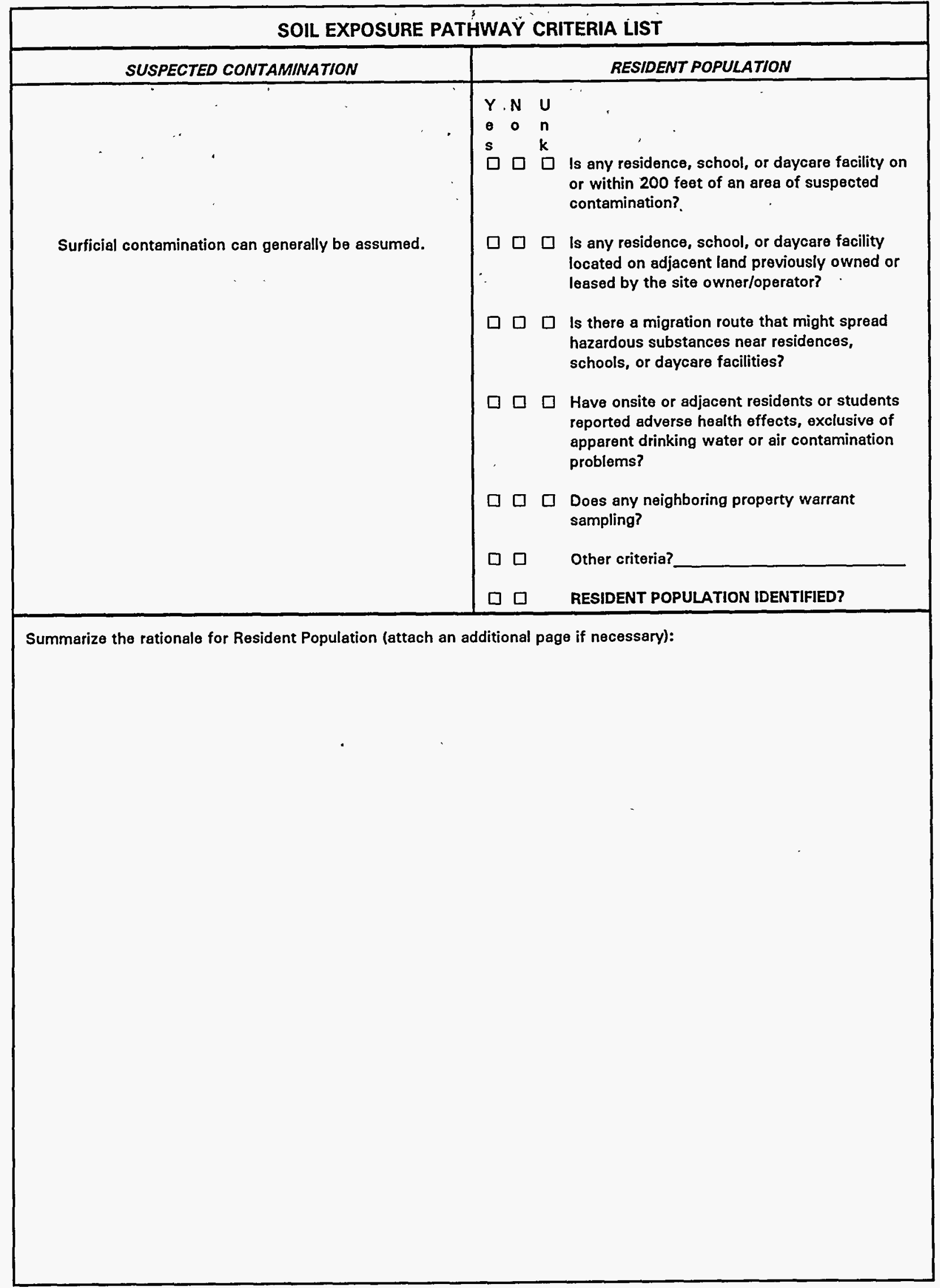




\section{Pathway Characteristics}

Answer the questions at the top of the page. Identify people who may be exposed to a hazardous substance because they work at the facility, or reside or attend school or daycare on or within 200 feet of an area of suspected contamination. If the site is active, estimate the number of full and part-time workers. Note that evaluation of targets is based on current site conditions.

\section{Likelihood of Exposure (LE)}

1. Suspected Contamination: Areas of surficial contamination are present at most sites, and a score of 550 can generally be assigned as a default measure. Assign zero, which effectively eliminates the pathway from further consideration, only if there is no surficial contamination; reliable analytical data are generally necessary to make this determination.

\section{Resident Population Threat Targets (T)}

2. Resident Population corresponds to "primary targets" for the migration pathways. Use professional judgment guided by the Soil Exposure Pathway Criteria List (page 18) to determine if there are people living or attending school or daycare on or within 200 feet of areas of suspected contamination. Record the number of people identified as resident population and multiply by 10 to determine the Resident Population factor score.

3. Resident Individual: Assign 50 if you have identified a resident population; otherwise, assign zero.

4. Workers: Estimate the number of full and part-time workers at this facility and adjacent facilities where contamination is also suspected. Assign a score for the Workers factor from the table.

5. Terrestrial Sensitive Environments: In the table provided, list each terrestrial sensitive environment located on an area of suspected contamination. Use PA Table 7 (page 20) to assign a value for each. Sum the values and assign the total as the factor score.

6. Resources: A score of 5 can generally be assigned as a default measure. Assign zero only if there is no land resource use on an area of suspected contamination.

Sum the target scores.

\section{Waste Characteristics (WC)}

7. Enter the WC score determined on page 4.

Resident Population Threat Score: Multiply the scores for LE, T, and WC. Divide the product by 82,500 . Round the result to the nearest integer. If the result is greater than 100, assign 100 .

Nearby Population Threat Score: Do not evaluate this threat if you gave a zero score to Likelihood of Exposure. Otherwise, assign a score based on the population within a 1-mile radius (use the same 1-mile radius population you evaluate for air pathway population targets):

$\begin{array}{cc}\text { Population Within One Mile } & \text { Nearby Population Threat Score } \\ \text { to } 50,000 & 1 \\ >50,000 & 2 \\ & 4\end{array}$

Soil Exposure Pathway Score: Sum the Resident Population Threat score and the Nearby Population Threat score, subject to a maximum of 100 . 
SOIL EXPOSURE PATHWAY SCORESHEET

\begin{tabular}{|l|l|}
\hline Do any people live on or within $200 \mathrm{ft}$ of areas of suspected contamination? & Yes \\
Do any people attend school or daycare on or within $200 \mathrm{ft}$ of areas \\
of suspected contamination? \\
Is the facility active?. Yes _. No No if yes; estimate the number of workers:
\end{tabular}

LIKELIHOOD OF EXPOSURE

1. SUSPECTED CONTAMINATION: Surficial contamination can generally be assumed, and a score of $\mathbf{5 5 0}$ assigned. Assign zero only if the absence of surficial contamination can be confidently demonstrated.

\section{LE $=$}

\section{RESIDENT POPULATION.THREAT TARGETS}

2. RESIDENT POPULATION: Determine the number of people occupying residences or attending school or daycare on or within 200 feet of areas of suspected contamination (see Soil Exposure Pathway Criteria List, page 18).

people $\times 10$

3. RESIDENT INDIVIDUAL: If you have identified a resident population (factor 2), assign a score of 50; otherwise, assign a score of 0.

4. WORKERS: Use the following table to assign a score based on the total number of workers at the facility and nearby facilities with suspected contamination:

\begin{tabular}{|c|c|}
\hline Number of Workere & Score \\
\hline 0 & 0 \\
\hline 1 to 100 & 5 \\
\hline 101 to 1,000 & 10 \\
\hline$>1,000$ & 15 \\
\hline
\end{tabular}

5. TERRESTRIAL SENSITIVE ENVIRONMENTS: Use PA Table 7 to assign a value for each terrestrial sensitive environment on an area of suspected contarnination:

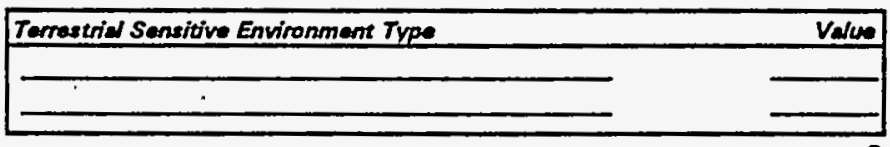

Suspected

(5000

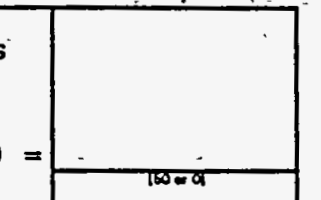

of

$\sin =$

6. RESOURCES

WASTE CHARACTERISTICS

$$
T=
$$

\begin{tabular}{|lr|r|}
\hline 7. Assign the waste characteristics score calculated on page 4. & WC $=$ & $1100,22,019$ \\
\hline
\end{tabular}

RESIDENT POPULATION THREAT SCORE:

NEARBY POPULATION THREAT SCORE:

SOIL EXPOSURE PATHWAY SCORE:

Resident Population Threat + Nearby Population Threat
LE $\times$ T X WC 82,500 .

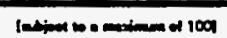

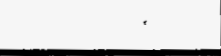

$[1,2+1]$

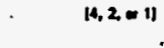

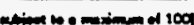




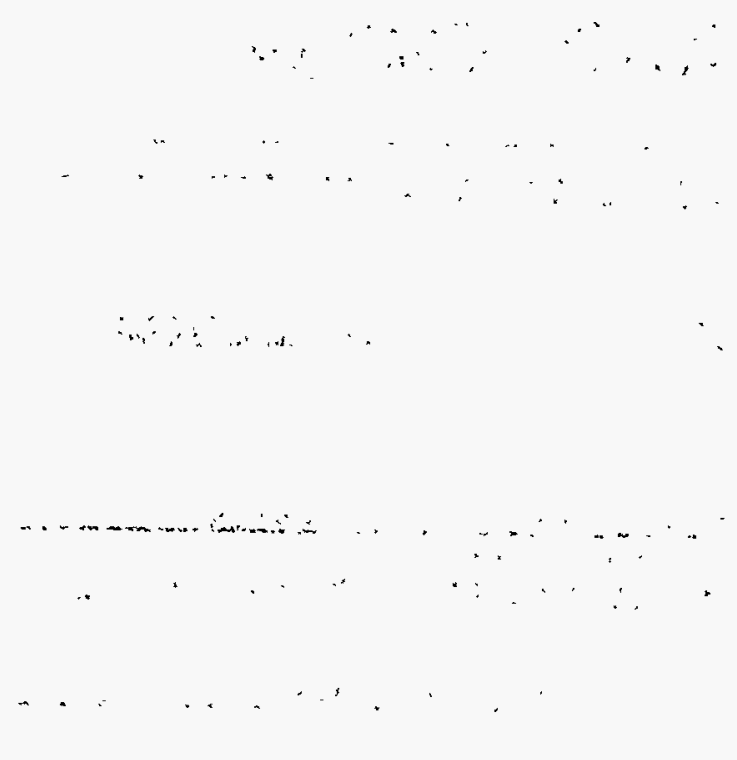


PA TABLE 7: SOIL EXPOSURE PATHWAY

TERRESTRIAL SENSITIVE ENVIRONMENT VALUES

Terrestral Sensitive Environment

Assigned Value

Terrestrial critical habitat for Federally designated endangered or threatened species

National Park

Designated Federal Wilderness Area

National Monument

Terrestrial habitat known to be used by Federally designated or proposed threatened or endangered species

National Preserve (terrestrial)

National or State terrestrial Wildlife Refuge

Federal land designated for protection of natural ecosystems

Administratively proposed Federal Wilderness Area

Terrestrial areas utilized by large or dense aggregations of animals (vertebrate species) for breeding

Terrestrial habitat used by State designated endangered or threatened species

Terrestrial habitat used by species under review for Federal designated endangered or threatened status

State lands designated for wildlife or game management

State designated Natural Areas

Particular areas, relatively small in size, important to maintenance of unique biotic communities 


\section{AIR PATHWAY CRITERIA LIST}

This "Criteria List" helps guide the process of developing a hypothesis as to whether a release to the air is likely to be detected. The check-boxes record your professional judgment. Answers to all of the listed questions may not be available during the PA. Also, the list is not all-inclusive; if other criteria help shape your hypothesis, list them at the bottom of the page or attach an additional page.

The "Suspected Release" section identifies severaliconditions that could provide insight as to whether a release from the site is likely to be detected. If a release is suspected, primary targets are any residents, workers, students, and sensitive environments on or within $1 / 4$ mile of the site.

Check the boxes to indicate a "yes," "no," or "unknown" answer to each question. If you check the "Suspected Release" box as "yes," make sure you assign a Likelihood of. Release value of 550 for the. pathway. 


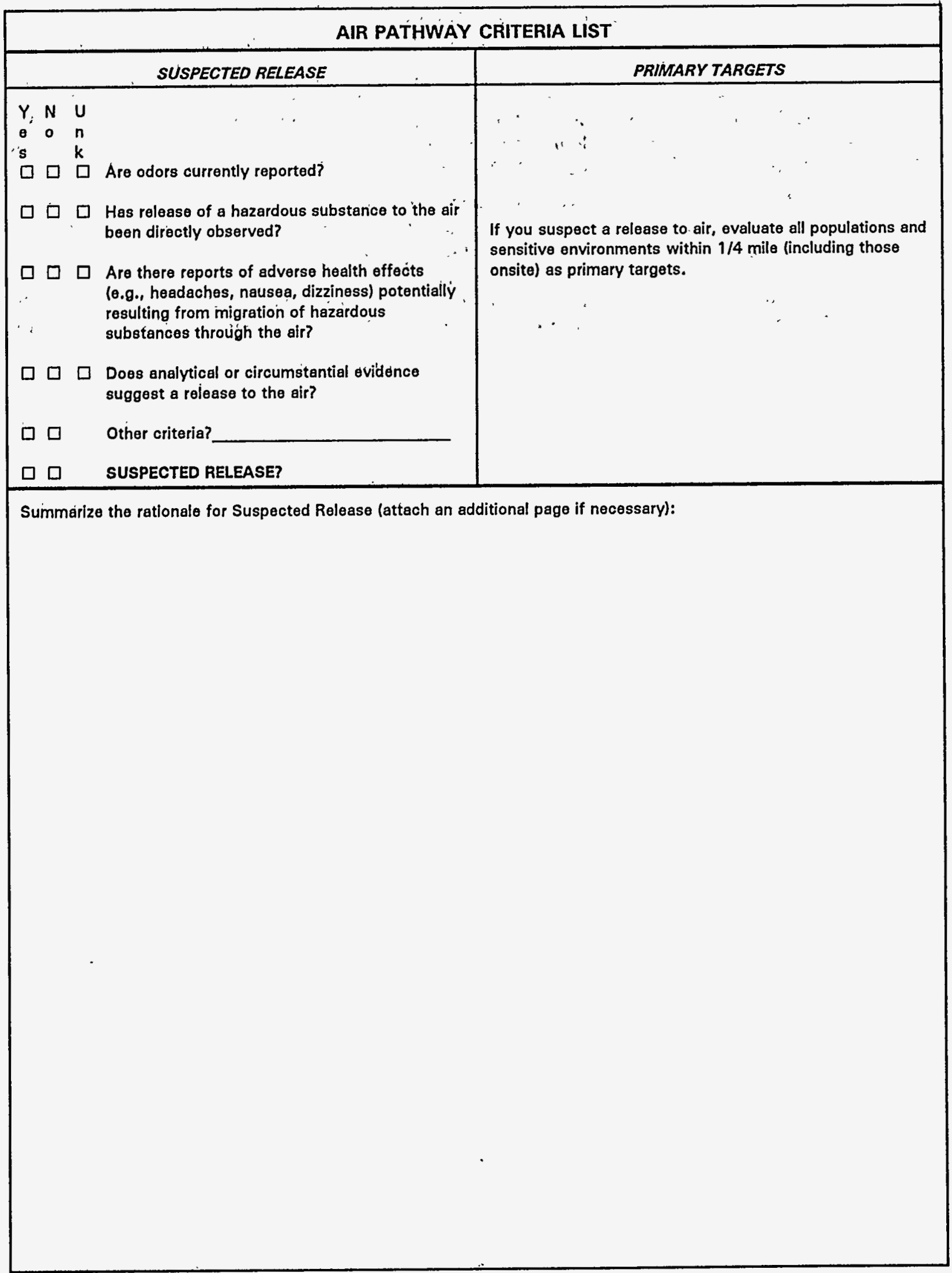




\section{AIR PATHWAY SCORESHEET}

\section{Pathway Characteristics}

Answer the questions at the top of the page. Refer to the Air Pathway Criteria List (page 21) to hypothesize whether you suspect that a hazardous substance release to the air could be detected. Due to dispersion, releases to air are not as persistent as releases to water migration pathways and are much more difficuit to detect. Develop your hypothesis concerning the release of hazardous substances to air based on "real time" considerations. Record the distance (in feet) from any source to the nearest regularly occupied building.

\section{Likelihood of Releasé (LR)}

1. Suspected Release: Hypothesize based on professional judgment guided by the Air Pathway Criteria List (page 21). If you suspect a release to air, use only Column A for this pathway and do not evaluate factor 2.

2. No Suspected Release: If you do not suspect a release, enter 500 and use only Column B for this pathway.

\section{Targets (T)}

3. Primary Target Population: Evaluate populations subject to exposure from release of a hazardous substance from the site. If you suspect a release, the resident, student, and worker populations on and within $1 / 4$ mile of the site are considered primary target population. If only the number of residences is known, use the average county residents per household (rounded up to the next integer) to determine the population. In the space provided, enter this population. Multiply the population by 10 to determine the Primary Target Population score. Note that if you do not suspect a release, there can be no primary target population.

4. Secondary Target Population: Evaluate populations in distance categories not suspected to be subject to exposure from release of a hazardous substance from the site. If you suspect a release, residents, students, and workers in the $1 / 4-$ to 4-mile distance categories are secondary target population. If you do not suspect a release, all residents, students, and workers onsite and within 4 miles are considered secondary target population.

Use PA Table 8 (page 23). Enter the population in each secondary target population distance category, circle the assigned value, and record it on the far-right side of the table. Sum the far-right column and enter the total as the Secondary Target Population factor score.

5. Nearest Individual represents the threat posed to the person most likely to be exposed to a hazardous substance release from the site. If you have identified a primary target population, enter 50. Otherwise, assign the score from PA Table 8 (page 23) for the closest distance category in which you have identified a secondary target population.

6. Primary Sensitive Environments: If a release is suspected, all sensitive environments on or within $1 / 4$ mile of the site are considered primary targets. List them and assign values for sensitive environment type (from PA Table 5 , page 16) and/or wetland acreage (from PA Table 9, page 23). Sum the values and enter the total as the factor score.

7. Secondary Sensitive Environments: If a release is suspected, sensitive environments in the $1 / 4-$ to $1 / 2$-mile distance category are secondary targets; greater distances need not be evaluated because distance weighting greatly diminishes the impact on site score. If you do not suspect a release, all sensitive environments on and within $1 / 2$ mile of the site are considered secondary targets. List each secondary sensitive environment on PA Table 10 (page 23) and assign a value to each using PA Tables 5 and 9 . Multiply each value by the indicated distance weight and record the product in the farright column. Sum the products and enter the total as the factor score.

8. Resources: A score of $\mathbf{5}$ can generally be assigned as a default measure. Assign zero only if there is no land resource use within $1 / 2$ mile.

Sum the target scores in Column A (Suspected Release) or Column B (No Suspected Release).

\section{Waste Characteristics (WC)}

9.Waste Characteristics: Score is assigned from page 4. However, if you have identified any primary target for the air pathway, assign either the score calculated on page 4 or a score of 32 , whichever is greater.

Air Pathway Score: Multiply the scores for LR, T, and WC. Divide the product by 82,500 . Round the result to the nearest integer. If the result is greater than 100, assign 100 . 
AIR PATHWAY SCORESHEET

\begin{tabular}{|c|c|}
\hline Pathway Charectadstes & \\
\hline Do you suspect a release (see Air Pathway Criteria List, page 21)? & Yes___ No _ \\
\hline
\end{tabular}

LIKELIHOOD OF RELEASE

1. SUSPECTED RELEASE: If you suspect a release to air (see page 21), assign a score of 550 . Use only column A for this pathway.

2. NO SUSPECTED RELEASE: If you do not suspect a release to air, assign a score of 500 . Use only column B for this pathway.

$L R=$

A

B

Suspected No Suspected

Relase 1 Retase

Reforences

TARGETS

3. PRIMARY TARGET POPULATION: Determine the number of people subject to exposure from a suspected release of hazardous substances to the air. people $\times 10$

4. SECONDARY TARGET POPULATION: Determine the number of people not suspected to be exposed to a release to air, and assign the total population score using PA Table 8.

5. NEAREST INDIVIDUAL: If you have identified any Ptimary Target Population for the air pathway, assign a score of 50; otherwise, assign the Nearest Individual score from PA Table 8.

6. PRIMARY SENSITIVE ENVIRONMENTS: SUm the sensitive environment values (PA Table 5) and wetland acreage values (PA Table 9) for environments subject to exposure from a suspected release to the air.

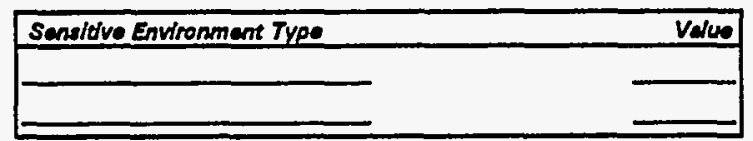

7. SECONDARY SENSITIVE ENVIRONMENTS: Use PA Table 10 to determine the score for secondary sensitive environments.

8. RESOURCES

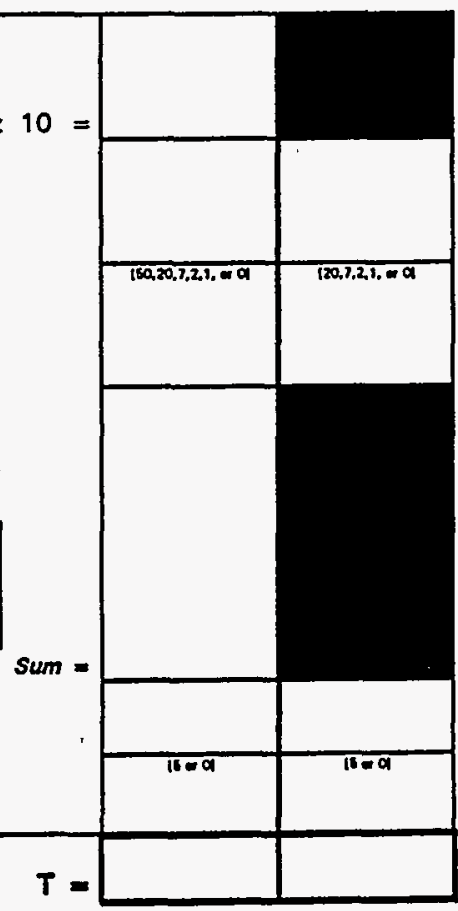

\section{WASTE CHARACTERISTICS}

9. A. If you have identified any Primary Target for the air pathway, assign the waste characteristics score calculated on page 4 , or a score of 32 , whichever is GREATER; do not evaluate part $B$ of this factor.

B. If you have NOT identified any Primary Target for the air pathway, assign the waste characteristics score calculated on page 4.

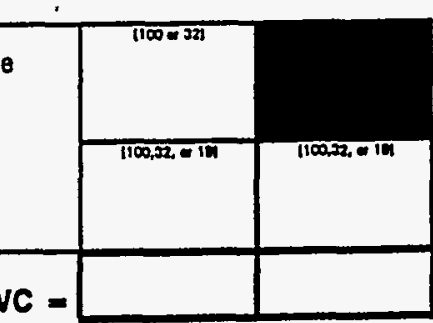

AIR PATHWAY SCORE:

$\frac{\operatorname{LR} \times T \times W C}{82,500}$



PA TABLE 8: VALUES FOR SECONDARY AIR TARGET POPULATIONS

\begin{tabular}{|c|c|c|c|c|c|c|c|c|c|c|c|c|c|c|c|}
\hline \multirow[b]{2}{*}{$\begin{array}{l}\text { Distance } \\
\text { from Site }\end{array}$} & \multirow[b]{2}{*}{ Population } & \multirow{2}{*}{\begin{tabular}{c|} 
Nearest \\
Individual \\
(chooso \\
highest)
\end{tabular}} & \multicolumn{12}{|c|}{ Population Within Distance Catogary } & \multirow[b]{2}{*}{$\begin{array}{c}\text { Population } \\
\text { Valuse }\end{array}$} \\
\hline & & & $\begin{array}{l}1 \\
10 \\
10\end{array}$ & $\begin{array}{l}11 \\
10 \\
30 \\
\end{array}$ & $\begin{array}{l}31 \\
10 \\
100 \\
\end{array}$ & $\begin{array}{c}107 \\
t 0 \\
300 \\
\end{array}$ & $\begin{array}{r}301 \\
t 0 \\
1.000 \\
\end{array}$ & $\begin{array}{c}1.001 \\
t 0 \\
3.000 \\
\end{array}$ & $\begin{array}{c}3.001 \\
50 \\
10.000 \\
\end{array}$ & $\begin{array}{c}10,001 \\
t 0 \\
30,000 \\
\end{array}$ & $\begin{array}{c}30,001 \\
10 \\
100,000 \\
\end{array}$ & $\begin{array}{c}100,001 \\
t 0 \\
300,000 \\
\end{array}$ & $\begin{array}{c}300,001 \\
\text { to } \\
7,000,000\end{array}$ & $\begin{array}{c}\text { Orester } \\
\text { then } \\
1,000,000\end{array}$ & \\
\hline Onsite & & 20 & 1 & 2 & 5 & 16 & $\mathbf{5 2}$ & 163 & 521 & 1,633 & 5,214 & 16,325 & 52,136 & 163.246 & \\
\hline$>0$ to $\times$ milo & & 20 & 1 & 1 & 1 & 4 & 13 & 41 & 130 & 408 & 1,303 & 4,081 & 13,034 & 40,811 & \\
\hline$>y_{4}$ to $y_{2}$ milo & & 2 & $\mathbf{0}$ & $\mathbf{0}$ & 1 & 1 & 3 & 9 & 28 & 88 & 282 & 882 & 2,815 & 8,815 & \\
\hline$>$ \& to 1 milo & & 1 & 0 & $\mathbf{0}$ & $\mathbf{0}$ & 1 & 1 & 3 & 8 & 26 & 83 & 261 & 834 & 2,612 & \\
\hline$>1$ to 2 milos & & 0 & 0 & 0 & 0 & 0 & 1 & 1 & 3 & 8 & 27 & 83 & 266 & 833 & \\
\hline$>2$ to 3 milos & & 0 & 0 & 0 & 0 & 0 & 1 & 1 & 1 & 4 & 12 & 38 & 120 & 376 & \\
\hline$>3$ to 4 milos & & 0 & 0 & 0 & 0 & 0 & 0 & 1 & 1 & 2 & 7 & 23 & 73 & 229 & \\
\hline
\end{tabular}

PA TABLE 9: AIR PATHWAY VALUES FOR WETLAND AREA

\begin{tabular}{|lc|}
\hline Wetland Area & Assigned Value \\
\hline Less than 1 acro & 0 \\
1 to 50 acres & 25 \\
Greator than 50 to 100 acres & 75 \\
Greater than 100 to 150 acres & 125 \\
Groater then 150 to 200 acres & 175 \\
Groator than 200 to 300 acres & 250 \\
Groater than 300 to 400 acros & 350 \\
Groator than 400 to 500 acres & 450 \\
Groater than 500 acros & 500 \\
\hline
\end{tabular}

PA TABLE 10: DISTANCE WEIGHTS AND CALCULATIONS FOR AIR PATHWAY SECONDARY SENSITIVE ENVIRONMENTS

\begin{tabular}{|c|c|c|c|}
\hline Distance & $\begin{array}{l}\text { Distance } \\
\text { Wolght }\end{array}$ & $\begin{array}{l}\text { Sensitive Environment Typo and Value } \\
\text { (from PA Table } 5 \text { or } 9 \text { ) }\end{array}$ & Product \\
\hline \multirow[t]{2}{*}{ Onsito } & \multirow[t]{2}{*}{0.10} & $\underline{x}$ & \\
\hline & & $x$ & \\
\hline \multirow{3}{*}{$0-1 / 4 \mathrm{mi}$} & \multirow{3}{*}{0.025} & $x$ & \\
\hline & & $x$ & \\
\hline & & $x$ & \\
\hline \multirow{4}{*}{$1 / 4-1 / 2 \mathrm{mi}$} & \multirow{4}{*}{0.0054} & $x$ & \\
\hline & & $x$ & \\
\hline & & $x$ & \\
\hline & & $x$ & \\
\hline
\end{tabular}




\section{SITE SCORE CALCULATION}

In the column labeled S, record the Ground Water Pathway score, the Surface Water Pathway score, the Soil Exposure Pathway score, and the Air Pathway score. Square each pathway score and record the result in the $S^{2}$ column. Sum the squared pathway scores. Divide the sum by 4 , and take the square root of the result to obtain the Site Score.

\section{SUMMARY}

Answer the-summary questions, which ask for a qualitative evaluation of the relative risk of targets being exposed to a hazardous substance from the site. You may find your responses to these questions a good cross-check against the way you scored the individual pathways. For example, if you scored the ground water pathway on the basis of no suspected release and secondary targets only, yet your response to question \#1 is "yes," this presents apparently conflicting conclusions that you need to reconsider and resolve: Your answers to the questions on page 24 should be consistent with your èvaluations elsewhere in the PA scoresheets package. 


\section{SITE SCORE CALCULATION}

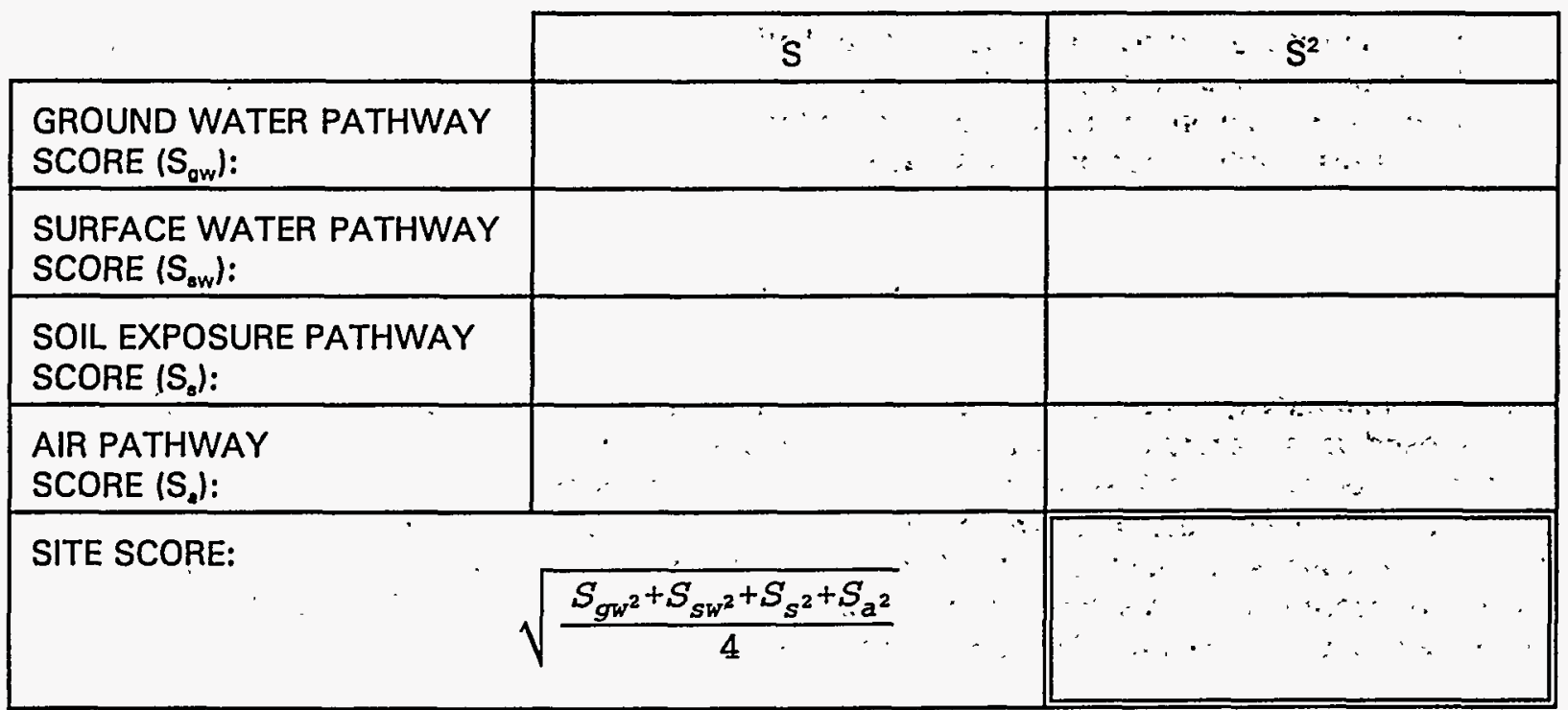

\section{SUMMARY}

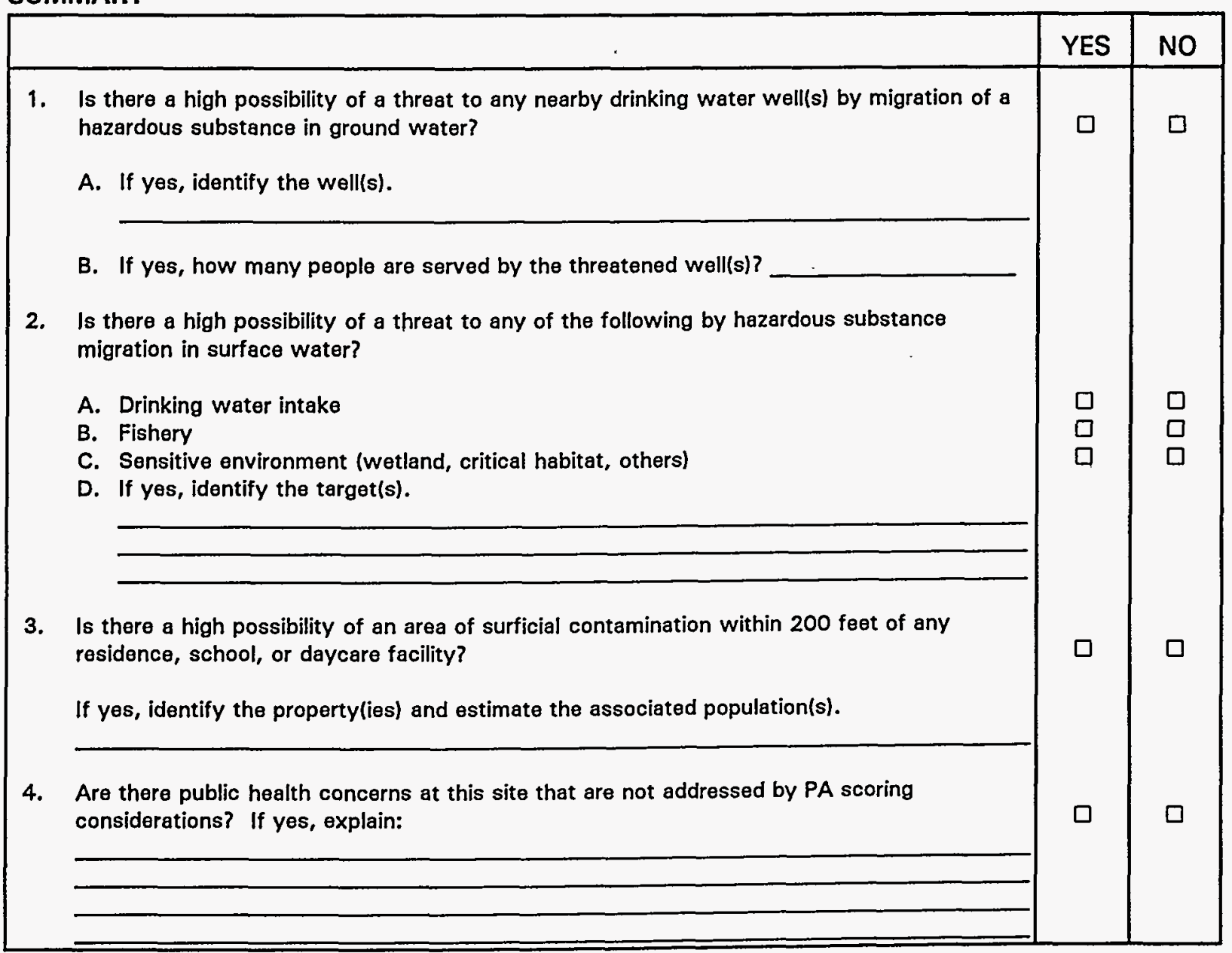





\section{APPENDIX B}

\section{PA INFORMATION SOURCES}

This appendix provides lists of information sources often useful to PA investigations. The lists are organized in two ways:

- Lists beginning on page B-2 identify information sources by category and explain information provided by each source. The categories are:

-- Databases

- Maps and aerial photographs

-. Files

-- Expert and other sources

- The reverse approach begins on page B-12. Categories of information needs are listed and appropriate information sources are identified for each. The categories are:

-- General site information

-- Source and waste characteristics

-- Ground water use and characteristics

-- Surface water use and characteristics

-- Soil exposure characteristics

-- Air characteristics

More complete listings of PA information sources are available in EPA's "Site Assessment Information Directory." This reference volume provides office names, addresses, and telephone numbers of Federal, State, county, and municipal information sources. 
PA INFORMATION SOURCES

(Organized by Information Source)

\section{DATABASES}

\begin{tabular}{|ll|}
\hline Source: & $\begin{array}{l}\text { CERCLIS (Comprehensive Environmental Response, Compensation, and Liability } \\
\text { Information System) }\end{array}$ \\
Provides: & $\begin{array}{l}\text { EPA's inventory of potential hazardous waste sites. Provides site name, EPA } \\
\text { identification number, site address, and the dates and types of previous } \\
\text { investigations. }\end{array}$ \\
Supports: & Site location and general descriptive information. \\
Contact: & EPA Regional office \\
\hline Source: & HWDMS (Hazardous Waste Data Management System) \\
Provides: & $\begin{array}{l}\text { EPA's inventory of hazardous waste producers. Contains information such as } \\
\text { facility type, status, and ownership; RCRA status and permits held; treatment, } \\
\text { storage, and disposal activities; amount of wastes generated. }\end{array}$ \\
Supports: & $\begin{array}{l}\text { Site descriptive information and operational history, information on waste types } \\
\text { and quantities. }\end{array}$ \\
& \begin{tabular}{l} 
EPA Regional office \\
\hline
\end{tabular}
\end{tabular}

Source: $\quad$ RCRA (Resource Conservation and Recovery Act) Database Printouts

Provides: EPA's inventory of hazardous waste generators. Contains facility name, address, phone number, and contact name; EPA identification number; treatment, storage, and disposal history; and date of notification.

Supports: Site descriptive information and operational history, information on waste types and quantities.

Contact: $\quad$ EPA Regional office

Source: $\quad$ NPDES (National Pollutant Discharge Elimination System) Database Printouts

Provides: $\quad$ EPA's list of sites which have (or had) permits for wastewater disposal.

Supports: $\quad$ Site descriptive information and operational history, information on waste types and quantities, permits.

Contact: $\quad$ EPA Regional office 


\begin{tabular}{|c|c|}
\hline Source: & PATHSCAN \\
\hline Provides: & Identifies surface water drinking water intakes and populations served. \\
\hline Supports: & $\begin{array}{l}\text { Locations of surface water drinking water intakes; populations served by surface } \\
\text { water drinking water intakes; stream flow of surface water bodies. }\end{array}$ \\
\hline Contact: & EPA's Office of Water Regulations and Standards \\
\hline Sọrce: & WellFax \\
\hline Provides: & $\begin{array}{l}\text { National Water Well Association's inventory of municipal and community water } \\
\text { supplies. Identifies public and private wells within specified distances around a } \\
\text { point location and the number of households served by each. }\end{array}$ \\
\hline Supports: & Drinking water populations served by ground water. \\
\hline Contact: & $\begin{array}{l}\text { National Water Well Association (NWWA) } \\
6375 \text { Riverside Drive } \\
\text { Dublin, Ohio } 43017\end{array}$ \\
\hline
\end{tabular}

\begin{tabular}{|ll|}
\hline Source: & Graphical Exposure Modeling System (GEMS) \\
Provides: & $\begin{array}{l}\text { EPA's database of U.S. census data. Provides residential populations in specified } \\
\text { distance rings around a point location. }\end{array}$ \\
Supports: & Residential populations. \\
Contact: & EPA's Office of Toxic Substances \\
\hline
\end{tabular}

\begin{tabular}{|ll|}
\hline Source: & National Planning Data Corporation (NPDC) \\
Provides: & $\begin{array}{l}\text { Commercial database of U.S. census data. Provides residential populations in } \\
\text { specified distance rings around a point location. }\end{array}$ \\
Supports: & Residential populations. \\
Contact: & $\begin{array}{l}\text { National Planning Data Corporation } \\
20 \text { Terrace Hill } \\
\text { Ithaca, New York 14850-5686 }\end{array}$ \\
\hline
\end{tabular}




\begin{tabular}{|ll}
\hline Source: & STORET \\
Provides: & EPA's repository of water quality data for waterways within the United States. \\
& $\begin{array}{l}\text { The system is capable of performing a broad range of reporting, statistical } \\
\text { analysis, and graphics functions. }\end{array}$ \\
Supports: & $\begin{array}{l}\text { Geögráphic and descriptive information on various waterways; analytical data } \\
\text { from surface water, fish tissue } ;\end{array}$ \\
Contact: & EPA sediment samples; stream flow data.
\end{tabular}

\begin{tabular}{|ll|}
\hline Source: & Federal Reporting Data System (FRDS) \\
Provides: & $\begin{array}{l}\text { General information on public water supply utilities using ground water or surface } \\
\text { water, updated annually. Developed for monitoring compliance with the Safe } \\
\text { Drinking Water Act of } 1974 . \\
\text { Supports: }\end{array}$ \\
$\begin{array}{l}\text { Name and address of public water sumply, facility location, hydrological } \\
\text { identification, water source type and name, population served. }\end{array}$ \\
Contact: & EPA's Office of Drinking Water
\end{tabular}

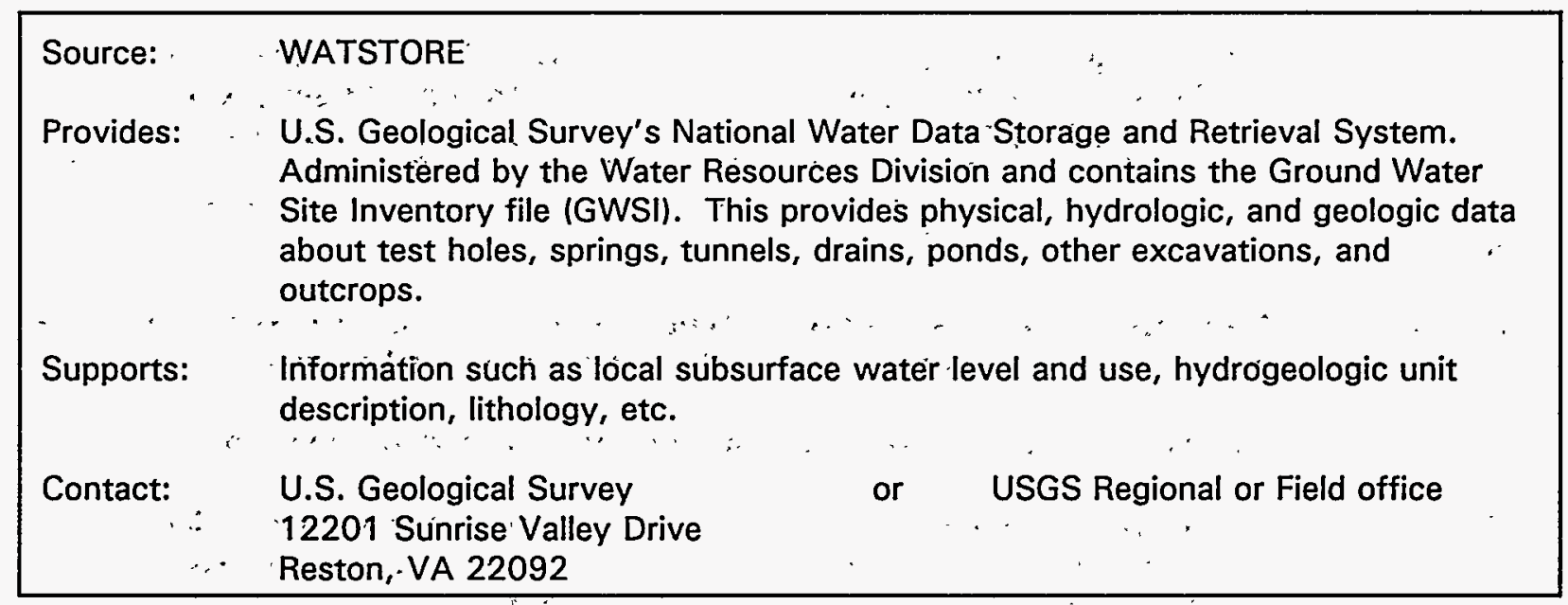

Source: - Compliance Monitoring and Enforcement Logs (CMELs)

Provides: $\quad$ EPA's summary of compliance monitoring and enforcement logs used to review the compliance and enforcement history of a facility and to correct and update the data in HWDMS.

Supports: Site descriptive information and operational history, information on waste types and quantities.

Contact: $\quad$ EPA Regional office 
Source: $\quad$ U.S. Geological Survey (USGS) Topographic Quadrangles

Provides: - Maps detailing topographic, geographical, political, and cultural features. Available in 7.5- and 15-minute series.

Supports: Site location and environmental setting; latitude/longitude; houses, schools; and other buildings; distances to targets; sürface water body types; drainage routes; wetlands and sensitive environments; karst terrain features.

Contact: U.S. Geological Survey or USGS Regional or Field office

12201. Sunrise Valley Drive

Reston, VA 22092

Source: National Wetland Inventory Maps

Provides: Maps delineating boundaries and acreage of wetlands.

Supports: Environmental setting and wetlands locations.

Contact: U.S. Geological Survey or U.S. Fish and Wildlife Service 12201 Sunrise Valley Drive 18th and C Streets, NW

Reston, VA $22092 \quad$ Washington, DC 20240

Source: Ecological Inventory Maps

Provides: Maps delineating sensitive environments and habitats, including special land use areas, wetlands, study areas, and native plant and animal species.

Supports: Environmental setting, sensitive environments, wetland locations and size.

Contact: U.S. Geological Survey or U.S. Fish and Wildlife Service 12201 Sunrise Valley Drive 18th and C Streets, NW

Reston, VA $22092 \quad$ Washington, DC 20240

Source: $\quad$ Flood Insurance Rate Maps (FIRM)

Provides: Maps delineating flood hazard boundaries for flood insurance purposes.

Supports: Flood frequency.

Contact: Federal Emergency Management or Local Zoning and Planning office

Agency (FEMA)

Federal Insurance Administration

Office of Risk Assessment

500 C Street, SW

Washington, DC 20472 
Source: $\quad$ State Department of Transportation Maps

Provides: $\quad$ State maps detailing road systems, surface water systems, and other geographical, cultural, and political features.

Supports: Site location and environmental setting, distances to targets, wetlands, and sensitive environments.

Contact: $\quad$ State or Local Government Agency

Source: $\quad$ Geologic and Bedrock Maps

Provides: $\quad$ Maps detailing surficial exposure and outcrop of formations for interpreting subsurface geology. Bedrock maps describe depth and lateral distribution of bedrock.

Supports: General stratigraphy beneath and surrounding the site.

Contact: $\quad$ U.S. Geological Survey 12201 Sunrise Valley Drive

or USGS Regional or Field Office Reston, VA 22092

\section{Source: $\quad$ Aerial Photographs}

Provides: Black and white and/or color photographic images detailing topographic, physical, and cultural features.

Supports: Site location and size, location and extent of waste sources, identification of surrounding surficial geology, distances to targets, wetlands and sensitive environments. May provide information on historical site operations, waste quantity, and waste handling practices.

Contact: $\quad$ State Department of Transportation Local Zoning and Planning office County Tax Assessor's office Colleges and Universities (geology or geography departments) EPA's Environmental Monitoring Services Laboratory (EMSL) EPA's Environmental Photographic Interpretation Center (EPIC) U.S. Army Corps of Engineers

U.S. Department of Agriculture, Forest Service

U.S. Geological Survey 


\section{FILES}

Source: Office project files

Provides: Site investigation reports, logbooks, telecons, references, etc. -

Supports: Information on nearby sites such as town populations, public and private water supplies, well locations, targets, and general stratigraphy descriptions.

Source: $\quad$ EPA Regional Office files

Provides: $\quad$ Historical information on CERCLIS sites, permits, violations, and notifications.

Supports: General site information and operational history, source descriptions, waste quantities and waste handling practices. May provide results of previous site investigations.

Source: $\quad$ State Environmental Agency files

Provides: . Historical site information, permits, violations, and notifications.

Supports: General site information and operational history, source descriptions, waste quantities and waste, handling practices. May provide results of previous site investigations. 


\begin{tabular}{|c|c|}
\hline Source: & U.S. Geologiçal Survey \\
\hline Provides: & $\begin{array}{l}\text { Geologic, hydrogeologic, and hydraulic information including maps, reports, } \\
\text { studies, and databases. }\end{array}$ \\
\hline Supports: & $\begin{array}{l}\text { General stratigraphy descriptions, karst terrain, depth to aquifer, stream flow, } \\
\text { ground water and surface water use and characteristics. }\end{array}$ \\
\hline Contact: & $\begin{array}{l}\text { U.S. Geological Survey } \\
12201 \text { Sunrise Valley Drive } \\
\text { Reston, VA } 22092\end{array}$ \\
\hline
\end{tabular}

Source: U.S. Army Corps of Engineers

Provides: Records and data surrounding engineering projects involving surface waters.

Supports: Ground water and surface water characteristics, stream flow, locations of wetlands and sensitive environments.

Contact: $\quad$ U.S. Army Corps of Engineers

Source: State Geological Survey

Provides: State-specific geologic and hydrogeologic information including maps, reports, studies, and databases.

Supports: General stratigraphy descriptions, karst terrain, depth to aquifer, ground water use and characteristics.

Contact: State Geological Survey (Local or Field office)

Source: Natural Heritage Program

Provides: Information on Federal and State designated endangered and threatened plants, animals, and natural communities. Maps, lists, and general information may be available.

Supports: Location of sensitive environments and wetlands.

Contact: $\quad$ State Environmental Agency 


\begin{tabular}{|lll|}
\hline Source: & U.S. Fish and Wildlife Service & \\
Provides: & Environmental information. & \\
Supports: & $\begin{array}{l}\text { Locations of sensitive environments, wetlands, fisheries; surface water } \\
\text { characteristics and stream flow. }\end{array}$ & \\
Contact: & $\begin{array}{l}\text { U.S. Fish and Wildlife Service } \\
\text { 18th \& C Streets, NW } \\
\text { Washington, DC 20240 }\end{array}$ & or $\quad$ U.S: Fish and Wildlife Service \\
&
\end{tabular}

\begin{tabular}{|ll|}
\hline Source: & "Local Fish and Wildife Officials \\
Provides: & Local environmental information. \\
Supports: & $\begin{array}{l}\text { Locations of sensitive environments, wetlands, fisheries; surface water } \\
\text { characteristics and stream flow. }\end{array}$ \\
Contact: & $\begin{array}{l}\text { State or Local Environmental Agency } \\
\text { State or Local Game or Conservation office }\end{array}$ \\
\hline
\end{tabular}

$\begin{array}{ll}\text { Source: } & \text { Local Tax Assessor } \\ \text { Provides: } & \begin{array}{l}\text { Past and present land ownership records, lot and building sizes, assessors maps. } \\ \text { May also provide historical aerial photographs. }\end{array} \\ \text { Supports: } & \begin{array}{l}\text { Name of present and past owners/operators, years of ownership, size of site, } \\ \text { and operational history. }\end{array} \\ \text { Contact: } & \text { Local Town Government office }\end{array}$

\begin{tabular}{|ll|}
\hline Source: & Local Water Authority \\
Provides: & $\begin{array}{l}\text { Public and private water supply information, including service area maps, well } \\
\text { locations and depths, well logs, surface water intake locations, information } \\
\text { regarding water supply contamination. }\end{array}$ \\
Supports: & $\begin{array}{l}\text { Locations and populations served by municipal and private drinking water } \\
\text { sources (wells and surface water intakes), pumpage and production, blended } \\
\text { systems, depth to aquifer, general stratigraphic descriptions, ground water and } \\
\text { surface water characteristics, stream flow. }\end{array}$ \\
Contact: & Local Town Government office
\end{tabular}




\section{Source: $\quad$ Local Health Department}

Provides: Information and reports regarding health-related problems that may be associated with a site. Information on private and municipal water supplies, and onsite monitoring wells.

Supports: Primary/secondary targets differentiation, locations and characteristics of public and private drinking water supplies, possible identification of hazardous substances present at the site.

Contact: Local Town Government office

\section{Source: $\quad$ Local Zoning Board or Planning Commission}

Provides: Records of local land development, including historical land use and ownership, and general stratigraphy descriptions.

Supports: General site description and history, previous ownership, and land use.

Contact: Local Town Government office

\section{Source: $\quad$ Local Fire Department}

Provides: Records of underground storage tanks in the area, material safety data sheets (MSDS) for local commercial and industrial businesses, and other information on hazardous substances used by those businesses.

Supports: Location and use of underground storage tanks and other potential sources of hazardous substances, identification of hazardous substances present at the site.

Contact: Local Town Government office

\section{Source: $\quad$ Local Well Drillers}

Provides: Public and private water supply information including well locations and depths, well logs, pumpage and production.

Supports: Populations served by private and municipal drinking water wells, depth to aquifer, general stratigraphic information.

\section{Source: $\quad$ Local University or College}

Provides: Geology/environmental studies departments may have relevant published materials (reports, theses, dissertations) and faculty experts knowledgeable in local geologic, hydrologic, and environmental conditions.

Supports: General stratigraphic information, ground water and surface water use and characteristics, stream flow. 
Source:

Provides:

Supports:
Site Reconnaissance

Onsite and/or offsite visual observation of the site and surrounding area.

General site information; source identification and descriptions; general ground water, surface water, soil, and air pathway characteristics; nearby targets; probable point of entry to surface water. 
PA INFORMATION SOURCES

(Organized by Information Need)

\section{GENERAL SITE INFORMATION}

Site Location, Latitude/Longitude.

CERCLIS

USGS Topographic Maps

State Department of Transportation Maps

Site Reconnaissance

\section{Owner/Operator Information}

EPA Regional Office Files

State Environmental Agency Files

Local Tax Assessor

HWDMS

NPDES

CMELS
Type of Operation and Site Status

EPA Regional Office Files

State Environmental Agency Files

Site Reconnaissance

HWDMS

NPDES

CMELS

Environmental Setting, Size of Site

USGS Topographic Maps

Aerial Photographs

Site Reconnaissance

\section{SOURCE AND WASTE CHARACTERISTICS}

Source Types, Locations, Sizes

EPA Regional Office Files

State Environmental Agency Files

Aerial Photographs

Site Reconnaissance

Waste Types and Quantities

EPA Regional Office Files

State Environmental Agency Files

RCRA

HWDMS

NPDES

CMELS

Local Fire Department

Aerial Photographs

Site Reconnaissance

\section{Hazardous Substances Present}

EPA Regional Office Files

State Environmental Agency Files

RCRA

HWDMS

NPDES

Local Health Department

Local Fire Department 


\section{General Stratigraphy}

USGS Topographic Maps

U.S. Geological Survey

State Geological Surveys

Geologic and Bedrock Maps

Local Experts

Local University or College

Karst Terrain

USGS Topographic Maps

U.S. Geological Survey

State Geological Surveys

Geologic and Bedrock Maps

Local Experts

Local University or College

Depth to Aquifer

U.S. Geological Survey

State Geological Surveys

Geologic and Bedrock Maps

Local Well Drillers

Local Experts

FRDS

WATSTORE
Private and Municipal Wells

Local Water Authority

Local Health Department.

Local Well Drillers

State Environmental Agency files

WellFax

FRDS

WATSTORE

\section{Distance to Nearest Drinking Water Well}

USGS Topographic Maps

Local Water Authority

Local Well Drillers

Local Health Department

WellFax

FRDS

WATSTORE

Site Reconnaissance

Wellhead Protection Areas

State Environmental Agency

Local Water Authority.

Local Well Drillers

Local Health Department

EPA Regional Water Officials 


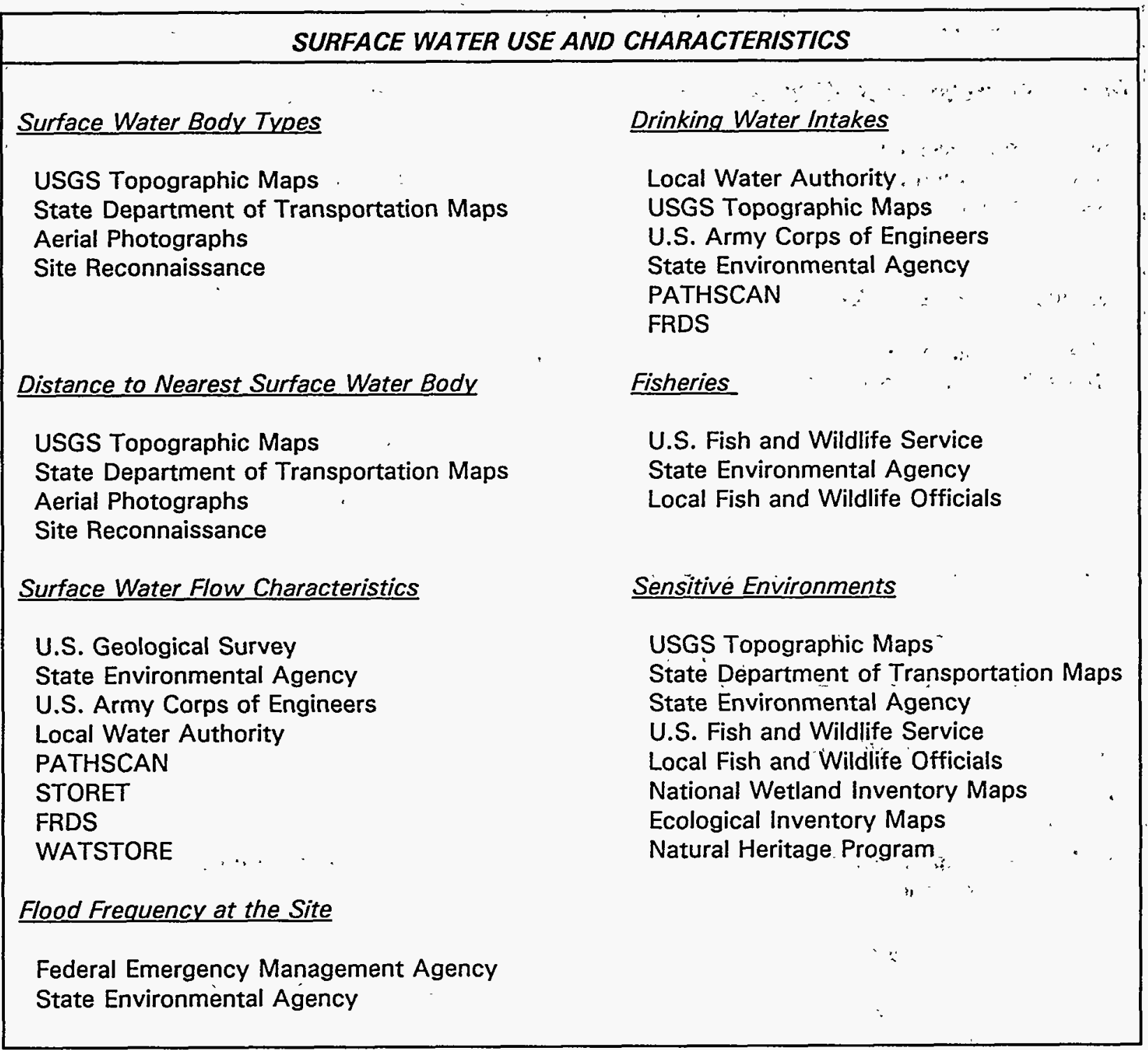


Number of People Living Within 200 feet

Site Reconnaissance USGS Topographic Maps

Aerial Photographs

Number of Workers Onsite

Site Reconnaissance

Owner/Operator Interviews

\section{Schools or Day Care Within 200 feet}

Site Reconnaissance

USGS Topographic Maps

Local Street Maps

Locations of Terrestrial Sensitive Environments

USGS Topographic Maps

State Department of Transportation Maps

State Environmental Agency

U.S. Fish and Wildlife Service

Local Fish. and Wildlife Officials

Ecological Inventory Maps

Natural Heritage Program

AIR PATHWAY CHARACTERISTICS

Populations Within Four Miles

GEMS

NPDC

USGS Topographic Maps

Site Reconnaissance

Distance to Nearest Individual

USGS Topographic Maps

Site Reconnaissance
Locations of Sensitive Environments, Acreage of Wetlands

USGS Topographic Maps

State Department of Transportation Maps

State Environmental Agency

U.S. Fish and Wildlife Service

Local Fish and Wildlife Officials

National Wetland Inventory Maps

Ecological Inventory Maps

Natural Heritage Program 



\section{APPENDIX C}

\section{SAMPLE PA NARRATIVE REPORT}

This appendix provides a sample narrative report for a fictitious site. The report follows the form and content discussed in Section 4.2. Example reference material for information sources cited in the report are also included.

Due to format and space constraints of this guidance document, not all references are reproduced as they should appear in a typical PA narrative report. Not included in this example report are:

- Full-size maps such as USGS topographic quadrangles.

- Copies of pertinent sections or pages of published documents. Only the title pages are included here.

- Original photographs accompanying the photodocumentation log. 
PRELIMINARY ASSESSMENT

PALMETTO LANDFILL

PALMETTO COUNTY, SOUTH CAROLINA

TDD NO. Y9-8765-43

JUNE 10, 1991

XYZ CORPORATION

Prepared By

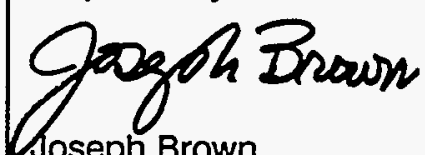

Joseph Brown

Project Manager
Reviewed By

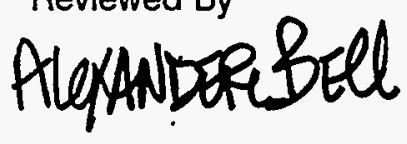

Alexander Bell

PA Section Leader
Approved By

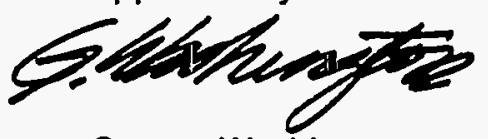

George Washington

Office Manager 
Date: June 10, 1991

Prepared by: Joseph Brown, XYZ Corporation

Region 4, Atlanta, Georgia

Site: Palmetto Landfill

6250 Palmetto Drive

Palmetto County, South Carolina

EPA ID No.: SCD123456789

TDD No.: Y9-8765-43

\section{INTRODUCTION}

Under authority of the Comprehensive Environmental Response, Compensation, and Liability Act of 1980 (CERCLA) and the Superfund Amendments and Reauthorization Act of 1986 (SARA), the U.S. Environmental Protection Agency (EPA), Waste Management Division, Region 4 conducted a Preliminary Assessment (PA) at the Palmetto Landfill site in Palmetto County, South Carolina.

The purpose of this investigation was to collect information concerning conditions at the Palmetto Landfill sufficient to assess the threat posed to human health and the environment and to determine the need for additional CERCLA/SARA or other appropriate action. The scope of the investigation included review of available file information, a comprehensive target survey, and an offsite reconnaissance (May 7, 1991).

\section{SITE DESCRIPTION, OPERATIONAL HISTORY, AND WASTE CHARACTERISTICS}

\subsection{Location}

Palmetto Landfill is located at 6250 Palmetto Drive in a rural area of Palmetto County, South Carolina, just east of the town of Angleton (Figure 1). The geographic coordinates are $18^{\circ} 28^{\prime} 43^{\prime \prime}$ $\mathrm{N}$ latitude and $66^{\circ} 07^{\prime} 33^{\prime \prime} \mathrm{W}$ longitude (Reference 1; Reference 2). To reach the site, travel east from the town of Angleton approximately 1.5 miles on Rt. 149, and turn left on Palmetto Drive. The site is approximately 0.25 mile from the intersection of Rt. 149 and Palmetto Drive.

Palmetto County is characterized by a mild, temperate climate. Summers are warm and humid with daily temperatures reaching $90^{\circ} \mathrm{F}$ or higher. The winter months are generally mild with daily average temperatures of $55^{\circ}$ to $60^{\circ} \mathrm{F}$. Mean annual precipitation is 46 inches, while net precipitation for the area is 10.87 inches (Reference $3, \mathrm{pp} .7,10$ ).

\subsection{Site Description}

The total area of the landfill property is approximately 10 acres, of which approximately 6 acres were used for disposal of wastes (Reference 4). The landfill property is located on relatively flat terrain that slopes gently toward the northeast boundary (Reference 5) and Wildlife Creek, a small, slow flowing stream (Reference 6, p. 124). The landfill property is rectangular in shape and bordered on three sides by a perimeter ditch approximately 8 to 10 feet deep (Reference 4) (Figure 2). 


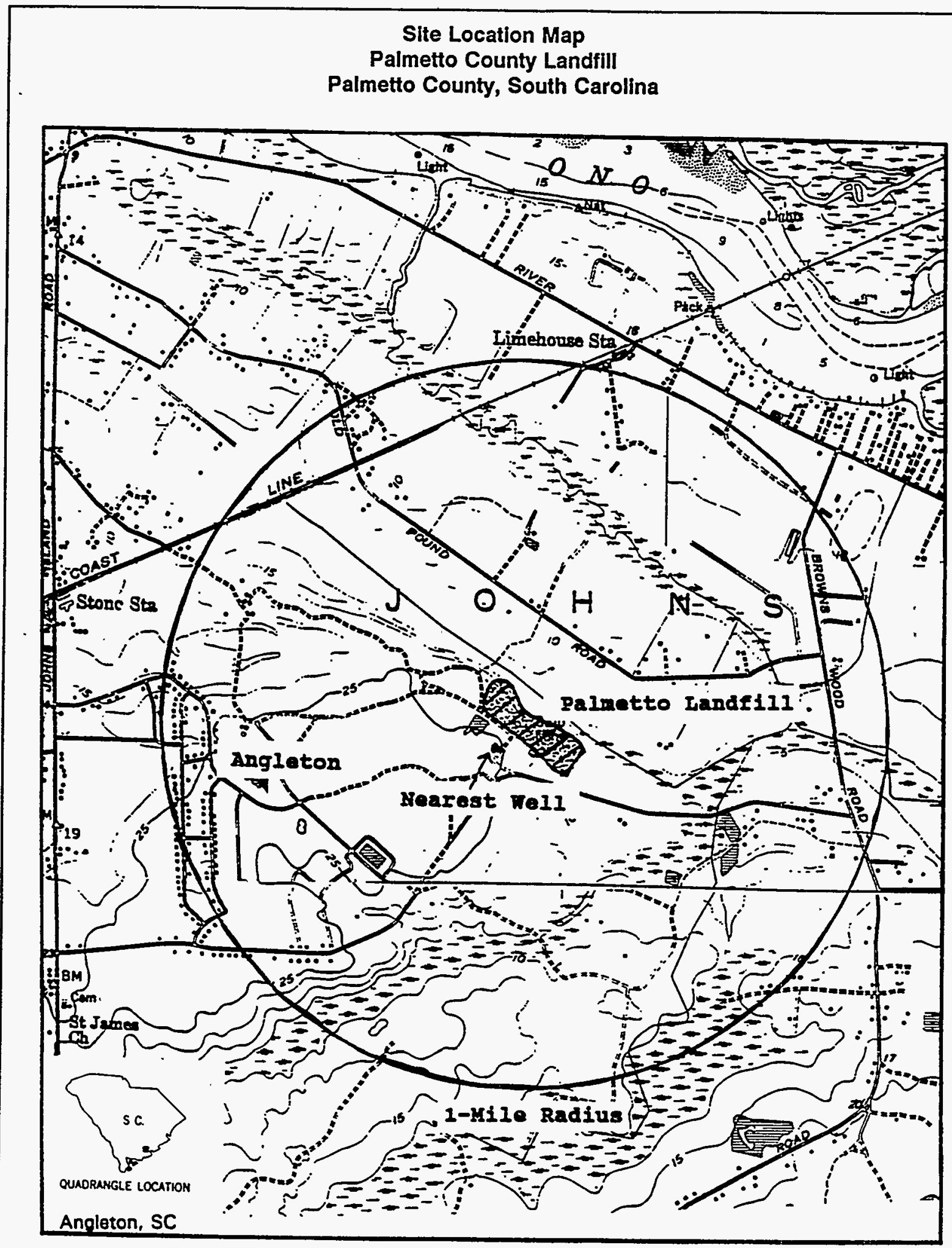

Figure 1 


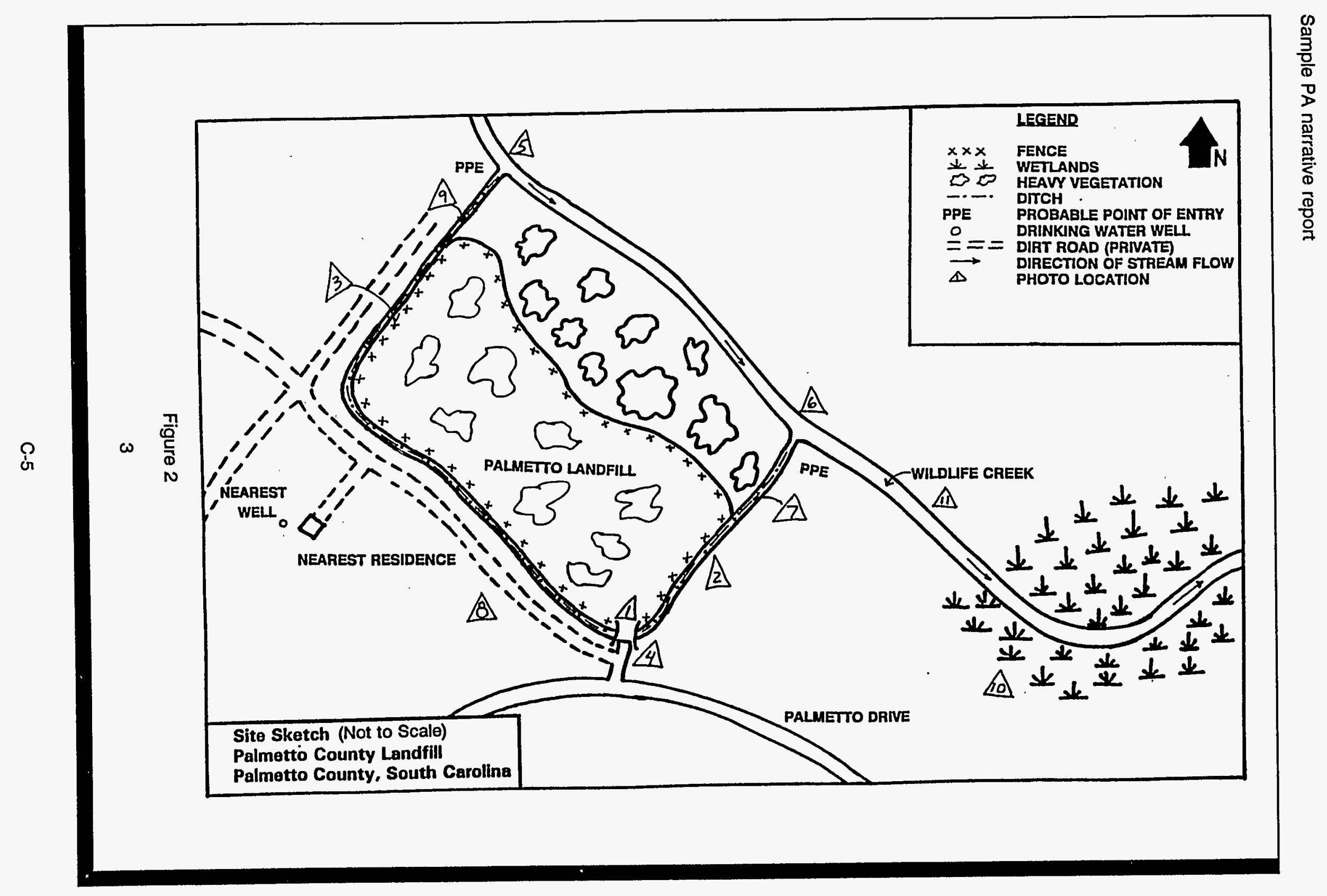


The original purpose of the perimeter ditch was to intercept ground water upgradient of the site and direct it around the buried waste (Reference 4). Since the ditch is only 8 to 10 feet deep, it does not fulfill this function as it does not completely transect the aquifer. It does, however, create a barrier to runoff from areas upgradient of the site. Along the banks of the perimeter ditch there is evidence of stressed vegetation (Reference 5). Water in the ditch is an orange/brown color and is oily in appearance (Reference 5; Reference 7, p. 4).

There are no buildings or other structures on the property. The perimeter of the property is fenced, the fencing appears to be in good condition, and there is a locked entrance gate across the access road to the facility (Reference 5; Reference 7, p. 3).

\subsection{Operational History and Waste Characteristics}

Smith and Moore Disposal Services, 1111 Main Street, Angleton, South Carolina, owns Palmetto Landfill and operated it from 1970 to 1980. The landfill was opened in April 1970 for the disposal of municipal garbage and household debris. Beginning in October 1978, the landfill accepted industrial waste on a limited basis. Smith and Moore kept no formal records of the amounts and types of wastes received. However, there is evidence indicating that the landfill received a onetime shipment of approximately 500 gallons of TCE waste (Reference 4). The common practice of disposal at Palmetto Landfill was to excavate trenches 7 to 10 feet deep, fill the trenches with waste material, and emplace a daily cover of soil. Landfilling operations were discontinued in July 1980 when the landfill reached capacity. Upon closure; a two-foot soil cover was placed over the entire landfill and seeded (Reference 4).

Palmetto Landfill operated under permit number 999-999 issued by the South Carolina Department of Health and Environmental Concerns (SCDHEC). SCDHEC personnel conducted an inspection of the landfill when it closed to ensure that all closure requirements of the permit were met. SCDHEC personnel have since inspected the landfill several times at irregular intervals. To date, no sampling or response action has taken place at Palmetto Landfill (Reference 8).

\section{GROUND WATER PATHWAY}

\subsection{Hydrogeologic Setting}

Palmetto County is in the Lower Coastal Plain Physiographic Province. Geologically this area is characterized by a wedge of overlapping formations that increase in thickness towards the coast. Pleistocene terrace deposits underlie the Palmetto County area. These deposits include the following formations (from youngest to oldest): Jacksonville, Charlestown, Peerless, and Jacob. The deposition of these formations resulted from the transgressive/regressive sequences of a glacially controlled Pleistocene sea (Reference 9, p. 12). According to the literature and local well logs, the Jacksonville, Charlestown and Peerless Formations are the only Pleistocene strata underlying the vicinity of Palmetto Landfill; only the Jacksonville produces potable water (Reference 9; Reference 10; Reference 11).

The Jacksonville Formation ( 5 to 25 feet thick) is composed of well-sorted, fine-grained sand and shell with interfingering layers of silt and clay. This formation is the only water supply aquifer for rural residents not served by a municipal system (Reference 10). The water is produced under water table conditions at a rate of 25 to $100 \mathrm{gpm}$ (Reference 9, p. 14). 
The Charlestown Formation consists of a sandy phosphatic limestone which has altered to a clayey, fine-grained dolomite at depth. The formation is considered to be a confining unit and has an estimated thickness of 25 to 45 feet in the southern Palmetto County area (Reference 9, p. 16).

The Peerless Formation consists of a porous, dark gray, fine-grained, fossiliferous limestone. This unit is approximately 45 to 60 feet thick, is under artesian conditions, and produces brackish water. Beneath the limestone is the Jacob Formation (60 to 105 feet thick) consisting of sand, silt and clay. The Jacob Formation also produces brackish water (Reference 9; pp. 17-19).

The Jacksonville Formation is the only water supply aquifer in the area of Palmetto Landfill. Precipitation is the primary means of recharge. Discharge other than by well production is by natural seepage (springs) and evapotranspiration. Flow direction for this surficial aquifer varies from area to area as water moves by gravity, from areas of high to low elevations. Depth to ground water varies from 3 to 15 feet below land surface (bls) in Palmetto County (Reference 9, p. 15; Reference 10). At Palmetto Landfill, the depth to ground water is approximately 10 feet, as determined from a well log of a nearby drinking water well (Reference 11).

\subsection{Ground Water Targets}

The majority of the population within a 4-mile radius relies on municipal water supplies taken from a reservoir, operated by the Palmetto County Water Authority (PCWA), on the Ono River 35 miles west of Angleton. There are three municipal water systems within a 4-mile radius of Palmetto Landfill, all of which purchase water from the PCWA. Residences not connected to the municipal supply system have been identified through discussions with PCWA officials (Reference 12), review of a municipal water supply distribution map (Reference 13), and verification during the reconnaissance of the immediate site vicinity (Reference 7, p.11). These residences rely on private wells completed in the Jacksonville Formation for their drinking water supply (Reference 9; Reference 10).

There are approximately 239 homes within 4 miles which use private wells for drinking water (Reference 13). At 2.7 persons per household (the average for Palmetto County) (Reference 14, p. 4), this equates to 645 residents. The nearest residence relying on a private drinking water well is approximately 300 feet southwest of the landfill (Figure 1); within a 0.25 -mile radius of the landfill are 6 residences relying on private wells (Reference 7, p. 10).

\subsection{Ground Water Conclusions}

A release of hazardous substances from Palmetto Landfill to the Jacksonville aquifer is suspected due to the trenching method of waste disposal, shallow depth to aquifer, and documented deposition of TCE waste. Due to the relatively high conductivity (16 ft/day) (Reference 9, p. 14), potential for widespread migration of contaminants is high. Six residences within 0.25 mile are considered primary targets.

\section{SURFACE WATER PATHWAY}

\subsection{Hydrologic Setting}

Overland drainage from the site flows northeast approximately 250 feet into Wildlife Creek, which has an average flow rate of 5 to $10 \mathrm{cfs}$ (Reference 6,p. 124). Drainage from the perimeter ditch around the landfill also flows into the creek (Reference 5; Reference 7, p. 3). 
The perimeter drainage ditch which bounds most of the landfill prevents upgradient runoff from . reaching the landfill surface. The ditch,creates a localized drainage basin coincident with the landfill. Wildlife Creek flows approximately 3.0 miles and enters Ono River (Reference 1), which has an average flow of $1,150 \mathrm{cfs}$ (Reference $6, \mathrm{p} .132$ ). Approximately 16 miles downstream, the Ono River merges with the East River (Reference 6, p. 150).

\subsection{Surface Water Targets}

There are no drinking water intakes located within 15 downstream miles of the site. Most residents are served by a reservoir 35 miles upstream of Palmetto Landfill. Residents not served by a municipal system obtain drinking water from individual private wells (Reference 12).

Wildlife Creek and Ono River are used for recreational fishing. Aquatic species commonly caught include large mouth bass, shrimp, crabs, and clams. Recreational crawfish fishing occurs in Wildlife Creek and the surrounding wetlands (Reference 15, pp. 13, 15).

There are numerous wetlands located within 15 downstream miles of the site. The nearest wetland (approximately 250 acres, 0.5 mile frontage) is located approximately 0.1 mile downstream from the site on Wildlife Creek (Figure 1, Figure 2) (Reference 1). Two Federally designated endangered species, the Bald Eagle and the Salt Marsh Harvest Mouse, can be found in Palmetto County (Reference 16).

\subsection{Surface Water Conclusions.}

There are indications of a release of contaminants to surface water. The banks of the perimeter ditch, which drains directly into Wildlife Creek, show signs of stressed vegetation. The water in the ditch is an orange-brown color and has an oily sheen (Reference 5; Reference 7, p. 4). There are no drinking water intakes within 15 miles downistream of the site. There are numerous wetlands along Wildlife Creek and Ono River, and two Federally designated endangered species are found in Palmetto County. Primary targets include the fishery in Wildlife Creek and wetlands associated with Wildlife Creek, and the habitats of endangered species in Palmetto County which may also be associated with Wildlife Creek.

\section{SOIL EXPOSURE AND AIR PATHWAYS}

\subsection{Physical Conditions}

When closed, Palmetto Landfill was covered by 2 feet of clean soil (Reference 4) and is currently heavily vegetated by grass, weeds, and shrubs (Reference 5; Reference $7, \mathrm{p} .2$ ). The site has been closed since 1980 (Reference 4), and is totally fenced around the perimeter. There is also a locked gate across the access road to the site (Reference 5; Reference 7, p. 2).

\subsection{Soll and Air Targets}

There are no residents or workers onsite. The nearest residence is 300 feet to the southwest, and the nearest school is located 0.5 mile to the north of the site (Reference 7, p. 10). There are 6 residences within 0.25 mile of the site (Reference 1 ; Reference 7 ). The total population within a 4-mile radius of the site is 7,989 (Reference 18) as determined by the GEMS database (Reference 17), supplemented by a windshield survey housecount within 0.5 -mile radius of the site (Reference 7, p. 10; Reference 18). 
There is a 250-acre wetland located on Wildlife Creek approximately 0.1 mile from Palmetto Landfill (Figure 1, Figure 2) (Reference 1). There is also the possibility that terrestrial sensitive environments of the Federally designated endangered Bald Eagle and Salt Marsh Harvest Mouse habitats may be found within the boundaries of Palmetto Landfill, as the species are known to inhabit Palmetto County (Reference 16).

\subsection{Soll Exposure and Air Pathway Conclusions}

The soil exposure pathway appears to pose a minimal threat at Palmetto Landfill due to the 2-foot soil cover emplaced when the landfill was closed, the lack of a resident population, and fencing around the entire property. A release to the air is not suspected because the landfill is covered by 2 feet of clean soil and is heavily vegetated. In addition, during the perimeter survey, no odors were detected and there was no indication of any blowing dust or soil (Reference 7, p. 5).

\section{SUMMARY AND CONCLUSIONS}

Smith and Moore operated Palmetto Landfill, Palmetto County, South Carolina from 1970 to 1980. During this period, the landfill accepted an unknown quantity of municipal and industrial waste for burial in shallow trenches, including approximately 500 gallons of TCE waste. As a result of this practice, ground water in the vicinity of the landfill may have been adversely affected. Surface water also has a high potential for contamination via drainage from the perimeter ditch, which poses a threat to the environment and to human targets through food chain contamination. Due to the good condition of cover at the landfill and the rural nature of the area, the likelihood of human exposure to contaminated soil is probably minimal. No release to the air is suspected due to the heavily vegetated cover and the lack of any odors or blowing particulates during the site reconnaissance. 


\section{REFERENCES}

1. U.S. Geological Survey, 7.5-minute topographic quadrangle maps of South Carolina: Angleton, 1963, photorevised 1983; Palmetto, 1975; Winchester, 1975; Danvers, 1963.

2. U.S. Environmental Protection Agency, "Standard Operating Procedure to Determine Site Latitude and Longitude Coordinates," 1991. Calculation worksheet for Palmetto Landfill.

3. U.S. Department of Commerce, "The Climatic Atlas of the United States," 1983, pp. 7,10.

4. Jennifer Doe, Manager for Smith and Moore Disposal Services, telephone conversation with Joe Brown, XYZ Corporation, May 1, 1991. Re: Palmetto Landfill Operations.

5. Joseph Brown, XYZ Corporation, Photodocumentation Log of Palmetto Landfill Preliminary Assessment, May 7, 1991.

6. A.P. Park, "The Surface Water Resources of Palmetto County, South Carolina," South Carolina Water Resources Commission Report No. 101B, 1984, pp. 124,132,150.

7. Joseph Brown, XYZ Corporation, Field Logbook No. 311 for Offsite Reconnaissance of Palmetto Landfill, TDD Y9-8765-43, May 1991.

8. John Hill, Technician for South Carolina Department of Health and Environmental Concerns, telephone conversation with Joe Brown, XYZ Corporation, May 1, 1991. Re: Remediation and Sampling at Palmetto Landfill.

9. J.P. Adams, "The Ground Water Resources of Palmetto County, South Carolina," South Carolina Water Resources Commission Report No. 99A, 1982, pp. 12,14,15,16,17,19.

10. Donna Johnson, Driller for Johnson Drilling Co., telephone conversation with Joe Brown, XYZ Corporation, May 1, 1991. Re: Ground Water Wells in Palmetto County.

11. Johnson Drilling Company, J.J. Jones Residential Well Log, drilled March 25, 1984.

12. Mark Allen, Technician for Palmetto County Water Authority, telephone conversation with Joe Brown, XYZ Corporation, May 2, 1991. Re: Palmetto County Municipal Water Systems.

13. Palmetto County Water Authority, Municipal Water Supply Distribution System Map, April 1991.

14. U.S. Department of Commerce, Bureau of the Census, "1990 Census of Population and Housing," South Carolina.

15. A.J. Houston, "South Carolina Guide to Recreational Hunting and Fishing," South Carolina Department of Natural Resources, Wildlife and Game Division Report Number A22, 1975, pp. 13,15 .

16. U.S. Fish and Wildife Service, "Atlantic Coast Ecological Inventory Maps, Palmetto County Panels," 1980.

17. U.S. Environmental Protection Agency, Geographical Exposure Modeling System (GEMS) database, compiled from U.S. Census Bureau 1990 data, accessed May 8, 1991.

18. Joseph Brown, XYZ Corporation, 4-Mile Radius Population Calculation Worksheet, developed during the Preliminary Assessment of Palmetto Landfill, Palmetto County, South Carolina, May 8, 1991. 


\section{REF 1}

These U.S. Geological Survey 7.5 minute topographic quadrangle maps show site location and 4mile radius:

Angleton, South Carolina

Palmetto, South Carolina

Winchester, South Carolina

Danvers, South Carolina

Note: Full-size maps are typically included as a reference in the PA narrative report. The quadrangles are only listed here. 


\section{STANDARD OPERATING PROCEDURE}

TO DETERMINE SITE LATITUDE

\section{AND LONGITUDE COORDINATES}

Site Assessment Branch

Hazardous Site Evaluation Division

Office of Solid Waste and Emergency Response

U.S. Environmental Protection Agency

Washington, D.C. 
REF 2., 99.2

LATITUDE AND LONGITUDE CALCULATION WORKSERET \$1 UEEN USING CUSTOM RULER OR COORDINATOR (TH)

SITE: PALMETTO LANDFILL NUKBER:SCD123456789 ARA: SSID:

ADDRESS: 6250 PALMETTO DRIVE CITY: ANGLETON (PALMETTO) STATE: SC SITE REFERENCE POINT: CENTER OF SITE TOPO MAP: ANGLETON, SC TOWNSETP: N/A W/S RANGB: N/A E/W SCALE: 1:24,000 MAP DATE: 1963 SECTION: _1/4: ${ }^{1 / 4}-^{1 / 4}$ MAP DATUM: 1927 PHOTOREVISED 1983 MERTDIAN:

COORDINATES FROM LOKER RIGET (SOUTHEAST) CORNER OP 7.5' HAP:
'LONGITUDE: $66^{\circ}$ O2'
LATITUD: $18^{\circ} 28^{\prime} 30^{\prime \prime}$

COORDINATES FROM LOTER RICBT (SOUTARAST) CORNER OP 2.50 SUB-KAP:

$$
\text { LONGITUDB: } 66^{\circ} \underline{07^{\prime}}-\quad \text { LATITUDB: } 18^{\circ} 28^{\prime} 30^{\prime \prime}
$$

\section{CALCULATIONS: LATITUDE (7.5 IINUTR QUADRANGLB MAP)}

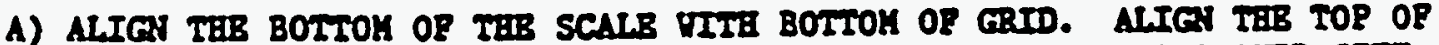 OP TAB SCALB YITB TBR TOP OP GRTD. POSIITON EDCB OI RULRR OVBR SITE REPEREYCB POINT VIILLS KEBPING IOP AND BOTTOM ALIERBD.
B) RBAD IICS ON RULBR AT 1 OR 0.5 SECOND INTERVALS. (DRTSRPOLATE IF POSSIBLB)
c) RECORD LATITUDs: $18^{\circ} 28^{\prime} 43^{\prime \prime}$-N. - - - -

\section{CALCULATTOWB LOASTIUDS (7.5 MTNUTB QUADRANGLS MAP)}

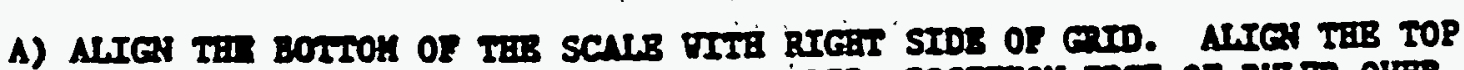

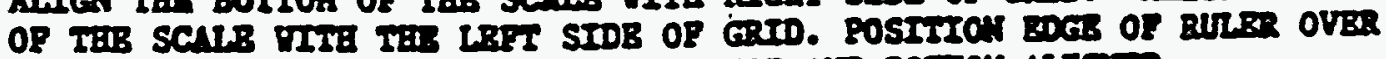

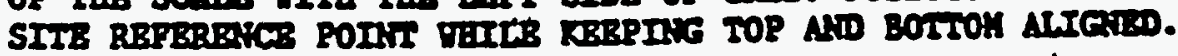

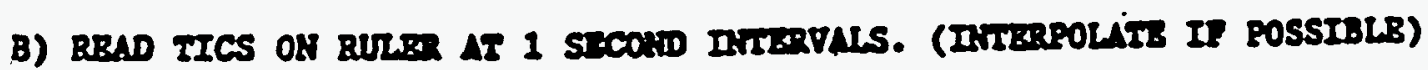

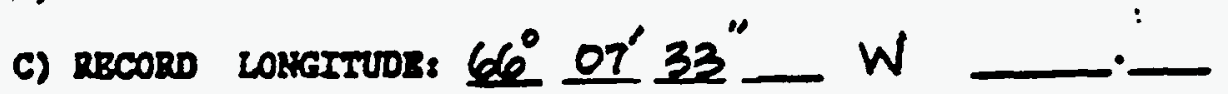
IIVESIIGATOR: Gospeph Browone DAIZ: GMAY 1991 


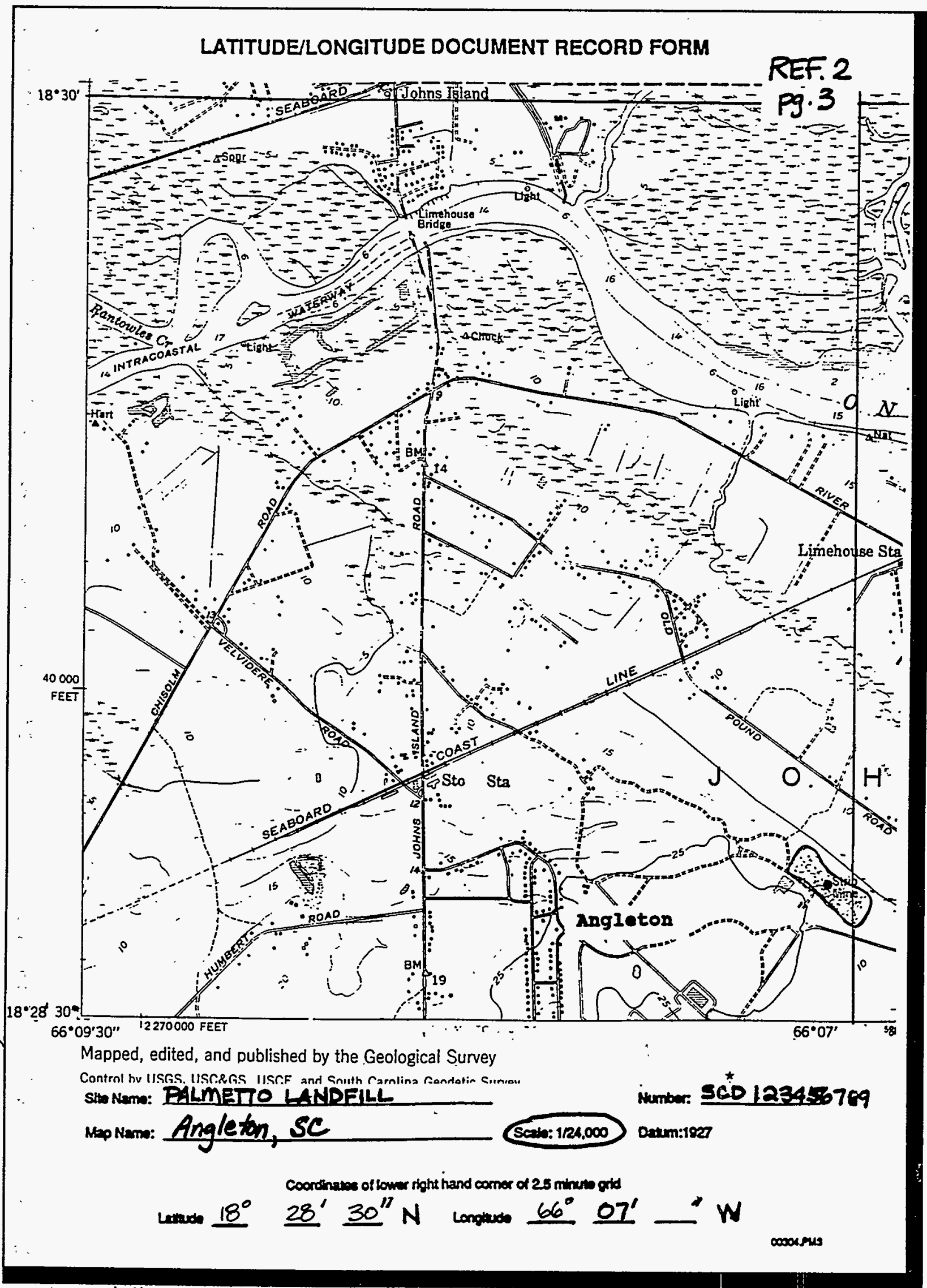


REF. 3

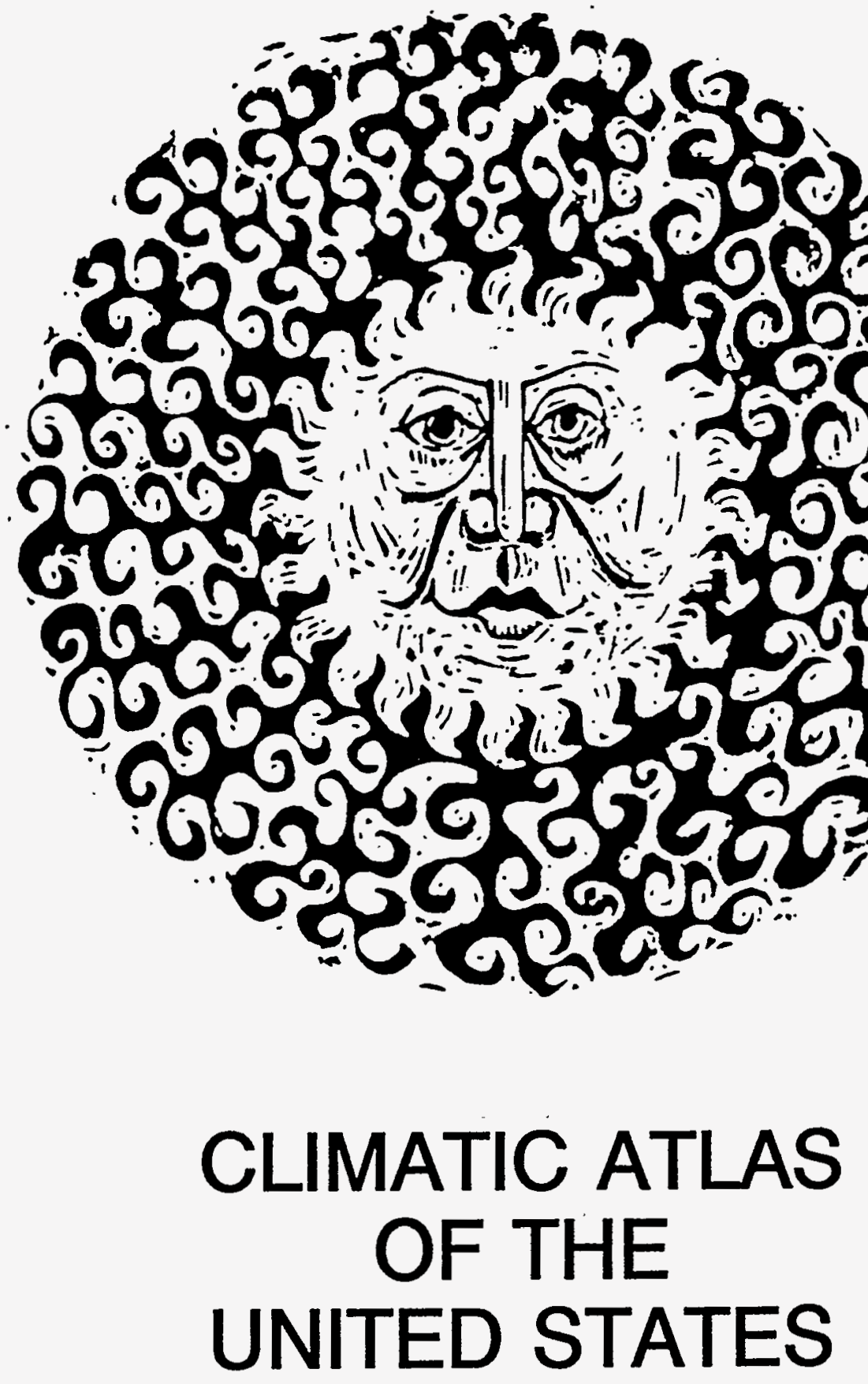


REF 4

XYZ CORPORATION AND SUBSIDIARIES

TELECON NOTE

\begin{tabular}{|c|c|c|}
\hline $\begin{array}{l}\text { CONTROL NO: } \\
\$ 295 \text { BAGC\$\$ }\end{array}$ & DATE: May 1, 1991 & TIME: 0900 \\
\hline
\end{tabular}

Palmetto County, South Cardina

File TDD: Y9-8765.43

BETWEEN:

Jennifer Doe $\quad \begin{gathered}\text { of: Smith is Moore } \\ \text { Disposal Services }\end{gathered} \mid \begin{aligned} & \text { PHowe: } \\ & \text { (999) } 999-9999\end{aligned}$

AND: Joe Browf, $x y z$ Corporation

Discussion:

Obtained background operating info. about Palmetto Landfill:

1. Utilized trench and fill procedure - trenches of up to 7 to $b$ feet were filled with waste materials and covered daily with soils.

2. Two feet of clean soil was placed aver the landfill as cover when the land fill was closed. The soil wes seeded and trees and shrubs were planted.

3. 8-10 foot deep perimeter ditch around the site that was to drain/ divert water from upgradient of the site around buried wastos.

4. The area used for landfilling was approximately 6 dores.

5. Operations began April 1970. The landfill weriginally opened for the disposal of numicipal and househald weste, but in October 1978, the landfill began accepting industrial wastes on a limited basis.

6. No formal records were kept of the types and quantities of wastes received, but the landfill did receive a ore-time shipment of approximately 500 gallens of TCE waste.

7. Opexations were discontinted in July 1980 when the landfill reached its permitted capacity.

Spech Brown

Projicet Manazer

5-1-91

C-16 
REF. 5

$X Y Z$ CORPORATION AND SUBSIDIARIES

PROJECT NOTES

\section{PHOTO DOCUMENTATION LOG}

All Photo** taken by Joe Brown, Project Manager, during site reconnal ssance of Palmetto Landfill, May 7, 1991.

\begin{tabular}{|c|c|c|}
\hline Number & Time & Descaption \\
\hline 1 & 0900 & Locked aate - entrance to landfill \\
\hline 2 & 0920 & Perimeter fencing - east side of site \\
\hline 3 & 0935 & Perimeter fencing - west side of site \\
\hline 4 & 0945 & $\begin{array}{l}\text { Panoramic view of site from gate, showing } \\
\text { heavy regetation. }\end{array}$ \\
\hline 5. & 1000 & $\begin{array}{l}\text { Probable paint of entry of perimeter ditch into } \\
\text { widdlife Creet, northwest side }\end{array}$ \\
\hline 6. & 1010 & $\begin{array}{l}\text { Probadble point of entry of perimeter ditch into } \\
\text { Wildlife creek, southeast side }\end{array}$ \\
\hline 7 & 1040 & $\begin{array}{l}\text { Water in perimetev ditch, showing orange-brewn } \\
\text { color, oilly. Sheon }\end{array}$ \\
\hline 8 & 1100 & Panoramic view of site showing relatively flot \\
\hline & & terrain, gently sloping tonvard wild life Creek \\
\hline 9 & 1105 & Stressed veaetation - banks of cor meter ditch \\
\hline 10 & 1130 & $\begin{array}{l}\text { Typical regetation of wetlands } 0.1 \text { mile down- } \\
\text { stream of landfill }\end{array}$ \\
\hline 11 & 1135 & $\begin{array}{l}\text { Wildlife Creek taken just downstreem of the } \\
\text { probable point of entru. }\end{array}$ \\
\hline & & 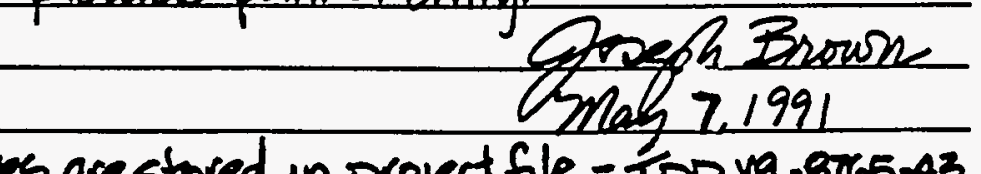 \\
\hline & & \\
\hline
\end{tabular}




\section{REF. 6}

\section{THE SURFACE WATER RESOURCES OF PALMETTO COUNTY SOUTH CAROLINA}

STATE OF SOUTH CAROLINA

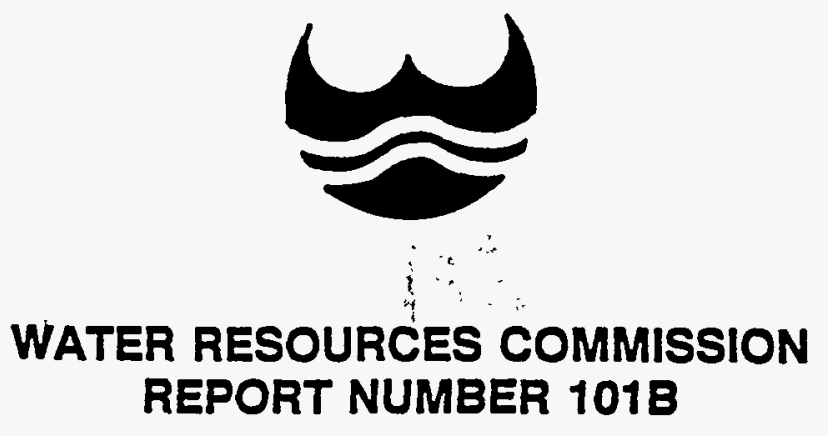

1984 
REF 7

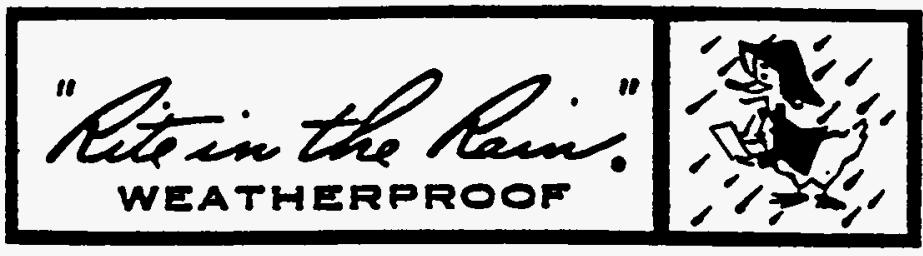

\section{LEVEL \\ NOTEBOOK NO. 311}

TDD Y9-8765-43

Palmetto Land fill

Palmetto Co, S.C.

Project Mgr: Toeseph Brown 
PA narrative report, sample reference

REF. 8

YR CORPORATION AND SUBSIDIARIES

TELECON NOTE

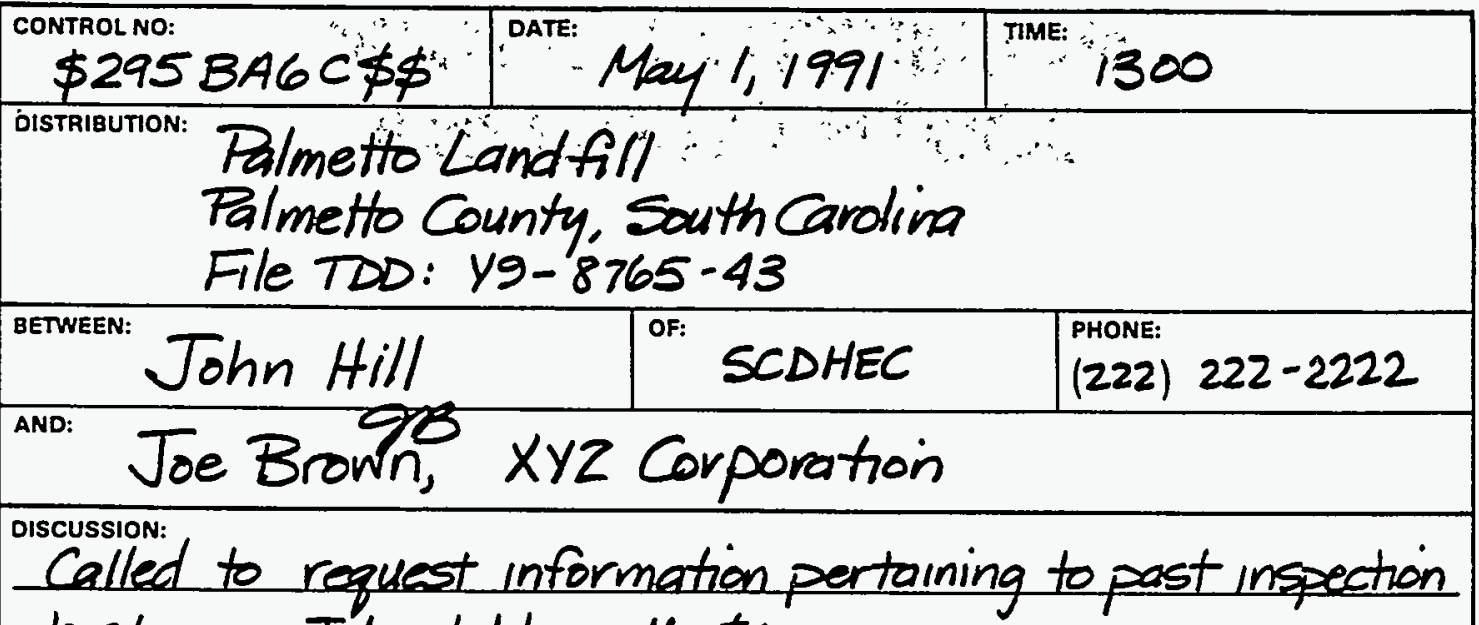
history; John told me that:

1. Site was open from April 1970 to July 1980 (industrial waste October 1978 to July 1980) and operated under permit No. $999-999$.

2. No sampling or remediation has been done since the site was opened.

3. An inspection of the site was done at closure to ensure that the site was covered and access restricted according to the terms of the permit, periodic inspections have taken place since then.

4. Due to the rural location of the site SCDHEC has not considered the sited high priority for detailed investigation

ACTION ITEMS:

Gogh Brown

Manager

May 1, 1991

C-20 


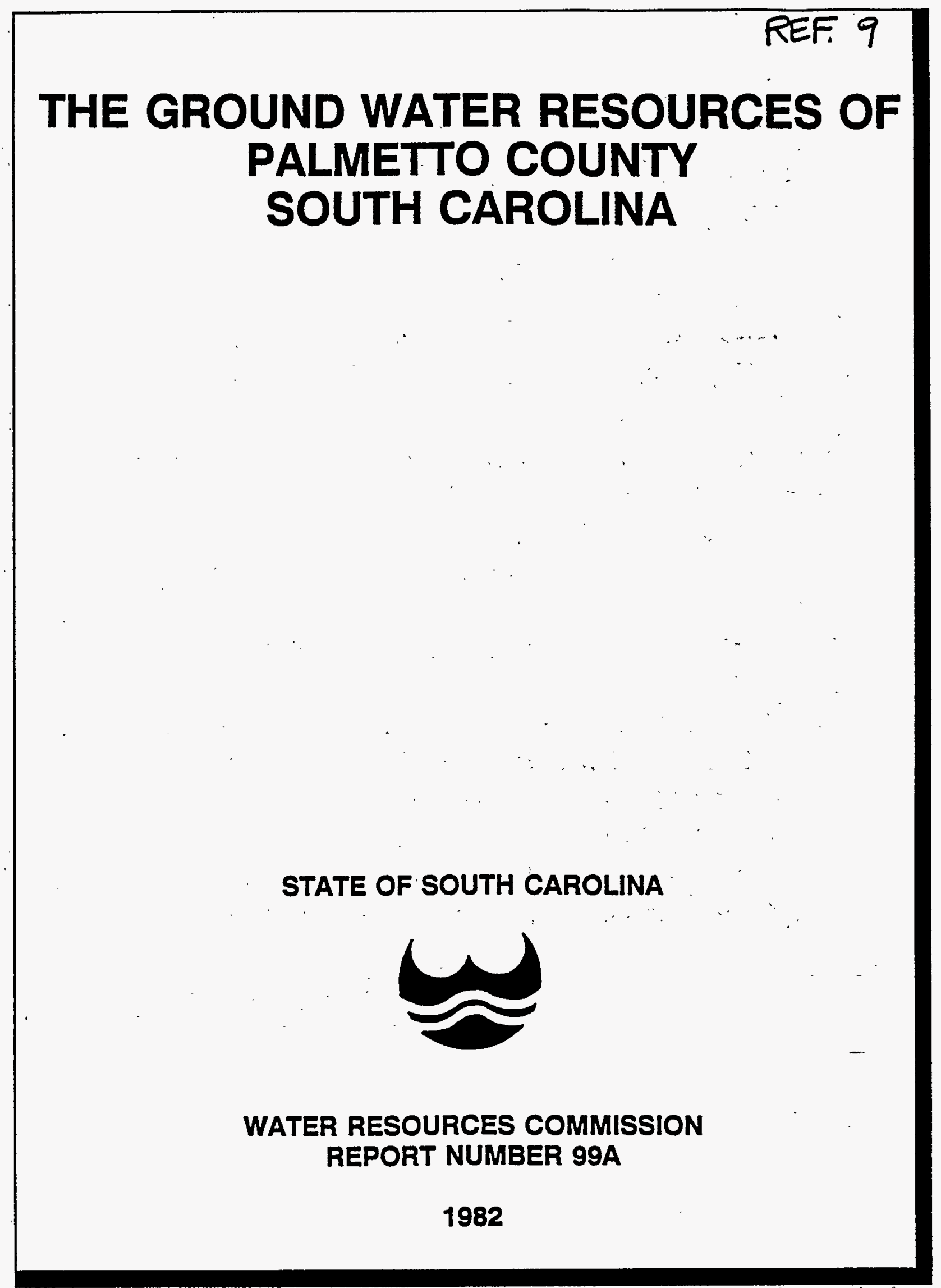


REF. 10

XYZ CORPORATION AND SUBSIDIARIES

TELECON NOTE

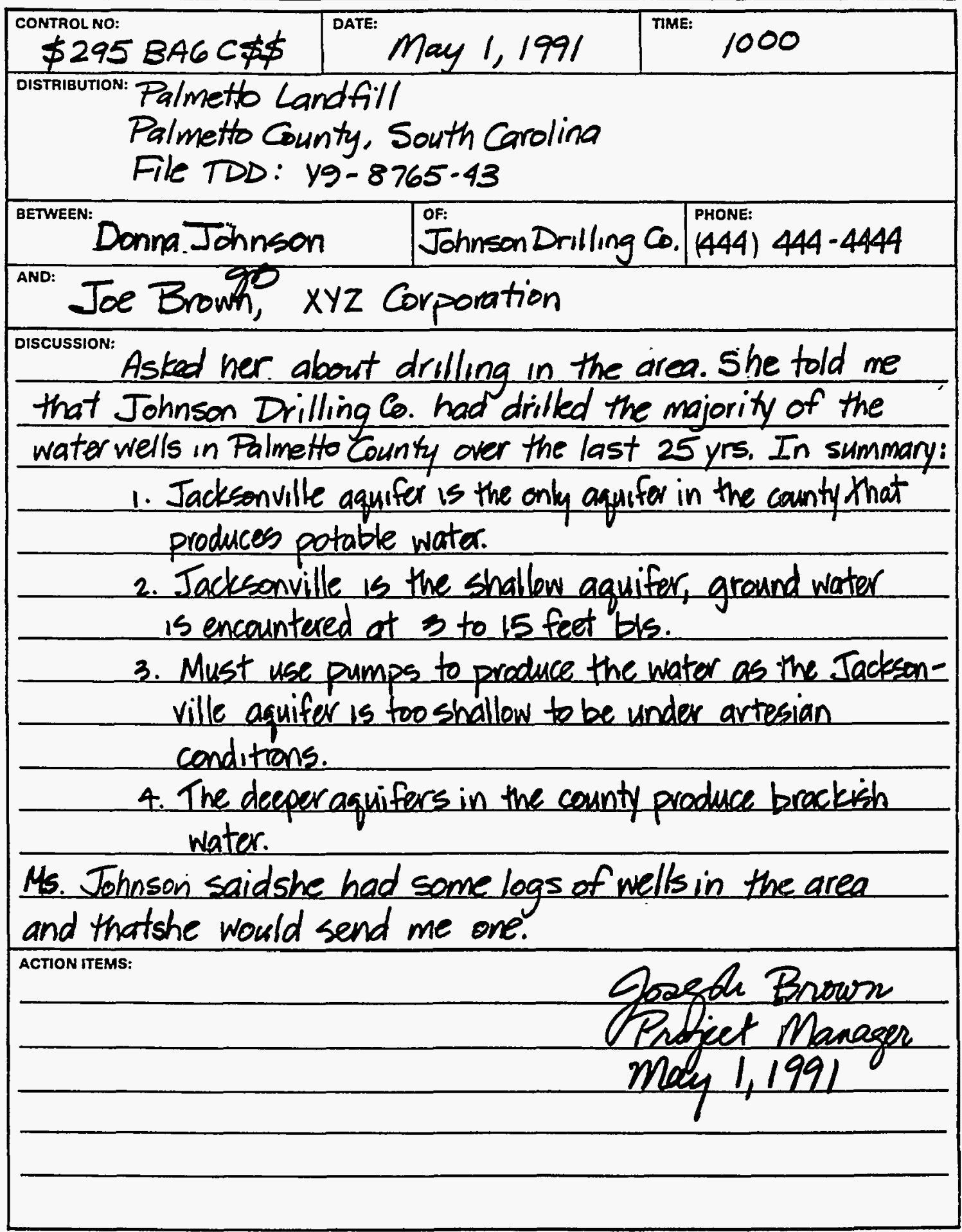




\section{JDC}

Johnson Drilling Company

1245 Keystone Way

Angleton, South Carolina 22222

\section{J.J. JONES HOUSEHOLD \\ 19 Palmetto Lane \\ Angleton, South Carolina}

Drilled March 25, 1984 by Johnson Drilling Company

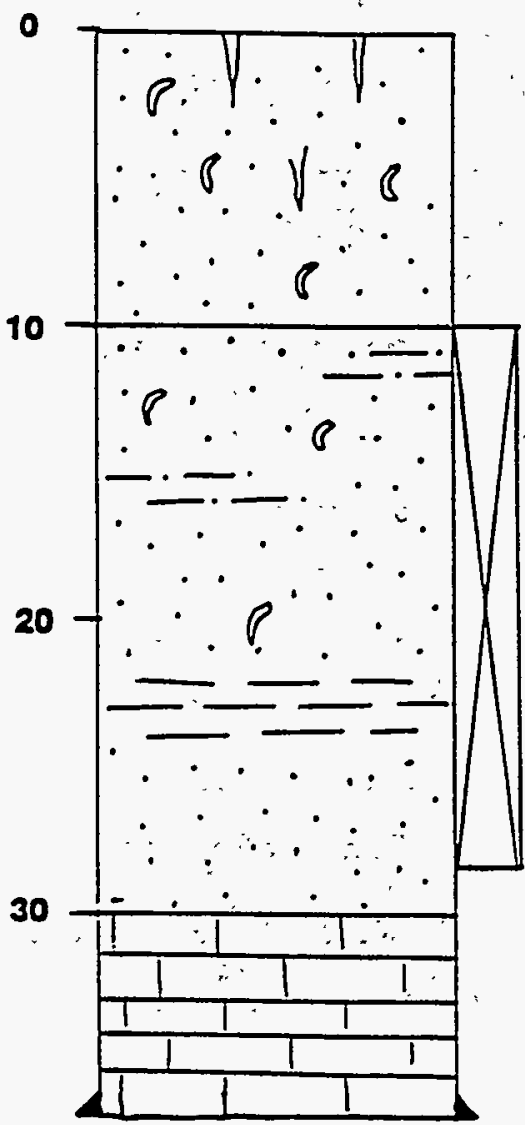

SURFACE SOIL

Weathered, Red, Sandy,

Roots, Shells

JACKSONVILLE FORMATION TOP WATER TABLE

Fine Grained, Well Sorted,

Unconsolidated Sand,

Scattered Shells, Thin

Layers of Silt and Clay

COMPLETED INTERVAL 10 - 28'

PRODUCED 75 GPM (INITIAL TEST)

\section{CHARLESTOWN FORMATION}

White to Gray, Dense Limestone, No Visible Porosity 
REF 12

XYZ CORPORATION AND SUBSIDIARIES

TELECON NOTE

\begin{tabular}{|l|l|l|}
\hline CONTROI NO: $\$ 295$ BA6C $\$ \$$ & DATE: May 2,1991 & TIME: \\
\hline
\end{tabular}

Palmetto Landfill

Palmetto County, South Cavolina

File TDD: y9-8765.43

BETWEEN:

\begin{tabular}{ll|l|l|} 
Mark Allen & PCWA & (333) $333-3333$ \\
\hline AND: Joe Browh, XYZ Corporation
\end{tabular}

Discussion:

Called to request information concerning the populations senved by the Palmetto Co. Water Authority, and about the overall water supply system in the vicinity of Angle ton.

He told me that PCWA operiates a reservir on the Ono River, approximately 35 miles upstream of where wildlife Creek flows into the Ono. He also informed me that there were no intakes dounstream of the confluene of Wildlife Creek and Ono River. The majority of the population in Palmetto County is served by the reservoir. There are three municipal water supply systems in the vicinity of Angleton; all three purchase all of their water from PCWA. Mr Allen told me that he had maps that detailed all of the municipal water supply systam lines for the entire county and that I was welcame to review them.

ACTION ITEMS:

Scheduled to meet w/ Mr. Allen during the day of the site reconnalssarce to review water supply system maps. 
Municipal Water Supply Distribution System Map -- obtained from the Palmetto County Water Authority

(In a typical PA narrative report, the full-size map would be included. Due to the format and space constraints of this guidance document, the map is not included here.) 
REF. 14

\section{Census Tracts}

\section{SOUTH CAROLINA}

STANDARD METROPOLITAN STATISTICAL AREA

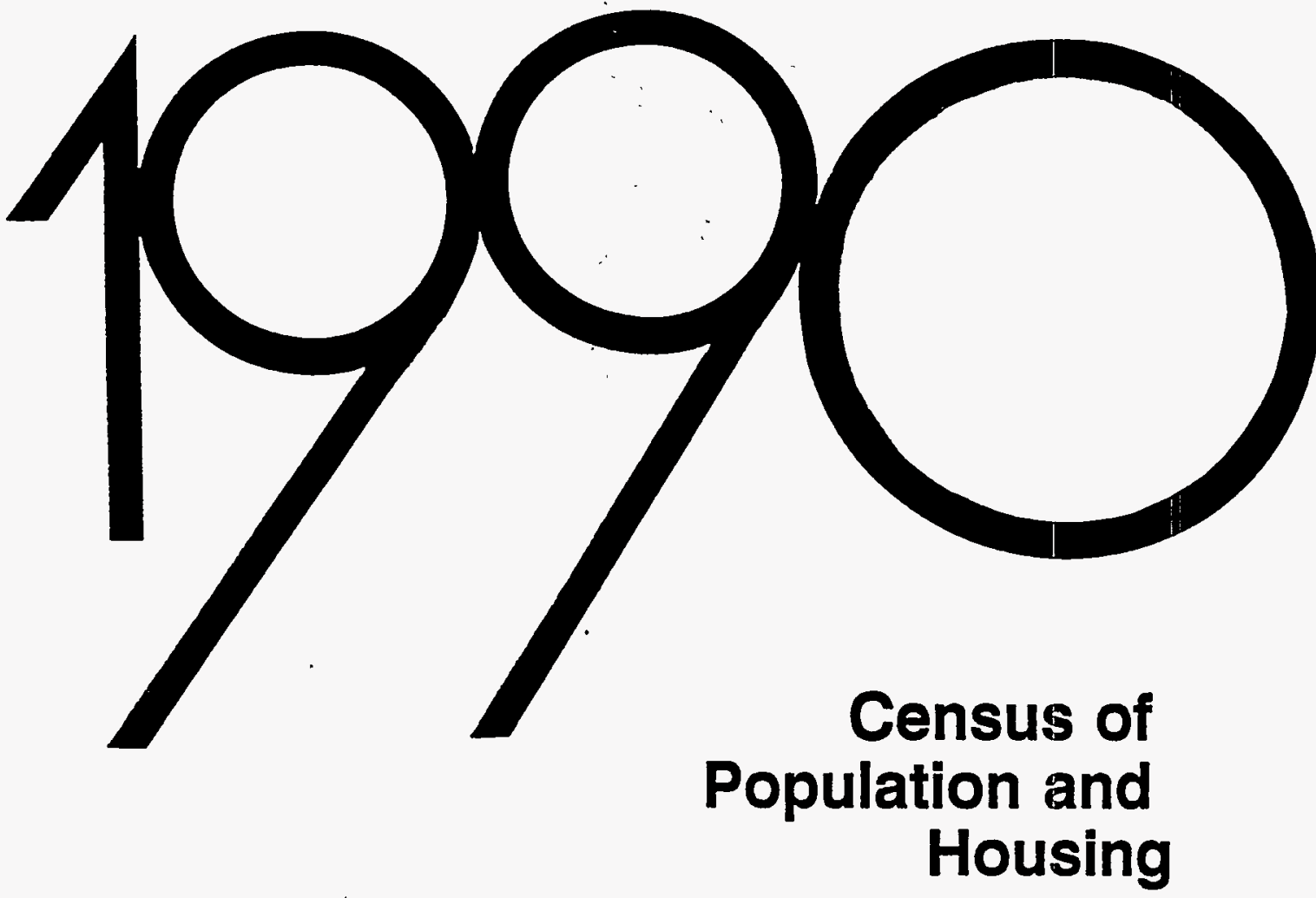

U.S Department of Commerce BUREAU OF THE CENSUS 


\section{REF. 15}

\section{SOUTH CAROLINA GUIDE TO RECREATIONAL HUNTING AND FISHING}

\section{DEPARTMENT OF NATURAL RESOURCES STATE OF SOUTH CAROLINA}

\section{WILDLIFE AND GAME DIVISION} REPORT NUMBER A22

$$
1975
$$




\section{PALMETTO COUNTY} SOUTH CAROLINA

\section{1:250,000-scale map of ATLANTIC COAST ECOLOGICAL INVENTORY}
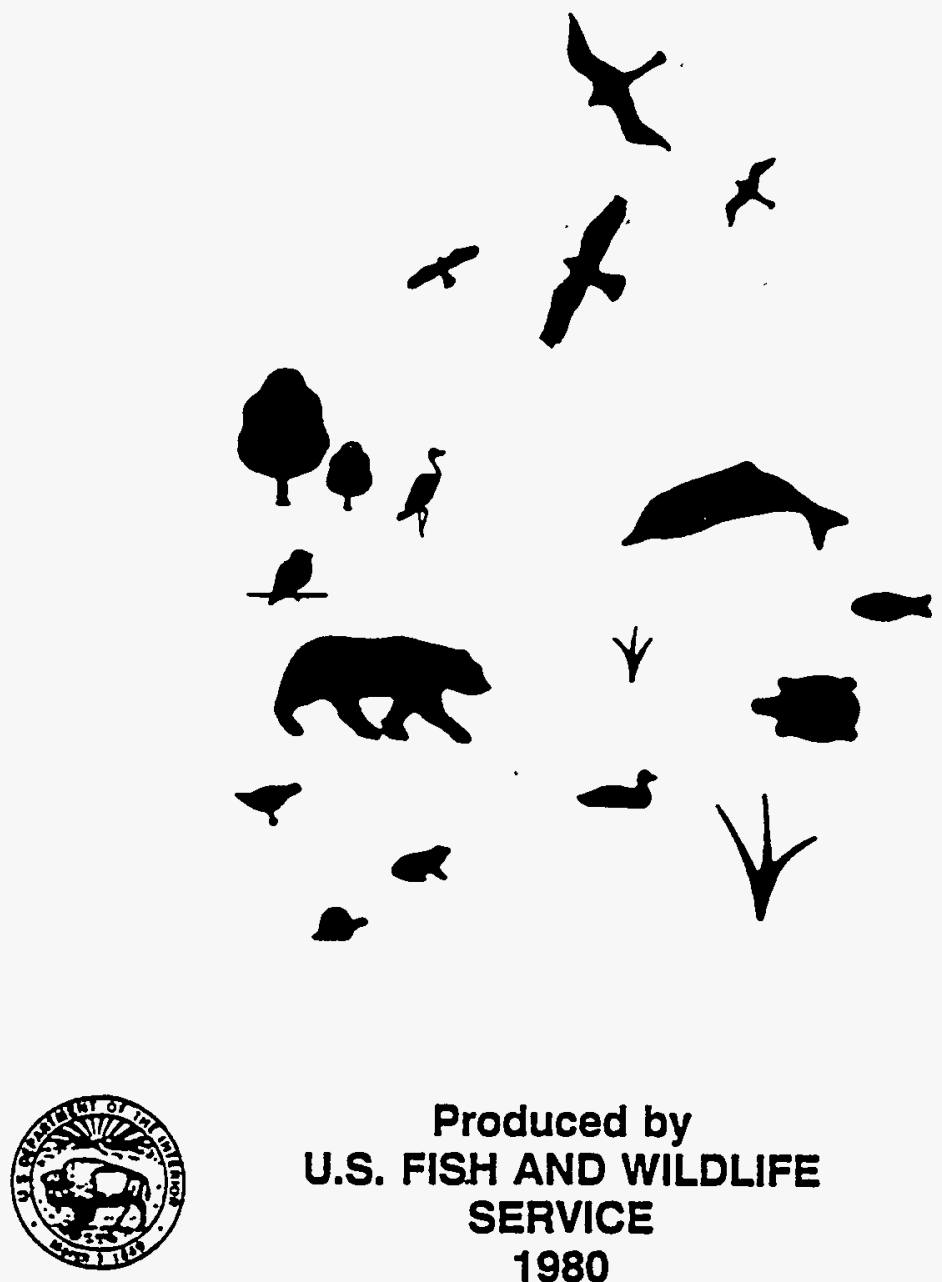

Produced by U.S. FISH AND WILDLIFE SERVICE 1980 
REF. 17

GEMS Database Printout

Palmetto Landfill Latitude: 32:45:23
Longitude: 80:05:05

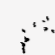

1990 Population

4.80-6.40 SECTORTOTALS

$\underline{K M}$

S1

$\underline{0.00-.400}$

$.400-.810$

0

$.810-1.60$

188

437.

2560

4732

7917

TOTALS

0

188

437

$2560 \quad 4732$

7917

Access Date: May 8, 1991 
REF. 18

\section{4-Mile Radius Population Worksheet}

Total population within a 4-mile radius of the Falmetho landfill was determined from data obtained from the GEMS database (Reference 17) and supplemented by a house count of the 0.5-mile radus performed during the site reconnalssance (Reference?).

Distance Categary Residences Proulation* Data Soure

ensite

0. to 0.25 mile 0.25 to 0.5 mile 0.5 to 1 mile L to 2 miles 2 to 3 miles

3 to 4 miles *2.7 persons per hausehold avg. for Palmetto Co. (Reference
Goeph Brinon
$5-3-91$
Site recon.

site recon.

$15 \quad 40$. Site recon.

GEMS

GEMS GEMS

2560

\section{GEMS \\ $-$ \\ 4732 \\ 14)}




\section{APPENDIX D}

\section{PA DATA AND SITE CHARACTERISTICS FORM}

This form summarizes PA information and serves three functions:

- Records administrative information to update and maintain CERCLIS

- Records descriptive site information to update and maintain EPA's database of CERCLIS site characteristics

- Identifies and provides space to record technical data to evaluate PA sites 


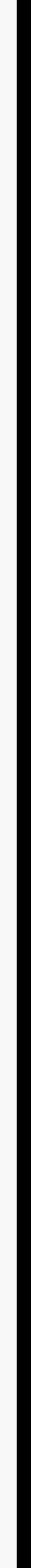


OMB Approval Number: 2050-0095

Approved for Use Through: 1/92

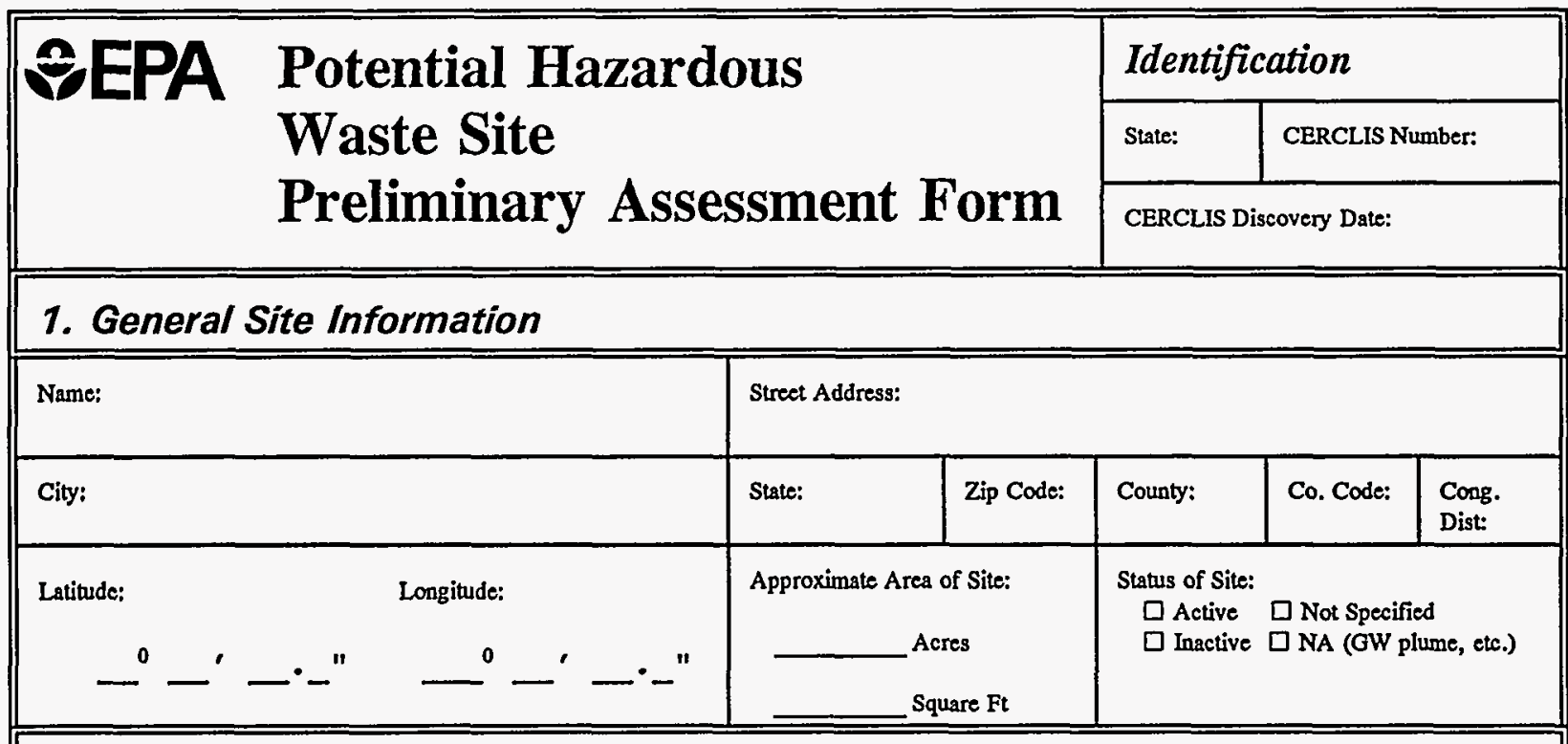

\section{Owner/Operator Information}

\begin{tabular}{|c|c|c|c|c|c|c|}
\hline \multicolumn{3}{|c|}{ Owner: } & \multicolumn{4}{|c|}{ Operator: } \\
\hline \multicolumn{3}{|c|}{ Street Address: } & \multicolumn{4}{|c|}{ Street Address: } \\
\hline \multicolumn{3}{|l|}{ City: } & \multicolumn{4}{|l|}{ City: } \\
\hline State: & Zip Code: & $\begin{array}{r}\text { Telephone: } \\
(1\end{array}$ & State: & Zip Code: & $\begin{array}{r}\text { Telephone: } \\
\text { ( }\end{array}$ & \\
\hline \multicolumn{2}{|c|}{$\begin{array}{l}\text { Type of Ownership: } \\
\square \text { Private } \\
\square \text { Federal Agency } \\
\text { Name } \\
\square \text { State } \\
\square \text { Indian }\end{array}$} & $\begin{array}{l}\square \text { County } \\
\square \text { Municipal } \\
\square \text { Not Specified } \\
\square \text { Other }\end{array}$ & \multicolumn{3}{|c|}{$\begin{array}{l}\text { How Initially Identified: } \\
\square \text { Citizen Complaint } \\
\square \text { PA Petition } \\
\square \text { State/Local Program } \\
\square \text { RCRA/CERCLA Notification }\end{array}$} & $\begin{array}{l}\square \text { Federal Program } \\
\square \text { Incidental } \\
\square \text { Not Specified } \\
\square \text { Other }\end{array}$ \\
\hline
\end{tabular}

\section{Site Evaluator Information}

\begin{tabular}{||l|l|l|l||}
\hline Name of Evaluator: & Agency/Organization: & \multicolumn{2}{l|}{ Daté Prepared: } \\
\hline Street Address: & City: & State: \\
\hline Name of EPA or State Agency Contact: & Strect Address: \\
\hline City: & State: & $\begin{array}{c}\text { Telephone: } \\
(\end{array}$ \\
\hline
\end{tabular}

\section{Site Disposition (for EPA use on/y)}

\begin{tabular}{|l|l|l||}
\hline Emergency Response/Removal & CERCLIS Reconmendation: & Signature: \\
Assessment Recommendation: & $\square$ Higher Priority SI & \\
$\square$ Yes & $\square$ Lower Priority SI & \\
$\square$ No & N NFRAP & Name (typed): \\
Date: & $\square$ RCRA & \\
& $\square$ Other & \\
& Date: & Position: \\
\hline
\end{tabular}




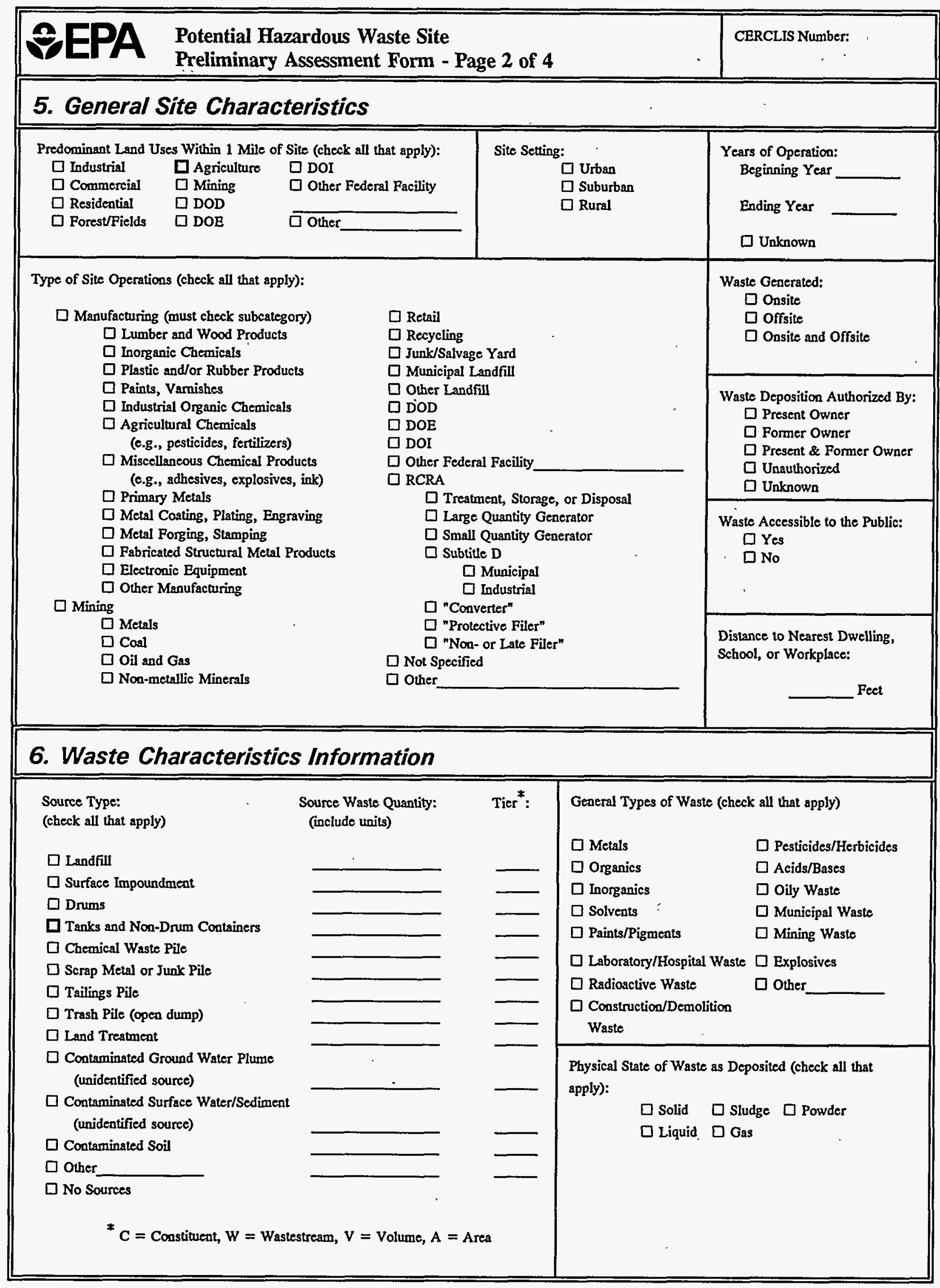




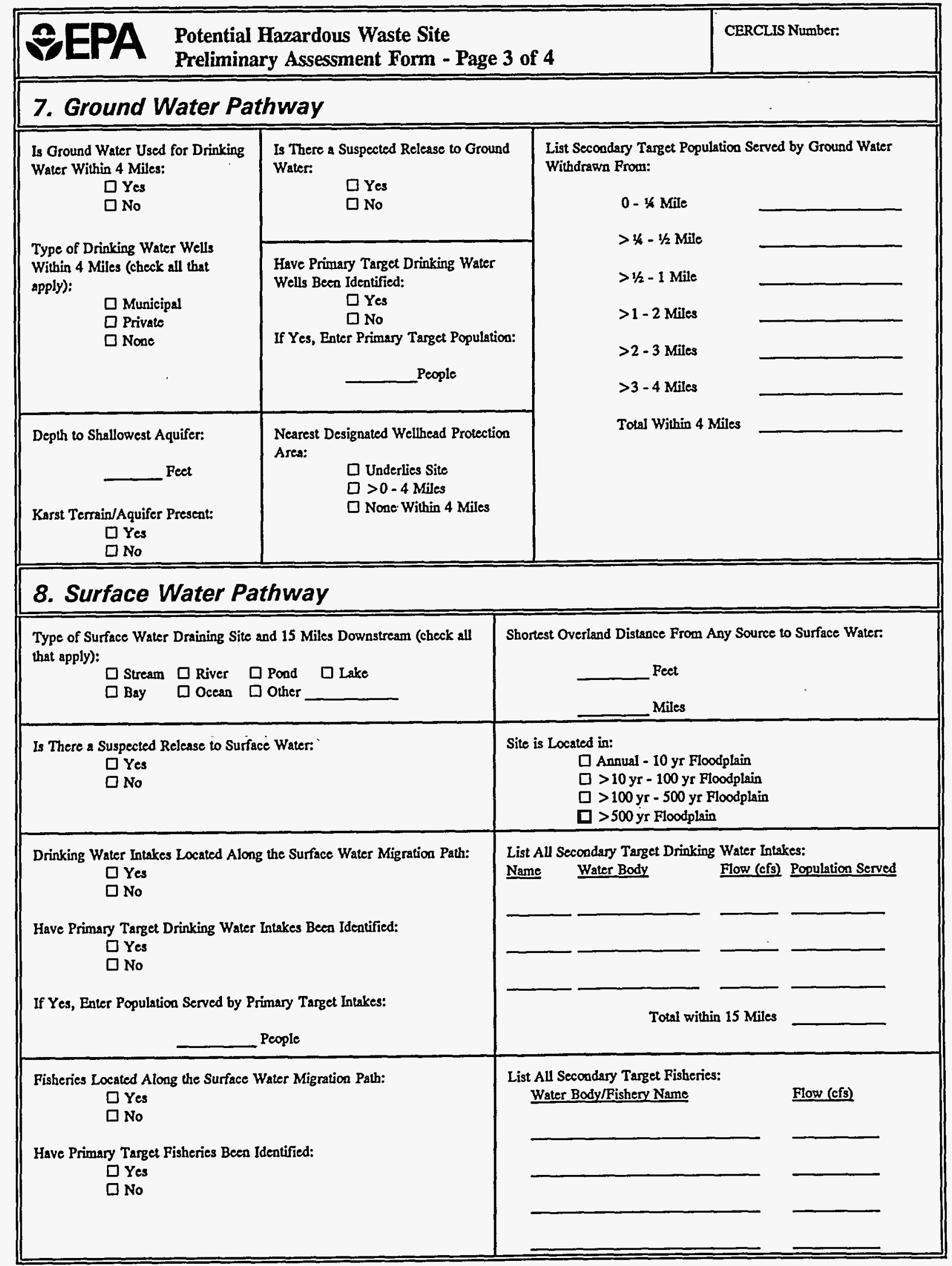




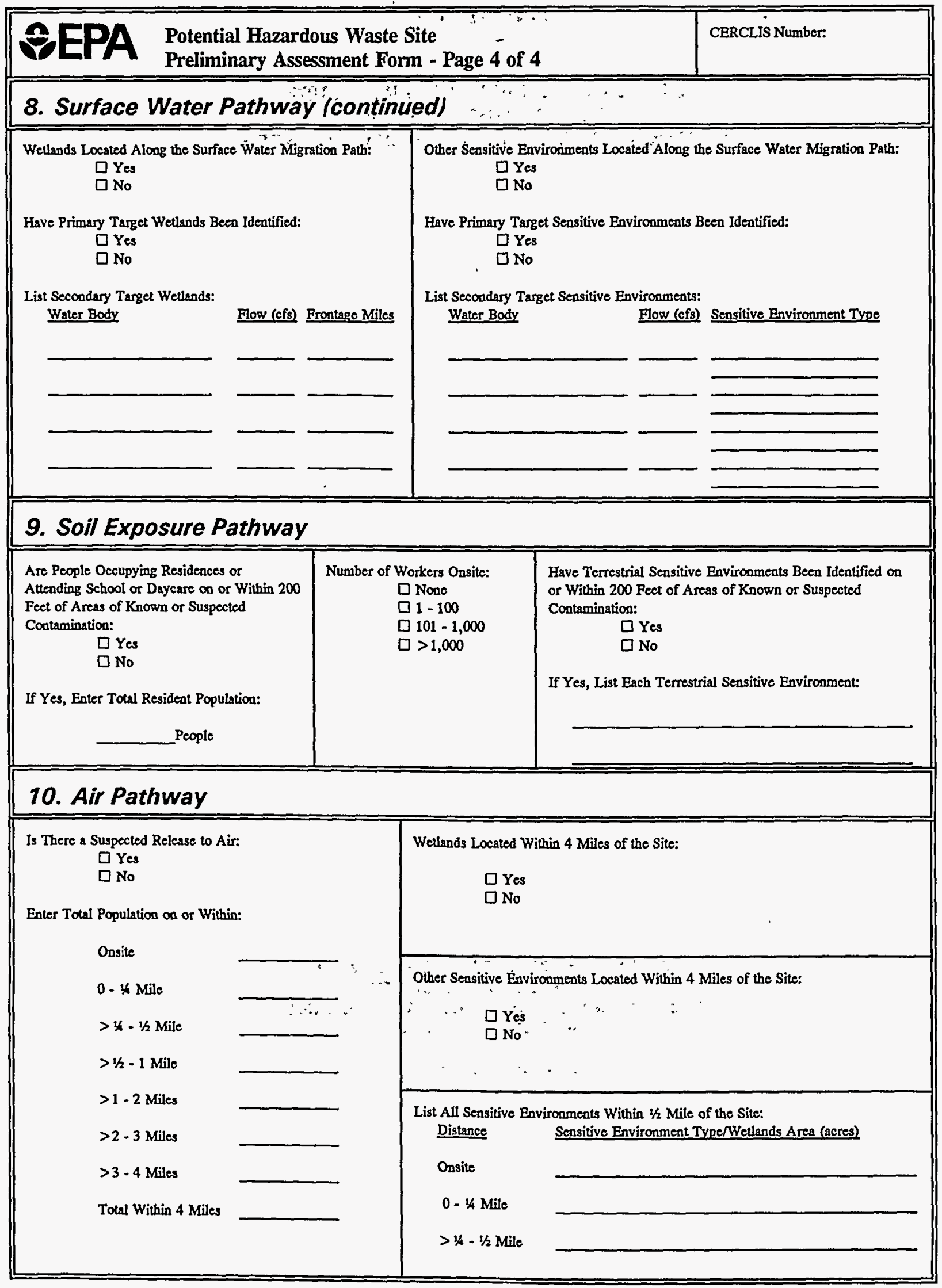




\section{APPENDIX E}

$\therefore$ STANDARD OPERATING PROCEDURE

TO DETERMINE S.ITE

LATITUDE AND LONGITUDE COORDINATES

HAŻARDOUS SITE EVALUATION DIVISION

SITE ASSE'SSMENT BRANCH

U.S ENVIRONMENTAL PROTECTION AGËNCY

WASHINGTON, D.C.

September 1991

$\mathrm{E}-1$ 


\section{STATEMENT OF PROBLEM}

Location information is critical to the site investigation process. This standard Operating Procedure (SOP) describes the minimum standard to which latitudinal and longitudinal measurements should be recorded and how to obtain measurements from topographic maps. The investigator should complete a worksheet and attach supporting documentation, which record measurements and provide computations for review.

The purpose of this SOP is to provide a method to measure latitude and longitude which is accurate and practical. The procedure uses linear measurement and interpolation, referred to as Linear Interpolation (LI) to measure latitude and longitude. Compared to other techniques, II:

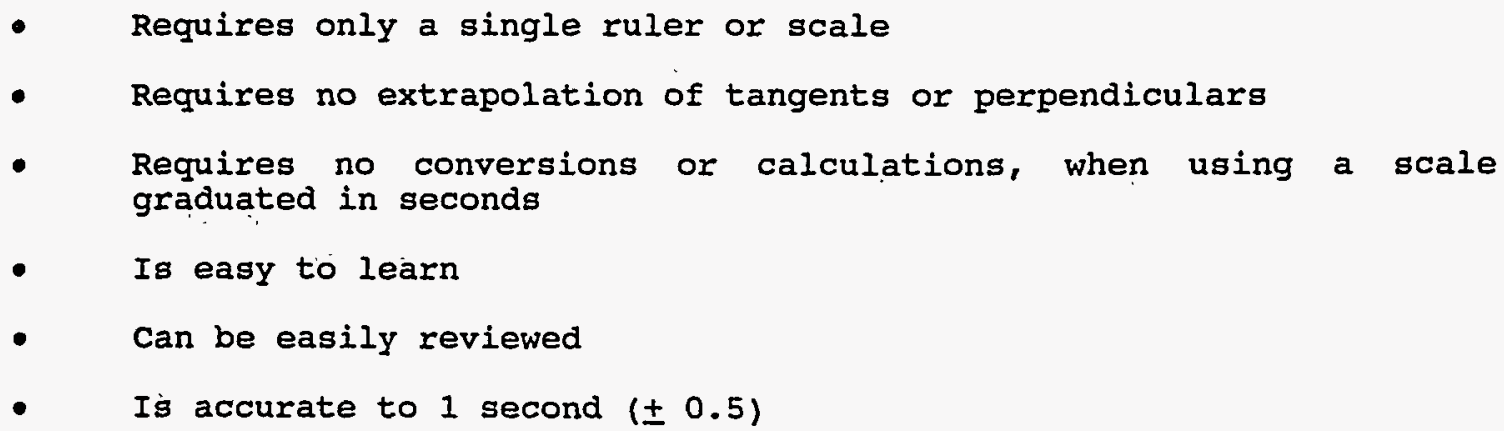

\section{SITE REFERENCE POINT}

The investigator should determine the site's geographic coordinates of a specified reference point. EPA's June 1989 draft policy simply requires describing the reference point for a site (e.g., northeast corner of site, entrance to facility, point of discharge). The January 1990 revision states: "...latitude and longitude coordinates may be made in reference to any convenient aspect of a site...". The language was intentionally vague due to the potentially infinite range of site spatial characteristics.

Latitude and longitude determination relies on 7.5 -minute topographic maps published by: the U:S. Geological survey (USGS). At the scale of these maps $(1: 24,000)$, the small black square used to identify a single family dwelling is a little less in width than 1 second of latitude; the latitude and longitude of a house can be accurately determined to 1 second. When the building, facility, site, etc., is larger in width than 1 second, the question becomes, "From where should I take the measurement?" In some cases, the site could encompass hundreds of square miles, and several degrees or minutes of latitude. To specify a pair of geographic coordinates for the site location, a reference point must be determined for each site on a map for the official record.

To specify a single point location, remember that both natural and man-made features can change with time, and contamination can be documented outside a facility boundary. Property lines, water bodies, and buildings are particularly vulnerable to change. Give priority to the following situations when determining site reference points:

- Point representing the approximate center of the area of greatest concern or a major source as chosen by the project officer in the Region most familiar with the site; or

- Location of largest permanent structure, identified to the corner being measured. 
On a 7.5-minute topographic map, mark the boundaries of the site, the area encompassing waste sources, with a very sharp pencil. If the site is a single point or building, use that point. If the building is large, select a corner and describe it for later worksheets. If the site is larger than a single building, draw a center line along the long axis' (longest part) of the site (curving or segmenting the line so the line is always centered within the site); and designate the midpoint of the line as the center of the site. Mark this. spot in pencil keeping the dot or cross-hair as fine as possible.

Chooge a permanent site reference point that is accessible to field verification. During the site reconnaissance, verify the point location relative to topographic and physical structures on the map. coordinates of known point locations (e.g.; landfills, impoundments, wells) can also be calculated and recorded.

\section{EQUIPMENT}

The only equipment required for II is an original version of the scale template, the coordinator ${ }^{\mathrm{TM}}$ (see attached page), a fine mechanical pencil (0.3 or $0.5 \mathrm{~mm}$ ), a large flat work surface, and the topographic map(s) containing the site. Mylar films of maps are preferable. Do not use folded or wrinkled field maps.

The accuracy of II depends on several factors; specifically the accuracy of the map and measuring device, the width of. the pencil, and the cartographic ability of the person making the measurements.

The accuracy of maps printed on paper is approximately 50 feet (1 millimeter map distance) due to paper shrinking or swelling in varying humidity, or by creases in the map. This exror can be considerable at the 1:24,000 scale, but these problems can be overcome by using Mylar film versions of the USGS maps. Similarly, measuring tools can have different levels of precision. Do not use the Topo-Aid ${ }^{\mathrm{TM}}$, a map aid used in the past, which does not provide the 1-second precision now required by EPA.

A second area where precision can be lost is the pencil used to mark reference lines. The smaller the width of the scribe (or line drawn by the pencil), the greater the ability to align measurements to the ruler. If the width of the scribe is broader than the graduation marks on the ruler, precision cannot be greater than the width of the scribe or ruler calibration.

A third critical factor of accuracy is the cartographic ability of the measurer. There are basically two ways to measure latitude and longitude: on maps. The first requires extrapolating data from the site reference point out to the map boundaries. This method requires moderate cartographic skill and accurate drafting supplies, and can magnify resulting errors in proportion to the map edge distance from the reference point. The second requires measuring data interpolated within known map reference points, thereby reducing drafting errors.

Methodologies that required drawing tangents from an unknown point on a map to the map boundary using straight-edges or right-triangles are no longer supported by EPA. The ability to align edges parallel to the map boundaries while extrapolating the tangent line is critical to the accuracy of the calculation. A difference of only a few millimeters will create coordinate errors of 1 or more seconds. Error will result from aligning the straight edge directly over the unknown point and not allowing for the width of the scribe while drawing the tangent line. Another way that locational error is introduced is by relying on other features inside the map -- such as straight roads, apparentyy straight survey lines, and section lines -- to extrapolate tangents. 


\section{PROCEDURE}

\subsection{DEFINING THE GRID}

Nine 2.5-minute map grid cells make up a usGs 7.5-minute topographic map (scale $1: 24,000$ ). These nine grid cells are defined by 2.5 -minute tic marks at the edges of the map and 2.5-minute cross-hairs within the map. Determine which of the nine 2.5-minute grid cells contains the site center or reference point. Depending on the location of the grid, you will be required to draw two, three, or four framing lines. All measurements will be made within this grid. To draw the lines, align a straight edge so the point of the pencil will intersect two of the 2.5-minute cross-hairs. Be sure that the edge is not directly over the cross-hairs or the width of the pencil will be offset and the framing line will not exactly intersect the two cross-hairs (see Figure 4-1).

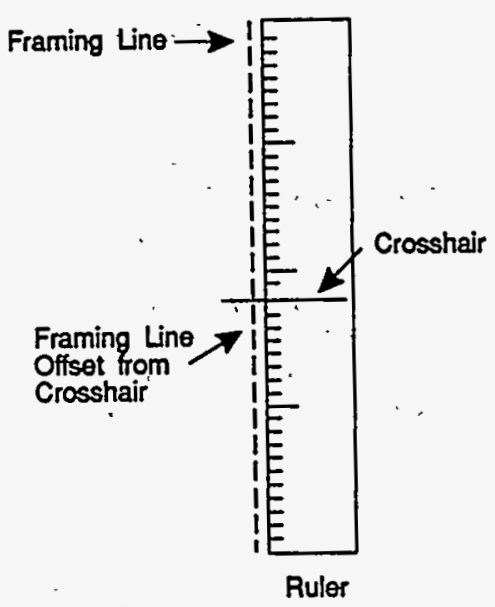

Incorrect Method

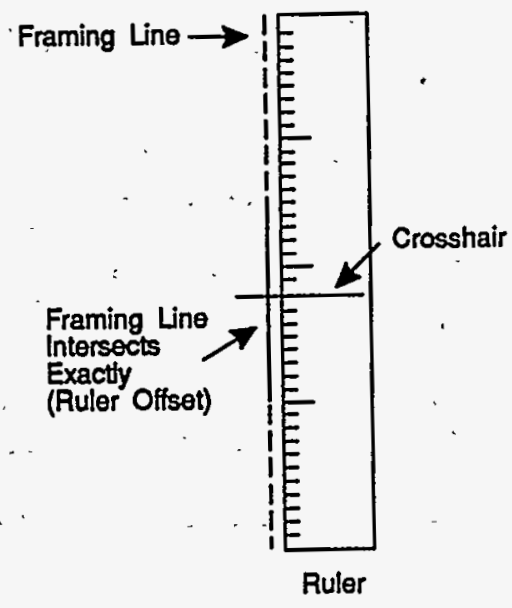

Correct Method

Figure 4-1. Aligning Framing Lines

Lightly draw the framing line, being careful to keep the pencil at an angle less than vertical, between 60 and 80 degrees. Strive to keep the pencil point against the straight edge at all times (see Figure 4-2).

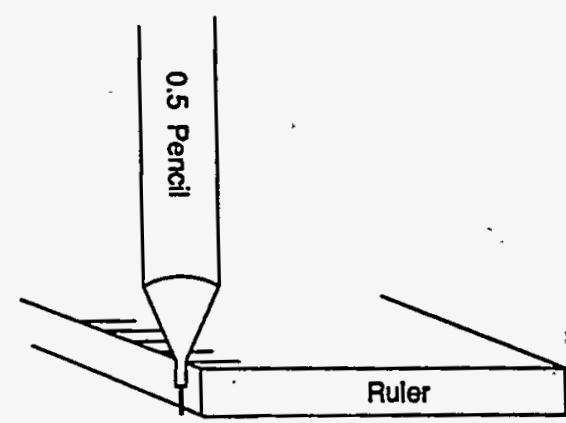

Incorrect Mothod

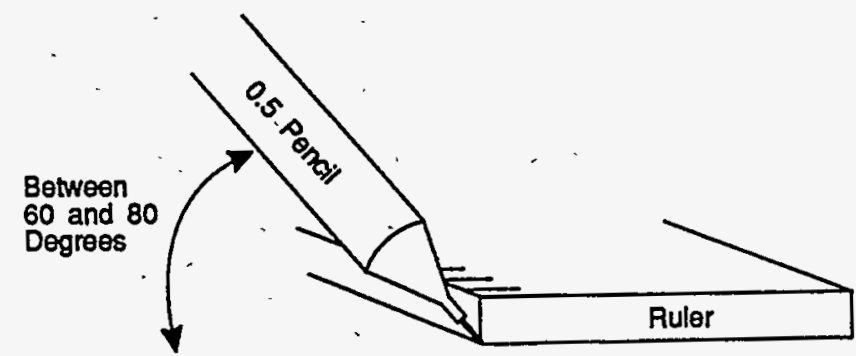

Correct Method

Figure 4-2. Scribing Framing Lines 
After completing one of the lines, remove the straight edge and examine the line. If it does not intersect the center of the cross-hairs exactly on each end, erase the line completely and repeat the process.

NOTE: The corners of more recent 7.5 minute topographic maps may have dashed cross-hairs that differ slightly from the corners of the map. Measure from the corners of the map and not the dashed corner cross-hairs, a USGS correction for the 1983 datum. Most maps still rely on the 1927 datum. Consult the lower left legend of the map for more information on geodetic datum.

\subsection{USING RULER GRADUATED IN SECONDS}

The coordinator ${ }^{\mathrm{TM}}$ is a clear template that is essentially eight custom rulers corresponding to the most common map scales. (The Coordinator ${ }^{\mathrm{TM}}$ can be obtained from drafting supply stores or 145 Cedar Hill Road, Bedford, NY 10506.) other custom rulers can be used if the 1-second (or better) level of precision is maintained and documented.

Custom rulers' are directly graduated in seconds of latitude. This is possible because map representations of latitude are essentially constant. One scale on the Coordinator ${ }^{\mathrm{TM}}$ fits precisely within a 2.5 minute arc of latitude on a 7.5 minute quadrangle map. By laying the scale over the site location precisely between the scribed latitude lines, latitude is read directly off the scale and added to the latitude of the lower line. With scale graduations in seconds, the accuracy of latitude to 1.0 second is ensured through direct measurement and interpolation. Directly measuring seconds prevents errors caused by conversion and ratio calculations.

Measuring Latitude Using a Custom Ruler (Coordinator ${ }^{\mathrm{TM}}$ )

1. Set out Coordinator ${ }^{\mathrm{TM}} 1: 24,000$ scale and map with the site center or reference point identified.

2. Draw 2.5-minute framing lines around the grid with the site center or reference point (see section 4.1 ).

3. Fill out background information on latitude/longitude worksheet.

4. Lay the scale on the map so that the bottom of the scale coincides with the bottom framing line and the top of the scale coincides with the top framing line (see Figure 4-3).

5. Move the scale laterally until it intersects the point to be measured. Be very careful to keep the top and bottom edges of the scale on the framing lines.

6. The scale has two sets of incremental designations; the left set begins at 30 seconds and the right set begins at 0 seconds. Use the scale that corresponds to the latitude number of the lower framing line. If it ends in 30 seconds, read along the left side. If it ends in 0 seconds; read along the right side.

7. Read up the scale from the lower framing line to the point to be measured. Note at each 00 second reading on the coordinator scale, add 1 minute to the beginning latitude number of the lower framing line. Record that number on the worksheet.

Measuring Longitude Using a Custom Ruler (Coordinator ${ }^{\mathrm{TM}}$ )

Longitude is calculated using the same principle and scale as for latitude. The difference is that the ground distances of 2.5 minutes of latitude and longitude are not the same. If, however, you use the same scale and align your 
divisions to those of the known longitude lines, the ratios and conversions become a linear measurement. Since the scale is exactly 2.5 minutes long, place each end of the scale on one of the longitude lines. Next, slide the scale up or down until it intersects the reference point. When the edges of the scale are precisely touching the longitude lines and the scale intersects the unknown point, read up the scale from right to left to measure the longitude.

1. Set up longitude framing lines as described in section 4.1.

2. Lay the 1:24,000 scale on the map so that the bottom of the scale coincides with the right framing line and the top of the scale coincides with the left framing line (see Figure 4-3).

3. Move the scale up or down until it intersects the point to be measured. Be very careful to keep the top and bottom edges of the scale on the framing lines.

4. The scale has two sets of increments: the left set beging at 30 seconds and the right set begins at 0 seconds. Use the scale that corresponds to the longitude number of the right framing line. If it ends in 30 seconds, read along the left side. If it ends in 0 seconds, read along the right side.

5. Read the scale up from the right framing line to the point to be measured. Note at each 00 " on the Coordinator ${ }^{\mathrm{TM}}$ scale, add 1 minute to the beginning longitude number of the lower framing line. Record that number on the worksheet.

Note: Be sure to identify starting latitude right-hand corner of the 2.5 minute grid. read off the 30 -second side on the scale; read off the 00 side.

\subsection{USING AN ENGINEER'S SCALE}

Alternative equipment to determine latitude and longitude coordinates is an "engineer's scale." An engineer's scale is a multi-sided ruler containing series of graduations per inch corresponding to map scales. For the 1:24,000 topographic maps, use the 60 divisions per inch scale; on this scale 454 divisions equal to 2.5 minutes. Use the 0 as 00 " and 454 as 2 '30" and follow the alignment process of section 4.2. Record the number of divisions on the ruler, divide by 454 , and multiply the resultant by 150 . The number is now in seconds and can be added to the starting latitude or longitude to get the coordinates of the site.

Measuring Latitude and Longitude Using an Engineer's scale

1. Display the $1 / 60$ engineer's scale and map with the site center or reference point site identified.

2. Draw 2.5-minute framing lines on the grid with the site center or reference point (see section 4.1 ).

3. Fill out background information on: the latitude/longitude worksheet.

4. For latitude: place the 1/60 scale on the map so that the bottom of the ruler coincides with the bottom framing line and 454 coincides with the top framing line (see Figure 4-3).

For longitude: place the scale on the map so that the bottom of the ruler coincides with the right framing line and 454 coincides with the left framing line (see Figure 4-3). 
5. Move the scale laterally (for latitude) or vertically (for longitude) until the scale intersects the point to be measured. Be very careful to keep the 0 and 454 edges of the scale on the framing lines.

6. Record the number on the ruler where it intersects the point to be measured on the appropriate worksheet. Divide that number by 454 and multiply the resultant by 150. on multiply the number by 0.3304 . The number is now in seconds and can be added to the starting latitude or longitude of the grid to get the latitude or longitude coordinates of the site. Complete the worksheet.

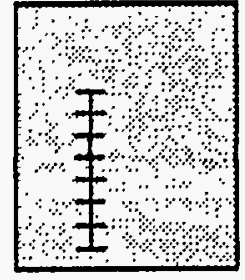

Coordinator

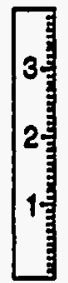

Custom Ruler

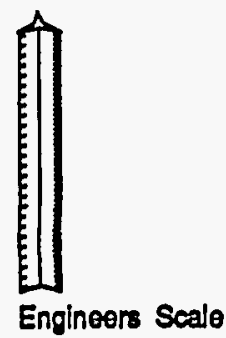

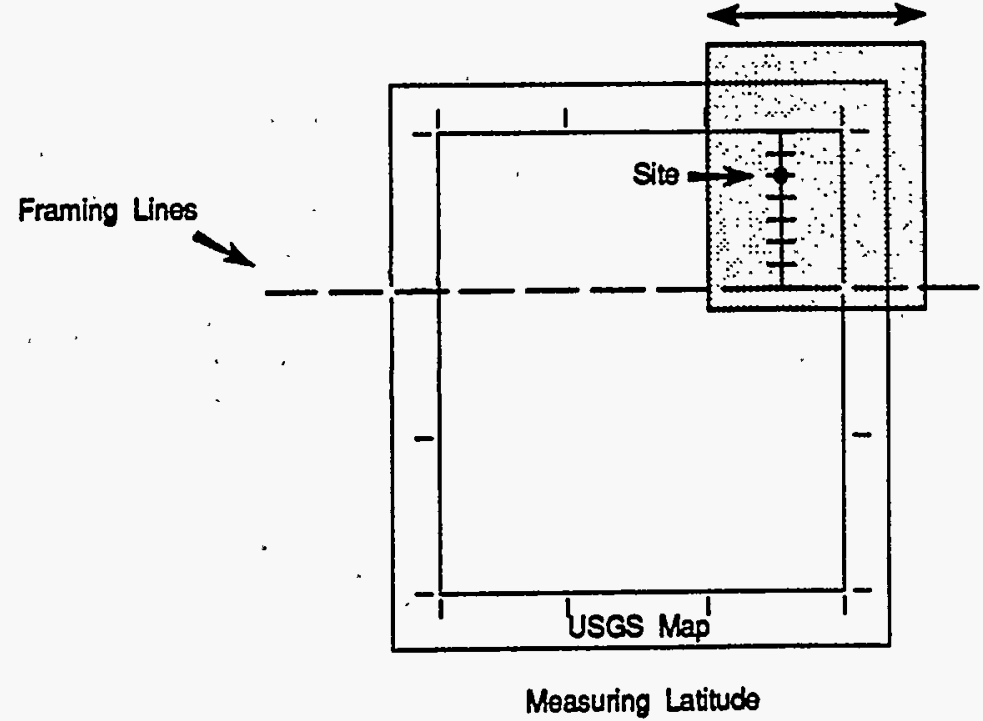

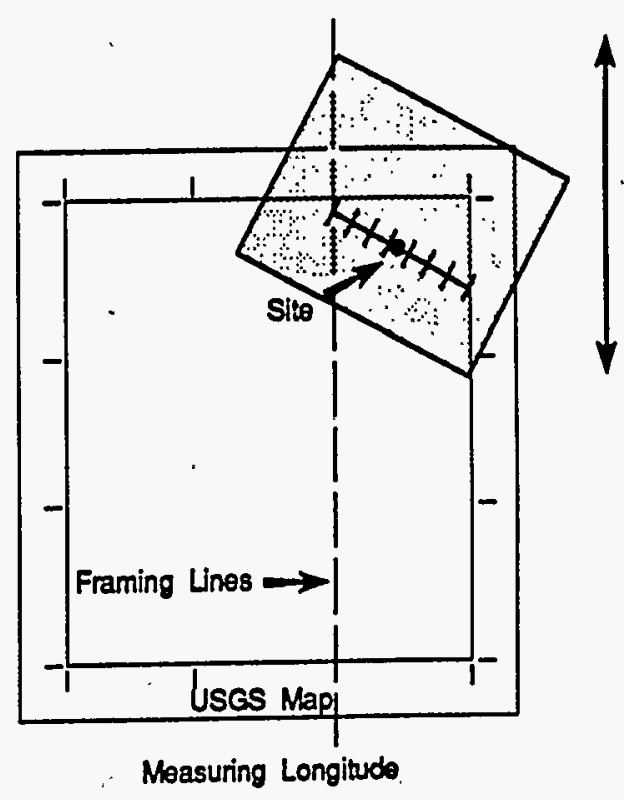

Figure 4-3. Determining Latitude and Longitudé Using Iinear Interpolation 


\section{QUALITY ASSURANCE}

For QA purposes, a method must be developed to track how latitude and longitude coordinates have been verified and calculated. A datasheet (worksheet) is part of the required documentation for each PA. A completed worksheet allows a reviewer to follow the original steps and check the calculations. Completing each form is estimated to take approximately 10 minutes. Attach a complete 2:5minute grid on a separate page with the site center or reference point clearly marked. All four corners of the grid must be clearly visible. 
LATITUDE AND LONGITUDE CALCULATION WORKSHEET \#1

LI USING CUSTOM RULER OR COORDINATOR ${ }^{\text {TM }}$

SITE NAME: CËRCLIS \#:

AKA : SSID:

ADDRESS:

CITY :

STATE : ZIP CODE:

SITE REFERENCE POINT:

USGS QUAD MAP NAME: TOWNSHIP: N/S RANGE: $E / W$

SCALE: $1: 24,000$ MAP DATE: SECTION : $1 / 4$ $1 / 4$ $1 / 4$

MAP DATUM: 19271983 (CIRCLE ONE) MERIDIAN: COORDINATES FROM LOWER RIGHT (SOUTHEAST) CORNER OF $7.5^{\circ}$ MAP (attach photocopY): LONGITUDE: $\circ$ LATITUDE: COORDINATES FROM LOWER RIGHT (SOUTHEAST) CORNER OF 2.5' GRID CELL: LONGITUDE : " LATITUDE:

\section{CALCULÁtIONS: LATITUDE $(7.5$ ' QUADRANGLE MAP)}

A) ALIGN THE BOTTOM OF THE SCALE WITH BOTTOM OF GRID. ALIGN THE TOP OF THE SCALE WITH THE TOP OF GRID. POSITION EDGE OF RULER OVER SITE REFERENCE POINT WHILE KEEPING TOP AND BOTTOM ALIGNED.

B) READ TICS ON RULER AT 1- OR 0.5-SECOND INTERVALS (INTERPOLATE).

C) EXPRESS IN MINUTES AND SECONDS $\left(1^{\prime}=60^{\prime \prime}\right)$

D) ADD TO STARTING LATITUDE:

SITE LATITUDE: $\circ$ , "

\section{CALCULATIONS: LONGITUDE $\quad\left(7.5^{\prime}\right.$ QUADRANGLE MAP)}

A) ALIGN THE BOTTOM OF THE SCALE WITH RIGHT SIDE OF GRID. ALIGN THE TOP OF THE SCALE WITH THE LEFT SIDE OF GRID. POSITION EDGE OF RULER OVER SITE REFERENCE POINT WHILE KEEPING TOP AND BOTTOM ALIGNED.

B) READ TICS ON RULER AT 1- or 0.5-SECOND INTERVALS. (INTERPOLATE)

C) EXPRESS IN MINUTES AND SECONDS $\left(1^{\prime}=60^{\prime \prime}\right)$ :

D) ADD TO STARTING LONGITUDE:

SITE LONGITUDE: $\circ$ $\therefore$ DATE: 
SITE NAME : CERCLIS \#:

AKA: SSID :

ADDRESS :

CITY : STATE: ZIP CODE:

SITE REFERENCE POINT:

USGS QUAD MAP NAME:

SCALE : 1:24,000 MAP DATE: TOWNSHIP : N/S RANGE: $E / W$

MAP DATUM: 19271983 (CIRCLE ONE) MERIDIAN:

COORDINATES FROM LOWER RIGHT (SOUTHEAST) CORNER OF 7.5' MAP (attach photocopy): LONGITUDE: : COORDINATES FROM LOWER RIGHT (SOUTHEAST) CORNER OF $2.5^{\prime}$ GRID CELL: LONGITUDE:

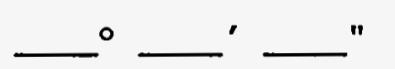
LATITUDE :

CALCULATIONS: LATITUDE - $\left(7.5^{\prime}\right.$ QUADRANGLE MAP)

A) NUMBER OF RULER GRADUATIONS FROM LATITUDE GRID IINE TO SITE REF POINT:

B) MULTIPLY (A) BY 0.3304 TO CONVERT TO SECONDS: A $\times 0.3304=$

C) EXPRESS IN MINUTES AND SECONDS $\left(1^{\prime}=60^{\prime \prime}\right)$ :

D) ADD TO STARTING IATITUDE:

SITE LATITUDE: $\circ$

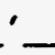
-

CALCULATIONS: LONGITUDE (7.5' QUADRANGLE MAP)

A) NUMBER OF RULER GRADUATIONS FROM RIGHT LONGITUDE LINE TO SITE REF POINT:

B) MULTIPIY (A) BY 0.3304 TO CONVERT TO SECONDS:

A $\times 0.3304=$

C) EXPRESS IN MINUTES AND SECONDS $\left(1^{\prime}=60^{\prime \prime}\right)$ :

D) ADD TO STARTING LONGITUDE:

SITE LONGITUDE:

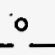

\section{,} -

INVESTIGATOR: DATE : 


\section{AFFIX MAP GRID CELL HERE}

Map must have a minimum of $1 / 4$ inch around the $2.5^{\prime}$ grid cell and show all four grid tic marks.

- Indicate permanent site reference point

- Indicate boundary of site/sources COORDINATES OF LOWER RIGHT-HAND CORNER OF 2.5-MINUTE GRID:

LATITUDE: " LONGITUDE: 